UNIVERSIDADE DE SÃO PAULO

FACULDADE DE ECONOMIA, ADMINISTRAÇÃO E CONTABILIDADE DEPARTAMENTO DE ADMINISTRAÇÃO PROGRAMA DE PÓS-GRADUAÇÃO EM ADMINSITRAÇÃO

O GRAU DE INTERNACIONALIZAÇÃO, AS COMPETÊNCIAS E O DESEMPENHO DA PME BRASILEIRA

Dinorá Eliete Floriani

Orientadora: Profa. Dra. Maria Tereza Leme Fleury

SÃO PAULO 
Prof. Dr. João Grandino Rodas

Reitor da Universidade de São Paulo

Prof. Dr. Carlos Roberto Azzoni

Diretor da Faculdade de Administração, Economia e Contabilidade

Prof. Dr. Adalberto Américo Fischmann

Chefe do Departamento de Administração

Prof. Dr. Lindolfo Galvão de Albuquerque

Coordenador do Programa de Pós-Graduação em Administração 


\section{O GRAU DE INTERNACIONALIZAÇÃO, AS COMPETÊNCIAS E O DESEMPENHO DA PME BRASILEIRA}

Tese apresentada ao Departamento de Administração da Faculdade de Economia, Administração e Contabilidade da Universidade de São Paulo como requisito para a obtenção do título de Doutor em Administração.

Orientadora: Profa. Dra. Maria Tereza Leme Fleury

SÃO PAULO

2010 


\section{FICHA CATALOGRÁFICA}

Elaborada pela Seção de Processamento Técnico do SBD/FEA/USP

Floriani, Dinorá Eliete

O grau de internacionalização, as competências e o desempenho da PME brasileira / Dinorá Eliete Floriani. - São Paulo, 2010. $307 \mathrm{p}$.

Tese (Doutorado) - Universidade de São Paulo, 2010. Orientador : Maria Tereza Leme Fleury

1. Internacionalização de empresas 2. Pequenas e médias empresas 3. Competência organizacional 4. Desempenho organizacional I. Universidade de São Paulo. Faculdade de Economia, Administração e Contabilidade. II. Título.

CDD -658.049 
Os quatro anos que marcaram o período de construção desta tese representam uma densa trajetória de aprendizado pessoal, acadêmico e profissional. Durante esse período muitas pessoas ajudaram neste trajeto. Não tenho espaço físico para formalmente nomear a todos os que contribuíram com o meu projeto, fica aqui registrado os meus mais sinceros agradecimentos e, em especial:

Agradeço primeiramente à Profa. Maria Tereza L. Fleury, que com as suas aulas e de seus precisos insigts me direcionaram e me inspiraram, não somente para a tese, mas também para a vida. Meus agradecimentos são extensivos ao Prof. Dr. Martinho Isnard Ribeiro, que me apoiou no início do doutorado.

Agradeço a CAPES, pelo apoio financeiro no meu doutorado sanduíche em Grenoble, na França. Aos Professores Hubert Drouvot e Didier Retour; da Université Pièrre Mendes, France, que me receberam e me orientaram no doutorado sanduíche.

Agradeço à Universidade do Vale do Itajaí (UNIVALI), pelo apoio em meus projetos profissionais. Em especial, gostaria de agradecer à minha amiga Profa. Dra. Rosilene Marcon e ao Pró-Reitor de Pesquisa, Pós-Graduação e Extensão, Prof. Dr. Valdir Cechinel, que compreenderam minhas dificuldades e apoiaram minhas ideias. Sou igualmente grata à companheira de coordenação dos MBAs, Profa. Dra. Joana Stelzer, por compreender a minha ausência.

Nas dificuldades estatísticas desta tese, sou grata a Profa. Tatiana Melhado. Para vários e importantes direcionamentos, agradeço ao Prof. Rodrigo Bandeira-de-Mello. Aos professores, Jorge Carneiro e Moacir Miranda pelos importantes conselhos durante a banca de qualificação. Desejo manifestar minha gratidão aos professores e executivos que dedicaram o seu tempo aos meus estudos de caso e me auxiliaram no pré-teste do questionário. E também a todas as 114 empresas que responderam a minha pesquisa. Meus colegas de doutorado, que durante o período de aulas e de tese, foram muito importantes para o meu desenvolvimento. Em especial, quero agradecer ao Felipe Borini pelos ensinamentos e pela parceria nos artigos. A todos os meus amigos, que entenderam que a distância não afasta as pessoas.

Aos meus pais, pela liberdade concedida para trilhar o meu caminho e pelo apoio em meus projetos. Aos meus irmãos, Delton e Keila, que são presença constante em minha caminhada, sei que sempre posso contar com eles. Aos demais familiares, nona, tios, primos muito obrigada pelo carinho.

Por fim, mas não menos importante, gostaria de deixar expresso, de todo o coração, os meus sinceros agradecimentos ao Flavio, que com seu carinho e dedicação fez do meu projeto o nosso projeto, e me proporcionou muitas alegrias. Estendo minha gratidão aos seus filhos e noras, Alexandre, Tatiana, Daniel e Daniela, pelo carinho. 



\section{RESUMO}

Nesta tese foi realizada uma pesquisa identificando a relação entre o Grau de internacionalização das Pequenas e Médias Empresas (PMEs) brasileiras e o desempenho financeiro e operacional, utilizando as competências internacionais como um fator mediador. Por meio de uma survey aplicada em 114 empresas de até 200 funcionários, esta pesquisa identificou que as PMEs brasileiras estão aumentando o seu Grau de Internacionalização (GRI), passando a investir diretamente no exterior (IDE). Das empresas entrevistas, 44 possuem algum tipo de IDE, como escritórios, centros de distribuição até fábricas no exterior. Com a amostra de 114 PMEs brasileiras, testou-se e se confirmou a hipótese que o aumento do GRI desenvolve novas competências e melhora o desempenho organizacional. Devido à utilização de construtos de natureza complexa, a existência de erros e a necessidade de se identificar múltiplas relações simultaneamente, a modelagem de equações estruturais (SEM) foi utilizada como técnica estatística. Uma vez identificada a relação significativa do modelo inicial proposto, outros modelos concorrentes foram analisados a fim de identificar outras relações entre as variáveis pesquisadas. Para estimar os parâmetros iniciais, utilizou-se o método de estimação de máxima verossimilhança (MV) assumindo a distribuição multivariada normal (HAIR JR. et al., 2009). Os construtos do modelo final explicaram $70 \%$ da variabilidade dos dados e foi composto por três variáveis latentes, sendo a variável GRI uma variável exógena, e competência e desempenho, variáveis endógenas. Os resultados demonstram que há uma relação direta e positiva do GRI com o desenvolvimento de novas competências e com um melhor desempenho na PME. Especificamente, há uma relação maior do GRI com o desenvolvimento de novas competências no concernente ao melhor desempenho operacional nas PMEs do que no que tange ao aumento do desempenho financeiro. No entanto, quando se verificou a relação entre o GRI e o desempenho financeiro e operacional sem a mediação do desenvolvimento de novas competências, o modelo não se mostrou significativo, corroborando os resultados de outras pesquisas internacionais que identificaram que o melhor desempenho financeiro e operacional não será alcançado somente pelo aumento do grau de internacionalização. (SETHI; JUDGE, 2009; PORTER, 1990; ZAHRA et al., 2000; FLEURY; FLEURY, 2004; GHOSHAK, 1987; GRANT, 1987; QIAN, 2002; PANGARKAR, 2008; CAMISÓN; VILLAR-LÓPEZ, 2010). Os resultados desta pesquisa indicam que com o aumento do grau de internacionalização a PME desenvolve novas competências e assim apresenta um desempenho superior. A relação de mediação do desenvolvimento de novas competências entre o aumento do GRI e o desempenho organizacional explora uma nova abordagem nos negócios internacionais, principalmente para as PMEs. 



\begin{abstract}
In this thesis, we conducted a survey identifying the relationship between the degree of internationalization of Brazilian's Small and Medium-sized Enterprises (SMEs) and financial and operational performance by using international competences as a mediating factor.

Through a survey applied to 114 companies with up to 200 employees, this survey has identified that Brazilian SMEs are increasing their Degree of Internationalization (GRI) by starting to invest directly abroad (FDI). Out of the companies interviewed, 44 have some form of FDI, such as offices, distribution centers and even factories abroad.

With this sampling of 114 Brazilian SMEs, the hypothesis that by increasing the GRI new competences are developed and organizational performance is improved has been tested and confirmed. Due to the use of constructs of a complex nature, the existence of errors and the need to identify multiple relationships simultaneously, structural equation modeling (SEM) was used as a statistical technique. Once the significant relationship of the initial model proposed was identified, other competing models were examined in order to identify other relationships between the variables researched. We used the maximum likelihood estimation method (ML) to estimate the initial parameters by assuming a normal multivariate distribution (Hair Jr. et al., 2009). The constructs of the final model explained $70 \%$ of the data variability and was comprised of three latent variables, with the GRI variable as an exogenous variable, and competence and performance as endogenous variables.

Results show that there is a direct and positive relationship of the GRI with the development of new competences and better performance in SMC's. Specifically, there is a higher ratio of GRI with the development of new competences with regard to improved operational performance in SMC's than in relation to increased financial performance.

However, when the relationship between the GRI and the financial and operational performance without the mediation of the development of new competences was examined, the model did not turn out to be significant, corroborating the results of other international studies which identified that the best financial and operational performance will not be achieved just by increasing the degree of internationalization (SETHI; JUDGE, 2009; PORTER, 1990; ZAHRA et al., 2000; FLEURY; FLEURY, 2004; GHOSHAK, 1987; GRANT, 1987; QIAN, 2002; PANGARKAR, 2008; CAMISÓN; VILLAR-LÓPEZ, 2010). These results indicate that by increasing their degree of internationalization, the SMEs develop new competences and therefore display superior performance.

The mediation relationship of the development of new competences between the increase of GRI and the organizational performance explores a new approach in international business, especially for SMEs.
\end{abstract}





\section{SUMÁRIO}

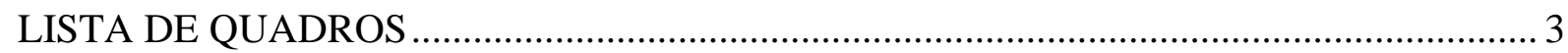

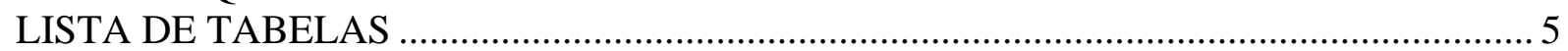

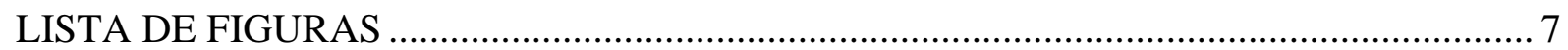

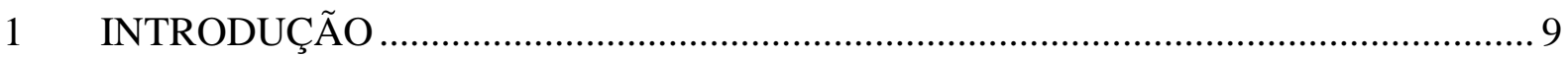

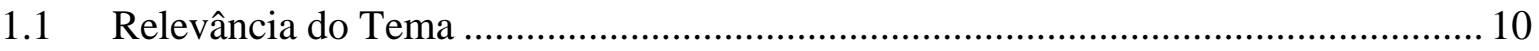

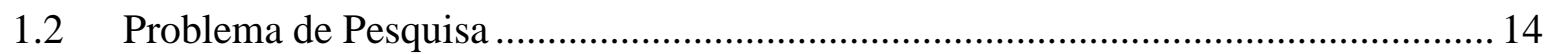

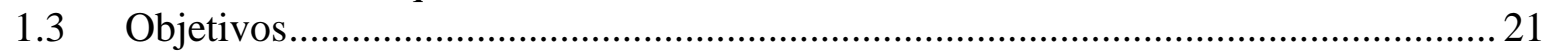

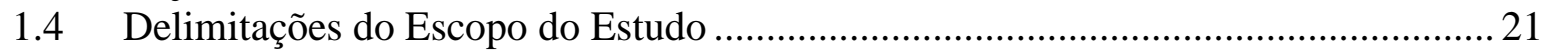

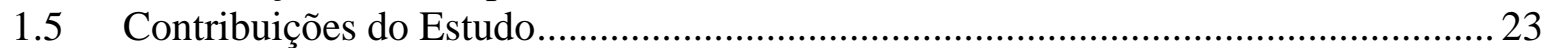

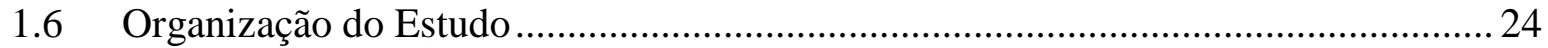

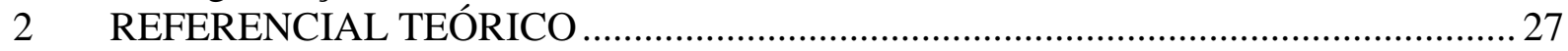

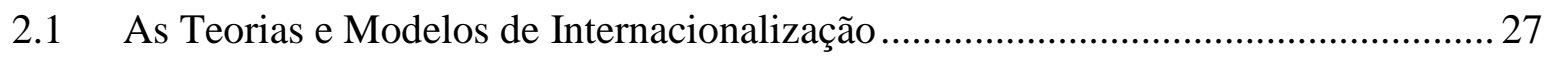

2.1.1 A teoria econômica da internacionalização.....................................................2 29

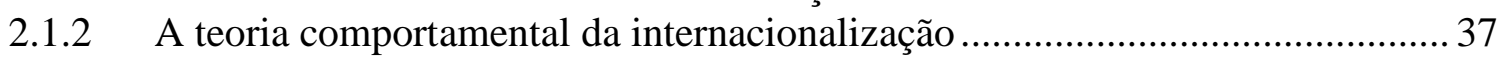

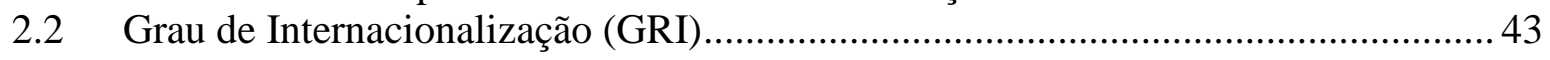

2.2.1 Vertente comportamental para grau de internacionalização .................................. 55

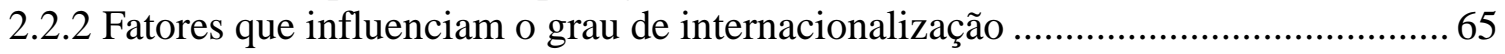

2.3 As Competências Organizacionais das PMEs Internacionalizadas ............................ 75

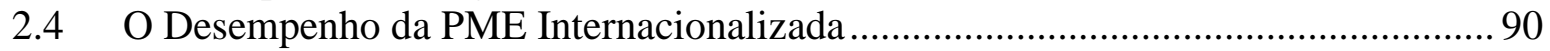

2.5 As PMEs Brasileiras, o GRI, as Competências e o Desempenho ............................ 103

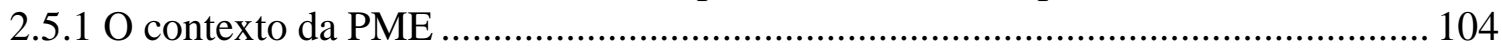

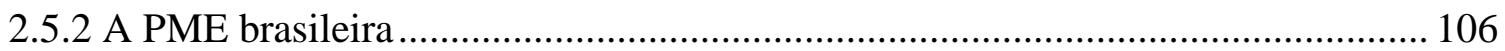

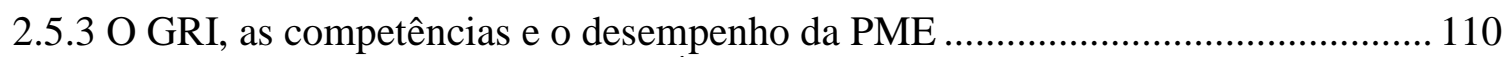

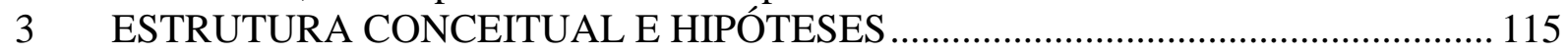

3.1 Os Indicadores de GRI, de Competência e de Desempenho para a Presente

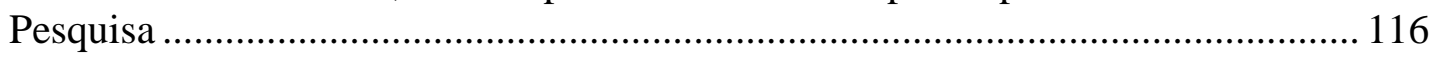

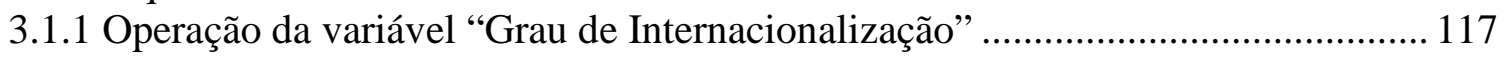

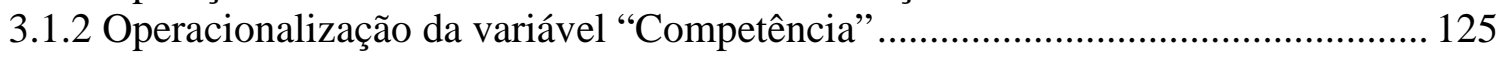

3.1.3 Operacionalização da variável "Desempenho da empresa" ............................. 131

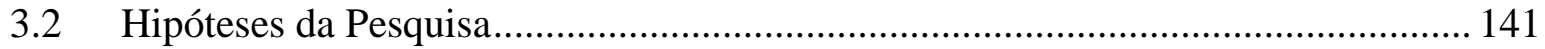

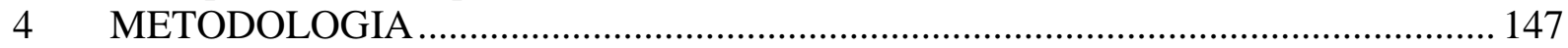

4.1 Procedimentos de Campo - Primeira Fase: Abordagem Qualitativa ....................... 148

4.2 Procedimentos de Campo - Segunda Fase: Abordagem Quantitativa ..................... 153

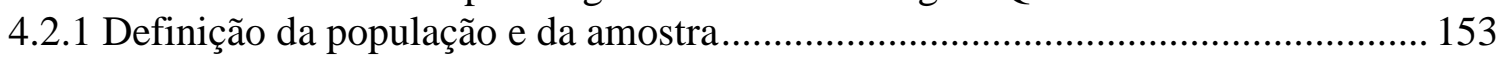

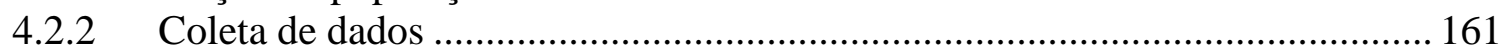

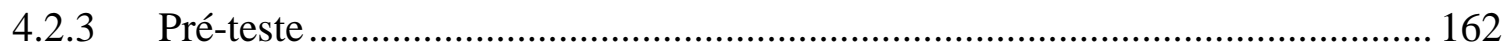

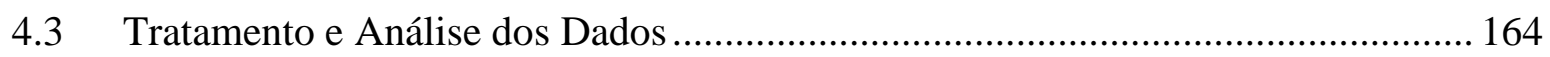

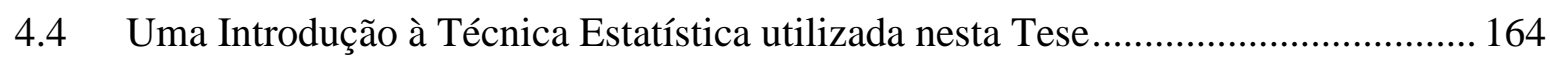

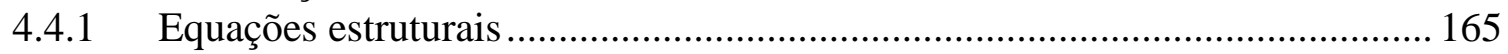

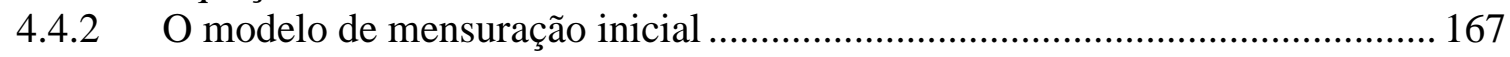

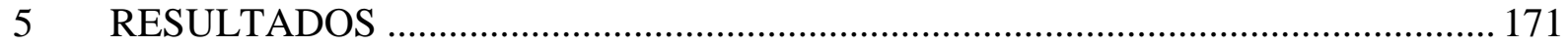

5.1 Estudos de Casos das PMEs Brasileiras ................................................................... 171

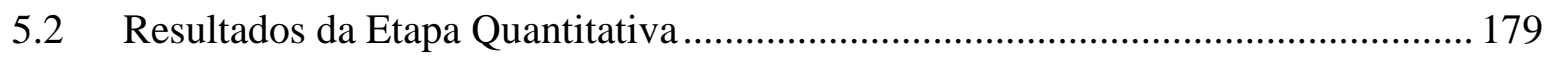

5.2.1 O perfil das empresas pesquisadas e dados gerais da internacionalização ....... 179

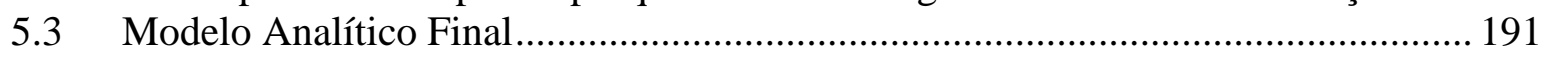

5.3.1 Passos seguidos para o uso da modelagem de equações estruturais ................. 191

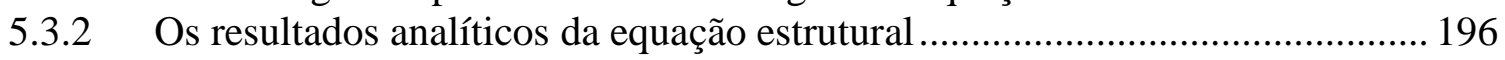




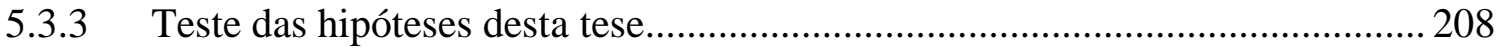

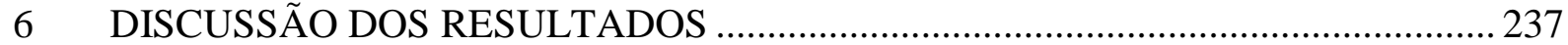

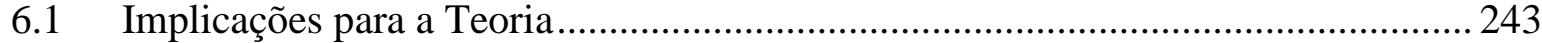

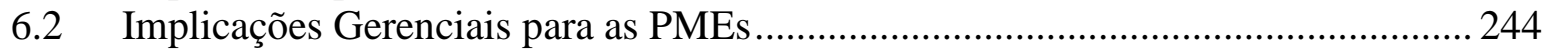

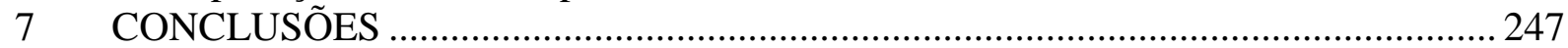

7.1 Limitações e Sugestão para Novos Estudos ........................................................ 248

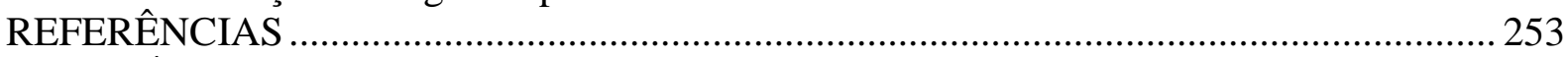

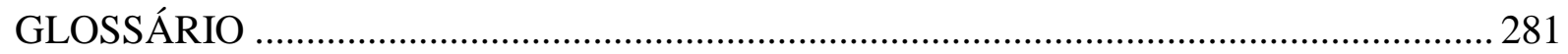

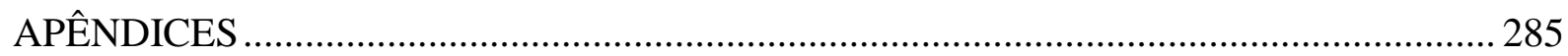

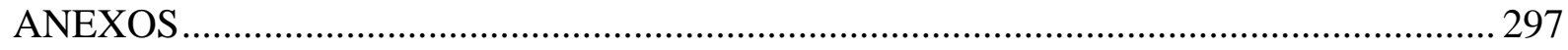




\section{LISTA DE QUADROS}

Quadro 1 - Principais abordagens teóricas da internacionalização das PMEs 42

Quadro 2 - Resumo dos estudos empíricos da relação entre desempenho e GRI .....................51

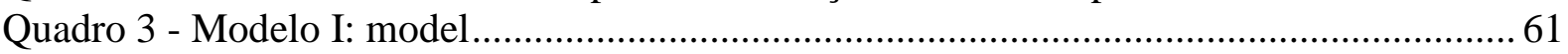

Quadro 4 - Formas de investimento conforme Berger e Uhlmann, 1985 ................................62 62

Quadro 5 - Funções do Negócio conforme Hollensteinm, 2005 ............................................. 63

Quadro 6 - Resumo das Principais variáveis para medir o Grau de internacionalização

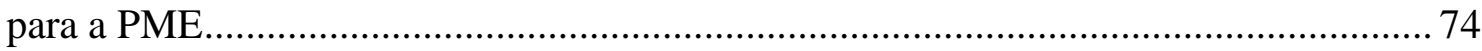

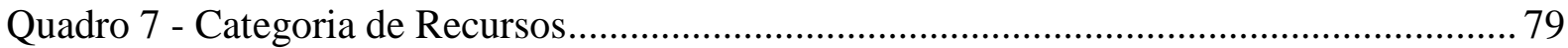

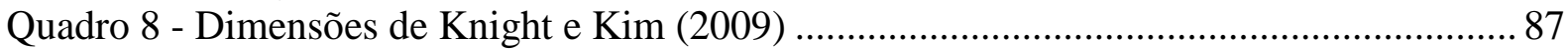

Quadro 9 - Principais variáveis de competência para a PME internacionalizada ..................... 88

Quadro 10 - Indicadores de desempenho de Zou et al. (1998) ............................................. 95

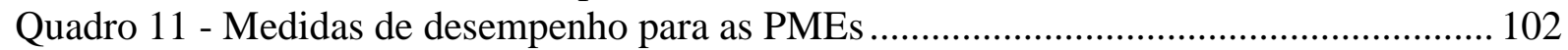

Quadro 12 - Perspectiva histórica dos fatores e os impactos na internacionalização

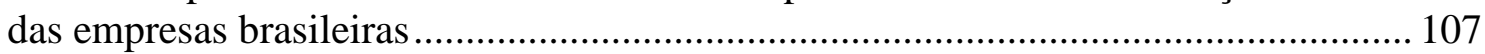

Quadro 13 - Resumo das definições constitutivas e operacionais da presente tese ............... 139

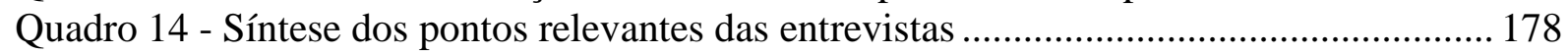

Quadro 15 - Síntese do perfil e dos resultados da internacionalização da PME entrevistada 191 



\section{LISTA DE TABELAS}

Tabela 1 - Exportação: comparativo entre países e porte de empresa ..................................... 12

Tabela 2 - Resumo dos resultados de Sullivan (1994) .............................................................. 52

Tabela 3 - Número de empresas exportadoras segundo seu tamanho em 2008 ..................... 108

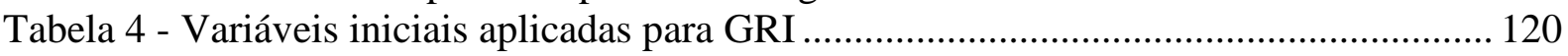

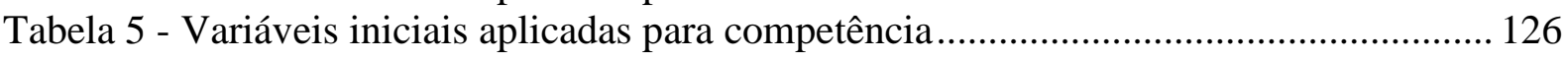

Tabela 6 - Indicadores iniciais de desempenho financeiro da organização ........................... 136

Tabela 7 - Indicadores de desempenho operacional da organização...................................... 136

Tabela 8 - Critério para a classificação das empresas no Brasil pelo SEBRAE .................... 155

Tabela 9 - Critério para a classificação das empresas no Brasil pelo MDIC ........................... 155

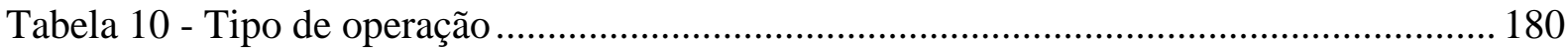

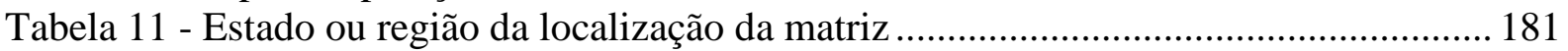

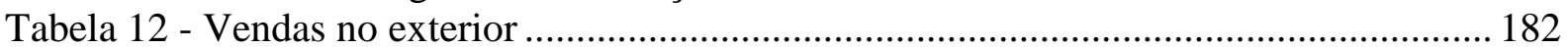

Tabela 13 - Número de empresas que selecionaram cada país na exportação ....................... 183

Tabela 14 - Número de funcionários no Brasil e no exterior ................................................. 184

Tabela 15 - Ano de fundação e de início da exportação das empresas pesquisadas ............... 185

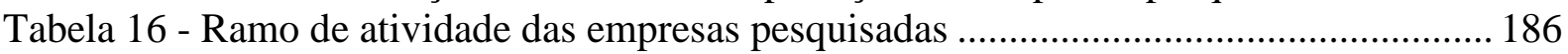

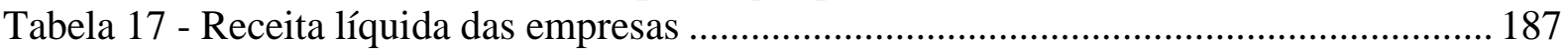

Tabela 18 - Auxílio para a internacionalização às empresas pesquisadas .............................. 188

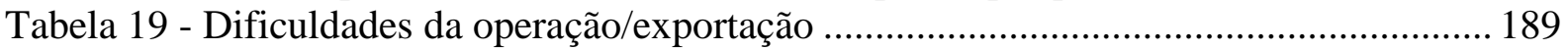

Tabela 20 - Intenção em investimento para os três próximos anos......................................... 190

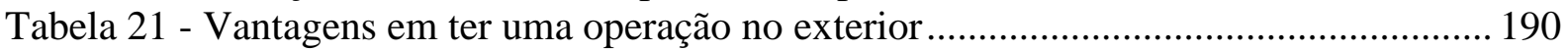

Tabela 22 - Principais medidas de ajuste e sua utilização...................................................... 195

Tabela 23 - Cargas fatoriais para o modelo de AFE inicial .................................................. 197

Tabela 24 - Cargas fatoriais para o modelo de AFE sem idade, país e vendas....................... 198

Tabela 25 - Cargas fatoriais para o modelo de AFE final (sem idade, país, vendas e

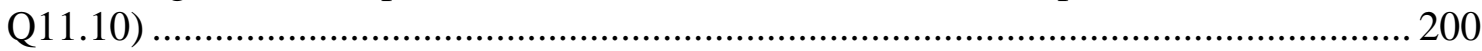

Tabela 26 - Confiabilidade das questões que mensuram as variáveis latentes ...................... 201

Tabela 27 - Testes de significância: análise fatorial confirmatória inicial para GRI............. 203

Tabela 28 - Testes de significância: análise fatorial confirmatória final - GRI ..................... 203

Tabela 29 - Testes de significância do modelo de análise fatorial confirmatória

inicial/final para desempenho financeiro ...................................................................... 204

Tabela 30 - Testes de significância do modelo de análise fatorial confirmatória inicial/final para desempenho operacional ................................................................. 205

Tabela 31 - Testes de significância do modelo de análise fatorial confirmatória

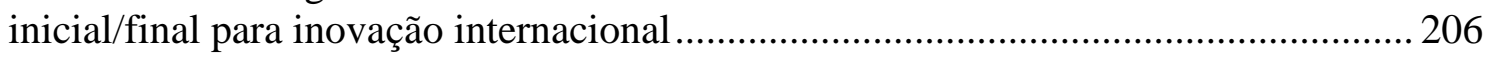

Tabela 32 - Testes de significância do modelo de análise fatorial confirmatória inicial/final para habilidade em marketing internacional ............................................ 206

Tabela 33 - Testes de significância do modelo de análise fatorial confirmatória

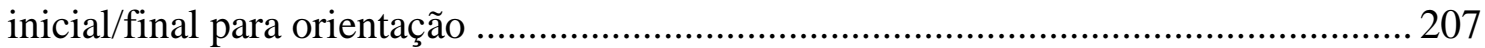

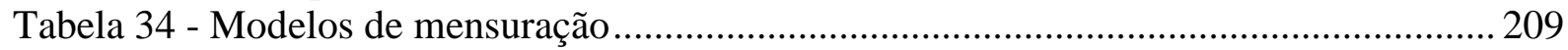

Tabela 35 - Medidas de assimetria e curtose -Variáveis observadas - Modelo inicial 1a...... 213

Tabela 36 - Testes de significância do modelo inicial/final 1 .............................................. 214

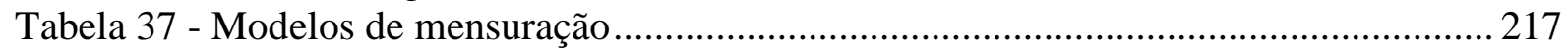

Tabela 38 - Testes de significância do modelo inicial/final 2a ........................................... 220

Tabela 39 - Medidas de ajuste para o modelo 3a ............................................................ 221

Tabela 40 - Testes de significância do modelo inicial/final 3a ........................................... 223

Tabela 41 - Resumos dos ajustes do Modelo 1a e do Modelo 3a ........................................ 224 
Tabela 42 - Medidas de ajuste para comparação de modelos ...............................................225

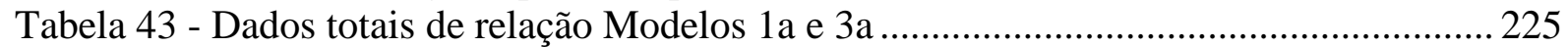

Tabela 44 - Medidas de assimetria e curtose - desempenho operacional..............................228

Tabela 45 - Testes de significância do modelo inicial/final 1b- ........................................ 228

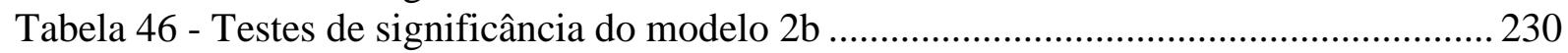

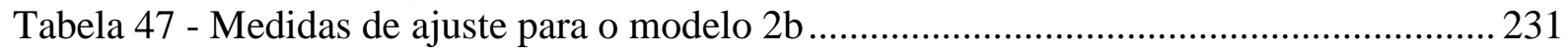

Tabela 48 - Testes de significância do modelo $3 b$.............................................................. 233

Tabela 49 - Medidas de ajuste para comparação de modelos .............................................. 234

Tabela 50 - Resumos dos ajustes do Modelo $1 \mathrm{~b}$ e do Modelo 2b ......................................... 234

Tabela 51 - Dados totais de relação Modelos 1b e 3b............................................................ 235 


\section{LISTA DE FIGURAS}

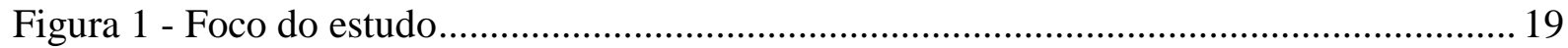

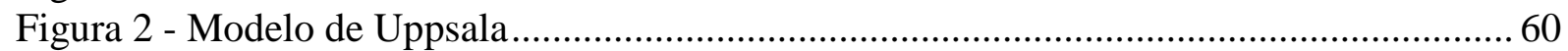

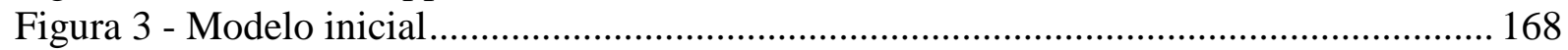

Figura 4 - Diagrama de caminho: análise fatorial confirmatória - GRI ................................ 201

Figura 5 - Diagrama de caminho: análise fatorial confirmatória inicial -

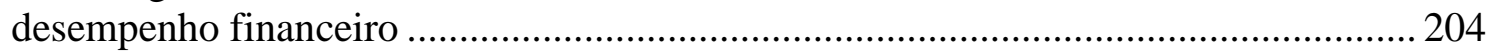

Figura 6 - Diagrama de caminho do modelo de análise fatorial confirmatória inicial

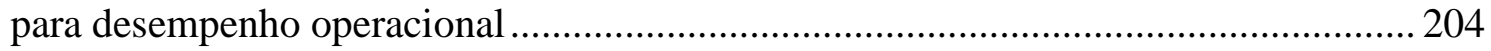

Figura 7 - Diagrama de caminho do modelo de análise fatorial confirmatória inicial

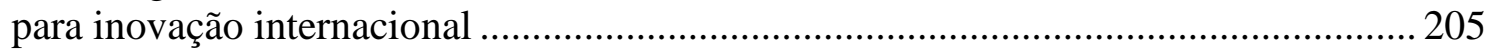

Figura 8 - Diagrama de caminho do modelo de análise fatorial confirmatória inicial

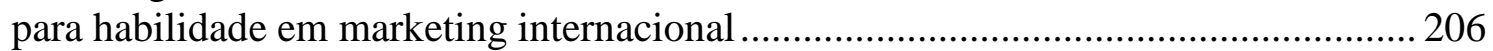

Figura 9 - Diagrama de caminho do modelo de análise fatorial confirmatória inicial

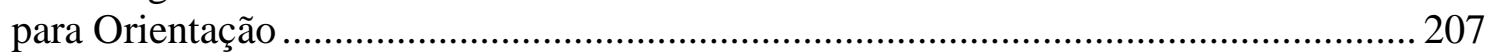

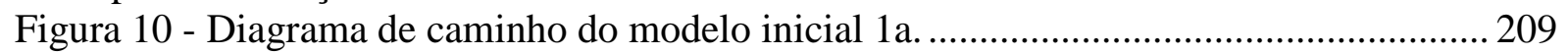

Figura 11 - Diagrama de caminho do modelo inicial 2a .................................................. 216

Figura 12 - Diagrama de caminho do modelo de mensuração - Modelo 2a -

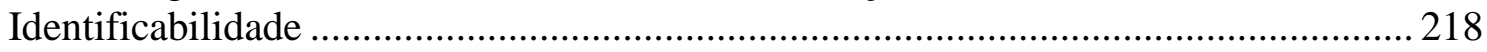

Figura 13 - Diagrama de caminho do modelo estrutural - Modelo 2a - Identificabilidade... 219

Figura 14 - Diagrama de caminho do modelo inicial 3a ...................................................... 222

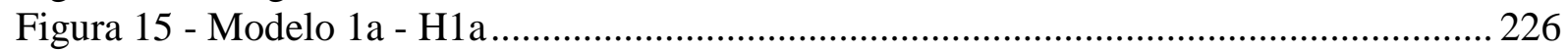

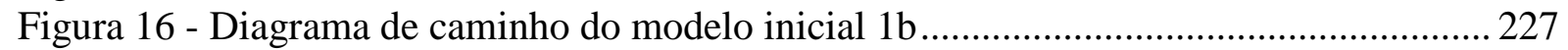

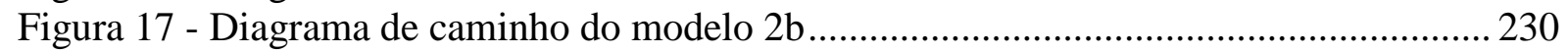

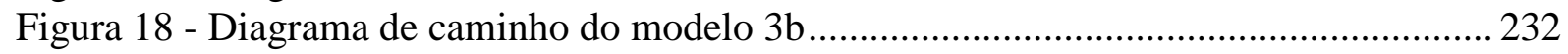

Figura 19 - Relação final entre os construtos H2 ............................................................ 235 



\section{INTRODUÇÃO}

Esta pesquisa de tese investiga a relação entre o grau de internacionalização das Pequenas e Médias Empresas (PMEs) brasileiras com o desenvolvimento de competências organizacionais mediando o desempenho. Entende-se como Pequena e Média Empresa (PME) aquelas que contam com até 200 funcionários no país de origem, desconsiderando-se, para a classificação da população, o número de empregados no exterior. (MDIC, 2010).

Apesar da abertura tardia do País para o mercado internacional, grandes empresas brasileiras se destacam no ambiente competitivo global. Pesquisadores nacionais e internacionais tentam compreender os desafios que as empresas brasileiras enfrentam e as estratégias que utilizam para se manterem competitivas. O foco dos estudos dos diversos núcleos, inclusive o da FEA/USP (GINEBRA), sobre a internacionalização, está nas empresas representativas no cenário nacional ou que movimentam um grande volume de valores e/ou mercadorias, ou seja, empresas de grande porte.

Esta tese procura suprir uma deficiência dos estudos sobre a internacionalização das PMEs brasileiras, as quais têm influência significativa no desenvolvimento do País. Utilizando a teoria de Negócios Internacionais, o enfoque do presente estudo está na atuação direta da PME no exterior, ou seja, nas formas de internacionalização, e também da exportação, o que será aqui chamado de formas mais complexas e empresas com operação no exterior. Embora a exportação seja ainda a forma mais frequente de internacionalização, as PMEs estão tendo, cada vez mais, uma atuação direta no exterior por meio de atividades de distribuição, produção, entre outras. (COVIELLO; McAULEY, 1999; HOLLENSTEIN, 2005; PRATER; GHOSH, 2005; IBEH et al., 2004). O Governo Federal do Brasil colocou a internacionalização da PME como foco das políticas de incentivos para o ano de 2010, com o objetivo de aumentar, em 10\%, a participação efetiva da PME no exterior MDIC (2009 apud CEBRI, 2009). 


\subsection{Relevância do Tema}

Mesmo após a abertura comercial, as barreiras para o comércio internacional têm continuado, mas as economias mundiais tornam-se mais integradas, que acaba se refletindo em uma crescente atuação rumo à internacionalização das Pequenas e Médias Empresas. (LU; BEAMISH, 2001). À medida que a competição vai se tornando cada vez mais intensa, o número de empresas que buscam o mercado internacional como alternativa também cresce. Com o aumento da concorrência, há também uma redução da capacidade da PME em controlar e planificar sua evolução e desenvolvimento no mercado internacional em virtude de sua escassez de recursos comparativamente à grande empresa. (KALANTARIDIS, 2004). Com um ambiente extremamente competitivo, há necessidade de identificar e compreender os fatores que têm impacto sobre o desempenho das empresas, especialmente as PMES, quando estas atuam no exterior. (ETEMAD, 2004).

Apesar de a globalização propiciar às PMEs certa igualdade de condições com as grandes empresas no que tange ao acesso à informação, pelas facilidades da Internet e das telecomunicações, principalmente para as empresas que participam de cadeias globais, existe um conjunto de problemas com os quais as PMEs convivem. A falta de recursos, políticas de treinamento ineficientes e inadequadas, inexistência de sistemas de controle de custos, atraso e deficiência tecnológica e falta de orientação para o mercado são problemas correntes que, de um modo geral, as caracterizam como empresas com baixa capacidade competitiva. Percebese que as empresas de pequeno e médio porte têm grandes dificuldades em ser competitivas em um mercado globalizado e marcado por concorrentes maiores, muitas vezes mais qualificados e mais aptos para enfrentar as mudanças do ambiente devido à estrutura de recursos disponíveis. (FUJITA, 1995).

Por outro lado, apesar das dificuldades que enfrentam, as PMEs produzem uma parte substancial do total de bens e serviços e possuem algumas características que as tornam mais do que simples versões em miniatura das grandes corporações. Elas oferecem contribuições excepcionais, na medida em que fornecem novos empregos, sendo que muitas delas até introduzem inovações, estimulam a competição, auxiliam as grandes empresas e muitas produzem bens e serviços com eficiência. Essas características se sobressaem nas PMEs pela 
rapidez na tomada de decisão, na possibilidade de adaptação dos produtos, entre outras. (LONGENECKER et al., 1998).

As PMEs representam, para o País, a geração de emprego, inovação, flexibilidade, diversificação da competição e uma parte considerável do processo produtivo. Para o Brasil, as PMEs são ainda mais importantes, pois a possibilidade de estas atenderem às necessidades locais, pela flexibilidade e conhecimento local, é muito maior do que a das grandes empresas, podendo, assim, adaptar produtos e serviços às diversas comunidades existentes no País. O relatório da Organization for Economic Co-operation and Development (OECD, 1996) indica que as PMEs estão envolvidas na reestruturação da indústria global de diversas formas, como parceiras em alianças estratégicas internacionais, participantes ou alvo de fusões/aquisições estrangeiras; fornecedores especializados para MNCs; membros do network global informal e/ou do network eletrônico.

No Brasil, o valor das exportações está concentrado nas grandes empresas. Do total de 23.032 estabelecimentos que exportaram em 2008, 23,9 \% são empresas de grande porte (acima de 200 funcionários), cuja participação sobre o valor exportado em 2008 corresponde a 94,2\%. As 16.913 PMEs participaram com 5,7\% do valor das exportações brasileiras no mesmo ano. (SECEX, 2009). Quando se abordam as formas de internacionalização mais complexas, essa concentração deve ser ainda mais expressiva, mas, infelizmente, não há, no Brasil, números oficiais que forneçam essa informação por porte de empresa. (BACEN, 2009; FUNCEX, 2009; SECEX, 2009). As Instituições contatadas para identificar os dados das empresas internacionalizadas por número de empregados são: Banco Central do Brasil (BACEN); Fundação Centro de Estudos do Comércio Exterior (FUNCEX); Secretaria de Comércio Exterior (SECEX) Sociedade Brasileira de Estudos de Empresas Transnacionais e da Globalização Econômica (SOBEET).

A participação das PMEs no mercado internacional em outros países também é inexpressa. $\mathrm{Na}$ União Europeia (UE) -Considerando os 27 países e dados de 2005, do total de 19 milhões de empresas existentes, $91,8 \%$ são microempresas, $6,9 \%$ são pequenas, menos de $1,1 \%$ são médias e somente $0,2 \%$ são grandes empresas. Nas PMEs pesquisadas, conforme demonstra os dados do European Network for SME Research de 2003 (ENSR), 63\% nem mesmo exportam. Esse número aumenta para $80 \%$ se forem consideradas as empresas que somente fornecem para suas próprias subsidiárias no exterior. Das PMEs exportadoras da UE, 3\% 
possuem filiais ou sucursais no exterior. Ainda em relação aos dados da Pesquisa do ENSR (2003), 30\% das PMEs na Europa utilizam como principal forma de internacionalização a importação. Já a exportação aparece em segundo lugar, com 18\% das PMEs estudadas.

Como se pode verificar na Tabela 1, tanto no Brasil como nos Estados Unidos da América (EUA) e na França as PMEs representam o maior número entre as empresas exportadoras, fato que não se repete quando são analisados, na mesma tabela, os valores referentes ao total exportado. Nesse aspecto, as empresas de grande porte apresentam valores expressivamente mais altos que os das PMEs.

Tabela 1 - Exportação: comparativo entre países e porte de empresa

\begin{tabular}{llll}
\hline & Brasil* & EUA** & França*** \\
N. empresas exportadoras & $\mathbf{2 3 . 0 3 2}$ & $\mathbf{2 4 5 . 9 4 5}^{\mathbf{a}}$ & $\mathbf{9 6 . 4 0 0}$ \\
PMEs & 16.913 & 238.566 & 92.544 \\
Grandes exportadoras & 5.508 & 7.378 & 3.856 \\
Outros (pessoa física) & 611 & - & - \\
Valor total exportado (US\$ Milhões) & $\mathbf{1 9 7 . 9 4 2}$ & $\mathbf{1 . 0 3 6 . 6 3 5}$ & $\mathbf{3 1 6 . 5 0 0}$ \\
PMEs & 11.209 & 300.624 & 138.627 \\
Grandes exportadoras & 186.389 & 736.010 & 177.873 \\
Outros & 345 & - & - \\
\hline * PMEs: até 200 funcionários & $* *$ Até 500 funcionários & *** Até 250 funcionários
\end{tabular}

a) Número de exportadores reconhecidos, ou seja, empresas que podem ser vinculadas às transações de exportação, exportações que podem ser vinculadas a empresas específicas.

Fonte: Brasil: SEBRAE (2009), dados de 2008; EUA: International Bureau (2008), dados de 2006; França: Aduana (2006) dados de 2005.

Pesquisas realizadas no Brasil (ALMEIDA, 2007; FORTE; MOREIRA, 2007; FORTE et al., 2008; ROCHA, 2003; SEBRAE, 2006) e em outros países, como Espanha (ARMARIO et al., 2008; CARDOZA; FORNÉS, 2007) e França (BARBAT, 2007; FILION, 2001; MOEN; SERVAIS, 2002; VERSTRAETE; LECERF, 2006), comprovam a baixa participação das PMEs no processo de internacionalização.

Alguns indícios de que a PME brasileira está se internacionalizando de forma mais complexa são apresentados em estudos de casos isolados ou surveys, os quais fornecem alguns números sobre o tema. Pesquisas como as de Ferraz e Ribeiro (2002) e Iglesias e Veiga (2002), realizadas para o BNDES, demonstram que de 460 empresas exportadoras pesquisadas em 13 estados, 20\% possuem Investimento Estrangeiro Direto (IED) e, destas somente 12 empresas são PMEs. Quando os autores apresentam as empresas de capital nacional, esses números são ainda menores: do total da amostra, 17,1\% têm IED e destas 12,3\% são PMEs. 
$\mathrm{Na}$ pesquisa realizada por Rocha e Blundi (2002), foram encontradas somente $8 \%$ das empresas ( 7 entre as 83 empresas analisadas) com investimento direto no exterior. Dib (2008) pesquisou 218 PMEs brasileiras de software e 79 já haviam experimentado algum tipo de internacionalização. Dessas, 35 empresas foram classificadas como Born Globals, ou seja, se internacionalizaram em até cinco anos após sua fundação, e 44 empresas segundo um processo tradicional de internacionalização, ou seja, por meio de um processo mais lento. Verificou-se que fatores ligados à empresa, networks e ao empreendedor mostraram-se importantes para a definição do processo de internacionalização.

O SEBRAE (2006) realizou uma pesquisa, no ano de 2008, com 89 Micro e Pequenas Empresas (MPE) Exportadoras de 18 unidades da federação. Dentre as empresas pesquisadas, $36,10 \%$ afirmam ter representantes no exterior, $14,30 \%$ escritórios de vendas, 13,4\% asseveram ter algum tipo de acordo internacional, 8,4\% possuem fábricas no exterior e 4,2\% atuam no exterior para transferência de tecnologia. O estudo da consultoria Deloitte (2008) evidenciou as 100 PMEs que mais crescem no Brasil. Dessas, 15\% possuem operação no exterior. Os demais estudos que abordam o grau de internacionalização focalizam a grande empresa brasileira e/ou a exportação. Não foram encontrados outros estudos, no Brasil, que abordassem as formas mais complexas de internacionalização em PMEs.

O Brasil é considerado um late mover no processo de globalização e sua participação em mercados internacionais é ainda muito limitada. (FLEURY; FLEURY, 2005). Segundo Rocha (2003), as empresas brasileiras não se internacionalizam em razão de quatro fatores: geográfico (fronteiras demarcadas por intransponíveis obstáculos naturais), ambiental (questões relativas aos macroambientes político e econômico), motivacional (grande mercado doméstico inibe a motivação para internacionalizar-se) e cultural. Quanto a este último fator, cabe ressaltar que "a orientação dos brasileiros, de forma geral, tende a ser predominantemente local." (Ibid., p. 25). A autora afirma também que segundo as teorias da distância cultural os brasileiros tendem a se ver mais distantes do que próximos da maioria dos povos, com exceção dos latino-americanos e portugueses, além de terem dificuldades de confiar em estranhos. Essas colocações evidenciam como as questões culturais são importantes e, no caso brasileiro, parecem entraves. No processo de internacionalização das PMEs, esses entraves são ainda mais expressivos, tendo em vista a falta de recursos humanos especializados e com visão internacional. 
Estudos por mim realizados sobre as competências e a internacionalização na Empresa WEG identificam que a grande empresa brasileira enfrenta inúmeras dificuldades no processo de internacionalização, mesmo com disponibilidade de recursos e com informação. Em consultorias que realizei em empresas de menor porte, essas dificuldades são ainda mais evidentes. De acordo com Shuman e Seeger (1986), um pequeno negócio não é uma pequena versão de um grande negócio. A PME busca retorno em curto prazo, faz baixo investimento e ainda há certo receio em realizar investimentos fora do mercado de origem. Mas o tamanho da empresa não é necessariamente uma barreira à internacionalização (CALOF, 1994); PMEs também encontram saídas para sobrepor seu tamanho, apesar das limitações de capital, gerenciamento, tempo, experiência e informações. (BUCKLEY, 1989). Em outro estudo, Floriani (2003) verificou que os negociadores brasileiros possuem um fator limitador quanto à adaptação e ao conhecimento da cultura nacional, quando comparados a negociadores italianos. Em empresários e dirigentes de PME, essa limitação é ainda maior.

Com base nos estudos realizados e em consultorias desenvolvidas em PMEs brasileiras, percebe-se a necessidade de aprofundar o tema e oferecer à academia, aos órgãos públicos e ao empresariado brasileiro informações que possam servir de subsídios à internacionalização das PMEs.

\subsection{Problema de Pesquisa}

Cada vez mais empresas se instalam em outras regiões buscando algum tipo de atratividade para o seu desenvolvimento e/ou crescimento. (IBEH et al., 2004). Este fenômeno é resultado da busca das empresas por novos mercados e também por vantagens que lhes tragam maior lucratividade ou o acesso a novo mercado. A globalização é uma forma de as empresas se tornarem mais competitivas, a concentração permite a produção em larga escala, o que reduz custos e, consequentemente, beneficia o consumidor.

O cenário atual - caracterizado, em particular, pela interdependência das economias-, a globalização dos mercados e a mundialização da concorrência criaram novas oportunidades, mas também desafios, que levarão as empresas a envidar esforços para a sua inserção internacional. (KOTLER; KELLER, 2006). Por isso, as empresas, ao procurar não só 
vantagens específicas que cada país pode oferecer (vantagens comparativas), mas também competitivas, para abater custos, estão elevando as forças produtivas para se manterem em posição competitiva.

No Brasil, pesquisas que buscaram verificar o grau de internacionalização das empresas abordam as de grande porte. (SOBEET, 2008; FDC, 2006). O paradigma volta-se para a grande empresa, que se internacionaliza com aportes expressivos de recursos, e para as PMEs, que se internacionalizam pela exportação. Porém, após os anos 1990, casos de internacionalização de PMEs contrariam o paradigma quando empresas brasileiras de menor porte veem-se, muitas vezes, obrigadas a sair do País de forma mais efetiva, ou por exigência de grandes clientes já internacionalizados para manter a rede de negócios, ou por necessidade de atender mais de perto os clientes, ou até mesmo por questões logísticas.

Nesse cenário, para muitas PMEs brasileiras, acostumadas com o conforto de estar em um país com 180 milhões de habitantes, com disponibilidade de recursos naturais e humanos e que falam o mesmo idioma, a internacionalização torna-se secundária. Mas, para aquelas que decidem evoluir em seu grau de internacionalização por meio de formas mais complexas, as vantagens de estar no mercado brasileiro tornam-se desvantagens, visto que a empresa, para ter sucesso no mercado internacional, deverá desenvolver competências específicas para atender e atuar num mercado culturalmente diferente. Em consequência desta acomodação proporcionada pelo mercado brasileiro, muitas PMEs, ao se internacionalizarem, não possuem competências para atuar internacionalmente. Acredita-se, contudo, que ao se defrontar com o novo, desenvolvem o "passivo da estranheza" - Tradução realizada pela autora para "liabilities of foreignness". (HYMER, 1976), ou seja, conhecimento e capacidade para operar em um novo mercado.

Estima-se que à medida que o grau de internacionalização aumenta, as empresas vão ganhando experiência, o que tenderia a torná-las mais eficientes, melhorando, consequentemente, seu desempenho. Sabe-se que quanto maior o grau de internacionalização, mais recursos, em especial financeiros e humanos, devem ser deslocados para as atividades internacionais, podendo tirar, principalmente no início do processo de internacionalização, os recursos de outras áreas da empresa que poderiam ser mais lucrativas. 
Principalmente para a PME brasileira, onde os recursos financeiros e humanos são escassos e a falta de experiência internacional é um fato identificado em várias pesquisas (SEBRAE, 2008; DELOITTE, 2008), o início do processo de internacionalização poderá apresentar um resultado inferior ao esperado ou até mesmo negativo, impactando no desempenho financeiro da organização. Acredita-se, no entanto, que à medida que o grau de internacionalização aumenta, também aumentarão tanto as experiências e o consequente aprendizado organizacional como a escala de operações, supondo, assim, que também haveria um melhor desempenho operacional.

Um dos desafios de se pesquisar a internacionalização da PME é a dificuldade de se obter informações acerca dessas empresas, visto que não existem dados primários publicados, e estes são necessários para que se possa analisá-las. Nesta pesquisa, dados primários foram levantados para responder ao seguinte questionamento: $O$ maior grau de internacionalização da PME brasileira desenvolve novas competências e melhor será o desempenho organizacional financeiro e operacional?

Após pesquisas sobre a internacionalização da PME nas principais revistas acadêmicas e em teses da área de negócios internacionais, verificou-se que não há um número expressivo de artigos ou ensaios que apresentem a internacionalização da PME em formas mais complexas. Entretanto, encontraram-se na literatura algumas linhas de pesquisa sobre a internacionalização da PME que são, a seguir, apresentadas.

A linha mais encontrada é a que visa à internacionalização de PME como sinônimo da exportação e limitando-se à ela. (CAGLIANO et al., 2001; CZINKOTA; JOHNSTON, 1983; PRATER; GHOSH, 2005). Considerando os artigos acadêmicos que se referem à PME brasileira, este dado ainda é mais expressivo. (KLOTZLE; CAIRES, 2006; ROCHA, 2003; 1989; SEBRAE, 2008). Tais estudos investigam principalmente as barreiras à internacionalização e o desempenho verificado em estudos de casos isolados de sucesso. Ademais, grande parte dos estudos sobre a internacionalização das PMEs identificou que estas se internacionalizam pelo processo de aprendizagem, onde o acúmulo de conhecimento em operar em mercados externos torna a empresa mais hábil para aumentar o comprometimento dos recursos e expandir as operações internacionais. (CAVUSGIL, 1980; JOHANSON; VAHLNE, 1977, 1990; LEONIDOU; KATSIKEAS, 1996). Diferenças entre as 
empresas exportadoras e as não exportadoras também podem ser encontradas como tema de estudo em PMEs. (CAVUSGIL; NEVIN, 1981; FIGUEIREDO; MARTINELLI, 2002; LEONIDOU, 2004).

Outra linha de pesquisa sobre a internacionalização da PME tem se desenvolvido na academia, principalmente a internacional, apresentando casos de empresas que nascem e que em menos de cinco anos de sua criação já estão exportando: são as chamadas Born Globals. Uma vez mais, o foco dos artigos é a exportação. (BELL, 1995; COVIELLO; MUNRO, 1997; DIB; 2008; MADSEN et al., 2000; MOEN; SERVAIS, 2002; OVIATT; McDOUGALL, 1994; RENNIE, 1993). Neste caso, os temas abordados referem-se principalmente às empresas de alta tecnologia, com foco no comércio eletrônico. (AUGER et al. 2003; LEE et al., 2001). De acordo com Knight (1997), empresas que, a partir da sua criação, se envolvem rapidamente no processo de internacionalização tendem a ser mais orientadas para a internacionalização, ou seja, a operar no exterior de forma mais complexa do que aquelas que somente depois de muito tempo de atuação no mercado interno iniciam o processo de exportação. $\mathrm{O}$ autor sugere que isso acontece devido às rotinas organizacionais que são estabelecidas na organização.

Uma terceira linha de pesquisa é a que aborda o empreendedorismo, ou seja, o papel do dirigente no sucesso da internacionalização da PME. (CALOF, 1994; KNIGHT, 1997; KNIGHT; CAVUSGIL, 2004; OVIATT; McDOUGALL, 1994; STYLES; SEYMOUR, 2006). Estes estudos, na sua maioria, comparam o envolvimento, o grau de escolaridade e o número de viagens ao exterior do dirigente ao aumento do volume das exportações (em valores ou percentual). Pesquisas identificaram que dirigentes orientados para o mercado externo ou que têm atitudes positivas voltadas para a internacionalização apresentam as seguintes características: a) baixa distância psíquica dos mercados estrangeiros; b) são bem educados e possuem experiências em lidar com mercados estrangeiros; c) são menos avessos ao risco e não são resistentes às mudanças; d) são geralmente mais extrovertidos e intuitivos; e) viajam, pelo menos, uma vez ao ano. (DICHTL et al., 1990; HOLZMÜLLER; KASPER, 1990; NUMMELA et al., 2004).

Existem ainda artigos que comparam as PMEs às grandes empresas no que tange à internacionalização com foco em exportação, mas há uma grande disparidade nos resultados encontrados. De acordo com Shuman e Seeger (1986) e Hollenstein (2005), tais empresas se 
comportam de modo diverso devido à limitação de tamanho, de recursos e, consequentemente, apresentam desempenho menor. (CARSON et al., 1995; SMITH et al., 1988).

Por fim, encontra-se na literatura uma linha de pesquisadores que estudam as PMEs com Investimentos Estrangeiro Direto (IED). Dimitratos et al. (2003) e Ibeh et al. (2004) utilizam o termo Micromultinacionais (mMNCs) para caracterizar um certo tipo de PME. De acordo com Dimitratos et al. (2003), mMNCs são uma parte separada das PMEs internacionalizadas que controlam e gerenciam atividades de valor agregado em mais de um país, utilizando estratégias como acordos de licenciamento, franchising, joint-ventures ou subsidiárias. Ibeh et al. (2004) complementam que as mMNCs não são definidas pela sua velocidade de internacionalização, mas pela tendência em adotar formas mais avançadas de servir o mercado em controle e gerenciamento das atividades de valor agregado. Já Fujita (1995) utiliza o termo "Pequena e Média Corporação Transnacional" para generalizar PMEs com operação no exterior. Podem ser encontrados alguns poucos trabalhos internacionais abordando o tema (BIJMOLT; ZWART, 1994; FUJITA, 1995; HOLLESTEIN, 2005), mas, no Brasil, não foram localizados estudos com PMEs focalizando as formas mais complexas de internacionalização.

Tendo verificado a baixa representatividade da internacionalização das PMEs no volume global de empresas brasileiras, pesquisá-las é um desafio. Apesar dos indícios já apresentados sobre as formas mais complexas de internacionalização pelas PMEs brasileiras, não se conhece o seu grau de internacionalização. Entender os motivos que levam as PMEs a atuarem no mercado externo de forma mais complexa, identificando as competências desenvolvidas e o desempenho, torna-se relevante para se criar políticas públicas direcionadas ao aumento da participação efetiva das PMEs brasileiras no mercado global.

O presente estudo aponta necessidade de um olhar mais cuidadoso por parte dos governantes para o desenvolvimento de políticas de apoio à formação de joint-ventures, estabelecimentos de ativos no exterior, transferência de tecnologia e conhecimento, entre outros aspectos que indicam um grau mais avançado de internacionalização. Pesquisas na União Europeia, (p.e. European Network for SME Research-ENSR, 2003; Majocchi e Zucchella, 2003) 
identificaram que quanto mais avançado o grau de internacionalização da empresa, melhor o seu desempenho. A Figura 1 demonstra o foco da presente pesquisa:

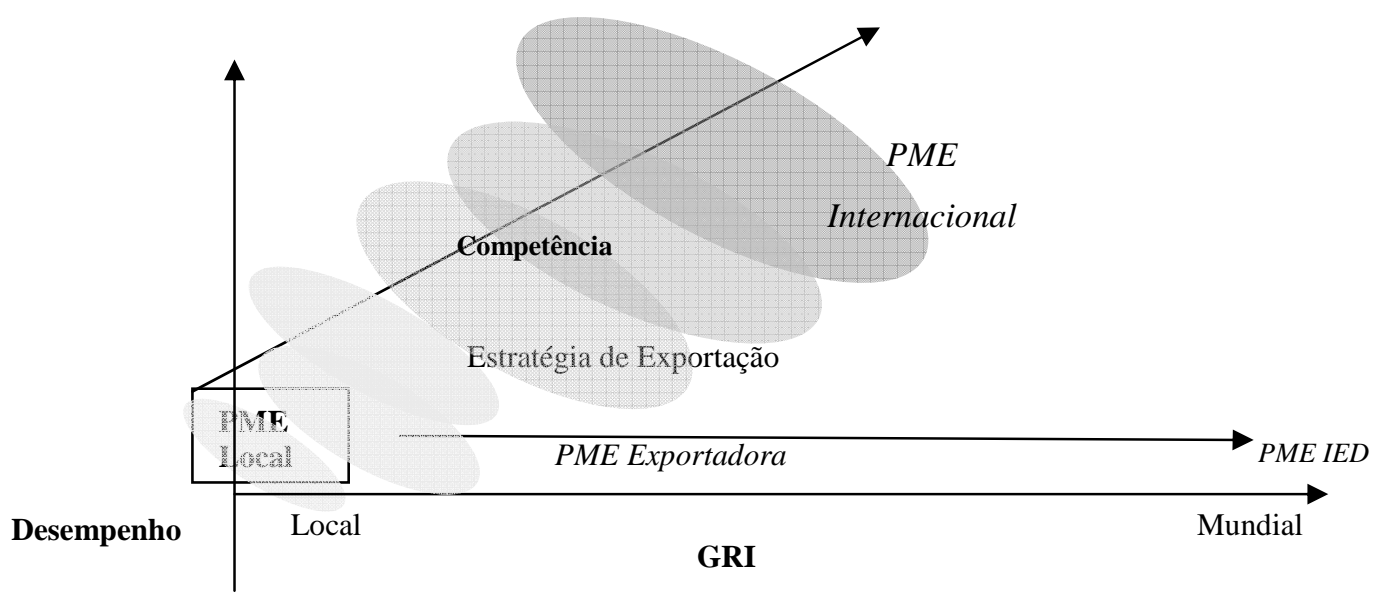

Figura 1: Foco do estudo

Sendo o foco deste estudo a PME brasileira, o Grau de Internacionalização, denominado adiante de GRI, é apresentado mediante um construto multivariado (SULLIVAN, 1994), baseando-se nas Teorias Econômicas (PENROSE, 1959) e Comportamental (JOHANSON, VAHLNE, 1990). Para tal, considera-se além do gradualismo do modo de internacionalização e da aprendizagem apresentados pela Escola de Uppsala, indicadores econômicos provindos de estudos mais voltados para as Teorias Econômicas.

As competências são analisadas partindo-se do conceito organizacional (FLEURY; FLEURY, 2004), que identifica que o GRI gera, para a PME, a possibilidade de buscar recursos e desenvolver capacidades ao redor do mundo, mobilizando-os em prol da empresa como um todo. (PENROSE, 1959; MILLS et al., 2002). Sabe-se que as PMEs, diferentemente das MNCs, são escassas em recursos e dificilmente desenvolverão competências não locais estando em seu país de origem. Portanto, o grau de internacionalização mais avançado propiciará à PME a busca dessas competências para torná-la mais competitiva. Por meio da contribuição de Penrose (1959) com a Teoria baseada em Recursos da Empresa (RBV) e da Escola de Uppsala (Comportamental), entende-se, nesta tese, que as PMEs desenvolvem novas competências à medida que o grau de internacionalização aumenta, entregando às PMEs internacionalizadas a renovação da vantagem competitiva e a sustentação do processo de internacionalização. 
O desempenho é analisado como o resultado financeiro e operacional para a organização.

Para esta pesquisa, a internacionalização se limita às atividades de negócios das empresas que buscam prosperar em mercados internacionais, intrinsecamente ligadas à sua dinâmica de crescimento. (PENROSE, 1959). Admite-se aqui qualquer forma de atendimento a mercados externos, tais como exportação, licenciamento ou investimentos estrangeiros diretos. (BUCKLEY; GHAURI, 1999).

Para definir o problema desta pesquisa utilizam-se como referência teórica (Ver Quadro 1 no capítulo 2) os aspectos comportamentais e a vertente econômica, bem como os construtos de GRI, de competência e de desempenho. A partir dessas teorias, e com base nos estudos já validados e na adaptação à realidade brasileira, principalmente à PME, são construídas as variáveis de grau de internacionalização, de competência e de desempenho. Para estudar quão internacionalizadas são as PMEs brasileiras, e se o aumento do grau de internacionalização desenvolve mais competências influenciando o seu desempenho, utiliza-se de pesquisa teórica e empírica via estudos de caso realizados no Brasil e de pesquisa quantitativa (survey) levada a cabo nas PMEs brasileiras exportadoras.

Assim sendo, tendo verificado a relação entre o aumento do GRI e o desenvolvimento de competências organizacionais, procura-se também identificar nesta tese se há um aumento no desempenho financeiro e operacional das PMEs. Sabe-se que desempenho não é somente uma medida financeira (KNIGHT; KIM, 2009; DIMISTRATOS, 2002; PANGARKAR, 2008); medidas estratégicas também revelam o desempenho da empresa (CAVUSGIL; ZOU, 1994), mas para a PME que possui escassez, principalmente de recursos financeiros, esse indicador é ainda muito importante para que ela possa continuar investindo no mercado externo. Portanto, neste trabalho o foco do desempenho será o aspecto financeiro da organização e o operacional, que poderá também gerar ganho financeiro com o tempo. (PENROSE, 1959; MILLS et al. 2002).

Considerando os aspectos acima abordados, são apresentados no próximo item os objetivos desta tese. 


\section{$1.3 \quad$ Objetivos}

O objetivo geral deste trabalho é investigar se há relação entre o grau de internacionalização, as competências e o desempenho das PMEs brasileiras internacionalizadas. A partir de uma survey aplicada em empresas exportadoras brasileiras e de estudos de casos em PMEs brasileiras com operações no exterior, essa pesquisa procura contribuir para o entendimento da internacionalização das PMEs brasileiras.

Como objetivos específicos, esta pesquisa investiga:

- o Grau de Internacionalização (GRI) das PMEs brasileiras considerando a internacionalização de forma mais complexa.

- $\quad$ as competências que as PMEs brasileiras desenvolveram para enfrentar os desafios da internacionalização de forma mais complexa.

- $\quad$ o desempenho da PME internacionalizada de acordo com o GRI.

Considerando o exposto e os objetivos da tese, que contemplam modalidades mais complexas e desafiadoras em termos de investimentos e de gestão ligadas à internacionalização, indagase: o maior grau de internacionalização da PME brasileira possibilita o desenvolvimento de novas competências e isso afeta o seu desempenho organizacional?

\subsection{Delimitações do Escopo do Estudo}

A internacionalização não é somente um processo complexo necessário para a empresa se manter competitiva, mas também é um processo de alto custo. (DESS et al., 2007). A PME, restrita especialmente pelo tamanho e pelos recursos disponíveis, pode não ter a oportunidade ou pode até mesmo não se permitir envolver-se no mercado internacional, com custos e riscos mais elevados, ficando a exportação como principal meio de entrada da PME como forma de internacionalização. (HOLLENSTEIN, 2005; IBEH et al., 2004). 
Muitos debates têm sido suscitados na academia sobre a relação "grau de internacionalização" e desempenho (Ver detalhes do debate e das variáveis identificadas adequadas para esta pesquisa nos capítulos 3 e 4. Outros dados específicos para identificação da população do estudo para a fase qualitativa e para a fase quantitativa poderão ser encontrados no capítulo 4).

Não há um modelo único para mensurar dados a respeito dessas variáveis, e quando se aborda a PME, o tema fica ainda mais complexo, considerando a dificuldade de se conseguir informações acerca dos valores das empresas e dados dos executivos. Dada a complexidade e a divergência entre os autores sobre essas variáveis, nesta pesquisa foram selecionadas as seguintes fronteiras:

- Os construtos desta tese, como comentado, são bastante complexos. Diante da diversidade de testes utilizados em trabalhos nacionais e internacionais, fica impraticável mensurar todos os indicadores sugeridos pelos autores em virtude de problema de tempo e da dimensão do questionário. Assim, após avaliação das indicações dos autores sobre as variáveis que formam os construtos, selecionaram-se os que mais se adequavam à realidade brasileira da PME com auxílio das entrevistas dos estudos de caso;

- O trabalho limita-se a pesquisar empresas brasileiras de 5 até 200 funcionários, que de acordo com o MDIC (2008) são consideradas as PMEs no Brasil. Não será considerado, previamente, o número de empregados no exterior, tendo em vista a dificuldade de se conseguir esta informação pelo website da maioria das empresas ou outro meio a não ser a aplicação de questionários;

- As empresas analisadas são as PMEs exportadoras. Os órgãos brasileiros responsáveis não possuem ou não disponibilizam relatórios de Investimentos Diretos no Exterior (IDE) por porte de empresa, neste caso, o número de empregados. Por esse motivo verifica-se, dentre as PMEs exportadoras, qual o grau de internacionalização, mesmo que outros trabalhos tenham identificado que algumas empresas que atuam diretamente no exterior não exportem nenhum tipo de mercadoria ou serviço (HOLLENSTEIN, 2005);

- São aqui consideradas apenas empresas brasileiras exportadoras, tendo sido excluídas da abrangência deste estudo as empresas produtoras e exportadoras de commodities, 
trading companies, comercial exportadoras, bem como empresas sem fins lucrativos. Tal exclusão se deve ao fato de se querer focalizar empresas que desenvolvem algum produto ou serviço, envolvendo, assim, uma estrutura organizacional;

- Somente são consideradas empresas brasileiras aquelas em que o capital é, pelo menos, misto. O foco principal da análise de desempenho e do grau de internacionalização é a matriz, daí a limitação do foco em empresas de capital, pelo menos, misto. Seguindo essa mesma justificativa, a exclusão de empresas de controle estrangeiro se deve ao fato de que muitas delas podem ter interesses estratégicos diversos em suas operações no Brasil e, da mesma forma, distanciariam os dados finais das intenções da pesquisa;

- As PMEs que pertencem a grandes grupos empresariais serão parte integrante da pesquisa somente se foram adquiridas por esses grupos e, antes disso, se já estavam internacionalizadas (SIMON, 2003);

- O período temporal é caracterizado pelo início da internacionalização para questões relativas ao desempenho da empresa. Para as demais questões, a referência é o ano de 2009.

\subsection{Contribuições do Estudo}

Percebe-se a necessidade de desenvolver o tema aqui proposto procurando compreender o grau de internacionalização das PMEs brasileiras, buscando identificar a evolução da internacionalização via exportação, até a instalação de subsidiária própria no exterior.

Sabe-se que as PMEs tradicionalmente atuam no mercado local, mas, após 1990, essa realidade vem se modificando. De acordo com (OECD, 2000 apud Relatório do Thomson Financial, 2000) durante os anos de 1988 a 2000 mais de 2.400 alianças internacionais envolveram PMEs. Esse número representa 5\% do total das 42.000 alianças internacionais. De acordo com o estudo, ainda há poucas alianças envolvendo somente PME, a maioria envolve Grandes e PMEs. Cerca de 1/5 de PME de manufatura nos países pertencentes à OECD extrai entre $10 \%$ e $40 \%$ de suas receitas das atividades internacionais. PMEs contribuem com 30\% da manufatura mundial exportada e aportam 10\% dos Investimentos Estrangeiros Diretos. (OECD, 1996, 2000, 2004). 
Não se pretende-se, aqui, elaborar um modelo prescritivo para determinar o que as PMEs brasileiras deveriam fazer quando enfrentam determinadas condições ambientais complexas e dinâmicas na internacionalização, mas compreender quão internacionalizadas elas estão e como esse fator implica o desenvolvimento de competências organizacionais. Em virtude dessa combinação, o comportamento do desempenho financeiro e operacional é analisado.

Verifica-se, ainda, a necessidade de encorajar novos processos de internacionalização das PMEs, por meio da construção das competências necessárias para o sucesso da implantação estratégica.

A insuficiência de estudos disponíveis para compreender a internacionalização das PMEs estimula a realização desta pesquisa, pois identifica competências necessárias para o aumento da participação das PMEs brasileiras no mercado internacional. As PMEs no Brasil são desafiadas a promover o desenvolvimento do País, gerando novos empregos para impulsionar a economia. Para tal, empreendedores e dirigentes necessitam de orientação para atuar de forma mais complexa em mercados estrangeiros e governos necessitam de informações mais específicas para desenvolver políticas específicas para a atuação internacional das PMEs. Este estudo pretende contribuir não somente com a academia, por meio de teorias e de estudos de caso, mas também com as empresas e as entidades, fornecendo dados específicos sobre a realidade das PMEs que estão operando no exterior de forma mais complexa.

\subsection{Organização do Estudo}

No primeiro capítulo, são apresentados a relevância do tema proposto e o problema que instiga o estudo, vindo a seguir os objetivos e a questão de pesquisa. Como em todos os estudos, este não poderia deixar de apresentar suas delimitações, visto que não é possível abordar amplamente todos os aspectos que poderão influenciar o escopo da presente pesquisa. No final deste item, apresentam-se as contribuições do tema estudado.

No segundo capítulo, apresentam-se os conceitos abordados nesta pesquisa - As Teorias de Internacionalização, os principais trabalhos sobre Grau de internacionalização (GRI), Competência Organizacional e Desempenho - de acordo com os principais autores 
internacionais. (BARTLETT; GHOSHAL， 1992; DUNNING， 1977， 1988， 1998; GANKEMA, 2000; JOHANSON; VAHLNE, 1977; KNIGHT; KIM, 2009; LÊ BOTERF, 1998, McDONALD et al., 2003; MILLS et al., 2002; PENROSE, 1959; RAMASWAMY et al., 1996; ROOT, 1994; SULLIVAN, 1994;) e a posição dos diversos autores nacionais (DUTRA, 2001; FLEURY; FLEURY, 1995, 2004, 2005, 2007; FORTE; MOREIRA, 2007; ROCHA, 1989, 2003; RUAS, 2005; TANURE, 2005). Além do aporte geral das teorias, são apresentadas suas críticas, vinculando essas teorias às PMEs, sendo que os trabalhos empíricos publicados foram, na sua maioria, testados em empresas Multinacionais (MNCs). Ao se tratar de PMEs, faz-se mister apresentar as características que as diferenciam das grandes empresas bem como os trabalhos de internacionalização que fazem referência à PME. Ainda neste item são exibidos os dados das PMEs brasileiras com o intuito de identificar a classificação destas no Brasil, visto que há divergência desses números tanto internamente como em outros países, bem como em relação aos números referentes ao aspecto internacionalização.

No terceiro capítulo é apresentado o modelo conceitual que orienta as decisões metodológicas da pesquisa, o qual foi construído a partir da revisão da literatura constante do capítulo 2 e das entrevistas realizadas para a etapa qualitativa desta pesquisa e que se encontram no capítulo 5. Derivadas do referencial teórico, também são apresentadas as hipóteses que são analisadas no decorrer da fase quantitativa.

No quarto capítulo discorre-se sobre a metodologia que foi utilizada na apuração das questões e no atendimento aos objetivos da pesquisa. A fase qualitativa explica os procedimentos de coleta de dados nas PMEs brasileiras que foram utilizados para escolha das empresas e para as entrevistas. Na fase quantitativa, os procedimentos de aplicação do questionário são apresentados e justificados. A parte final deste capítulo contém uma introdução acerca da técnica estatística utilizada nesta pesquisa, as equações estruturais.

No quinto capítulo, os resultados qualitativos e quantitativos desta pesquisa são demonstrados, apresentando inicialmente parte das entrevistas realizadas com os executivos que auxiliaram no desenvolvimento do questionário e na compreensão do contexto PME. Em seguida, apresenta-se o perfil das PMEs estudadas e elaboraram-se os testes estatísticos das equações estruturais, por meio dos quais foi possível comprovar as hipóteses H1a e H1b. 
O capítulo 6 é dedicado à discussão dos resultados, com as implicações para a teoria e para o gerenciamento das PMEs brasileiras.

No último capítulo, além das conclusões do estudo, são expostas as limitações que são usuais em todo trabalho científico, bem como sugestões de novos estudos a respeito do tema aqui estudado. 


\section{REFERENCIAL TEÓRICO}

Este capítulo apresenta o referencial teórico que embasa esta pesquisa. Não se pretende exaurir as informações concernentes ao tema pesquisado, mas apresentar os principais autores e trabalhos que ajudam a compreender e desenhar a pesquisa em tela. Os temas apresentados são: as teorias e modelos de internacionalização, Grau de internacionalização (GRI), competências e desempenho.

\subsection{As Teorias e Modelos de Internacionalização}

Em um colóquio sobre o impacto do tamanho na internacionalização, organizado pela Universidade de Grenoble, na França, em novembro de 2008, estavam presentes diretores de várias empresas francesas (Micro, Pequena, Média e Grande). O diretor da empresa de médio porte, com aparente larga experiência de gerenciamento de projetos internacionais, finalizou sua apresentação da seguinte forma: "Para uma empresa de médio porte se internacionalizar, deve se perguntar: Why, Why, Why, Why and than How."(BLUM, 2009). As decisões que são consideradas pelas empresas no momento de internacionalização são inúmeras: escolha do país, modelos de gestão, forma de controle e de transferência de conhecimento, mas, para o executivo, por que internacionalizar é a decisão mais importante?

Objetivos claros permitem desenvolver estratégias mais consistentes, podendo tornar as operações internacionais menos onerosas e mais assertivas. O conhecimento das teorias que explicam a internacionalização pode auxiliar a PME a identificar seus objetivos e desenvolver as estratégias. A literatura acadêmica de internacionalização permite compreender a escolha do modo de entrada; o motivo entre uma forma de internacionalização e não outra, por exemplo, a fusão ou greenfild; especificidades para a organização da produção, como o uso de terceirização ou expansão interna; os diferentes padrões observáveis entre indústrias e entre empresas nas mesmas indústrias e, no nível macro, explicar o padrão industrial e geográfico do investimento estrangeiro direto através do tempo. (DUNNING, 1988; IETTO-GILLIES, 1997; JOHANSON; VAHLNE, 1977; SULLIVAN, 1994). 
Várias teorias e modelos identificam a internacionalização sob diversas óticas e/ou divergem em seus argumentos de estímulo ao mercado externo. Nesta seção serão apresentadas as teorias mais utilizadas, denominadas de teorias tradicionais. A descrição das teorias conforme seus autores, apresentada logo abaixo, será seguida de críticas e comentários de outros autores. Pretende-se também tecer comentários acerca das teorias, identificando especificidades para as PMEs, visto que essas teorias buscam explicar a internacionalização de empresas utilizando-se geralmente de modelos de grandes empresas ou multinacionais (MNCs).

As teorias tradicionais de internacionalização foram desenvolvidas por vários autores com diferentes abordagens. Encontram-se na revisão da literatura duas grandes correntes teóricas:

- Abordagens da internacionalização com base em decisões econômicas: como a Teoria dos Custos de Transação de Williamson (1975); a Teoria do Poder de Mercado de Hymer (1960/1976); a Teoria da Vantagem das Nações de Porter (1990); a Teoria da Internalização de Buckley e Casson (1976) e o Paradigma Eclético ou OLI de Dunning (1977; 1988) e Penrose (1959), com a Teoria Baseada em Recursos (RBV).

- A internacionalização como evolução comportamental: como o modelo de internacionalização de Uppsala - Johanson e Wiedershein-Paul (1975), evolução da internacionalização pelo aprendizado; Johanson e Vahlne (1977), com enfoque em processos e, em 1990, pelos mesmos autores, com foco em networks.

As correntes teóricas propiciaram a realização de várias pesquisas nas diferentes linhas, buscando identificar a internacionalização de empresas diante de diferentes motivações, como identificado por Andersen e Buvik (2002) e também citado por Carneiro (2007):

- Correntes Econômicas: explicam o processo de internacionalização baseado em critérios de escolhas racionais estruturadas, buscando a maximização dos retornos econômicos.

- Correntes Comportamentais: o processo de internacionalização é influenciado pelas percepções dos executivos e empreendedores, os quais tomariam suas decisões em um contexto de racionalidade limitada e de busca de minimização do risco. 
- Networks: abordam internacionalização como fruto da rede de relacionamentos entre pessoas e entre empresas.

Neste trabalho, o foco de estudo é a internacionalização mais complexa da PME, como já comentado. Não obstante as teorias não abordarem especificamente o tema, procurar-se-á, nos próximos itens desse capítulo, apresentar as principais correntes teóricas e a abordagem que pode melhor se adequar ao presente trabalho.

\subsubsection{A teoria econômica da internacionalização}

Apresenta-se, neste item, a vertente econômica das teorias de internacionalização. Abordamse, inicialmente, os conceitos gerais de seus autores e, em seguida, o posicionamento de outros autores, críticas, bem como a vinculação da teoria com as PMEs. Teorias econômicas que analisam o cenário da empresa, a indústria e o engajamento da Nação no comércio exterior não são tratadas neste item tendo em vista que são mais amplas que a empresa como unidade de análise. (CANNON, 1980; LEONIDOU; KATSIKEAS, 1996).

Dependendo do foco da empresa, a internacionalização, quando analisada sob o aspecto econômico, identifica aspectos relativos à vantagem e desvantagem dos custos. Assim, a primeira teoria a ser apresentada é a Teoria dos Custos de Transação (WILLIAMSON, 1975), que pressupõe que desde o instante que a empresa decide explorar o mercado estrangeiro na sua forma menos complexa, ou seja, por meio da exportação, ela enfrenta custos, sejam estes associados à busca de informação ou ao cumprimento de contratos. São os chamados custos de transação. Estes dois tipos de custos variam em sentido inverso. Quanto maior o custo na busca de informação, menor os problemas decorrentes do fechamento de um contrato e viceversa. Quando a empresa decide entrar no mercado de forma mais comprometida, tal como uma aliança estratégica, subsidiária própria ou adquirida, surgem novos custos - os chamados custos de internalização. Tais custos estão relacionados à obtenção de melhor conhecimento do mercado; construção da empresa no exterior; custo de controle e coordenação das atividades; custos de flexibilidade e reversibilidade dos investimentos. Quando estes custos de internalização forem maiores que os custos de transação, a empresa decide não se instalar com subsidiárias no mercado e vice-versa. Portanto, a decisão da empresa em incrementar suas formas de internacionalização perpassa pelo trade-off dos custos de transação e internacionalização. Para autores como Anderson e Gatignon (1986), os custos de transação 
visualizam os modos de entrada em países estrangeiros como uma transação individual que envolve um trade-off concomitante entre controle e recursos.

Não considerando somente os custos, mas focalizando a concentração do mercado, a teoria do Poder de Mercado preconiza, na visão de Hymer (1960/1976), que a empresa, nos estágios iniciais de seu crescimento, continuaria aumentando sua participação no mercado doméstico por aquisições ou aumento de capacidade produtora ou associações. Isto é, à medida que aumentasse a concentração industrial e o poder de mercado, a empresa melhoraria seu desempenho financeiro. $\mathrm{O}$ autor identificou a capacidade de firmas específicas, agindo sós ou em conluio, dominarem seus respectivos mercados e obterem maiores lucros, ou até mesmo ficando mais protegidas.

Quando o crescimento da empresa no mercado doméstico se estagnasse devido à impossibilidade de novas concentrações, a empresa utilizaria os lucros obtidos durante o período de alta concentração do poder no mercado doméstico em operações externas, iniciando, assim, um novo ciclo de crescimento via concentração crescente de poder em mercados estrangeiros. Hymer (1960/1976) apontou que operações internacionais ocorrem apenas sob condições especiais. Nem sempre seria possível prever, com precisão, a forma ou a extensão de tais operações, pois os mercados em que elas se desenvolvem podem ter natureza monopolística.

Já a teoria, a seguir exposta, a da Internalização, analisa os custos versus os benefícios decorrentes da internacionalização. Alguns autores fazem referência à Teoria da Internalização como inicialmente apresentada por um artigo de Coase (1937 apud CANTWELL, 1991; DIB, 2008), mas Buckley e Casson (1976) formalmente propuseram a teoria em que a empresa se internacionaliza passando do processo de exportação para outros modos de internacionalização mais complexos. Assim, os recursos e os conhecimentos compartilhados no exterior passam a ser de propriedade exclusiva da firma. A teoria analisa os benefícios versus custos, o que geraria um grau adequado de interação da empresa nas atividades internacionais.

Esta teoria foi baseada em evidências que mostram que as firmas maximizam lucros num mundo de mercados imperfeitos; quando os mercados em produtos intermediários são 
imperfeitos, existe um incentivo para deles se desviar ao se criar mercados internos; e, ainda, a internalização de mercados através de fronteiras geográficas torna as empresas multinacionais (MNCs). A teoria apresentou a MNC como aquela que pretendia ser suficientemente poderosa para suportar projeções de longo prazo do crescimento futuro e da estrutura das empresas. (DUNNING, 2003).

Buckley e Casson (1976) apontaram que uma das características mais notáveis da multinacionalidade era sua representatividade entre empresas muito grandes, empresas grandes, problemas grandes, ou seja, o tamanho refletia parte dos problemas das empresas.

Segundo os mesmos autores, em 1976, as características das MNC eram as seguintes:

- $\quad$ a expansão das multinacionais ocorreu no período logo após a Segunda Guerra;

- $\quad$ o investimento internacional direto do pós-guerra aparentemente não apoiava a teoria segundo a qual o capital se move de países abundantes em capital para países com escassez de capital;

- a multinacionalidade tendia a ser maior quanto maior fosse a empresa;

- $\quad$ as MNEs eram mais frequentes em alguns tipos de indústrias caracterizadas por alta concentração e alta intensidade de pesquisa e capacitação. Nestas indústrias, as MNEs pesquisavam mais, empregavam mais empregados qualificados e obtinham taxas de retornos maiores do que as empresas não multinacionais;

- a maior parte das MNEs era diversificada horizontalmente (produziam o mesmo produto em várias fábricas diferentes). Muitas das grandes MNEs eram diversificadas verticalmente (produziam produtos intermediários que correspondiam a diferentes estágios na mesma sequência produtiva);

- $\quad$ as MNEs apresentavam certas características associadas à sua nacionalidade.

Para Buckley e Casson (1976), a internalização seria feita até o ponto adequado, ou seja, benefícios iguais aos custos. A localização desta firma integrada verticalmente seria determinada pela inter-relação de vantagens comparativas, barreiras ao comércio e incentivos regionais para internalizar. Quando esses fatores fossem ótimos, a firma se tornaria uma MNC. Os autores comentam que há fatores que podem tornar a operação ineficiente, sendo a comunicação o maior entrave. Os fatores são: 
- $\quad$ fluxo de informações maior no mercado internalizado;

- $\quad$ necessidade de confidencialidade;

- $\quad$ visitas a locais dispendiosas para checar a informação.

Quanto maior a distância social, ou seja, diferença de cultura, idioma, costumes, regras, etc., maior seria o problema. Os autores mencionam quatro fatores que influenciam a decisão da internalização:

- fatores específicos da indústria: natureza do produto, estrutura do mercado externo, relação entre as escalas eficientes mínimas dos distintos estágios;

- fatores específicos da região: distâncias geográficas e sociais;

- fatores específicos do país: relações políticas e fiscais entre os países;

- $\quad$ fatores específicos da empresa: nível de especialização do corpo gerencial.

Coase (1937 apud CANTWELL, 1991) asseverou, em seu artigo, que com aumento da complexidade do trabalho, pela internacionalização, por exemplo, o empreendedor seria uma força de integração, garantindo o crescimento da diferenciação econômica.

De acordo com Fina e Rugman (1996), os teóricos da internalização sugerem que o Investimento Estrangeiro Direto (IED) ocorre quando os benefícios da internalização superam os custos. Sendo assim, a teoria da internalização considera que as falhas de mercado, como custos de informação e o oportunismo, muitas vezes motivam a empresa a utilizar o investimento direto como modo de entrada em um mercado externo, internalizando sua atividade ao mercado externo. A Teoria da Internalização possui limitações que reduzem sua capacidade de explicar o comportamento dos negócios internacionais, colocando a minimização dos custos como a principal razão para a internacionalização. (MTIGWE, 2006; DIB, 2008).

Como uma junção de várias teorias econômicas, Dunning (1988) desenvolveu, inicialmente, a teoria que explica a internacionalização da firma com foco no impacto nos países de origem e no hospedeiro. Partindo de princípios de economia, do conceito de custo de transação e da teoria da internalização, Dunning (1995) fez emergir o paradigma eclético da produção internacional. Trata-se de um modelo conceitual para internacionalização, que pretende 
explicar a amplitude, a forma e o padrão da produção internacional, com base em três tipos de vantagens: a propriedade da firma (Ownership), vantagem de localização (Location) e vantagens de internalização (Internalization), também conhecida como a Teoria OLI.

A vantagem específica da Propriedade das Firmas (Ownership) concerne à produção no exterior. Essa vantagem advém das capacidades de gerenciamento e da utilização de seus recursos como um diferencial para competir com seus concorrentes no exterior. As vantagens da firma podem ser advindas das forças de trabalho, propriedades tecnológicas, economia de escala ou outros.

A atratividade da localização da produção no exterior (Location) é relacionada a fatores específicos de onde o negócio está localizado, relacionando-se ao macroambiente do país receptor. Se positivo, fatores específicos de localização não estão presentes, então exportar é a melhor estratégia de entrada. (DUNNIG, 1998). Os fatores específicos podem ser a busca de baixos custos de mão de obra e de matéria-prima; menores custos de transporte e comunicação em relação à exportação; maior adaptação ao mercado estrangeiro, reduzindo a distância física da cultura, do idioma e dos hábitos locais; e a capacidade de explorar o potencial de mercado. Estes três elementos (propriedade, localização e internalização - OLI) seriam fundamentais em cada decisão de produção de uma empresa atuando nos mercados internacionais via produção no exterior.

A propensão a internalizar mercados (Internalization) aborda a estrutura interna da empresa e a força necessária para processos superiores relacionados às operações internas da empresa.

Dunning $(1988,1998)$ ainda considera que as empresas são motivadas a se internacionalizar pelos seguintes motivos: a) busca de matérias-primas e mão de obra (resource seeking); b) atendimento ao mercado local (market seeking); c) busca da eficiência (efficiency seeking) para conquista de outros mercados por meio de especialização e localização; d) estabelecer melhores condições de competitividade no mercado importador (trade and distribution); e) evitar ou usufruir das políticas governamentais (comerciais, tributárias e de preços).

Uma limitação desta teoria era a de não considerar a evolução do processo de expansão global no longo prazo. Uma recente revisão da Teoria OLI, contudo, enfatiza as alianças e networks, dando mais peso para a evolução dos processos de internacionalização. (DUNNING, 2003). 
Dunning defendeu que seu paradigma não deveria ser encarado como mais uma teoria, mas sim como um arcabouço teórico para o estudo da internacionalização. A principal contribuição da Teoria OLI, segundo Mtigwe (2006), foi aumentar a percepção de que uma empresa precisa construir e manter vantagens competitivas para ser bem-sucedida em mercados internacionais. Porém o autor apontou limitações a esta teoria, devido à ênfase dada no custo geral de se conduzir negócios internacionais, pois a Teoria OLI está focada em grandes empresas multinacionais. Para Mtigwe (2006), empresas de pequeno porte já são realidade nos negócios internacionais, as quais podem ou não possuir vantagens de propriedade e não são consideradas pela teoria.

Das classificações apresentadas por Dunning (1998), Cretoiu (2007 apud ALMEIDA, 2007) destaca que os objetivos mais comuns dos Investimentos Diretos no Exterior para as PMEs são Trade and distribution e o Marketing seeking. O primeiro é normalmente motivado por três forças: o desejo de aumentar a margem de lucratividade das operações; dificuldades relacionadas ao funcionamento do mercado e; por fim, a busca por diferenciação. Já o investimento marketing seeking pode se beneficiar da redução ou eliminação de custos de transporte, de incentivos governamentais à produção local e usufruir de preferências tarifárias geradas por acordos comerciais.

Hollenstein (2005) identificou, em seu trabalho sobre os determinantes das atividades internacionais e o porte das empresas, que para a PME a Teoria OLI poderia ser aplicada. Vantagens de Propriedade (Ownership) podem ser visualizadas nas características específicas das empresas e na capacidade de tornar a empresa superior aos concorrentes locais. Nessa vantagem, encontram-se o conhecimento do empreendedor ou dos executivos, patentes, capacidade de adpatação do produto e competência tecnológica. Como vantagem de Localização (Location) tem-se um ganho potencial que a empresa pode obter, otimizando suas atividades pela alocação na sua cadeia produtiva, principalmente quando realizada em países com diferentes fatores produtivos, como disponibilidade, qualidade e/ou preço, custo de transporte, diminuição de barreiras tarifárias ou não-tarifárias, entre outros. Já a vantagem de Internalização (Internalization) pode ser obtida pela internalização do mercado mediante fusões e aquisições ou formando parcerias e alianças. Com isso a empresa pode reduzir custos de pesquisa e de transação e mais segurança nos produtos chave para a empresa no mercado externo. O autor utiliza a Teoria OLI para explicar os resultados da sua pesquisa e identifica 
que para a PME a vantagem de Localização é um fator determinante para evoluir no grau de internacionalização.

Algumas empresas localizadas em determinado país apresentam vantagens diferenciadas relativamente a outras empresas do mesmo setor, localizadas em outros países. Neste sentido, a localização é tratada por Porter (1990) como a Teoria da Vantagem das Nações. $O$ autor identificou quatro atributos que podem explicar o “Diamante da Vantagem Nacional":

- Condições dos fatores: neste atributo aparecem os fatores ligados à produção, como, por exemplo, mão de obra qualificada e infraestrutura. Fatores específicos de produção que garantem a vantagem nacional são altamente especializados e relacionados com as necessidades de um setor, são escassos e difíceis de imitar.

- Condições da demanda: a composição, intensidade e natureza da demanda de um país faz com que as empresas identifiquem antecipadamente, para os seus concorrentes internacionais, as necessidades dos consumidores. Este atributo pode gerar um importante fator para a inovação e padrões de qualidade devido à demanda intensa e sofisticada, permitindo a antecipação às necessidades globais.

- Setores correlatos e de apoio no país: fornecedores qualificados, que fornecem os insumos com menor custo, maior rapidez e ainda apresentem as novidades do mercado global, permitem um benefício maior para a empresa local.

- Estratégia, estrutura e rivalidade das empresas: a competitividade do setor específico em um país é decorrente dos modelos organizacionais mais praticados. Por exemplo, a tradição pode justificar o motivo de maior rivalidade de um setor em um determinado país. Neste atributo não há uma vantagem específica para determinada empresa ou para as empresas estrageiras.

A teoria de Porter (1990) tem como objetivo explicar os motivos pelos quais um país apresenta condições domésticas que garantem uma competitividade não baseada em custos, mas em qualidade, diferenciação e inovação.

Embora as teorias econômicas tenham gerado mais publicações, algumas limitações podem ser apontadas: 
- $\quad$ abordaram apenas alguns aspectos da dinâmica da produção internacional;

- $\quad$ adotam a postura da tomada de decisão com foco na otimização dos custos;

- $\quad$ assumem que não existem restrições à racionalidade e que decisões "ótimas" poderiam ser alcançadas nas questões ligadas à internacionalização da firma. Ignoram o aspecto aprendizado e o papel do tomador de decisão e não consideram o network, mas que a empresa tomaria as decisões de maneira autônoma (WHITELOCK, 2002), apesar de considerarem (DUNNING, 1995; HYMER, 1976) a possibilidade de associações;

- na abordagem econômica, as empresas tornam-se internacionais muito tempo depois da sua formação, focalizando apenas empresas grandes (McDOUGALL et al., 1994). Para Etemad (2004, p. 1), tais teorias "têm oferecido pouca, se alguma, orientação teórica para as empresas de menor porte que aspiram internacionalizar-se."

Dunning (1988) considerou ainda a necessidade de integração das teorias econômica e comportamental da firma para um melhor entendimento da firma multinacional, em especial deveriam ser identificados e avaliados padrões sistemáticos de tais comportamentos.

Entre a teoria econômica e o modelo comportamental (apresentado no próximo item) está a obra de Penrose (1959), que por meio de sua teoria do conhecimento e mudanças dentro da firma contribui com a Teoria da Internacionalização. O crescimento da firma está diretamente vinculado à aquisição de conhecimento, que é um processo evolutivo baseado no acúmulo da experiência da firma. A visão de firma para Penrose (1959) difere da dos economistas tradicionais por não se limitar a um produto, já que é definida por uma unidade administrativa que pode produzir mais de um produto. Difere ainda ao não identificar como único objetivo da firma a maximização de lucros, pois defende que a firma deseja lucros com o objetivo de se expandir. Assim sendo, crescimento e lucro são fatores com o mesmo peso ao tomar decisões de expansão. (BARNEY, 1991; MILLS et al., 2002).

A firma cresce quando transfere habilidades inimitáveis, como, por exemplo, de marketing, produção e pesquisa de uma linha de negócios para outra, mas é o gerenciamento destas que vai permitir o crescimento continuado. Conforme as empresas crescem, elas desenvolvem técnicas para usar os recursos humanos de modo mais eficiente, e esses recursos ganham mais experiência. Como resultado, Penrose (1959) propôs que os recursos gerenciais cresceriam um pouco mais rápido do que o tamanho da empresa, o que atualmente pode ser justificado 
pelas pesquisas sobre o empreendedorismo nas PMEs. (KNIGHT; CAVUSGIL, 2004; OVIATT; McDOUGALL, 1994; CALOF, 1993).

Penrose (1959) afirma em sua obra que tudo é escasso, menos o conhecimento. A experiência desenvolveria um conhecimento crescente de possibilidades para ação e das maneiras pelas quais ações poderiam ser operacionalizadas pela firma. Este aumento de conhecimento causaria a mudança nas oportunidades produtivas de uma empresa.

Na visão de Penrose (1959), empreendedores teriam um papel crucial a desempenhar na interpretação das informações de resposta do ambiente, para entender e integrar serviços produtivos. As capacitações do pessoal gerencial existente na firma colocariam, necessariamente, um limite para a expansão daquela firma em certo período de tempo, visto que tal gerenciamento não poderia ser contratado no mercado rapidamente. (KNIGHT; CAVUSGIL, 2004; PENROSE, 1959). Os trabalhos sobre PMEs abordam essa importância para a expansão internacional das empresas, sendo esta uma das vantagens das PMEs sobre as MNCs. (HOLLESTEIN, 2005; TODD, 2006).

As contribuições de Penrose são apresentadas na definição de competência (item 2.3), pois, ao definir a Teoria dos Recursos da Firma, a autora explica a importância dos recursos tangíveis e dos recursos humanos nos processos de internacionalização; o desenvolvimento de competências essenciais e a manutenção delas para serem competitivas. O conceito de Penrose também foi utilizado por Johanson e Vahlne (1977) para distinguir dois tipos de conhecimentos: o conhecimento objetivo, ou seja, que pode ser ensinado; e o conhecimento experiencial, que pode ser apenas aprendido pela experiência pessoal. Os autores do Modelo de Uppsala (JOHANSON; VAHLNE, 1977, 1990; JOHANSON; WIEDERSHEIM-PAUL, 1975) utilizaram este conceito e o vincularam à expansão internacional lenta e gradual, considerando que o conhecimento experimental exige tempo para ser adquirido e, assim, apresentaram o Modelo que faz parte da teoria comportamental da internacionalização.

\subsubsection{A teoria comportamental da internacionalização}

Nas teorias que abordam o comportamento destaca-se o modelo proposto pela Escola Nórdica de Negócios Internacionais, cuja origem está na Escola de Uppsala. Dos estudiosos da Escola Nórdica, uma atenção especial foi dada aos estudos conduzidos por Johanson e Wiedersheim- 
Paul (1975) e Johanson e Vahlne (1977; 1990), os quais pressupõem a percepção de distância psíquica ou psicológica entre o país de origem e os países estrangeiros no processo de internacionalização da empresa. (HEMAIS; HILIAL, 2004; 2005). Um fato introduzido pela Escola de Uppsala foi o modo de se fazer negócios internacionais, que, além das vertentes econômicas, deveriam olhar sob o prisma e a perspectiva da Teoria do Comportamento Organizacional.

Johanson e Vahlne (1977) desenvolveram um modelo para explicar os processos de internacionalização baseados na gradual aquisição e uso do conhecimento nos mercados estrangeiros, bem como o aumento sucessivo do comprometimento nesses mercados. $\mathrm{O}$ comprometimento aumenta à medida que o conhecimento cresce. O comprometimento é, pois, medido de acordo com a quantidade de recursos investidos e cresceria em função da experiência acumulada. Assim, a percepção do risco diminui e o envolvimento tende a crescer. Para Hemais e Hilal (2002), na percepção do modelo da Escola de Uppsala, a empresa internacional seria uma organização que se caracterizaria por aprendizagens em uma estrutura complexa e difusa de recursos, competências e influências, incrementando as fases da internacionalização.

A incrementação seria decorrente de racionalidade limitada e de objetivos de redução de risco. De acordo com o modelo de Uppsala, a falta de conhecimento sobre mercados estrangeiros é um importante obstáculo para o desenvolvimento de operações internacionais e este conhecimento é adquirido principalmente por meio das operações internacionais. A internacionalização de uma empresa seria entendida como uma alternativa para se sair da saturação inicial de um mercado ou de uma estratégia. Então, ao partir para o exterior, a empresa encontraria maiores incertezas e, portanto, buscaria situações de mercado mais próximas possíveis das que já conhece.

Dois fatores foram considerados, por Johanson e Vahlne (1977), como fundamentais na tomada de decisão de internacionalização: a distância psíquica e o tamanho de mercado potencial. Entende-se por este último um mercado potencial grande ou pequeno; já a distância psíquica foi definida pelos autores Johanson e Wiedersheim-Paul, em 1975, como fatores que impedem ou perturbam os fluxos de informação entre a empresa e o mercado, como idioma, hábitos, sistema político, geração de renda, nível educacional de cada mercado, entre outros. 
Já Nordström e Vahlne (1994) conceituaram a distância psíquica como o conjunto de fatores que dificultam ou impedem o aprendizado e o entendimento das empresas acerca de um ambiente no exterior.

McDonald et al. (2003), ao analisarem o Modelo de Uppsala (JOHANSON; VAHLNE, 1990; JOHASON; WIEDERSHEIN, 1995) e a literatura da Distância Psíquica (NORDSTRÖM; VAHLNE, 1992), reforçaram que o processo de internacionalização segue caminhos e sequências de desenvolvimento que vão da simples atividade de negócio internacional com países que são geografica e psicologicamente próximos, para operações mais complexas e com países mais distantes, contribuindo com o aprendizado da empresa para ultrapassar as barreiras das atividades dos negócios internacionais.

Os estudos sobre a internacionalização das empresas brasileiras testaram o Modelo de Uppsala, por exemplo o de Hilal e Hemais (2001), que exemplificaram, com quatro estudos brasileiros sobre internacionalização, como o modelo permitia um entendimento mais claro da diversidade de evidências empíricas na área de Negócios Internacionais. Para os autores, o entendimento da internacionalização das empresas brasileiras ainda deveria considerar o conceito de distância psíquica no nível individual, em vez do nível nacional originalmente proposto; a existência de processos de internacionalização descontínuos; e o importante papel desempenhado tanto via networks quanto pelos empreendedores.

Críticas à teoria comportamental também são encontradas na literatura:

- $\quad$ adrões de internacionalização e dos processos de firmas individuais seriam únicos e muito dependentes das especificidades da situação. É muito determinístico. (REID, 1981);

- $\quad$ este modelo é relevante apenas em relação aos estágios iniciais da internacionalização, quando a falta de conhecimento de mercado e a falta de recursos ainda seriam fatores limitadores. (ADERSEN, 1993; FORSGREN, 1989);

- determinantes estratégicos não são considerados pelo modelo;

- a generalização dos processos de internacionalização, das indústrias e dos mercados tornaria o conhecimento do mercado não mais um limitador aos padrões de internacionalização das empresas. (HEDLUND; KVERNELAND, 1985); 
- da mesma forma, a distância psíquica teria diminuído. O mundo tornou-se muito mais homogêneo, o que levaria novas empresas a desejarem e serem capazes de entrar diretamente em mercados maiores. (NORDSTRÖM, 1991);

- $\quad$ o modelo não considera a interdependência entre os mercados de diferentes países. (JOHANSON; MATTSSON, 1986).

Em 2003, Johanson e Vahlne identificaram que os modelos de internacionalização incremental, anteriormente apresentados, não faziam mais sentido, pois o fato de o mundo estar estruturado em entidades nacionais com arranjos culturais e institucionais diferentes seria, na verdade, menor do que haviam pensado e proposto nos estudos anteriores. As razões para essa mudança seriam o processo da globalização, que aproximaria os países em termos culturais e institucionais e a maneira tendenciosa dos observadores da internacionalização com base em maneiras preexistentes de entendê-la e explicá-la, como as explicações econômicas.

Johanson e Vahlne (2003), ainda revendo o modelo tradicional, acrescentaram a perspectiva de network e do empreendedor. O processo empreendedor estaria ligado a aprendizado por experiência e por fazer uso de alguns relacionamentos previamente existentes (network). Conquanto mais próxima à PME que a vertente econômica para explicar os processos de internacionalização, ainda há muitas lacunas para serem preenchidas nos negócios internacionais. Com essa revisão, os autores acataram as críticas à Teoria comportamental e incrementaram à Teoria aspectos de Network. Para os autores (Ibid., 2003) um processo de internacionalização pode ser não sequencial, mas por meio de network que também traz conhecimento para a empresa na expansão internacional. (JOHANSON; MATTSSON, 1988; VATNE, 1995). Os autores concordaram com as críticas quando mencionaram que o modo de entrada em países estrangeiros, embora sendo ainda grande parte do esforço dos autores da área, seria menos importante na análise da internacionalização do que a subsequente expansão internacional.

Burgel e Murray (2000) apontaram que a decisão do modo de entrada é necessariamente um trade-off entre os recursos disponíveis e as necessidades de suporte ao consumidor. A inovação da tecnologia e a experiência histórica da empresa no mercado doméstico seriam determinantes na escolha do modo de entrada. Empresas que vendem produtos que 
incorporam tecnologias inovadoras e aquelas que já estão em grandes mercados, que já usassem intermediários em seus mercados domésticos, tenderiam a confiar mais em distribuidores estrangeiros. A exportação direta, em contraste, seria escolhida quando os gerentes apresentassem experiência de trabalho internacional prévia ou quando um produto requeresse uma significativa adaptação específica aos clientes. Os autores consideraram que uma perspectiva de capacitações organizacionais sobre o comportamento deste tipo de empresa explicaria melhor as decisões de entrada do que a abordagem de custo de transação ou a teoria de estágios.

Para a Escola de Uppsala, a empresa se internacionaliza investindo recursos (financeiros e outros) de maneira gradual até aprender com o novo mercado. Isto permite que a empresa construa a estratégia dos modos de entrada partindo do menor para o maior envolvimento. (CAVULSGIL, 1980; ROOT, 1987; VATNE, 1995). Mas, quando se trata de empresas de países emergentes, ou também chamados de late movers, a Escola de Uppsala não é completamente aplicada. São considerados late movers os países que se internacionalizaram tardiamente em comparação com países desenvolvidos. O Brasil é considerado um late mover, enquanto países como a Itália, França, Alemanha, EUA são considerados first movers. (FLEURY; FLEURY, 2005).

Isto se deve ao fato de as empresas não terem o mesmo tempo para ingressar no mercado externo e/ou decidir sobre o próximo passo. (MATHEWS, 2006). Em países emergentes, e ainda em PMEs, o que muitas vezes explica o aumento do grau de internacionalização é a oportunidade e as redes de relacionamento a que a empresa pertence. (ANDERSSON; FORSGREN, 2000).

O Modelo de Uppsala é considerado por muitos autores o ponto teórico inicial para explicar a internacionalização das PMEs. (ANDERSSON et al., 2004; ETEMAD, 2004).

As teorias econômicas e os modelos de estágios de internacionalização representam um ponto de vista econômico e comportamental das estratégias de expansão internacional. (BENITO; WELCH, 1994). Outros autores têm acrescentado a estes modelos e teorias a importância das relações interorganizacionais, como governo, clientes, fornecedores, concorrentes ou qualquer pessoa que possa ter impacto no sucesso da empresa. (COVIELLO; McAULEY, 1999). 
A limitação dessas teorias é o que concerne à PME, pois de forma geral essas teorias foram desenvolvidas focando grandes multinacionais. (BARBAT, 2007; TODD, 2006). Um resumo das principais abordagens é apresentado no Quadro1, que mostra as ideias fundamentais de cada teoria abordando aspectos vinculados a PME.

Quadro 1 - Principais abordagens teóricas da internacionalização das PMEs

\begin{tabular}{|c|c|c|c|}
\hline Abordagem teórica & $\begin{array}{c}\text { Exemplo de } \\
\text { modelos e de } \\
\text { trabalhos }\end{array}$ & Exemplo de autores & Ideias fundamentais \\
\hline \multirow{4}{*}{ Econômica } & $\begin{array}{l}\text { Foco em } \\
\text { recursos }\end{array}$ & $\begin{array}{l}\text { Penrose (1959), Mills } \\
\text { et al.(2002) }\end{array}$ & $\begin{array}{l}\text { Os recursos e as competências da PME, } \\
\text { determinantes nos diferentes níveis de } \\
\text { internacionalização, são passíveis de } \\
\text { explicar a passagem de um ao outro, de } \\
\text { estagnar ou de retornar às etapas } \\
\text { anteriores. }\end{array}$ \\
\hline & $\begin{array}{l}\text { Foco no custo de } \\
\text { transação }\end{array}$ & $\begin{array}{l}\text { Bucley e Casson } \\
\text { (1995) Dunning } \\
(1977 ; 1988 ; 1998) \\
\text { Willianson }(1975)\end{array}$ & $\begin{array}{l}\text { Análise de custo e beneficio. O } \\
\text { aproveitamento de vantagens competitivas } \\
\text { ou comparativas pode explicar a } \\
\text { internacionalização das PMEs.Não } \\
\text { identificam a importância do } \\
\text { conhecimento e da informação para } \\
\text { explicar o } \text { processo de } \\
\text { internacionalização. Os autores assumem } \\
\text { que a informação antecede a } \\
\text { internacionalização (LIESCH; KNIGHT, } \\
\text { 1999). }\end{array}$ \\
\hline & Foco no país & Porter (1990) & $\begin{array}{l}\text { As PMEs podem se diferenciar pela } \\
\text { vantagem do país onde nasceu e se } \\
\text { internacionalizar por essa vantagem. }\end{array}$ \\
\hline & $\begin{array}{l}\text { Foco no poder } \\
\text { monopolístico }\end{array}$ & Hymer (1960; 1976) & $\begin{array}{l}\text { Foco na concentração industrial e no } \\
\text { poder de mercado. Não há, no foco desta } \\
\text { abordagem, vinculação com a PME, visto } \\
\text { que é difícil para uma empresa deste porte } \\
\text { dominar o mercado. }\end{array}$ \\
\hline Comportamental & $\begin{array}{l}\text { Modelo de } \\
\text { Uppsala }\end{array}$ & $\begin{array}{l}\text { Johanson e } \\
\text { Wiedershein-Paul } \\
\text { (1975), Johanson e } \\
\text { Vahlne (1977; 1990), } \\
\text { Nordström e Vahlne } \\
\text { (1994) }\end{array}$ & $\begin{array}{l}\text { A internacionalização é um processo de } \\
\text { aprendizagem progressiva e incremental. } \\
\text { O empreendedorismo e o network foram } \\
\text { posteriormente abordados, aportando } \\
\text { justificativas ao processo de } \\
\text { internacionalização das PMEs. O } \\
\text { aprendizado gerencial sobre mercados } \\
\text { externos influencia fortemente a expansão } \\
\text { internacional }\end{array}$ \\
\hline
\end{tabular}

As teorias apresentadas tentam explicar os processos de internacionalização, que por sua vez são estabelecidos por meio de diferentes estratégias, processos, modo e/ou também chamados de grau de internacionalização. O Grau de Internacionalização, denominado neste trabalho de GRI, se apresenta sob duas vertentes: alguns autores utilizam o GRI por meio de métricas financeiras únicas ou multivariádas, e outros autores, ao identificar a evolução da etapa da internacionalização, identificam o GRI em que a empresa se encontra. No próximo item 
apresenta-se o conceito de GRI e as suas principais métricas, bem como os trabalhos mais significativos que as utilizaram.

\subsection{Grau de Internacionalização (GRI)}

O envolvimento internacional da firma é denominado de maneiras diversas, como grau de diversificação internacional (HITT et al., 1997) ou multinacionalidade (GOMES; RAMASWAMY, 1999; GRANT, 1987), e também classificado de modo diferente, como pela atitude gerencial e o processo de aprendizagem (p. e., RUZZIER et al., 2007), pelo tamanho da firma (p. e., MAJOCCHI et al., 2005), pela regularidade das exportações, entre outros (KOTABE; CZINKOTA, 1992; LAGES; MONTGOMERY, 2004). Um estudo conduzido por Welch e Luostarinen (1988), em sua busca com vistas a elaborar uma síntese acerca da literatura sobre conceito de internacionalização, não identificou um conceito único para o termo, pois foram encontradas diferentes interpretações.

Duas correntes predominantes analisam o grau de internacionalização das empresas. Uma delas é a que analisa o GRI de acordo com os diferentes estágios de seu envolvimento internacional, que abordam desde a fase de pré-exportação, passando, posteriormente, por uma etapa de exportação primária, até chegar, por fim, a um estágio avançado de internacionalização. (BILKEY; TESAR, 1977; CAVUSGIL, 1980; DIAMANTOPOULOS; INGLIS, 1988; JOHANSON; VAHLNE, 1977; JOHANSON; WIEDERSHEIM-PAUL, 1975; REID, 1981). Contudo, diversos autores rejeitam a tese de que as firmas se internacionalizam, incrementalmente, por estágios, pois há saltos nos estágios sequenciais de internacionalização.

A segunda corrente que analisa o GRI observa que variações de dotações de recursos, de oportunidades mercadológicas e de capacidades gerenciais geram diferenças não apenas entre firmas, mas também dentro da própria firma em diferentes instantes temporais. (COVIELLO; McAULEY, 1999; DUNNING, 1988; HASSEL et al., 2003; LEONIDOU; KATSIKEAS, 1996; MORGAN; KATSIKEAS, 1997; RAMASWAMY et al., 1996; RUZZIER et al., 2007; SULLIVAN, 1994; 1996). 
Para Dunning (1988), internacionalização é um modo de investimento em mercados estrangeiros explicados pela análise das vantagens econômicas, de propriedade e de localização. Johanson e Vahlne (1977) apresentaram o termo como um processo de evolução que, mediante o aumento do seu envolvimento internacional, aumenta o conhecimento e o compromisso com o mercado. Já Beamish (1990) definiu internacionalização como o processo simultâneo pelo qual cada empresa: a) evolui sua falta de conhecimento das influências diretas e indiretas das transações internacionais para o futuro do seu negócio; b) estabelece e conduz transações com outros países.

Autores como Dunning (1988), Hassel et al. (2003) e Hollenstein (2005) identificam a internacionalização como um fator multidimensional. Cavusgil e Kirpalani (1993), Sullivan (1994) e Reuber e Fischer (1997) se referem à internacionalização como "grau de internacionalização (Degree Of Internationalization - DOI)". Outros autores, em pesquisas anteriores, como Johanson e Vahlne (1977), Forsgreen (1989), Welch e Luostarinen (1988), tentaram determinar o grau de internacionalização analisando a evolução, a estrutura e o processo, relacionando tais aspectos a algumas características do processo de internacionalização, como demografia, estratégia, mercado e características atitudinais. É comum identificar uma confusão, na literatura, acerca do conceito do construto de GRI e suas partes. Grande parte dos trabalhos caracteriza a exportação, ou seja, um dos modos de internacionalização, como sinônimo de internacionalização. (BARCELLOS; CYRINO, 2007).

Além da falta de um conceito único para o construto, há também diversos índices para mensurar a internacionalização. Tais diferenças são encontradas principalmente entre as duas correntes teóricas. Inicialmente, estudos (JOHANSON; VAHLNE, 1977; FORSGREEN, 1989; WELCH; LUOSTARINEN, 1988) utilizavam como índices de internacionalização a evolução, a estrutura e o processo com outras características de internacionalização, como antes apresentado, que não demonstravam a confiabilidade das medições. (PHILLIPS; BAGOZZI, 1986). Tendo presente a limitação da confiabilidade, vários índices de apenas uma variável foram sendo testados, como lucros ou número de empregados. (DUNNING; PEARCE, 1981). Estudos atuais continuam testando outros índices, pois não há consenso sobre estes e ainda há necessidade de se pesquisar outras variáveis, considerando que os índices disponíveis ainda estão em seus estágios iniciais. (COVIELLO; McAULEY, 1999; 
HASSEL et al., 2003; RAMASWAMY et al., 1996; RUZZIER et al., 2007; SULLIVAN, 1994; 1996).

De acordo com Hassel et al. (2003), a validade das medidas de GRI depende de seu poder explicativo potencial. Os indicadores devem estar previstos dentro de um contexto de premissas teóricas utilizadas como base para o seu cálculo. Enquanto alguns trabalhos, principalmente no exterior, utilizam o conceito de internacionalização por etapas ou gradual (CAVUSGIL, 1980; DIAMANTOPOULOS; INGLIS, 1988; JOHANSON; VAHLE, 1977; JOHANSON; WIEDERSHEIM-PAUL, 1975), outros se utilizam das métricas econômicas para avaliar o grau de internacionalização. (DUNNING, 1996; HASSEL et al. 2003; RAMASWAMY et al., 1996; SULLIVAN, 1994).

Utilizando o Grau de Internacionalização por meio de métricas econômicas e voltado para a exportação, verifica-se que há trabalhos aplicados em empresas brasileiras de grande porte. (BARCELLOS; CYRINO, 2007; FORTE et al., 2008; FORTE; SETTE JR., 2007).

Durante a última década têm surgido, na academia, muitos debates sobre a aplicabilidade das fases da internacionalização, especialmente após os estudos de Born Globals. (WICKRAMASEKERA; OCZKOWSKI, 2006). Muitos estudos identificaram que a Teoria das Etapas não é adequada para explicar a internacionalização, principalmente das pequenas empresas de alta tecnologia e Born Globals. (BELL, 1995; DIB; 2008; KNIGHT; CAVUSGIL, 1996). Mas há estudos, como o de Madsen e Servais (1997), que demonstram que as Born Globals se internacionalizam de acordo com a teoria comportamental e evolucionária. O que os estudos inferem para justificar o uso dessas teorias em estudos de Born Globals, por exemplo, é o fato de a empresa ser nova, mas os executivos que as dirigem já terem muitos anos de experiência. (ARGYROUS, 2000). Andersen (1993), crítico dos modelos de etapas, identificou várias limitações dos modelos usados para medir o grau de internacionalização das empresas, como, por exemplo, uma medida de baixa significância, alto índice de erro e inabilidade para estabelecer um construto válido.

Autores como McDougall et al. (1994), Oviatt e McDougall (1994) e Reuber e Fischer (1997), oponentes da Teoria das Etapas, argumentam que as empresas podem pular etapas, pois os nichos globais têm se tornado cada vez menores e os custos de transporte e comunicação têm diminuído rapidamente. Ainda de acordo com os oponentes, empresas com 
um time de executivos experientes também podem pular etapas. Um estudo com empresas australianas, realizado em 2002, identificou que as empresas de maior desempenho exportador, que tiveram a habilidade de sobreviver internacionalmente em tempo de crises, foram aquelas que se internacionalizaram por etapas. (ACIL, 2002 apud WICKRAMASEKERA; OCZKOWSKI, 2006).

Sullivan (1994) menciona que apesar dos muitos estudos na área, o baixo progresso em medir o grau de internacionalização se dá em razão da falta de confiabilidade, medidas definitivas do fenômeno da internacionalização. "Não podemos prever com certeza que a diversificação internacional irá melhorar o desempenho da empresa." (SULLIVAN, 1994, p. 330). RAMASWAMY et al. (1996) apontam que pesquisadores tendem a buscar medidas baseadas em dados disponíveis em vez de buscar um raciocínio conceitual. Para verificar os impactos da evolução das etapas da internacionalização seria necessário dispor de uma pesquisa longitudinal que abordasse o tempo e o modo de internacionalização das empresas pesquisadas. (LU; BEAMISH, 2001).

Muitos dos estudos realizados pelos críticos foram conduzidos com aspectos similares aos dos modelos criticados, mesmo sem mencioná-los. (WICKRAMASEKERA; OCZKOWSKI, 2006). Apesar de todas essas críticas, parte dos estudos de grau de internacionalização se utiliza dos modelos econômicos mixando os comportamentais, como em um dos índices mais utilizados, o de Sullivan (1994), que além de aspectos de estrutura e desempenho da empresa aborda aspectos atitudinais.

Os critérios mais adotados para medir o grau de internacionalização baseiam-se em múltiplos indicadores (BARCELLOS; CYRINO, 2007; DÖRRENBÄCHER, 2000; DUNNING, 1996; HASSEL et al., 2003; LU; BEAMISH, 2001; RAMASWAMY et al., 1996; RUZZIER et al., 2007; SULLIVAN, 1994, entre outros) que são denominados de:

\section{a) Estruturais:}

Esse indicador está relacionado com as atividades externas ou com a estrutura de governança da empresa. As principais variáveis utilizadas para medir esse indicador são: Países onde a empresa atua; Número de subsidiárias no exterior; Ativos no exterior; Empregados no 
exterior; Mercado de ações mantidas por estrangeiros; Estrangeiros no conselho. Esses números são considerados uma fotografia de um determinado momento da empresa.

\section{b) Desempenho:}

Indicadores de desempenho são aqueles que medem o quanto o sucesso ou fracasso de uma atividade da empresa, durante um determinado período, está relacionado à presença em mercados externos. (DÖRRENBÄCHER, 2000). Encontram-se, na literatura, duas principais variáveis para medir desempenho: Vendas no mercado externo sobre vendas totais; Lucro mercado externo sobre o lucro total.

\section{c) Atitudinais:}

Neste indicador é verificado o comportamento da matriz perante suas subsidiárias no exterior. Há dúvidas quanto à confiabilidade na medição deste indicador, visto que as variáveis que se pretende medir são de caráter mais qualitativo, por exemplo, como os executivos tomam decisões sobre a empresa no exterior. Sullivan (1994) apresenta variáveis quantitativas para esse indicador, pois acredita que a orientação internacional de uma empresa aumenta com a experiência internacional dos executivos, medida pelo número de anos acumulados de trabalho no exterior dividido pelo número do total de anos de experiência de trabalho dos altos executivos da empresa. Corroborando a ideia quantitativa, outros autores acreditam que a experiência educacional no exterior também contribui para a orientação internacional da empresa.

\section{d) De Extensão:}

Contempla-se neste indicador a extensão geográfica de atuação da empresa. Ietto-Gillies (2001) considera que para medir a extensão geográfica do processo de internacionalização devem ser utilizadas variáveis como número de países onde a empresa atua, o grau de dispersão das atividades da empresa em áreas específicas ou ainda o índice de concentração espacial das atividades da empresa. O autor desenvolveu um "índice de extensão da rede", calculando o número de países nos quais a empresa possui subsidiárias pelo número total de países que recebem IED, diminuindo 1 , que já estaria representado pelo país de origem da empresa. Autores como Kutschker (1994) e Sullivan (1994) propõem atribuir pesos aos países externos, dependendo da sua distância cultural e geográfica em relação ao país de origem. Sullivan (1994) introduziu ainda neste indicador a "dispersão psíquica", dividindo o mundo em dez zonas com diferentes mapas cognitivos relacionados aos princípios gerenciais. 
Ramaswamy (1995) considerou que a simples soma do número de países que a empresa atua no exterior poderia ser uma medida mais consistente para compor o grau de internacionalização e, após esse trabalho, outros autores fizeram uso dessa métrica, como Delios e Beamish (1999), Lu e Beamish (2001) e Ruzzier et al. (2007). Outros índices são formulados e testados, geralmente em MNCs, e adaptados à realidade de cada país, e são adiante apresentados.

O índice de transnacionalização da UNCTAD, divulgado anualmente pelo World Investment Report, foi lançado em 1995 e apresentado pelos seguintes indicadores individuais: vendas externas por vendas totais (FSTS); ativos no exterior por ativos totais (FATA); empregados no exterior por empregados totais (FETE); número de países nos quais a empresa possui filiadas (subsidiárias controladas). Além dos indicadores individuais, os seguintes índices compostos são apresentados de acordo com a UNCTAD (2007):

a) II-Internationalization Index: corresponde ao número de afiliadas no exterior dividido pelo total de afiliadas;

b) GSI-Geographical Spread Index: calculado pela raiz quadrada do número de afiliadas no exterior dividido pelo total de afiliadas (raiz quadrada do II) e o resultado é multiplicado pelo número de países nos quais a empresa possui operações;

c) TNI-Transnationality Index: gerado pela média aritmética de FATA, FSTS e FETE.

Essa média permite não privilegiar os setores cuja mão de obra ou o capital é intensiva. Esses índices são calculados para empresas financeiras e não financeiras separadamente para as 100 maiores empresas transnacionais do mundo e para as 100 maiores transnacionais de países em desenvolvimento de cada segmento. A lista de empresas divulgada pela UNCTAD exclui as empresas, principalmente familiares e estatais não listadas em bolsa, que não divulgam as informações. A apresentação das empresas pelo volume de ativos no exterior pelo TNI e pelo II ocorre de forma não coincidente e, conforme o critério adotado, a posição das empresas também é alterada, o mesmo ocorrerá se os critérios forem as vendas no exterior ou os empregados no exterior. (UNCTAD, 2007).

Hassel et al. (2003), verificando o TNI por meio de uma análise fatorial, identificou que o percentual de empregados estrangeiros trabalhando para uma empresa não poderia ser 
agrupado na mesma categoria que a parcela de vendas e a parcela de ativos no exterior, devido à baixa correlação entre os fatores. Essa baixa correlação pode ser explicada, de acordo com os autores, pela correlação da variável ativos pelo número de empregados em diferentes países e ainda por considerar simultaneamente países grandes e pequenos. Os autores consideram que, dependendo do tamanho da economia de origem, o Investimento Estrangeiro Direto (IED) captado pela parcela de empregados no exterior pode variar muito. Ainda há outras críticas pelo fato de o índice não levar em conta a forma como as atividades internacionais estão dispersas. Por esses motivos, o Transnationality Index não é considerado uma métrica apropriada, segundo Ietto-Gillies e Seccombe-Hett (1997) e Hassel et al. (2003).

Já o índice de extensão da atividade transnacional de Ietto-Gillies (2001) utiliza o índice da UNCTAD (TNI) juntamente com o "índice de extensão de rede" criado pelo autor. Como o índice da UNCTAD abrange a intensidade de atividades no exterior, esse índice adicionou a extensão das atividades ou a diversificação regional que havia criticado no índice da UNCTAD. Tal índice acrescentou ao TNI a variável número de países nos quais a empresa está presente, como proporção do número total de países em que há IED, diminuindo o país de origem (-1).

O índice mais citado e utilizado pelos pesquisadores é a Escala de Grau de Internacionalização de Sullivan (1994), que utiliza dados públicos de nove indicadores estruturais, de desempenho e de atitude em uma amostra de 74 multinacionais listadas no top 100 das empresas norte-americanas em faturamento externo da Revista Forbes de 1979 a 1990. Para compor o seu índice, Sullivan (1994) estabeleceu que o DOI seria integrado por três atributos internos da internacionalização de uma empresa. São eles: a) Desempenho - o que acontece no exterior; b) Estrutura - que recursos estão aplicados no exterior e c) Atitudinais - qual a orientação internacional da alta administração. Estes conceitos foram operacionalizados pelas variáveis observáveis encontradas em fontes secundárias. Após análise de vários estudos, o autor identificou nove variáveis para formar seu modelo linear e aplicar correlação item-total para chegar a uma medida homogênea de correlação 0,291 como ponto de corte. Para confirmar os resultados, o autor utiliza a análise fatorial, gerando um fator único. Os índices identificados na pesquisa foram:

a) Desempenho: Proporção de vendas externas por vendas totais (FSTS). Outras variáveis foram propostas nesse item, como a intensidade da pesquisa e desenvolvimento (RDI), 
intensidade da publicidade (AI), vendas por exportação como percentual do total de vendas (ESTS) e lucros no exterior como percentual do total de lucros (FPTP). Essas variáveis foram desconsideradas no modelo, pois não atenderam ao nível mínimo de correlação da escala adotada.

b) Estruturais: as variáveis que compuseram esse índice foram: Proporção de ativos no exterior por ativos totais (FATA) e Número de subsidiárias no exterior como percentual do total de subsidiárias (OSTS).

c) Atitudinais: a experiência internacional do corpo diretivo (em anos) como percentual do total de anos de experiência do corpo diretivo (TMIE); para o autor este indicador se reflete na orientação organizacional da empresa, ou seja, quanto maior a experiência internacional dos executivos, mais internacionalizada a empresa será, diferentemente do que ocorre com aquelas com um corpo gerencial de experiência essencialmente doméstica. O outro indicador é a dispersão psíquica das subsidiárias no exterior (PDIO), medida como o número de zonas psíquicas onde a empresa está presente, dividida pelas 10 zonas psíquicas do mundo. Esse índice é medido pelo framework inicialmente proposto por Ronen e Shebkar (1985). Esta categorização divide o mundo em 10 zonas psíquicas, baseadas predominantemente em cultura e idioma. Assim, quanto maior o número de zonas psíquicas em que a firma mantém operações, maior é o seu DOI.

Sullivan (1994) desenvolveu uma pesquisa englobando dezessete estudos que estabeleceram uma relação entre o grau de internacionalização e o desempenho financeiro da empresa. Dentre os estudos analisados pelo autor, seis demonstraram relações positiva, seis indeterminadas e cinco negativas entre GRI e desempenho. $\mathrm{O}$ autor atribuiu o problema de inconsistência dos resultados aos indicadores utilizados para GRI. No Quadro 2, a seguir, apresenta-se a relação dos trabalhos pesquisados por Sullivan (1994) e que o auxiliaram a organizar o seu índice. 
Quadro 2 - Resumo dos estudos empíricos da relação entre desempenho e GRI

\begin{tabular}{|c|c|c|c|c|}
\hline Estudo & Amostra & DOI & Desempenho & Resultado \\
\hline Vernon (1971) & Fortune 500 em 1964 & FSTS & ROS, ROA & + \\
\hline Horst (1973) & 1191 indústrias dos EUA & FSTS & Lucro Líquido & 0 \\
\hline $\begin{array}{l}\text { Hughes, Logue e } \\
\text { Sweeny (1975) }\end{array}$ & $\begin{array}{l}46 \text { MNC EUA } \\
50 \text { EUA não MNC }\end{array}$ & FSTS & $\beta$, retorno ajustado ao risco & - \\
\hline $\begin{array}{l}\text { Siddharthan e Lall } \\
\text { (1982) }\end{array}$ & $\begin{array}{l}500 \text { maiores MNC EUA } \\
100 \text { MNC não EUA em } 1972\end{array}$ & FSTS & Crescimento da empresa & - \\
\hline Kumar (1984) & 672 UK MNC 1972-1976 & FSTS & ROS, ROA & - \\
\hline $\begin{array}{l}\text { Bucley, Dunning } \\
\text { e Pearce (1977) }\end{array}$ & $\begin{array}{l}636 \text { maiores em } 1972 \\
866 \text { maiores em } 1977\end{array}$ & FSTS & ROA & 0 \\
\hline Dunning (1985) & 188 maiores Uk 1979 & FSTS & ROS & + \\
\hline Yoshihara (1985) & 118 maiores Japão & FSTS & $\mathrm{ROE}$ & 0 \\
\hline $\begin{array}{l}\text { Rugman, Lecraw } \\
\text { e Booth (1985) }\end{array}$ & $\begin{array}{l}50 \text { maiores EUA } \\
50 \text { maiores Europa } \\
20 \text { maiores Japão } \\
10 \text { maiores Canadá } \\
24 \text { maiores terceiro mundo }\end{array}$ & FSTS & ROE & 0 \\
\hline Shaked (1986) & $\begin{array}{l}58 \text { MNC EUA } \\
43 \text { MNC não EUA 1980-1982 }\end{array}$ & FSTS & ROA, $\beta$ & - \\
\hline $\begin{array}{l}\text { Michel e Shaked } \\
\text { (1986) }\end{array}$ & $\begin{array}{l}58 \text { MNC EUA } \\
43 \text { MNC não EUA 1973-1982 }\end{array}$ & FSTS & Retorno ajustado ao risco & - \\
\hline Grant (1987) & 304 MNC UK 1968-1984 & FSTS & $\begin{array}{l}\text { Crescimento das vendas, } \\
\text { ROS, ROA, ROE }\end{array}$ & + \\
\hline Buhner (1987) & 40 Alemanha & FSTS & $\begin{array}{l}\text { Retorno ajustado ao risco, } \\
\text { ROA, ROE }\end{array}$ & 0 \\
\hline $\begin{array}{l}\text { Grant, Jammine e } \\
\text { Thomas (1988) }\end{array}$ & 304 MNC UK 1972-1984 & FSTS & $\mathrm{ROA}$ & + \\
\hline $\begin{array}{l}\text { Daniels e Bracker } \\
\text { (1989) }\end{array}$ & 116 MNC EUA & $\begin{array}{l}\text { FSTS, } \\
\text { FATA }\end{array}$ & ROS, ROA & + \\
\hline $\begin{array}{l}\text { Geringer, } \\
\text { Beamish e da } \\
\text { Costa (1989) }\end{array}$ & $\begin{array}{l}100 \text { maiores EUA } \\
100 \text { maiores Europa } 1981\end{array}$ & FSTS & ROS, ROA & + \\
\hline Collins (1990) & 150 MNC Fortune 500 & FSTS & Risco total, alavancagem, $\beta$ & - \\
\hline
\end{tabular}

Fonte: Adaptado de Sullivan (1994)

Apesar de autores contestarem a forma de medir o índice, apontam ser esse índice muito importante, mas ressaltam que além de investigar variáveis de cultura e idioma, o índice deveria examinar aspectos de tomada de decisão e dificuldade em se fazer negócios. 
(NORDSTRÖM; VAHLNE, 1992). A medida, como proposta, oferece um resultado mais de dispersão internacional do que de distância psíquica, argumentam Ramaswamy et al. (1996). Uma simples contagem do número de países em que a empresa mantém subsidiárias ou realiza vendas ofereceria uma melhor aproximação para a dispersão internacional da firma.

Sullivan (1994) elaborou uma combinação linear do significado das variáveis para mensurar o grau de internacionalização, conforme mostra a Tabela 2.

Tabela 2 - Resumo dos resultados de Sullivan (1994)

\begin{tabular}{c|c|c|c|c|c}
\hline Atributos & $\begin{array}{c}\text { Variáveis } \\
\text { Iniciais }\end{array}$ & $\begin{array}{c}\text { Variáveis } \\
\text { Retidas }\end{array}$ & $\begin{array}{c}\text { Carga } \\
\text { Fatorial }\end{array}$ & $\mathbf{h}^{\mathbf{2}}$ & $\begin{array}{c}\text { Correlação } \\
\text { Item-Total }\end{array}$ \\
\hline Desempenho & FSTS & & & & \\
& AI & & & & \\
& RDI & FSTS & 0,9137 & 0,8488 & 0,30 \\
& ESTS & & & & \\
Estrutura & FPTP & & & 0,7125 & 0,41 \\
& FATA & FATA & 0,8808 & 0,8515 & 0,32 \\
Atitude & OSTS & OSTS & 0,9228 & 0,4632 & 0,37 \\
& TMIE & TMIE & 0,6806 & 0,7125 & 0,42 \\
\hline
\end{tabular}

Fonte: Dados de Sullivan (1994)

Sullivan (1994) argumenta que as variáveis podem ser combinadas, pois são uma proporção de uma escala de 0 a 1 e todas têm a mesma escala. Medidas de múltiplos itens, como a proposta por Sullivan (1994), são consideradas superiores às de um único item para medir o grau de internacionalização. Mas Ramaswamy et al. (1996) argumentam que para reaplicar o Modelo de Sullivan é necessário considerar as variáveis separadamente e o conjunto de variáveis em combinação. Muitos autores consideram, ainda, que há necessidade de se aplicar pesos diferenciados para cada uma das variáveis, mas para a validação do índice é preciso usar critérios externos, pois o modelo atual não assume diferenças entre os efeitos de vendas, e as relações são lineares no tempo. Ramaswamy et al. (1996) criticaram ainda outro ponto do índice ao mencionar que juntar fatores de níveis diferentes (desempenho, atitude e estrutura) em um mesmo índice não é apropriado, considerando que os elementos são diferentes. Sullivan não padronizou as variáveis de seu índice antes de combiná-las linearmente, e em razão de existirem diferenças significativas nas médias e desvios padrões das cinco variáveis 
do índice, um valor elevado em uma variável não poderia ser simplesmente substituído por outro, pois não estão na mesma escala. Sullivan (1996) argumenta que essa equivalência está implícita, uma vez que o índice é uma ponderação simples dos itens que compõem o DOI.

O indicador de experiência internacional dos executivos também foi criticado por Ramaswamy et al. (1996), que acreditam que não se pode concluir, mesmo que do ponto de vista conceitual, que existe correlação positiva do indicador "duração da experiência do executivo no exterior" com a experiência internacional. Para os autores, tal conclusão é apenas conjuntural, ainda que a atitude dos executivos fosse um atributo para a internacionalização. Os autores sugerem que a qualidade da experiência no exterior seja mais relevante para determinar a predisposição no sentido de futuras atividades internacionais.

O índice de Sullivan enfoca a internacionalização de MNCs que possuem IED e focalizam os estágios mais avançados da internacionalização, não levando em conta modos de atuação no exterior, como a exportação, as franquias e as joint ventures, como considera Ramaswamy et al. (1996). Para reaplicar o mesmo índice à PME, este deverá passar por uma adequação, e também ser adequado ao fator Brasil. Muitos autores, apesar das críticas já mencionadas anteriormente, concordam que o índice de Sullivan (1994) é a melhor medida de internacionalização quando comparada a medidas de uma variável.

Lu e Beamish (2001) estudaram os efeitos da internacionalização sobre o desempenho das PMEs, identificando como as empresas podem se tornar mais competitivas quando se expandem geograficamente. As estratégias verificadas foram a exportação e o Investimento Estrangeiro Direto (IED). Os autores utilizaram dados publicados pelas PMEs japonesas de capital aberto em uma revista anual e estudaram o período de 1986 a 1997. O estudo longitudinal só foi possível porque as empresas pesquisadas divulgavam seus resultados. Para trabalhar os dados coletados, os autores mensuraram o desempenho pelo Retorno sobre os Ativos (ROA) e Retorno sobre as Vendas (ROS); para aquilatar o nível de exportação, utilizaram o percentual do lucro das exportações sobre o lucro total e; por fim, para identificar o nível de Investimento Estrangeiro Direto (IED) os autores lançaram mão de duas medidas: a primeira foi computando o número de IED que as empresas possuíam e a segunda calculando o número de países nos quais a empresa possuía IED. Para as PMEs que exportam, os autores atribuíram o valor 0 e para as empresas que possuíam IED o valor 1 . 
Os principais resultados encontrados indicam que a exportação e o IED apresentam um impacto diferente no desempenho da empresa, ou seja, um baixo nível de IED está associado com um baixo desempenho, mas um alto nível de IED se associa com um alto desempenho. Os autores não ignoram os acontecimentos políticos e sociais vividos no Japão no período estudado, mas não mensuram essas informações. As importantes diferenças identificadas na pesquisa entre a exportação e o IED suportam o argumento dos autores de que IED é o modo mais competitivo para operar em mercados internacionais. Os mesmos modelos foram utilizados por Ramaswamy (1995) e Delios e Beamish (1999).

No Brasil, os autores Sérgio Forte e Elmo Sette Júnior (2005) adaptaram a Escala de Sullivan (1994) à realidade brasileira, para aplicar em empresas exportadoras de grande porte de calçados e de nozes. Após esses estudos, outros trabalhos, como o de Barcellos e Cyrino (2007), também o utilizaram, mas nas maiores multinacionais brasileiras. Os autores brasileiros propuseram os seguintes indicadores:

a) Vendas externas/vendas totais; b) Ativos no exterior/ativos totais; c) Número de subsidiárias no exterior/Número total de subsidiárias: este indicador é obtido pela simples soma das subsidiárias no exterior da empresa, dividido pelo número total de subsidiárias. Considera-se que quanto maior este número, mais internacionalizada será a empresa; d) País de destino: soma do percentual dos três blocos econômicos com grande volume de exportação da empresa, com seus respectivos percentuais de exportação. Este será calculado pela média do percentual de exportação dos três principais destinos da empresa por blocos econômicos divididos por 100. Considera-se que quanto maior o valor deste indicador, mais internacionalizada será a empresa; quanto maior o índice, menor será a distância psíquica; e) Relação do número de anos da atividade internacional da empresa e o máximo de anos de fundação da amostra. Este indicador quer demonstrar que as empresas mais internacionalizadas são aquelas que tiveram sua primeira atividade internacional antes das demais. Este indicador é calculado pela relação entre a quantidade de anos de sobrevivência de atividade no mercado internacional e o número máximo de anos desde a fundação da empresa. Quanto maior este indicador, mais internacionalizada será a empresa. 
Barcelos e Cyrino (2007) identificaram quão internacionalizadas as MNCs brasileiras estavam, propondo uma metodologia para as MNCs brasileiras com atuação no exterior. Os autores adaptaram o DOI de Sullivan (1994), da UNCTAD (1995) e de Forte e Sette Jr. (2005) e analisaram, em 24 empresas, os indicadores de:

a) Mercado: considerando as receitas no exterior; b) Ativos: o valor dos ativos permanentes no exterior que sejam parte transformadora da empresa sobre o valor total dos ativos; c) Recursos humanos: por meio do número de empregados no exterior; d) Dispersão geográfica dos mercados, computando o número de regiões mundiais pelo número de regiões onde a empresa possui operações; e) Cadeia de valor, calculada pelas atividades prestadas: marketing, pós-venda, manufatura/operações, Pesquisa e Desenvolvimento (P\&D); f) Governança, medida pelo número de mercados financeiros relevantes em que a empresa é listada pelo número de mercado de ações consideradas importantes e acessibilidade às empresas brasileiras; g) Experiência: número de anos desde o estabelecimento da primeira subsidiária de produções no exterior pelo número de anos de anos do estabelecimento da subsidiária mais antiga dentre as empresas pesquisadas.

Os sete indicadores foram agregados num índice comum mediante a adição de cada um dos índices conforme os modelos utilizados propunham. Muitos dos dados necessários foram obtidos por meio dos dados publicados, principalmente via acionistas, e os demais por intermédio de questionários encaminhados a 50 empresas. Apesar da adaptação dos índices à realidade brasileira, os índices pesquisados têm enfoque nas $\mathrm{MNCs}$, sendo parte deles não aplicáveis às PMEs.

Como se pôde verificar, há uma diversidade de variáveis entre os diferentes autores quando considerados aspectos mais econômicos para mensurar o GRI. Da mesma forma, os autores que abordam o GRI levando em conta aspectos da teoria comportamental também utilizam diversas medidas e maneiras para identificar o GRI.

\subsubsection{Vertente comportamental para grau de internacionalização}

A dinâmica da corrente comportamental é conduzida, basicamente, pela crescente aquisição de informações, acumulação de experiência, consolidação gradativa de processos de 
aprendizagem, formação de conhecimento e comprometimento de recursos da empresa. (LEONIDOU; KATSIKEAS, 1996).

Nessa vertente, um dos principais indicadores é o gradualismo, ou seja, as fases da internacionalização. Muitos autores utilizam esse indicador como um dos componentes do Grau de internacionalização, outros utilizam as estratégias como pontuação para formar o índice. Alguns trabalhos de cunho mais qualitativo, como estudos de casos, o utilizam como modo de entrada e o denominam de grau de internacionalização sem considerar as variáveis quantitativas apresentadas no item anterior.

Encontram-se na literatura diversas denominações para esse indicador. As iniciativas fronteiriças, ou estratégias de internacionalização; sequências de decisões; modos de entrada; estágios; ou grau de internacionalização. Alguns autores, como Lu e Beamish (2001), Rasheed (2005) e Ruzzier et al. (2007), em trabalhos que consideram a PME, identificaram o modo de entrada como um dos itens indispensáveis para formar o grau de internacionalização e também que esse fator contribui para o desempenho da organização, apesar de faltar um framework teórico consistente, como comentado por Lu e Beamish (2001).

Para muitos autores, só é possível medir o grau de internacionalização por meio de medidas quantitativas; para outros, o grau de internacionalização é aquilatado por meio de variáveis qualitativas. Como identificado na vertente teórica comportamental, a internacionalização é um processo que evolui da forma mais simples para a mais complexa e, ainda, de maneira linear. (JOHANSON; VAHLNE, 1977, 1990; JOHANSON; WIEDERSHEIN, 1975).

Verificaram-se, na literatura, os fatores que influenciam o Grau de internacionalização. Esses fatores são utilizados pelos autores para auxiliar na mensuração do grau de internacionalização e evitar o viés do índice. Neste item serão apresentados alguns dos principais trabalhos que utilizaram a vertente comportamental para identificar o GRI das empresas.

A exportação é o caminho mais usual para a entrada em mercados internacionais. Formas mais complexas de internacionalização estão sendo praticadas por empresas para se diversificarem de seus concorrentes, buscar custos mais baixos, estar próximo ao consumidor 
ou por outros motivos. (COVIELLO; McAULEY, 1999; HOLLENSTEIN, 2005). As empresas definem suas estratégias mediante diferentes modos de entradas, tais como:

- Exportação Indireta: a empresa produtora, por falta de recursos, como conhecimento, por estratégia ou ainda por exigência do importador ou do produto, utiliza-se de um intermediário no país de origem para que este exporte as mercadorias. Os benefícios fiscais são os mesmos da exportação direta. Internacionalizar a empresa via exportação indireta requer da empresa baixo ou quase nenhum recurso adicional relativamente aos praticados no mercado interno. Exemplo: a empresa produtora brasileira encaminha sua produção para um distribuidor no Brasil para que este envie a mercadoria ao exterior. Esse distribuidor é geralmente uma comercial exportadora ou uma trading company. As desvantagens dessa operação estão no risco da escolha não apropriada de intermediários, na quantidade excessiva de intermediários, no custo do transporte, no risco da exposição cambial, e nas barreiras tarifárias e não tarifárias.

- Exportação Direta: A empresa produtora é responsável pela entrega da mercadoria ao importador no exterior, conforme negociação. Nessa condição a empresa produtora é a própria exportadora, exigindo da empresa conhecimento de negociação internacional, de custos internacionais, de câmbio, de documentação e de controle. Esses conhecimentos exigem que a empresa possua pelo menos uma pessoa responsável pelos processos de exportação ou até mesmo um departamento exclusivo, dependendo da quantidade de processos. A internacionalização por esta via é relativamente rápido e barato, considerando que não há investimento direto no exterior. As desvantagens da exportação indireta se repetem.

- Acordo de Distribuição ou Comercialização: a empresa produtora acorda formalmente para que o importador ou outro distribua e/ou comercialize suas mercadorias no exterior. A vantagem desse modo de entrada é o conhecimento do mercado alvo que o distribuidor possui. Há necessidade, nesta modalidade, de investimentos em conhecimento do processo de exportação, como no caso da exportação direta, e as desvantagens também são as mesmas.

- Licenciamento/Franquia: a empresa autoriza outra firma a produzir e/ou vender seus produtos, mantendo as características de marca, modelo, layout, etc., da empresa licenciadora. A companhia representante paga royalties para cada unidade produzida e vendida. Trata-se de um modo menos arriscado de ter suas operações no exterior, uma 
vez que o risco é de quem pagou pelo licenciamento da marca e não da empresa licenciadora da marca; no entanto, poderá haver um prejuízo na imagem da marca, caso algo não dê certo.

- Escritório de Vendas Próprio: a empresa produtora oficializa sua presença física no exterior por meio de um escritório para atender melhor aos clientes e conhecer o mercado. Neste modo de entrada, há benefícios, como o do aprendizado de mercado e do atendimento do cliente, mas há um investimento financeiro maior, considerando o ambiente físico de trabalho e a contratação de pessoas.

- Centro de Distribuição Próprio: os ativos no exterior aumentam com a decisão de distribuir os próprios produtos aos diversos importadores no exterior. A vantagem está em diminuir os riscos da exportação quanto à distribuição. Os recursos exigidos aumentam ainda mais se comparados ao escritório de vendas, tendo em vista a necessidade de atuar com transporte, com maior número de pessoas e ainda manter um estoque no exterior. Há também a necessidade de se conhecer o mercado para poder atuar, não só conhecimento cultural, mas também o de legislação e procedimentos burocráticos.

- Alianças Estratégicas e Joint-Ventures: permitem à empresa local e à estrangeira compartilhar riscos e recursos para expansão em iniciativas internacionais. Mediante esta estratégia de internacionalização, há a busca de oportunidades específicas, e em geral envolve uma empresa estrangeira com um novo produto ou tecnologia e uma companhia local com acesso à distribuição e ao conhecimento de clientes locais, às normas e às políticas. Há, ainda, a possibilidade de ultrapassar barreiras tarifárias e não tarifárias. O risco desse modo de entrada é a compatibilidade com o sócio, pois pessoas de culturas diferentes nem sempre conseguem atuar com facilidade e parcimônia.

- Fusão: junção entre duas empresas do mesmo setor, ou que se complementam, como estratégia para aumentar o market share ou aproveitar as sinergias. Há, neste caso, uma decisão estratégica importante e uma análise profunda dos ganhos da fusão. A possibilidade de redução de tempo para conquistar o novo mercado é já um grande ganho, mas para isso é necessário conhecer bem o que o mercado pensa sobre a empresa que se pretende juntar. Há também a redução de custo de pesquisa e de transação. (DUNNING, 1988). Neste modo de entrada, há a possibilidade de entrave por parte dos funcionários da empresa no exterior, sendo necessário um planejamento de gestão de recursos humanos culturalmente diferentes. 
- Aquisição: permite a entrada no mercado estrangeiro de forma mais rápida pela compra de uma empresa que já opera em outro país. As vantagens e desvantagens da fusão reaparecem nesse modo de entrada adicionando a necessidade de gerenciamento total e do domínio das leis do mercado do país hospedeiro. O recurso financeiro envolvido também é maior.

- Greenfield: apesar de implicar um processo mais lento e custoso de crescimento, garante um maior controle das operações e menor conflito da cultura organizacional ou nacional. A empresa inicia uma operação no exterior, começando do zero, ou seja, não havia anteriormente outra empresa. Neste modo de entrada, além dos recursos financeiros despendidos serem geralmente maioria, a necessidade de conhecimento das leis do país se torna ainda maior.

- Greenfiled com Pesquisa e Desenvolvimento (P\&D): o mesmo que o grau anterior, mas com uma complexidade adicional, que é ter na operação do exterior um setor ou Departamento P\&D para novos produtos ou para adaptar o produto ao país, implicando maior conhecimento da cultura do novo país. Muitos países, ao autorizar a entrada de empresas estrangeiras, exigem uma parcela de pesquisa no país hospedeiro e a contratação de locais no setor.

No momento da tomada de decisão da internacionalização, as variáveis que influenciam o projeto de internacionalização devem ser levadas em consideração e podem ter maior ou menor risco para a empresa, dependendo do modo de entrada, identificado como estratégico para a organização. (BARTLETT; GHOSHAL, 1992).

Verificou-se que não há uma escala padrão para identificar as fases da internacionalização. Segundo Johanson e Wiedershein-Paul (1975), a internacionalização é o produto de uma série de decisões incrementais, como já apresentado no item 2.1.2. O referido modelo está baseado em observações empíricas que mostravam que firmas suecas frequentemente desenvolviam suas operações internacionais em pequenos passos, em vez de fazer grandes investimentos de produção no exterior. Deste modo, uma empresa começa a exportar para um país por meio de representantes, depois estabelece uma subsidiária de vendas e, por fim, começa a produzir efetivamente naquele país. Para este modelo, a internacionalização é um processo de ajustes incrementais às condições variáveis da empresa e do seu ambiente, apresentando os estágios de envolvimento internacional, conforme pode se visualizar na Figura 2. 


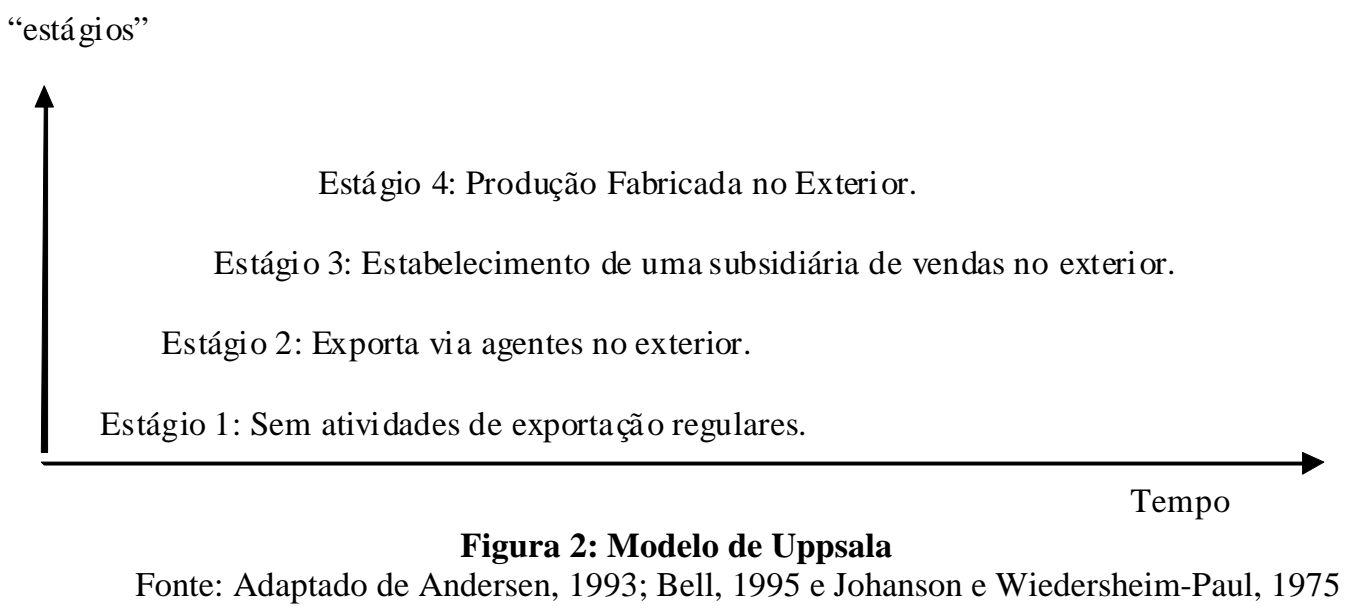

De acordo com Johanson e Vahlne (1990, p. 13), "essa sequiência de estágios indica o comprometimento crescente de recursos com o mercado. Ela indica, ainda, as atividades correntes (operações) que se diferenciam em razão da experiência acumulada." Esse modelo foi denominado de U-Model.

A operacionalização do U-Model é organizada pelas escolhas estratégicas e formas organizacionais que, por sua vez, são influenciadas por muitos outros fatores, como, por exemplo, forças que facilitam ou inibem as exportações, necessidades de informações e efeitos da distância cultural. (GANKEMA et al., 2000; LEONIDOU; KATSIKEAS, 1996). Para esses autores, a utilização do U-Model torna-se muito difícil, tendo em vista a influência de tantos fatores, precisando ser adaptado para explicar o processo de internacionalização, principalmente das PMEs. (SULLIVAN; BAUERSCHMIDT, 1990). Gankema et al. (2000), em uma revisão da literatura, verificaram a diminuição de estudos longitudinais e, por esse motivo, pouco ou nada se conhece sobre o tempo que leva para uma empresa mudar de um estágio para o outro.

Seguindo a mesma linha do Modelo de Uppsala, Bilkey e Tesar (1977) identificaram as seguintes fases das empresas: Estágio 1: Direção não tem interesse em exportar; Estágio 2: Desejo de atender aos pedidos não solicitados; Estágio 3: Exploração da viabilidade de exportar; Estágio 4: Experiências com exportação para países psicologicamente próximos; Estágio 5: Firma é exportadora experiente; Estágio 6: Exportação para países distantes psicologicamente. 
Já Cavusgil (1980) considerou a internacionalização como um processo análogo às etapas de produção. O autor elaborou um modelo para mensurar os estágios de internacionalização identificados pela média dos valores da exportação sobre as vendas totais e pontuando os diferentes estágios, identificando, desse modo, a dependência da empresa em mercados estrangeiros. Esse modelo é chamado de I-Model, e é demonstrado no Quadro 3.

Quadro 3 - Modelo I: model

\begin{tabular}{|l|l|}
\hline \multicolumn{2}{|c|}{ Estágios de internacionalização } \\
\hline \multicolumn{1}{|c|}{ Estágio } & \multicolumn{1}{c|}{ Descrição } \\
\hline Estágio 1: Mercado Doméstico & $\begin{array}{l}\text { A empresa está somente interessada no mercado doméstico e } \\
\text { nem mesmo exporta. A empresa não tem interesse em } \\
\text { exportar, pois está muito atarefada com outros negócios ou } \\
\text { não tem habilidades para trabalhar com a exportação. A média } \\
\text { da exportação/vendas é 0. }\end{array}$ \\
\hline Estágio 2: Pré-Exportadora & $\begin{array}{l}\text { A empresa busca informações sobre a atividade exportadora. } \\
\text { O envolvimento como uma exportadora experimental é } \\
\text { marginal e intermitente. A média exportação/vendas é } \\
\text { próxima a 0. }\end{array}$ \\
\hline Estágio 3: Envolvimento Experimental & $\begin{array}{l}\text { A empresa inicia a exportação com uma pequena parcela. A } \\
\text { distância cultural e psíquica é limitada. O envolvimento como } \\
\text { uma exportadora experimental é geralmente marginal e } \\
\text { intermitente. A média exportação/vendas varia de 0 a 9 por } \\
\text { cento. }\end{array}$ \\
\hline Estágio 4: Envolvimento Ativo & $\begin{array}{l}\text { Há um esforço sistemático para aumentar as vendas por meio } \\
\text { das exportações em múltiplos países. Uma estrutura } \\
\text { organizacional apropriada apoia as atividades de exportação. } \\
\text { A média exportação/vendas varia de 10 a 39 por cento. }\end{array}$ \\
\hline Estágio 5: Envolvimento Comprometido & $\begin{array}{l}\text { A empresa depende pesadamente do mercado externo. } \\
\text { Gerentes estão continuamente diante de alternativas para } \\
\text { alocar recursos no mercado doméstico e exterior. Muitas } \\
\text { empresas possuem contratos de licenciamento ou } \\
\text { investimentos diretos. A média exportação/vendas é de 40 por } \\
\text { cento ou mais. }\end{array}$ \\
\hline
\end{tabular}

Fonte: Adaptado de Cavusgil (1980)

Estudos como o de Bilkey e Tesar (1977), Reid (1981) e Czinkota (1982) limitam os seus trabalhos nas atividades de exportação, já o I-Model inclui outras formas de internacionalização. Alguns trabalhos, como o de Bell (1995) e Reuber e Fischer (1997), aplicaram o I-Model em PMEs, tendo constatado que o modelo traz resultados verdadeiros para esse porte de empresa. Gankema et al. (2000) estudaram a progressão das PMEs por meio das etapas de internacionalização e o tempo dessa progressão.

Gankema et al. (2000) identificaram em uma survey longitudinal (5 anos), aplicada em 144 PMEs europeias de manufatura, uma forte significância entre o porte da empresa e o grau de internacionalização, mas, em contrapartida, o estudo não mostrou diferença significativa entre países ou tipo de indústria no que tange aos estágios de internacionalização. A pesquisa 
Hollensteinm (2005) denominou o GRI de "Funções do Negócio", como se pode verificar no Quadro 5.

Quadro 5 - Funções do Negócio conforme Hollensteinm, 2005 Funções do Negócio

\begin{tabular}{|l|}
\hline \multicolumn{1}{|c|}{ Funções do Negócio } \\
\hline 1. Unicamente Vendas Domésticas \\
\hline 2. Vendas Domésticas e Exportações \\
\hline 3. Presença Direta em outros países: \\
3a Distribuição/somente atividades como franchising, licenciamento, contratos de \\
prestação de serviços, consultorias; \\
3b Produção/somente suprimento; \\
3c Somente Pesquisa e Desenvolvimento; \\
3d Distribuição (3a + 3b); \\
3e 3c + 3b + 3a.
\end{tabular}

Fonte: Adaptado de Hollensteinm (2005)

McDonald et al. (2003) constataram que as PMEs alemãs implementam estratégias que aparentam se aproximar do modo incremental de internacionalização. Os autores as denominaram "Fases" e as classificaram da seguinte forma: Exportação Direta (Distribuição 1); Exportação Indireta (Distribuição 2); Licenciamento (Distribuição 3); Franchising (Distribuição 4); Alianças Estratégicas (Distribuição 5); Unidades de Vendas no Exterior (Distribuição 6); Unidades de Produção no Exterior (Distribuição 7); Subsidiária Independente (Distribuição 8).

As críticas em relação à utilização de etapas é que há possibilidade de as empresas pularem as etapas, pois os nichos globais se estreitaram e os custos de transporte e de comunicação tiveram um considerável decréscimo. (McDOUGALL et al., 1994; OVIATT; McDOUGALL, 1994). Reuber e Fischer (1997) consideram que se a empresa tiver um corpo gerencial com experiência internacional, pode pular os estágios iniciais.

Como se pode perceber, também na vertente comportamental do GRI não há uma medida única que o identifique. Percebe-se, ademais, tal como no índice de Sullivan (1994), que há trabalhos que utilizam o GRI como um índice multivariado, ou seja, abordando conjuntamente os aspectos econômicos e os comportamentais.

Os autores Erramilli e Rao (1993) levam em conta, em seu trabalho, o modo de entrada como uma variável dicotômica ou dummy, com 0 para as empresas que atuam no exterior via 
controle pleno e 1 para as empresas que atuam no exterior por meio de parcerias, ou seja, com sócios locais. Os autores utilizaram o conceito de custo de transação e identificaram que a relação entre recursos específicos e o modo de entrada em mercados externos é moderada por inúmeros fatores, que ou aumenta o custo da integração ou diminui a habilidade de a empresa estabelecer modos de entrada com controle pleno. O resultado do trabalho dos autores demonstra que variações substanciais na escolha do modo de entrada ocorrem quando as empresas que possuem baixos recursos específicos abandonam o controle em resposta ao crescimento dos custos da integração ou a diminuição da habilidade de integração. Para estimar os efeitos e chegar a estes resultados os autores utilizaram uma regressão logística, pois trabalharam com variáveis dependentes binárias, e nas independentes havia variáveis qualitativas e quantitativas, seguindo o modelo de Manolova et al. (2002).

Andersson et al. (2004) identificaram, em uma pesquisa nas PMEs suecas, que a idade da empresa e a idade do executivo podem explicar a evolução do GRI. Nos resultados dos autores, a idade da empresa mostrou-se significante na evolução do GRI, mas não foi significante como fator explicativo do início da internacionalização. Assim, os autores identificaram que empresas que não se internacionalizam nos primeiros anos de fundação podem introduzir práticas organizacionais que reduzem as chances de identificar oportunidades no exterior. (AUTIO et al., 2000). Já o segundo resultado indica que executivos mais jovens podem explicar o crescimento da PME em mercados internacionais, mas essa variável também não se mostrou significativa quando pesquisadas as variáveis que explicam o início da internacionalização. Uma possível explicação é que executivos mais jovens têm uma visão maior do mundo e um acesso mais facilitado a escolas em outros países.

Outros modelos são propostos pela literatura (BILKEY; TESAR, 1977; CZINKOTA, 1982; LIM et al., 1991; RAO; NAIDU, 1992; REID, 1981), mas estes não serão apresentados neste trabalho, tendo em vista que o foco de tais trabalhos é a exportação e não a evolução das etapas de internacionalização.

Estudos sobre as empresas brasileiras com IED demonstram que as empresas brasileiras, principalmente as MNCs, seguem o estágio gradual de internacionalização. (BARRETO 1998; URBAN, 2006). Estes trabalhos serão expostos por meio de estudos de caso, sem que qualquer modelo seja apresentado. 
Além das discussões das duas grandes correntes sobre o conceito e a construção de GRI, muitos autores, independentemente da corrente teórica sustentada, discutem os fatores que mais influenciam o GRI. Por esse motivo, no próximo item será apresentado um esboço das principais discussões analisadas neste trabalho com o intuito de auxiliar na adequação das variáveis de GRI adequadas à PME brasileira.

\subsubsection{Fatores que influenciam o grau de internacionalização}

A literatura sobre o grau de internacionalização não mostra uma forma única de evolução, mas apresenta diversas maneiras de evoluir e de mensurar o grau de internacionalização. Inúmeros fatores foram estudados e apresentados na literatura internacional e brasileira como influenciadores da internacionalização das empresas. (DIMITRATOS, 2002; ETEMAD, 2004; FUJITA, 1995; GANKEMA et al., 2000; HOLLESTEIN, 2005; IBEH et al., 2004; KALANTARIDIS, 2004; LU; BEAMISH, 2006; McDONALD et al., 2003; RAMASWAMY, 1996; RASHEED, 2005; RUZZIER et al., 2007; SULLIVAN, 1994). Não se tem o intuito de estudar todos esses fatores, mas conhecer os principais fatores que auxiliam na adequação à realidade das PMEs brasileiras na pesquisa em tela.

Tendo em vista a experiência desenvolvida para operar no exterior, as barreiras culturais, econômicas, políticas, entre outras, a empresa com IED desenvolve competências diferentes daquelas das empresas que somente exportam. (MAJOCCHI; ZUCCHELLA, 2003). A internacionalização é o processo pelo qual uma empresa vai gradualmente se modificando em razão da competição internacional, da saturação dos mercados domésticos e da necessidade de expansão, de novos mercados e diversificação. A empresa se reorganiza à medida que se internacionaliza para acomodar novas estratégias. A evolução da internacionalização, as mudanças de mercado e o acirramento da concorrência demandam à empresa mudanças estruturais e não somente estratégicas. As variáveis que influenciam em um projeto de uma organização são incertas, mas as principais variáveis incluem a estratégia, o porte e a adequação tecnológica da empresa e, ainda, o cenário mundial em que a empresa opera. (DERESKY, 2004).

A literatura de internacionalização propõe uma vasta gama de fatores que influenciam a internacionalização das PMEs. Muitos autores os denominam de fatores de pressão e fatores 
de atração (ETEMAD, 2004) ou simplesmente de fatores que influenciam o processo de internacionalização.

Diante de tantas variáveis, demonstram-se, aqui, as mais utilizadas na literatura sobre PME.

\section{a) Experiência internacional do executivo}

"Fatores pessoais do empreendedor podem fortemente influenciar a internacionalização das PMEs." (RUZZIER et al., 2007, p. 17). A experiência internacional dos executivos é considerada por esses mesmos autores um recurso difícil de imitar e difícil de ser substituído.

Alguns estudos identificam que o empreendedor, o executivo e/ou o dirigente são os principais influenciadores do grau de internacionalização, chamando tal vertente de empreendedorismo internacional. (McDONALD et al., 2003; SULLIVAN, 1994; COVIELLO; MUNRO, 1997; IBEH; YOUNG, 2001). Esses estudiosos do tema explicam que muitos executivos são mais voltados ao risco do que outros, permitindo uma expansão internacional mais rápida. A experiência internacional, tanto acadêmica como executiva, também volta a empresa para o mercado externo. (SULLIVAN, 1994; IETTO-GILLIES, 1998).

Bloodgood et al. (1996) encontraram somente um suporte parcial das habilidades nos negócios internacionais (experiência internacional e escolaridade internacional) na internacionalização. Os referidos autores identificaram que a internacionalização está positivamente relacionada à experiência internacional da equipe dos principais executivos, mas não tem relação com a escolaridade de tal equipe.

Sullivan (1994) constatou que a experiência do executivo é um fator importante para mensurar o GRI, mas críticas, como a de Ramaswamy (1995), identificaram que não basta verificar a experiência, mas sim o tipo de experiência, pois deveria haver uma correlação com a duração deste período no exterior e a qualidade da experiência para determinar a predisposição das futuras atividades internacionais. Já Leonidou et al. (1998), Reid (1981) e Ruzzier et al. (2007) consideraram que viajar para o exterior torna o executivo mais propenso a aprender sobre o mercado, sobre as práticas de negócios internacionais e para identificar oportunidades de mercados. 
Leonidou et al. (1998) localizou dezessete estudos associando o tempo do executivo no exterior e o grau de internacionalização. Em seis deles, executivos de empresas exportadoras passaram mais tempo no exterior do que os das empresas não exportadoras. Outros quatro estudos identificaram a influência da exposição internacionacional do executivo no desempenho internacional. Destes, dois apresentaram relação significativamente positiva. Dichtl et al. (1990) encontraram uma relação positiva entre o tempo que o executivo morou no exterior e o grau de internacionalização.

Ruzzier et al. (2007) pesquisaram empresas eslovenas, e analisaram, por meio de equações estruturais, a relação entre o Capital Humano e a internacionalização. O resultado da pesquisa demonstrou que o capital humano tem relação direta e positiva com o grau de internacionalização. Para capital humano, os autores utilizaram medidas de orientação internacional do executivo, viagens internacionais do executivo, tempo de trabalho no exterior, entre outras que se mostraram significativamente correlacionadas. Para GRI, os autores utilizaram o modo de internacionalização, número de países nos quais a empresa opera, a distância psíquica e a idade da empresa. Esses itens também se mostraram significativa e positivamente correlacionados.

\section{b) O local de atuação}

O local em que a empresa atua ou passa a atuar com a internacionalização pode influenciar o desempenho da empresa, por duas razões: a econômica e a institucional. (GOLDSZMIDT et al., 2007). Alguns autores, como Ghemawat (2003) e Hawawini et al. (2003), defendem que o país pode ter um efeito sobre o desempenho da empresa pela existência de importantes barreiras à integração econômica dos países, em termos de comércio internacional, distribuição geográfica de IED, dispersão de preços entre países e fluxo de fatores de produção. Tais autores argumentam ainda que as atividades das empresas são fortemente dependentes do ambiente econômico de seu país de origem, considerando que o fator globalização não derrubou as fronteiras nacionais.

Já as diferenças decorrentes do ambiente institucional de cada país foram comentadas por Eggertson (1990). A vertente institucional pode impactar o desempenho das empresas pelas diferenças que influenciam a construção da base de recursos das empresas e a apropriação das rendas geradas por estes recursos. O governo é um elemento central do ambiente institucional das nações. (RING et al., 2005). Para Penrose, mediante a RBV, o ambiente nacional tem 
implicações sobre a construção da base de recursos das empresas, pois a estrutura industrial de um país pode ser distinta de outro, permitindo mais ou menos espaço para a formação de monopólios, o que também pode justificar o efeito país. (PENROSE, 1959). Já para Porter (1990), o país pode garantir uma vantagem competitiva baseada não em custos, mas em qualidade, diferenciação e inovação. Esse arranjo institucional com empresas de diferentes nações de origem envolve fatores complexos, como risco e políticas governamentais do país hospedeiro, ou seja, do país de destino do investimento, que podem influenciar na estrutura, nos recursos e na dinâmica das atividades internacionais. (GHOSAL, 1987).

Dentre os problemas de ordem culturais frequentemente encontrados pelas organizações em processos de internacionalização destacam-se o idioma, os costumes, as práticas de negócio, as regras, as leis, entre outros. Goulart et al. (1996), ao analisarem o motivo da internacionalização das empresas brasileiras, mostram que a cultura da organização e o perfil da liderança são, muitas vezes, o fator impulsionador para o desenvolvimento de projetos no exterior. Alinhando-se ao modelo mais comportamental das teorias de internacionalização, Maciariello e Kirby (1994) observam outro aspecto relevante, que é a estratégia que a organização adota para sua operação internacional, a fim de possibilitar a determinação dos fatores chave de sucesso para aquela estratégia. Desta forma, a identificação do tipo de atividade internacional que a empresa pretende realizar é primordial para o bom funcionamento do sistema de controle gerencial. Para Cintra e Mourão (2005), há várias formas de estruturar uma estratégia de internacionalização, sendo que sua adequação depende de um conjunto de fatores que permeiam a cultura empresarial, as condições materiais e as condições sociopolíticas.

Executivos vivem sob pressão para adaptar suas organizações às características do mercado, da legislação, do regime fiscal, do sistema sociopolítico e do sistema cultural (TROMPENAARS; TURNER, 2001). Fazer negócios em um meio cultural diferente impõe aos executivos responsáveis pela negociação um dever, comenta Sebenius (2002): o de levar em consideração aspectos culturais que vão além do comportamento exigido pela etiqueta e aspectos legais. Devem ser também considerados aspectos como a conduta e os valores. Além desses conhecimentos, Hofstede e Usunier (1996) citam que as diferenças culturais em negócios internacionais demandam habilidades específicas: 
- de comunicação das informações e emoções desejadas para a outra parte, por meio de palavras faladas, escritas e do comportamento;

- na preparação, no planejamento e na organização da negociação, fazendo uso apropriado de mediadores, escolha de local e momento adequado para reunião de negócios e reunião social.

Quando pessoas se caracterizam por diferentes culturas, há uma dificuldade maior em estabelecer a credibilidade e a confiança. As pessoas diferem nos seus modos de se relacionar, em seus pensamentos e suas ações. A comunicação torna-se difícil quando os parceiros da negociação não compartilham os mesmos pensamentos. O processo de comunicação intercultural é o componente chave da influência da cultura em uma negociação internacional. (USUNIER, 1996).

A cultura é um fenômeno coletivo. Hofstede (1997, p. 19) a define como "uma programação coletiva da mente, que distingue os membros de um grupo ou categoria de pessoas face a outro", ou seja, para o autor a cultura é adquirida e não herdada. Ela provém do ambiente social do indivíduo e não de sua informação genética. Considerando a definição de Hofstede e Hill (2005) ressalta que a cultura corresponde a um sistema de valores e normas que são compartilhados por um grupo de pessoas e que juntos constituem sua forma de viver. Valores significam ideias abstratas sobre o que grupo acredita ser bom, direito e desejável, enquanto que as normas são regras sociais e orientações que determinam um comportamento apropriado em situações particulares.

Hofstede (1997) foi um dos autores que se notabilizaram pelo estudo nas culturas das nações. Como resultado da pesquisa IBM, o autor definiu as dimensões culturais, nas quais agrupou os diferentes países pesquisados. Hofstede (1997, p. 33) assim define as dimensões de cultura nacional: "[...] uma dimensão cultural é um aspecto de uma cultura que pode ser mensurada em relação a outras culturas." Hofstede (1997) e Hofstede et al. (2002) identificaram padrões nacionais de cultura, ou seja, a população pesquisada pode ser situada em cinco dimensões: individualismo e coletivismo, distância do poder, nível em que se evita a incerteza, masculinidade e feminilidade e ainda a orientação a longo e curto prazo.

Como individualistas, são identificadas as sociedades em que há poucos laços entre as pessoas e se definem como indivíduos. O coletivismo, ao contrário, caracteriza as sociedades nas 
quais as pessoas são conectadas. A dimensão distância do poder ilustra como as pessoas de menor poder nas organizações aceitam a hierarquia. A terceira dimensão, que se refere ao nível em que se procura evitar incertezas, mede o desconforto perante situações ambíguas, assim como a forma pela qual essas situações são evitadas. Já a quarta dimensão (masculinidade), Hofstede (1997) a define como a maneira como a sociedade entende que sejam os papéis dos homens e das mulheres. A última dimensão demonstra como ocorrem os processos de mudança dentro da empresa, se de forma mais lenta ou abrupta.

O Brasil foi um dos países estudados por Hofstede (1997). Ele aparece como uma sociedade coletivista, com fortes características relacionadas às dimensões controle de incertezas e distância do poder. Contudo, apresenta a dimensão feminina muito próxima da masculina, sendo quase impossível situá-la com precisão. (HOFSTEDE et al., 2002).

De acordo com a Escola de Uppsala, as empresas começam seus processos de internacionalização em países cuja distância psíquica é menor, diminuindo, assim, as dificuldades de adaptação à cultura nacional. A partir do momento em que o investimento inicial construiu o network e gerou aprendizagem, essas experiências no país estrangeiro tendem a aumentar a probabilidade da escolha do mesmo local para subsequentes IED. (DAVISON, 1980).

Para mensurar a distância psíquica, os trabalhos encontrados na literatura utilizam modelos de diferentes autores, como Hofstede (1980), Ronen e Shenkar (1985), Sullivan (1994), Stöttinger e Schlegelmich (1998; 2000), Ietto-Gillies (2001). Os autores mais utilizados para identificar a distância psíquica são Hofstede (1997) e Sullivan (1994).

Para poder verificar as diferenças entre duas nacionalidades, há necessidade de considerar os níveis de cultura propostos por Hofstede (1997, p. 27), que afirma que “[...] a nacionalidade, tal qual figura num passaporte, deve ser utilizada com prudência num estudo sobre diferenças culturais. Entretanto, este é seguidamente o único critério possível de classificação.”

Sullivan (1994) dividiu o mundo em zonas psíquicas baseadas em cultura e idioma e acrescentou a proximidade geográfica para simplificar a divisão das áreas. Assim, sem considerar o país de origem (Brasil, por exemplo), dividiram-se em um total de 9 as zonas 
psíquicas: América do Sul, América Central, América do Norte, União Europeia, Leste Europeu, Oriente Médio, Ásia, África e Oceania. (BARCELlOS; CYRINO, 2007; FORTE; SETTE JR., 2005).

Para Bartlett e Ghoshal (1992, p. 3-42), as novas estratégias para a competitividade global levantaram questões, nas maiores empresas do mundo, sobre a adequação de suas estruturas e processos organizacionais no gerenciamento das operações mundiais. Mesmo dentro de determinadas indústrias, as companhias mundiais desenvolveram respostas estratégicas e organizacionais muito diferentes em relação às mudanças que estão ocorrendo em seu ambiente. As decepções e os fracassos que algumas companhias sofreram em suas operações internacionais não ocorreram devido à análise estratégica inadequada, mas a deficiências organizacionais.

De acordo com Bassi (1997, p. 142), “[...] a expansão internacional de uma empresa é uma decisão estratégica, pois implica enfrentar novos tipos de problemas e desafios, diferentes dos encontrados no mercado doméstico.” Já segundo Harbison e Pekar (1999), fazer negócios em um país estrangeiro requer a compreensão de questões culturais, políticas e econômicas. O aprimoramento da tecnologia facilita o acesso às informações referentes à multiculturalidade.

Outros autores mensuraram esse fator simplesmente computando o número de países nos quais as empresas possuíam investimentos ou exportassem, pois, como já comentado anteriormente, desta forma não haveria muita análise qualitativa (RAMASWAMY, 1995), diminuindo o viés da mensuração.

\section{c) A dimensão temporal}

A dimensão temporal é um fator importante quando se trata da internacionalização de PME. Aos primeiros competidores do mercado global, geralmente advindos de países desenvolvidos, dá-se o nome de first movers ou primeiro entrante. Já os competidores, normalmente de países em desenvolvimento ou emergentes, são denominados de late movers ou último entrante e tendem a competir num mercado já consolidado. (BARTLETT; GHOSHAL, 2000). Ainda considerando o fator tempo, verifica-se que empresas mais antigas se internacionalizaram há mais tempo e se vinculam às teorias mais comportamentais, ou seja, evoluíram no grau de internacionalização pelo aprendizado (Modelo de Uppsala). Já as empresas de abertura mais recente e de internacionalização rápida, chamadas na literatura de 
Born Globals, internacionalizam-se focando nos recursos disponíveis, nas competências e nos custos de transação. A rápida internacionalização das Born Globals, até em países geografica e culturalmente distantes da sua origem, mostra a proatividade, a inovação e o risco, e possuem pouco interesse em manter as competências essenciais na matriz. (McDONALD et al., 2003). Segundo Oviatt (1995), as empresas jovens que dispõem de recursos intangíveis têm a tendência à internacionalização mais rápida e com maiores chances de sucesso. Para as empresas start-up, como denomina Bürgel e Murray (1998), as que não se internacionalizam se caracterizam por oferecer produtos com menor nível de inovação.

\section{d) Número de funcionários}

Alguns estudos encontraram uma relação positiva entre o tamanho da empresa e o grau de internacionalização (p. ex., WAGNER, 1995; MAJOCCHI et al., 2005; ETEMAD, 2004); outros encontraram um baixo impacto, como o trabalho de Bonaccorsi (1992). Outros trabalhos não encontraram qualquer relação entre as variáveis em questão (p.e., CZINKOTA; JOHNSTON, 1983; DIAMANTOPOULOS; INGLIS, 1988; HOLZMULLER; KASPER, 1990a; KATSIKEAS et al., 1996), e outros, ainda, encontraram relação negativa entre tamanho da empresa e exportação (p.e., PATIBANDLA, 1995). Para Reid (1981), as empresas maiores tenderiam a ter menos restrições à exportação, considerando sua maior disponibilidade de recursos financeiros e humanos.

Muitos estudos analisam a relação entre tamanho da empresa, por meio de medidas como vendas ou ativos, e intensidade de exportação. Esta última medida gera muitas controvérsias, pois muitos trabalhos consideram as empresas não exportadoras, as vendas nacionais são impactadas por fatos diferentes das vendas no exterior, o que dificulta a identificação do efeito total e, ademais, como muitos trabalhos a utilizam como uma variável endógena entre 0 e 1, o modelo empírico precisa lidar com isso gerando dificuldades na análise final. (SINGH, 2009). Para o mesmo autor, utilizar a variável total da exportação como uma variável dependente sobre o total das vendas como um indicador de tamanho da empresa é também metodologica e teoricamente problemático.

Observa-se que, na apresentação das métricas para mensurar o grau de internacionalização, há, também, controvérsias na sua formulação e aplicação. Há necessidade de se adequar à realidade pesquisada (DUNNING, 1996), escolhendo critérios baseados em referencial teórico 
para poder explicar a causa e consequência da internacionalização. (HASSEL et al., 2003). A utilização de um índice unidimensional ou um índice individual desagregado vai depender da validade das medidas e de seu potencial de explicar a realidade.

Enquanto os modelos por etapas preveem um aumento gradativo de internacionalização em termos de custo e risco, os índices buscam, por meio dos percentuais de vendas e outros indicadores, explicar a graduação na internacionalização. Uma empresa com maior número de empregados no exterior, por exemplo, é mais internacionalizada para os modelos por etapa do que uma empresa que tem um maior percentual de vendas no exterior. $\mathrm{O}$ objetivo deste estudo vem corroborar com as discussões dessa aplicação, utilizando-se de um conjunto de métricas para medir o grau de internacionalização, adaptando-as à realidade do Brasil, e mais ainda às PMEs brasileiras. Conforme mencionam Hassel et al. (2003), não se pode confiar somente em uma variável singular. Os autores também defendem a utilização de um meio termo entre um índice universal e a medição de inúmeras variáveis individuais, bem como que as medidas devem ser multidimencionais, para refletir o processo de internacionalização, que é muito dinâmico.

Como se pode verificar, alguns pesquisadores buscam inferir o grau de internacionalização por meio da evolução, da estrutura e dos relacionamentos, do porte, da idade e diversos outros indicadores apresentados neste item. Entretanto, há muitas críticas acerca destes trabalhos, tendo em vista a dificuldade em se reconstruir a sequência de internacionalização das empresas e, simultaneamente, identificar todos os eventos que contribuíram para a internacionalização. (ERICSSON; SIMON, 1980; RAMASWAMY, 1996).

Assim, apresentam-se no Quadro 6, a seguir, alguns trabalhos que utilizaram as métricas apresentadas anteriormente e que adaptaram à realidade do respectivo país e que podem ser adaptadas à PME brasileira. Percebe-se que os autores consideram um modelo mais voltado a índices econômicos (vendas, taxa de crescimento), mas consideram também que as etapas da internacionalização devem ser verificadas por identificarem, além da estratégia, o nível de recurso que a empresa destinou para o processo de internacionalização, seguindo também a vertente teórica comportamental. 
Quadro 6 - Resumo das Principais variáveis para medir o Grau de internacionalização para a PME

\begin{tabular}{|c|c|c|}
\hline Autor & Variáveis & Descrição \\
\hline $\begin{array}{l}\text { Reid (1981), Cooper e } \\
\text { Kleinsschimidt (1985), Aaby e } \\
\text { Slater (1989), Cavusgil e } \\
\text { Kirpalany (1993), Riahi- } \\
\text { Belkaoui (1998), Gankema et al. } \\
\text { (2000) }\end{array}$ & $\begin{array}{l}\text { Intensidade de } \\
\text { Exportação }\end{array}$ & $\begin{array}{l}\text { Proporção das vendas de exportação sobre as } \\
\text { vendas totais; proporção das vendas externas sobre } \\
\text { as vendas totais }\end{array}$ \\
\hline $\begin{array}{l}\text { Cooper e Kleinschmidt (1985), } \\
\text { Aaby e Slater (1989) }\end{array}$ & $\begin{array}{l}\text { Crescimento das } \\
\text { exportações }\end{array}$ & $\begin{array}{l}\text { Um medida dinâmica da taxa do crescimento das } \\
\text { vendas externas, geralmente combinada com } \\
\text { intensidade de exportação. }\end{array}$ \\
\hline $\begin{array}{l}\text { World Investiment Report } \\
\text { (2002) UNCTAD (1995) }\end{array}$ & $\begin{array}{c}\text { Indice de } \\
\text { Transnacionalização }\end{array}$ & $\begin{array}{l}\text { Média de três taxas: Ativos estrangeiros sobre o } \\
\text { total de ativos, Vendas no exterior sobre o total de } \\
\text { vendas, Número de empregados no exterior sobre } \\
\text { o número total de empregados. }\end{array}$ \\
\hline Ietto-Gillies (2001) & $\begin{array}{l}\text { Índice de extensão } \\
\text { da atividade } \\
\text { transnacional }\end{array}$ & $\begin{array}{l}\text { Utilizao índice da UNCTAD e acrescenta o } \\
\text { número de países nos quais a empresa está } \\
\text { presente sobre o número de países total }-1 \text { (matriz). }\end{array}$ \\
\hline Sullivan (1994) & $\begin{array}{l}\text { Grau de } \\
\text { internacionalização } \\
\text { - Índice Múltiplo }\end{array}$ & $\begin{array}{l}\text { Inclui aspectos de desempenho da } \\
\text { internacionalização como proporção das vendas } \\
\text { externas sobre as vendas totais, Aspectos } \\
\text { estruturais como ativos no exterior sobre um } \\
\text { percentual do total de ativos e subsidiárias no } \\
\text { exterior sobre o percentual do total de subsidiárias, } \\
\text { Aspectos atitudinais da internacionalização como a } \\
\text { experiência internacional do executivo principal e } \\
\text { a distância psíquica das operações internacionais. }\end{array}$ \\
\hline Reuber e Fischer (1997) & $\begin{array}{l}\text { Grau de } \\
\text { internacionalização } \\
\text { - Índice Múltiplo }\end{array}$ & $\begin{array}{l}\text { Inclui três componentes: proporção das vendas } \\
\text { externas sobre as vendas totais, o percentual de } \\
\text { tempo que os empregados gastam nas atividades } \\
\text { internacionais da empresa, o escopo geográfico das } \\
\text { vendas no exterior. }\end{array}$ \\
\hline Brush et al. (2002) & $\begin{array}{l}\text { Escala de } \\
\text { internacionalização } \\
\text { e Escopo de } \\
\text { internacionalização }\end{array}$ & $\begin{array}{l}\text { Escala de internacionalização: Percentual das } \\
\text { vendas internacionais, número de países para os } \\
\text { quais a empresa vende, percentual de produtos } \\
\text { vendidos no exterior. } \\
\text { Escopo de internacionalização: Local e recursos } \\
\text { das diferentes atividades internacionais; os itens } \\
\text { são identificados por escores de } 0 \text { (nada- } \\
\text { internacional) a } 9 \text { (total-internacional) }\end{array}$ \\
\hline Manolova et al. (2002) & Internacionalização & $\begin{array}{l}\text { Empresas que realizam as seguintes atividades, } \\
\text { pontuando da seguinte forma: } \\
\text { (1) importação, (2) exportação direta, (3) } \\
\text { exportação mediante intermediário, (4) aquisição } \\
\text { (5) joint-venture, (6) licenciamento de produto ou } \\
\text { serviço (7) contratação (8) franchise, (9) qualquer } \\
\text { outra atividade no exterior. }\end{array}$ \\
\hline Erramilli e Rao (1993) & $\begin{array}{l}\text { Custo de transação e } \\
\text { modo de entrada }\end{array}$ & $\begin{array}{l}\text { O modo de entrada foi considerado como uma } \\
\text { variável dummy, identificando por } 1 \text { as empresas } \\
\text { se utilizam de parcerias como modo de entrada e } 0 \\
\text { quando as empresas entram no mercado externo } \\
\text { com controle pleno. }\end{array}$ \\
\hline Lu e Beamish (2001) & Exportação e IED & $\begin{array}{l}\text { Exportação foi medida por meio do \% do lucro } \\
\text { provindo das exportações e o IED foi mensurado } \\
\text { pelo número de investimentos no exterior e pelo } \\
\text { número de países onde os investimentos estão. }\end{array}$ \\
\hline
\end{tabular}


conclusão

\begin{tabular}{|c|c|c|}
\hline Forte e Sette Jr. (1994) & $\begin{array}{l}\text { Grau de } \\
\text { internacionalização } \\
\text { em Empresas } \\
\text { Brasileiras }\end{array}$ & $\begin{array}{l}\text { Adaptado de Sullivan (1994): Vendas externa } \\
\text { sobre vendas totais, ativos no exterior sobre ativos } \\
\text { totais, número de subsidiárias no exterior sobre } \\
\text { subsidiárias totais, \% de exportação para os } 3 \\
\text { principais destinos, relação do número de anos da } \\
\text { atividade internacional e o máximo de anos da } \\
\text { fundação da amostra. }\end{array}$ \\
\hline Ruzzier et al. (2007) & $\begin{array}{l}\text { Internacionalização } \\
\text { das PMEs com } \\
\text { ênfase no Capital } \\
\text { humano }\end{array}$ & $\begin{array}{l}\text { Por meio de um modelo de equações estruturais, os } \\
\text { autores mensuraram o capital humano } \\
\text { influenciando na internacionalização das PMEs. }\end{array}$ \\
\hline
\end{tabular}

\subsection{As Competências Organizacionais das PMEs Internacionalizadas}

Os processos de globalização e competição acirrada estão induzindo as empresas a procurarem estratégias diversificadas para permanecerem competitivas. Essas estratégias competitivas vêm sendo tratadas pela literatura sob os aspectos das competências organizacionais.

Para compreender o conceito de competências, a teoria baseada em Recursos da Firma, (RBV) de Penrose (1959), além da contribuição às Teorias de Internacionalização, conforme já apresentada, considera que toda a empresa deve ser visualizada como um conjunto de recursos tangíveis (ativos físicos, economia de escala, ativos financeiros, e seu sistema de distribuição) e intangíveis (imagem da marca, reputação da firma, e seus ativos organizacionais), que quando articulados com a realização de uma função organizacional, se transformam em capacidades organizacionais. (WERNEFELT, 1984; BARNEY, 1991; MILLS et al. 2002). Assim, a capacidade de coordenar e gerenciar recursos cria as capacidades organizacionais. Quando a empresa constrói um conjunto articulado de recursos e de capacidades (MILLS et al., 2002) que agregam valor à estratégia empresarial, por ser rara e difícil de imitar, a empresa tem uma competência organizacional. (PRAHALAD; HAMEL, 1990; FLEURY; FLEURY, 2004).

Peng (2001) afirma que a RBV pode contribuir significativamente para os negócios internacionais, identificando competências e conhecimentos específicos disponíveis, únicos e difíceis de imitar. Esses recursos são os que separam vencedores dos perdedores na competição global e, para as PMEs, as diferencia dos demais competidores, resultando em 
uma vantagem competitiva e em um desempenho financeiro superior. (DEV et al., 2002; HUNT, 2000).

A descrição de competência tem recebido atenção no meio acadêmico e empresarial e tem passado a ser distinguida como característica da empresa. A competência tem sido analisada, atualmente, como o elo entre o conhecimento e a estratégia empresarial, atuando como uma habilidade da empresa em interagir com outras organizações. (JOÃO, 2001). Nesse sentido, a competência passa a ser uma coadjuvante para a vantagem competitiva da empresa.

Para Zarifian (2001), as situações organizacionais podem ser tratadas como eventos, os quais representam os imprevistos de natureza singular que acontecem no dia a dia da vida das organizações. Não significam um acaso negativo, pelo contrário, fazem parte do cotidiano de uma empresa, desde que a mesma esteja receptiva às mudanças ambientais, ao foco de seus produtos e às estratégias inovadoras. Dessa forma, os conceitos de evento e de competência estão intimamente relacionados, pois evidenciam a necessidade de competência profissional e organizacional para trabalhar de maneira adequada com os distintos eventos pelos quais as organizações passam. Teece e Pisano (1994) afirmaram que a empresa se diferencia competitivamente devido à aquisição e exploração de recursos singulares. Esses recursos são constituídos, historicamente e particularizados, por sistemas sociais e mercadológicos complexos, como as relações interpessoais entre os gestores, a tradição, a cultura organizacional, e a reputação da firma perante seus clientes e fornecedores, apontaram os autores.

Ruas (2003) considera que são importantes algumas referências sobre a noção de competências, especialmente em situações organizacionais. Tais referências dizem respeito às capacidades, às competências e aos resultados desejados. As capacidades podem ser compreendidas como potenciais competências que estão à disposição para serem utilizadas em uma determinada situação.

Alguns autores identificam competências e capacidades de forma diferenciada. Para Prahalad e Hamel (1990), competências seriam as habilidades relacionadas à tecnologia. As capacidades seriam as habilidades em processos como Pesquisa e Desenvolvimento (P\&D), marketing, manufatura. (STALK et al., 1992). Mills et al. (2002) definem competência como 
uma forma de descrever como uma empresa desempenha as atividades necessárias ao seu sucesso.

O progresso das empresas no tema das competências para construir uma vantagem competitiva e duradoura, denominada de core competence por Hamel e Prahalad (1990), ou competência chave, para Auregan Joffre e Le Vigoureux (2000), é ainda lento. Numa pesquisa recente, Le Boulaire e Retour (2006) demonstraram que a maioria das empresas francesas apoia-se, em primeiro lugar, nas competências exigidas, oportunidades e ameaças do seu ambiente, para definir seu posicionamento, continuando prisioneiras de uma visão de curto prazo.

O destaque para os estudos de competência organizacionais surge em 1990 com o livro de Prahalad e Hamel (1990), que sugerem, a partir da ideia de que as competências proporcionam competitividade empresarial, a necessidade de inserção das habilidades técnicas e administrativas para a sobrevivência da empresa. Por essa característica, elas são chamadas de "competências essenciais". Ruas (2005) aponta a presença de pelo menos mais dois tipos de competências: "competências organizacionais seletivas", que são as competências responsáveis pelo grau de diferenciação de uma empresa para outra, dentro de um mercado regional, nacional ou internacional; e "competências organizacionais básicas", que são as competências responsáveis pela manutenção da empresa no mercado. Porém, de acordo com Prahalad e Hamel (1990), as competências devem ser reinventadas e alteradas para manter o princípio da raridade, não imitação e, então, geração de valor. As capacidades que formam cada uma das competências organizacionais se diferenciam pelas razões históricas, culturais e competitivas. (BARNEY, 2001).

A competência organizacional é resultante da articulação e mobilização de diferentes capacidades e recursos organizacionais, que em conjunto criam valor para o consumidor e posicionam a empresa um pouco a frente dos demais concorrentes, pois apresentam o princípio da raridade. (PRAHALAD; HAMEL, 1990; FLEURY; FLEURY, 2004).

Mills et al. (2002) propõem que as competências sejam avaliadas não como o que a empresa tem ou deixa de ter, mas como algo que realizam em determinado nível que será comparado com o dos concorrentes. Quando uma atividade é melhor do que a dos concorrentes, é de alta competência, se o contrário ocorre, é de baixa competência. 
Para as organizações, uma ou algumas competências que são consideradas essenciais. Para Prahalad e Hamel (1990), competências essenciais são recursos intangíveis que, em relação ao concorrente, são difíceis de serem imitados. Em relação a mercados e clientes, são essenciais para que a empresa possa se diferenciar; e, em relação ao processo de mudança e evolução da empresa permite maior flexibilidade para que a empresa possa explorar diferentes mercados.

A dificuldade de imitação existe quando há uma constante transformação das capacidades organizacionais conjuntamente e não de um destaque isolado da empresa. O conjunto das competências organizacionais permite a construção da competência essencial da empresa, que pode ser, por exemplo, o baixo custo, ou flexibilidade operacional, ou capilaridade de atendimento, dentre outras. (BORINI, 2009). Estes são os recursos que, articulados e coordenados, podem configurar competências. (MILLS et al. 2002). Para o mesmo autor, um recurso é o que a empresa tem ou tem acesso, já a competência é algo que a empresa faz.

Assim também visualizou Penrose (1959) quando diferencia o estoque de recursos da empresa do fluxo de atividades ou serviços (traduzido atualmente para a mesma ideia de competência). Para a autora, um conjunto de recursos combinados fornece um serviço ou um conjunto de serviços distintos (competência ou um conjunto de competências).

Os recursos são classificados de diferentes maneiras pelos autores. Para Penrose (1959 p. 24), os recursos podem ser físicos e humanos. Para os físicos, a autora apresenta os recursos tangíveis como prédios, máquinas, recursos naturais, matéria-prima, entre outros. Já os recursos humanos se referem à classe de empregados, do nível mais baixo da organização à equipe diretiva.

Proença (1999) contribuiu com a visão de Penrose (1959), mas agregou pontos interessantes para a compreensão e utilização dos recursos pelas empresas. Para o autor, os recursos podem ser divididos em ativos tangíveis, ativos intangíveis e capacitações organizacionais. Os ativos tangíveis são visíveis para os concorrentes e pouco contribuem para a vantagem competitiva. Os ativos intangíveis incluem marca, cultura, experiências acumuladas, e por não serem facilmente visíveis, contribuem mais para a estratégia da empresa. Já as capacitações organizacionais são habilidades específicas que nascem da combinação de ativos, pessoas e processos, contribuindo fortemente para a competitividade empresarial. 
Johanson e Vahlne (1997) identificaram três pontos fundamentais sobre os recursos tangíveis e intangíveis para a internacionalização: 1) a internacionalização requer recursos apropriados; 2) requer atitudes gerenciais adequadas ao tamanho da empresa que impactam o comportamento nos negócios internacionais; 3) as empresas não empreenderão internacionalmente até não crescerem suficientemente no seu mercado doméstico.

Mills et al. (2002) aumentam o leque da caracterização dos recursos. Os autores alertaram que os recursos não se apresentam separadamente. Os recursos podem ser uma mistura de conhecimento, sistema e um equipamento que não são fáceis de separar com claras definições (Ibid., 2002, p. 21). Outro exemplo dado pelos autores é que "gerentes experientes são particularmente fonte complexa de recursos. São tipicamente tangíveis, parte de muitos networks, são influentes guardiões de recursos culturais, possuem uma grande variedade de ativos de conhecimento que são certamente importantes para a mudança.” (p. 21). O Quadro 7 apresenta a divisão de recursos dada por Mills et al. (2002).

Quadro 7 - Categoria de Recursos

\begin{tabular}{|l|l|}
\hline \multicolumn{1}{|c|}{ Categoria de Recursos } & \multicolumn{1}{c|}{ Descrição } \\
\hline Recursos Tangíveis & $\begin{array}{l}\text { Prédios, equipamentos, empregados, patentes, } \\
\text { posição geográfica, mais ou menos qualquer coisa de } \\
\text { forma física }\end{array}$ \\
\hline Conhecimento, Habilidade e Experiência & $\begin{array}{l}\text { Geralmente não escrito, tácito, cujos possuidores } \\
\text { muitas vezes não sabem que os têm. }\end{array}$ \\
\hline Procedimentos e sistemas & $\begin{array}{l}\text { Conjunto de documentos tangíveis, mas que } \\
\text { necessitam de recursos intangíveis como } \\
\text { conhecimento para poder operá-los. }\end{array}$ \\
\hline Valores e Cultura & $\begin{array}{l}\text { Recurso intangível desenvolvido ao longo do tempo, } \\
\text { dependendo geralmente de eventos passados e da } \\
\text { atitude dos fundadores. Inclui memórias, valores, } \\
\text { crenças. }\end{array}$ \\
\hline Network & $\begin{array}{l}\text { Grupos de interesse dentro da empresa, networks } \\
\text { envolvendo pessoas da empresa com fornecedores, } \\
\text { clientes, governo ou consultores. Incluem-se aqui } \\
\text { reputação e marca. }\end{array}$ \\
\hline Recursos importantes para a mudança & $\begin{array}{l}\text { Um recurso chave é o de reconhecer quando um } \\
\text { determinado recurso está ultrapassado e necessita ser } \\
\text { modificado. }\end{array}$ \\
\hline
\end{tabular}

Fonte: Mills et al. (2002, p. 20-21)

Além da categoria de recursos, os autores diferenciam as competências por áreas de desenvolvimento com as quais as empresas podem se relacionar e competir no mercado. Zarifian (2001) propõe a seguinte classificação: 
- Competência sobre processos: os conhecimentos sobre o processo de trabalho;

- Competência técnica: conhecimentos específicos sobre o trabalho a ser realizado;

- Competência sobre a organização: saber organizar os fluxos de trabalho;

- Competência de serviço: identificar o impacto que o produto ou serviço terá sobre o consumidor final;

- Competência social: saber ser, atitudes que sustentam o comportamento das pessoas, como: autonomia, responsabilidade e comunicação.

Apesar de empresas do mesmo setor de atuação poder ter a mesma competência, as capacidades que formam cada uma das competências organizacionais se diferenciam pela competitividade que a empresa enfrenta, por razões históricas, culturais e até mesmo o contexto em que está inserida. (BARNEY, 2001). Entretanto, sabe-se que além de explicar como as companhias defendem sua posição de vantagem competitiva, é igualmente necessário conhecer como as empresas atingem e constroem tais posições em um ambiente dinâmico e em constante mutação. Assim, insere-se o conceito de capacidade dinâmica.

Ao abordar capacidades dinâmicas, Penrose (1959) afirma que as capacidades dinâmicas provêm de um modelo coerente (e inovador) de como as firmas desenvolvem vantagens competitivas e as mantêm ao longo do tempo. Já Mills et al. (2002) afirmam que capacidades dinâmicas consistem no desenvolvimento de competências que permitem a renovação das competências da empresa, enquanto Eisenhardt e Martin (2000, p. 1107) definem capacidades dinâmicas como:

Os processos da empresa que usam recursos - especificamente os processos para integrar, reconfigurar, obter e liberar recursos - para encontrar e mesmo criar mudanças no mercado. Capacidades dinâmicas são rotinas organizacionais e estratégicas com as quais as empresas atingem novas configurações de recursos quando ocorre o surgimento, a colisão, a divisão, o desenvolvimento ou o desaparecimento dos mercados.

A visão de capacidade dinâmica envolve processos de como a empresa constrói, integra e reconfigura posições de recursos valiosos. A visão baseada nos recursos da firma em um sentido mais amplo inclui trabalho, capital, tecnologia, conhecimento, as rotinas e processos que são necessárias para dar suporte às suas atividades produtivas (por exemplo, estruturas organizacionais e capacidades). As capacidades dinâmicas consistem de estruturas e processos que constituem sua habilidade de reconfigurar seus recursos base para satisfazer às 
necessidades de mudança de um ambiente dinâmico. (JANTUNEN et al., 2005; FLORIANI et al., 2009).

A definição introduzida por Zollo e Winter (2002) sintetiza o conceito e se concentra em aprendizado: a capacidade dinâmica é um modelo aprendido, estável, de atividade coletiva, por meio do qual a organização sistematicamente gera e modifica suas rotinas operacionais.

Para Nielsen (2006), uma implicação chave para o conceito de capacidades dinâmicas é que as firmas não estão só competindo em sua habilidade de explorar seus recursos existentes e capacidades organizacionais, mas também competindo em sua habilidade de renovar e desenvolver suas capacidades organizacionais. Ambas as capacidades, dinâmicas e organizacionais, podem ser vistas como rotinas organizacionais, porém com resultados diferentes. Capacidades organizacionais permitem à empresa produzir bens e serviços, enquanto capacidades dinâmicas asseguram a renovação e desenvolvimento das capacidades organizacionais. (FLORIANI et al., 2009).

Com relação aos resultados desejados, a partir das competências "a mobilização das capacidades e recursos e, portanto, o exercício da competência vai estar sujeita aos resultados desejados e às condições que se colocam no contexto.” (RUAS, 2005, p. 40). Assim, quando analisada a noção de competência em empresas que atuam no exterior, tem-se outro contexto, o das competências locais, competências não locais e competências específicas. (DUNNING, 1993; RUGMAN; VERBEKE, 2001; MOORE, 2001).

De acordo com Dunning (1993), as competências não locais são aquelas provenientes das vantagens de propriedade da firma e transferidas para a rede da empresa, ou seja, as competências desenvolvidas tanto na matriz como nas subsidiárias ou filiais no exterior e transferida para a matriz ou para as demais empresas do grupo. $\mathrm{O}$ autor admite que nem todas as competências desenvolvidas podem ser transferidas, principalmente quando se trata de mercados externos, pois são competências que interessam restritamente a um país. Isso acontece pela especificidade da organização política ou cultural do país, ou até mesmo pela posição da empresa perante a concorrência em determinado mercado. Essas competências são chamadas de locais, por Dunning (1993). 
Há ainda as competências específicas das subsidiárias apresentadas por Birkinshaw e Moore (1998) e Rugman e Vebeke (2001). A competência especifica provém do conhecimento tácito e são dependentes do contexto específico de atuação (ANDERSSON; FORSGREN, 2000) e da história da empresa. (HAKANSSON; WALUSZEWSKI, 2002). Essas competências são difíceis de serem imitadas e transferidas, não apresentando a internalização da competência, conforme apontado pelo Paradigma Eclético.

As empresas transnacionais, cujas subsidiárias desenvolvem competências no país hospedeiro, respondem a três estímulos, conforme apresentam Fleury e Fleury (2004): o tamanho do mercado local; a especificidade do produto nos mercados locais e a existência de competências locais para apoiar o desenvolvimento de estratégias. Para as empresas brasileiras, os autores supracitados observam que são poucas as que se internacionalizam de forma mais complexa, mas que com a recente onda de aquisições e fusões, as empresas estão ganhando escala para competir no mercado externo.

Mediante o processo de internacionalização há um processo de aprendizagem para as empresas brasileiras, pois aprender a atuar em mercados e em culturas diferentes das suas de origem gera conhecimentos e competências para lidar com a nova realidade, segundo apontam Porter (1990), Zahra et al. (2000) e Fleury e Fleury (2004).

As empresas de países emergentes (late movers), que passaram a se internacionalizar muito mais tarde que as empresas tradicionais (first movers), dependem da aprendizagem de competências que desenvolvem no exterior para se tornarem e se manterem competitivas. (WELLS, 1983; MATHEWS, 2006).

Mathews (2006), analisando as MNCs de países emergentes, ressalva que suas estratégias são marcadas por três fatores: a) busca por recursos no exterior por meio de aquisições, parceiras ou inserção nas redes de negócios internacionais; b) aproveitamento desses recursos adquiridos e também dos desenvolvidos no exterior para alavancar os negócios da empresa como um todo e, c) grande capacidade de aprendizagem dos novos recursos adquiridos ou desenvolvidos. 
Alguns autores identificaram diferentes fatores que são responsáveis pelo desenvolvimento e transferência das competências. Bartlett e Ghoshal (1992) consideram a estratégia de gestão internacional como o fator responsável pelo desenvolvimento de competências. A integração ou não entre matriz e subsidiárias e a autonomia na tomada de decisões são exemplos citados pelos autores. Já os fatores ambientais externos inerentes ao contexto competitivo são tratados por Porter (1990), na Teoria da Vantagem Competitiva das Nações, e as condições de infraestrutura do país, como fator de desenvolvimento de competências específicas, foram apresentadas por Rugman e Vebeke (2001) e por Frost (2001).

Já para Dunning (2003), o mercado externo é uma extensão do mercado nacional, e que para ser bem-sucedida no mercado internacional a empresa precisa construir antes uma vantagem competitiva.

Outros autores, ao abordarem as competências voltadas para uma atuação da empresa, como a da exportação, defendem que quanto maior a competência de exportação desenvolvida pelas empresas maior será a capacidade de influência e a habilidade da empresa em usar adequadamente a informação/conhecimento para ter uma vantagem competitiva ou como oportunidade de crescimento. (SERINGHAUS, 1993; CAVUSGIL; ZOU, 1994). Os autores utilizam o termo competências de exportação como experiência de exportação e domínio da área para explorá-las como recurso e assim aumentar o seu envolvimento com a exportação. (JULIEN; RAMANGALAHY 2003).

Knight e Kim (2009) conceituaram competência nas PMEs como um conceito multidimensional que reflete o grau segundo o qual a PME adota um conjunto de competências internacionais para realizar atividades de negócios nos mercados externos de uma forma eficaz. Para Etemand (2004), os recursos específicos e possivelmente únicos serão a estratégia base para a internacionalização da PME e deverá ser mais potente que a dos concorrentes de, provavelmente, maior tamanho. O referido autor complementa que a sobrevivência da PME neste ambiente excessivamente globalizado e competitivo sugere que não somente a PME possui competências distintas, mas efetivamente também as utilizam.

No contexto das PMEs, as competências de adaptação, tomada de decisões mais rápida e de desenvolvimento de habilidades gerenciais específicas fazem com que essas empresas detenham uma vantagem competitiva em detrimento das grandes MNCs (CRETOIU 2007, in 
ALMEIDA, 2007). Apesar dessas habilidades e recursos específicos em função do porte da empresa, a PME encontra dificuldade em ingressar no mercado externo de forma mais complexa e de se diferenciar dos fortes concorrentes encontrados no exterior, por necessitar recursos e capacidades específicas exigidas pelo ambiente dinâmico internacional. (IBEH et al., 2004).

Para Knight e Kim (2009), as PMEs internacionais devem deixar manifesto que possuem recursos específicos, que compreende o direcionamento e as competências que são instrumentais para a concepção e implementação das atividades internacionais. Apesar de faltar, para as PMEs, parte substancial de recursos financeiros e humanos, os autores argumentam que elas disponibilizam um conjunto de recursos fundamentais que facilitam o sucesso internacional. Esses recursos são principalmente conhecimento, habilidades e, sobretudo, competências do administrador do negócio.

Eriksson et al. (1997) testaram um modelo de pesquisa sobre os administradores e o custo percebido no processo de internacionalização. Este estudo revelou que o conhecimento experiencial no processo de internacionalização tem influência significativa nos custos percebidos.

Borch et al. (1999) estudaram os recursos da PME por meio de seis variáveis: Recursos Humanos, Sociais, Organizacionais, Tecnológicos, Financeiros e Locacional. Os recursos humanos foram mensurados por uma variável dicotômica indicando se o gerente tinha um curso de graduação e o número de anos que ele já atuava como gerente de negócios. Recursos sociais foram medidos pela participação em networks. Para identificar recursos organizacionais foram utilizados os sistemas administrativos formais de governança. Recursos tecnológicos foram mensurados pelos produtos e tecnologias não imitáveis. Recursos financeiros, por uma opinião do próprio executivo sobre os vantajosos recursos financeiros da própria empresa. Por fim, mais um item foi estudado, e corresponde ao posicionamento do respondente sobre a sua localização comparada com os concorrentes.

Suh et al. (2007) identificaram, em Pequenas empresas coreanas, que a falta de conhecimento experiencial tem um impacto positivo significante nos custos percebidos no exterior. A falta de recursos tangíveis observada nas PMEs não estava significativamente associada aos custos 
percebidos em fazer negócios no exterior. Assim, esse estudo identificou que a Pequena empresa enfrenta barreiras significativas decorrentes da falta de conhecimento experiencial e recursos tangíveis para ingressar no mercado internacional. Executivos de PMEs constataram que a ausência de conhecimento e de experiência internacional contribui mais para os custos percebidos da expansão internacional. Em comparação, a falta de recursos físicos e financeiros não impacta a percepção gerencial dos custos da expansão internacional.

Julien e Ramangalahy (2003) pesquisaram 3.403 PMEs exportadoras de Quebec (até 250 empregados) para verificar se quanto mais competências na exportação a PME tivesse, melhor seria sua estratégia competitiva e melhor seria o seu desempenho. Para mensurar competência de exportação das 346 respondentes, os autores utilizaram as seguintes métricas indiretas dos problemas de gestão encontrados pelas PMEs na exportação:

- $\quad$ nível de conhecimento de exportação;

- $\quad$ dificuldades na exportação;

- gerenciamento de exportação:

- Capacidade Geral de Exportação;

- Competência de Marketing para a Exportação (adaptação etc..);

- Capacidade de obter informação.

Menos de $20 \%$ dos respondentes consideraram a empresa apta a lidar com todas as variáveis medidas, e aproximadamente $40 \%$ dos respondentes consideraram que a empresa possui certo nível de conhecimento, mas que precisa aprender mais para ser mais competitiva. As dificuldades mais apontadas pelos respondentes, por ordem decrescente de importância, foram: encontrar o intermediário correto, forte competição no exterior, falta de tempo para desenvolver e gerenciar as exportações, conhecimento de mercado, preço competitivo para o produto e encontrar consumidor.

Etemad (2004) realizou uma pesquisa utilizando a "Grounded Theory" (Uma estratégia de pesquisa que intenciona gerar uma teoria substantiva, por meio da análise sistemática dos dados sobre uma realidade específica e delimitada da ocorrência de um fenômeno social, explica a ocorrência desse fenômeno a partir dos significados atribuídos pelos envolvidos às suas experiências no dia a dia. (BANDEIRA-DE-MELLO, 2009). 
$\mathrm{O}$ autor identificou que, no seu país de origem, a PME possui sua própria e forte base de conhecimento local, seu network social, bem como sua cadeia de suprimentos funcional, o que denominou de Base local de capacidades e competências (LBCs). Com base nisso, as PMEs poderão facilmente basear suas estratégias, e com isso poderão se diferenciar dos concorrentes. A LBCs pode também funcionar como moeda de troca com parceiros para ingressar em mercados estrangeiros e utilizar as vantagens específicas do local (LSAs). O autor levantou os fatores impulsionadores, os fatores de atração e os fatores intermediários que levam à internacionalização da PM, ou seja, como ator: a) empreendedores orientados ao mercado internacional; como ação: b) empresas orientadas ao crescimento; e como fator: c) um envolvimento constante no ambiente competitivo.

Ruzzier et al. (2007) consideraram o capital humano como positivo e fortemente relacionado com a internacionalização. O construto capital humano foi formado pelas seguintes variáveis: a) Orientação Internacional; (b) Conhecimento dos gerentes; (c) Percepção do risco e (d) habilidades nos negócios internacionais. Todas essas variáveis tiveram uma alta e significativa relação com o Grau de internacionalização, que por sua vez foi mensurado pelo tempo que a empresa exporta, pela quantidade de países e distância psíquica, pelo grau de internacionalização e pelo percentual de produtos vendidos no exterior sobre o total.

O trabalho de Knight e Kim (2009) incide sobre os específicos fatores que suportam o desempenho superior das PMEs internacionalizadas. Os autores desenvolveram um conjunto de capacidades intangíveis e denominaram de Internactional Business Competence (IBC). Por meio de estudos de casos e de uma pesquisa quantitativa, atribuíram ao IBC quatro dimensões: orientação internacional, habilidades de marketing internacional, inovação internacional e orientação ao mercado internacional. O IBC identifica a existência, nas PMEs, de recursos intangíveis, de orientação cultural, bem como de processos que somam para o sucesso dos negócios internacionais. O IBC reflete as competências em várias áreas, incluindo a aprendizagem sobre ambientes internacionais de toda a organização e a adaptação a novos ambientes via interações com os mercados estrangeiros. $\mathrm{O}$ objetivo do estudo foi verificar se os fatores identificados no IBC refletem as competências das PMEs internacionalizadas e contribuem para um maior desempenho internacional. 
O IBC foi contextualizado pelos autores como um conceito multidimensional que reflete a extensão segundo a qual as PMEs adotam suas competências internacionais para fazer negócios em mercados estrangeiros. As quatro dimensões foram trabalhadas pelos autores, conforme o Quadro 8.

Quadro 8 - Dimensões de Knight e Kim (2009)

\begin{tabular}{|c|c|}
\hline Dimensões & Características específicas \\
\hline Orientação internacional & $\begin{array}{l}\text { Empresas com uma forte orientação internacional } \\
\text { tendem a possuir competências distintivas } \\
\text { (McDOUGALL; SHANE; OVIATT, 1994), implica } \\
\text { explorar novas oportunidades no exterior. Uma } \\
\text { orientação internacional é como instigar processos, } \\
\text { práticas e tomadas de decisões associados a novos } \\
\text { mercados externos, contribuindo para o desempenho } \\
\text { da empresa. (KNIGHT; CAVUSGIL, 2004). }\end{array}$ \\
\hline Habilidades de Marketing Internacional & $\begin{array}{l}\text { Refere-se à habilidade da empresa em criar valor para } \\
\text { os clientes internacionais por meio de uma efetiva } \\
\text { segmentação e avaliando como as ferramentas de } \\
\text { Marketing estão organizadas para diferenciar as } \\
\text { ofertas dos seus competidores (KNIGHT; } \\
\text { CAVUSGIL, 2004) e tornar a PME mais eficaz para } \\
\text { atender aos seus consumidores no exterior. }\end{array}$ \\
\hline Inovação internacional & $\begin{array}{l}\text { A definição desta dimensão para os autores é a } \\
\text { capacidade de desenvolver e introduzir novos } \\
\text { processos, produtos ou ideias em mercados } \\
\text { internacionais (HURLEY; HULT, 1998). } \\
\text { Concordando com Knight e Cavusgil (2004), } \\
\text { inovação internacional é uma dimensão crucial para o } \\
\text { sucesso internacional influenciando positivamente o } \\
\text { desempenho das PMEs internacionais. }\end{array}$ \\
\hline Orientação para o Mercado Internacional & $\begin{array}{l}\text { A habilidade de realmente entender o cliente, o } \\
\text { mercado e os concorrentes, e então responder a este } \\
\text { entendimento (NARVER; SLATER, 1990) para ter } \\
\text { um melhor desempenho internacional (WREN et al., } \\
\text { 2000) }\end{array}$ \\
\hline
\end{tabular}

Fonte: Adaptado de Knight e Kim (2009)

Cada uma dessas dimensões foi composta por um conjunto de questões (capacidades) de diversas fontes, formando assim o IBC.

Os resultados desse trabalho demonstram que PMEs que possuem um alto nível de IBC apresentam um melhor desempenho. Das quatro dimensões apresentadas pelos autores, as dimensões orientação para o mercado internacional e orientação internacional apareceram com os maiores pesos na identificação do IBC. 
No ano anterior ao trabalho de Knight e Kim (2009), Pangarkar (2008) pesquisou o desenvolvimento de competências e o impacto no desempenho das PMEs japonesas. $\mathrm{O}$ autor solicitou respostas, utilizando um escala de Likert de 5 pontos, para as seguintes perguntas sobre as competências das empresas: a) Nossa empresa direciona recursos para o desenvolvimento de novos produtos para o mercado externo? b) Nossa empresa possui as capacidades gerenciais para coordenar a expansão internacional? c) Nossa empresa é financeiramente capaz de coordenar a expansão internacional, nossa empresa tem forte foco em pesquisa e desenvolvimento? d) Nossa empresa realiza pesquisa de mercado para identificar oportunidades no exterior? e) Nossa empresa possui uma forte reputação da marca? Os resultados desta pesquisa demonstram que há uma correlação significativa (nível 0,01) entre grau de internacionalização e competências, e competências com desempenho. No Quadro 9, resumem-se as principais variáveis que se identificou na literatura para mensurar as competências das PMEs internacionalizadas.

Quadro 9 - Principais variáveis de competência para a PME internacionalizada

\begin{tabular}{|c|c|c|}
\hline Autor & Variáveis & Descrição \\
\hline Knight e Kim (2009) & $\begin{array}{l}\text { International Business } \\
\text { Competence (IBC) }\end{array}$ & $\begin{array}{l}\text { Por meio de } 4 \text { construtos, os } \\
\text { autores elaboraram o índice de } \\
\text { Competência nos Negócios } \\
\text { Internacionais para as PMEs. Os } \\
\text { construtos são: Orientação } \\
\text { internacional, Habilidades de } \\
\text { Marketing Internacional, Inovação } \\
\text { internacional, Orientação para o } \\
\text { mercado internacional. }\end{array}$ \\
\hline Fleury e Fleury (2004) & $\begin{array}{l}\text { Tipologia de competências } \\
\text { organizacionais }\end{array}$ & $\begin{array}{l}\text { Os autores consideram que toda a } \\
\text { empresa possui, em diferentes } \\
\text { proporções, competências } \\
\text { relacionadas a três diferentes } \\
\text { funções: Operações (Produção e } \\
\text { Logística), Desenvolvimento de } \\
\text { Produto (ou Serviços) e } \\
\text { Comercialização (Vendas e } \\
\text { Marketing) e que as funções de } \\
\text { suporte seriam: Contábil- } \\
\text { Financeira, Recursos Humanos, } \\
\text { Sistemas de Informação, entre } \\
\text { outras. }\end{array}$ \\
\hline Julien e Ramangalahy (2003) & Competências exportadoras & $\begin{array}{l}\text { Utilizando um grupo de variáveis, } \\
\text { os autores identificaram as } \\
\text { competências exportadoras que } \\
\text { melhoram o desempenho da PME. } \\
\text { As variáveis foram: } \\
\text { Conhecimentos Gerais, Marketing, } \\
\text { Recursos e Informação. }\end{array}$ \\
\hline
\end{tabular}

continua 
conclusão

\begin{tabular}{|c|c|c|}
\hline Mills et al. (2002) & $\begin{array}{l}\text { Framework de competência } \\
\text { medindo desempenho }\end{array}$ & $\begin{array}{l}\text { Os autores desenvolveram um } \\
\text { modelo que identificam as } \\
\text { competências que geram um } \\
\text { melhor desempenho. As variáveis } \\
\text { são: Medidas internas, Medidas de } \\
\text { processo, Medidas de produção, } \\
\text { Medidas de resultados. }\end{array}$ \\
\hline Pangarkar (2008) & Capabilities & $\begin{array}{l}\text { O autor, ao mensurar o impacto } \\
\text { das competências no desempenho } \\
\text { das PMEs japonesas, focou em } \\
\text { competências de Marketing, } \\
\text { pessoas, pesquisa } \\
\text { desenvolvimento e marca. }\end{array}$ \\
\hline Borch, Huse e Senneseth (1999) & Recursos da PME & $\begin{array}{l}\text { Mensurou os recursos da PME por } \\
\text { meio de seis variáveis: Recursos } \\
\text { Humanos, } \\
\text { Organizacionais, Tecnológicos, } \\
\text { Financeiros e Locacional. }\end{array}$ \\
\hline Ruzzier et al. (2007) & Capital Humano & 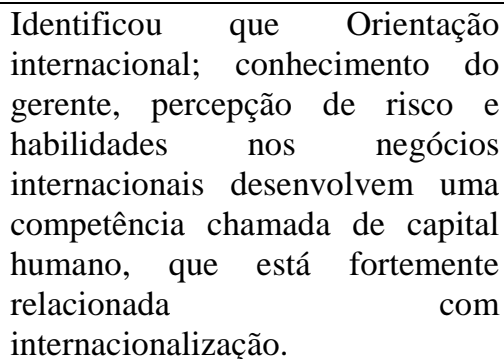 \\
\hline
\end{tabular}

Fonte: Adaptado dos autores apresentados (2010)

Para caracterizar competência organizacional não se pode esquecer de que essas competências precisam criar valor em fatores chaves de sucesso da empresa para impactar positivamente o desempenho organizacional.

Verifica-se, neste item, que as PMEs com atuação no exterior possuem certa vantagem com relação à empresa exportadora, considerando que as PMEs podem desenvolver competências diferentes por seu contexto de atuação. Da mesma forma, a PME exportadora pode apresentar essa mesma vantagem em relação às PMEs de atuação local. A dificuldade maior para a PME está, como mostram os trabalhos apresentados, na coordenação e internalização das capacidades e dos recursos desenvolvidos durante o processo de internacionalização para torná-las uma competência e, como consequência, melhorar o desempenho organizacional. 


\subsection{O Desempenho da PME Internacionalizada}

Neste item é apresentada uma revisão da literatura sobre desempenho, focando a corrente de pesquisa dos Negócios Internacionais. O desempenho estudado será o da empresa em geral, como será explicado no decorrer desta seção. Por ser um tema bastante complexo, não se pretende exauri-lo, mas sim identificar os principais trabalhos nesta área que auxiliam o desenvolvimento do tema aqui proposto.

Concorda-se com o posicionamento de Kindleberger (1974) ao analisar o Investimento Estrangeiro Direto (IED) de que uma empresa local tem vantagens sobre uma empresa estrangeira, pois é dispendioso operar à distância, dispendioso em viagens, em comunicação e, inclusive, em mal-entendidos. O autor supracitado identifica que a empresa estrangeira precisa superar a vantagem local, devendo ter alguma vantagem não partilhada com a sua competidora local. Ainda segundo Kindleberger (1974, p. 423), “A empresa estrangeira deve ser capaz não somente de obter lucros mais altos no exterior do que em seu país, mas também ser capaz de ganhar lucros maiores no exterior do que as firmas locais em seus próprios mercados." Há, por outro lado, o ganho da diferenciação e da especialização, complementa o autor.

Diferentes autores têm utilizado variados aspectos conceituais de desempenho e muitos deles utilizam somente parte do conceito para explicar as relações sobre o desempenho organizacional. Por ser um fenômeno complexo, limitação de tempo, de recursos ou de dados faz com que as pesquisas sobre o desempenho continuem sendo testadas sem um fechamento conclusivo.

Na área de gestão, desempenho é um termo multifacetado que apresenta diversas conotações. Styles (1998) afirma que a dificuldade de disponibilização de dados constrange a operacionalização e definição do construto de desempenho. Essa dificuldade se torna ainda maior quando se pesquisa a PME. Na área da Administração, observa-se que o desempenho é conceituado e mensurado de diversas maneiras, como, por exemplo, o nível da qualidade de serviço, o desempenho no trabalho, a percepção de sucesso, a satisfação percebida, o desempenho geral percebido presente e/ou futuro, além de diferentes óticas de eficiência 
econômica no que tange à empresa em geral e/ou a exportação especificamente, como retorno sobre os ativos e retorno sobre os investimentos. (DIAMANTOPOULOS, 1999).

Para Boshoff e Mels (1995) o objetivo de medir o desempenho está associado à otimização do uso de recursos, e para Shoham (1998), que além de corroborar a afirmação anterior, adicionou que o conceito de desempenho depende da visão do stakeholder. Acionistas, empregados, corpo dirigente, governo, e outros grupos de interesse que interagem com a firma podem ter concepções distintas de otimização de recursos, ou seja, a definição de desempenho depende do contexto específico que está sendo estudado. Para Cameron (1986), há diversas áreas de resultados em uma empresa, tantas quantas forem os seus stakeholders com diferentes interesses de resultados.

Em pesquisas sobre o desempenho da organização, Dess e Robinson (1984) consideraram que se deveria atentar para duas questões: a) escolha de um referencial para definir desempenho; b) identificação de medidas acuradas e disponíveis para operacionalizar desempenho.

Para auxiliar na escolha da definição de um conceito bastante complexo, como o de desempenho, buscaram-se algumas informações da corrente da estratégia, como as análises de Cameron (1986), que apresentou algumas considerações importantes relativas ao tema. Para o referido autor, a conceituação de desempenho organizacional diz respeito, inicialmente, à concepção e abrangência. Uma vez que nenhuma concepção do que seja uma organização será suficientemente abrangente, então a conceituação de uma organização de sucesso ou com bom desempenho também não poderá ser suficientemente abrangente. Após a conceituação, Cameron (1986) verificou que uma vez que os critérios para avaliação do desempenho dependeriam dos valores e das preferências dos indivíduos envolvidos, não é possível se chegar a um consenso sobre os melhores indicadores de desempenho ou ao número suficiente de indicadores. O contexto da pesquisa também é importante para o autor, pois dependendo das circunstâncias, da disponibilidade dos dados, ou ainda dos diferentes objetivos da pesquisa, certos indicadores de desempenho serão mais indicados que outros. Por esse motivo, o construto depende do problema da pesquisa.

Já na corrente de negócios internacionais, Leonidou et al. (2002) realizaram um levantamento de diversos estudos sobre desempenho e identificaram doze dimensões de desempenho de exportação, que foram classificadas em sete grupos: a) intensidade de exportação (proporção 
das receitas de exportação em relação às receitas totais), b) crescimento de receitas de exportação, c) nível de lucro da exportação, d) volumes de exportação, e) market share de exportação, f) contribuição das exportações para o lucro, g) "outras medidas de desempenho" (que incluíram retorno sobre o investimento, satisfação com a exportação, percepção de sucesso, crescimento percebido da exportação, lucratividade percebida e market share percebido). Parte dessas medidas é de natureza contábil-financeira, enquanto outras são de mercado. Algumas podem ser consideradas objetivas, enquanto outras seriam subjetivas.

Ainda para Leonidou et al. (2002), as medidas contábeis-financeiras podem apresentar diversas limitações para a pesquisa, ou pela insuficiência de dados segregados sobre as atividades gerais da empresa ou sobre as atividades das exportações, em especial em PMEs, ou pela diversidade de práticas contábeis observadas entre países e até entre empresas, dificultando estudos comparativos. Por outro lado, medidas de mercado (tais como market share) também poderiam ser imprecisas e estar sujeitas a viés de interpretação do respondente. Os autores também consideraram que medidas perceptuais ou subjetivas poderiam exibir problemas de confiabilidade e, portanto, seria recomendável o uso de mais de um respondente para cada empresa. Contudo, indicadores considerados objetivos, tais como medidas contábeis, poderiam estar sujeitos a viés idiossincrático, tendo em vista a exigência de dados sigilosos e confidenciais na área gerencial. Meyer (1994) e Drucker (1995) também criticam o uso de medidas exclusivamente financeiras para medir o desempenho.

O conceito de desempenho é um tema de muita controvérsia. Muitos critérios de medida têm sido propostos na literatura, sendo que a maioria dos trabalhos propõe um esquema multidimensional. (KAYNAK, 1992; BIJMOLT; ZWART, 1994; CARNEIRO, 2007). O desempenho é um construto complexo do ponto de vista da empresa. O sucesso financeiro de uma empresa pode constituir um fracasso para outra, e a avaliação de desempenho é frequentemente idiossincrática ao tipo de empresa e ao seu ambiente. (GREVE, 1998).

Para Oliveira (2006), o sistema de mensuração de desempenho pode estar distribuído em diversos níveis, tais como o corporativo, a unidade de negócios, os processos de negócios, e até mesmo em um nível mais micro, como uma atividade específica de exportação, por exemplo. 
Ao se fazer esta introdução sobre as dificuldades conceituais e operacionais de avaliação de desempenho da empresa percebeu-se que as dificuldades em operacionalizar o construto também geram muitas discussões e controvérsias, que são discutidas na academia e na prática das empresas.

Lages e Lages (2004) verificaram em suas pesquisas que as principais variáveis utilizadas para a mensuração do desempenho das exportações são o volume de vendas, a lucratividade, e o market-share. As duas primeiras são quantificadas em termos relativos, ou seja, o resultado das exportações em relação ao resultado global da firma.

Na pesquisa de Morgan e Katsikeas (1997) a participação relativa das exportações nas vendas totais da empresa é a mais encontrada na literatura, representando cerca de $60 \%$ dos indicadores utilizados.

Muitos esforços têm sido envidados na literatura que explora a métrica desempenho. Analisando os artigos publicados, percebe-se que grande parte apresenta métricas diferentes e acabam por não explicar o desempenho internacional das empresas. (AABY; SLATER, 1989; ZOU; STAN, 1998; LAGES; MONTGOMERY, 2004).

Shoham (1998) apresentou como resultado da sua pesquisa que o desempenho de exportação poderia ser caracterizado por três dimensões principais: a) receitas de exportação, b) lucratividade e c) crescimento. $\mathrm{O}$ autor ainda classificou as dimensões principais em subdimensões para melhor capturar os diversos aspectos do desempenho. As receitas de exportação poderiam ser representadas pelo conjunto de intensidade de exportação (receitas de exportação e receitas totais), montante absoluto de receitas de exportação e parcela de mercado. Já a lucratividade poderia ser caracterizada por retorno sobre vendas, retorno sobre os ativos e participação da exportação nos lucros totais. E crescimento incorporaria tanto mudanças nas receitas de exportação quanto mudanças na lucratividade ao longo do tempo.

Na opinião de Shoham (1998), alguns cuidados deveriam ser tomados na comparação entre os resultados de diferentes empresas, pois a comparação de resultados de vendas somente seria válida caso as empresas possuíssem objetivos estratégicos semelhantes. Para o autor, mais do que simplesmente representar uma subdimensão independente adicional, o uso de medidas mais amplas, como indicadores de satisfação, ofereceria maior riqueza ao entendimento de 
cada subdimensão. Contudo, o autor recomendou o uso de medidas mais específicas, tais como satisfação com as vendas, em vez de medidas globais. Considerou, ainda, a possível existência de correlação entre diversas medidas de desempenho. $\mathrm{O}$ autor apontou, ademais, a aparente contradição entre objetivos de faturamento e lucratividade, tanto em termos pontuais como dinâmicos, ou seja, variações ao longo do tempo. Uma firma pode apresentar elevada lucratividade e baixo crescimento das vendas, ou, com intuito de aumentar sua fatia de mercado, diminui a sua margem de lucro para elevar as vendas. Contudo, no longo prazo, o faturamento, a lucratividade, e a mudança desses indicadores tendem a estar relacionados entre si.

Shoham (1998) acrescentou que a definição de desempenho de exportação deve ser consistente com a definição de desempenho da empresa de forma geral. Ou seja, para empresas que utilizem crescimento de vendas como uma medida de desempenho, a medida para desempenho de exportação deveria ser crescimento de receitas de exportação.

Os principais trabalhos acadêmicos e seus resultados abordando as principais teorias de internacionalização foram amplamente apresentados na tese de doutorado de Carneiro (2007). O autor, não simplificando um fenômeno que é bastante complexo, apresentou uma extensa e apropriada revisão da literatura e dos estudos dos fatores explicativos sobre as diferenças de desempenho, especialmente nas operações de exportação. Para o autor, desempenho abrange três principais fatores de influência: a) Fatores externos à empresa (ambiente externo); b) Fatores internos à empresa (características da empresas); c) Fatores que relacionam a empresa ao ambiente externo, em especial, sua postura competitiva e os métodos competitivos adotados (estratégia). $\mathrm{O}$ autor ainda elaborou uma lista não exaustiva, mas bastante completa, dos fatores intervenientes sobre o desempenho de exportação.

O estudo de Carneiro (2007), além da contribuição dos detalhados procedimentos para depuração de construtos, identificou que as receitas passadas de exportação (e seu respectivo crescimento) se mostraram positiva e fortemente associadas ao status da atividade de exportação e negativa e fortemente associadas com barreiras no país de destino, sugerindo que uma forma de aumentar as receitas de exportação seria conferir maior autonomia, prestígio e importância à atividade exportadora. Já a lucratividade passada da exportação se revelou positiva e fortemente associada com sistematização do planejamento de exportação e negativa 
e moderadamente associada tanto com distância psíquica quanto com barreiras no país de destino. Contudo, o autor não constatou associação estatisticamente significativa entre distância psíquica e receitas de exportação. Também não foi confirmada a associação negativa de distância de negócios com receitas de exportação e com lucratividade da exportação. $\mathrm{O}$ autor justificou que tal relação pode ter sido mascarada pelo fato de não terem sido testadas como variáveis de controle, como, por exemplo, o tipo de indústria, o tamanho da empresa, seu grau de internacionalização ou a experiência internacional de seus executivos.

Os autores Katsikeas et al. (2000) realizaram uma análise sobre as medidas que avaliam o desempenho das empresas internacionalizadas, tendo identificado que a grande maioria dos estudos que avaliam o desempenho o mensuram no nível corporativo, e $12 \%$ apenas no nível específico da exportação. Apesar dos esforços notáveis nos últimos anos para operacionalizar desempenho das exportações como uma construção usando uma unidade específica de análise, muitas vezes estes esforços não são explícitos nas questões e acabam mensurando a organização como um todo e não a exportação especificamente. (LAGES et al., 2005).

Kotabe e Czinkota (1992) salientam que a lucratividade não é o único indicador apropriado para avaliar o desempenho da empresa, porquanto medidas de competitividade também avaliam o desempenho.

Zou et al. (1998) desenvolveram a escala EXPERF para verificar o desempenho entre dois países. Os autores utilizaram nove itens para mensurar desempenho via percepção dos respondentes. Os indicadores foram divididos em 3 componentes maiores e mensurados por uma escala Likert de 5 pontos, como demonstra o Quadro 10:

Quadro 10 - Indicadores de desempenho de Zou et al. (1998)

\begin{tabular}{|l|l|}
\hline Desempenho financeiro da exportação & Discordo totalmente \\
Totalmente & Concordo \\
\hline Tem sido muito lucrativa & \\
Gerou altos volumes de vendas & \\
Alcançou um rápido crescimento & \\
\hline Desempenho estratégico da exportação & \\
\hline Melhorou nossa competitividade global & \\
Fortaleceu nossa posição estratégica & \\
\hline Satisfação & \\
\hline O desempenho da nossa operação no exterior tem sido muito satisfatório \\
Nossa operação no exterior é bem-sucedida \\
Nossa operação no exterior atingiu completamente nossas expectativas \\
\hline
\end{tabular}

Fonte: ZOU et al. (1998) 
Como resultado, este trabalhado mostrou que a escala EXPERF é consistente quando se realiza estudo entre países (EUA e Japão), como no caso estudado. Como já mencionado, esse trabalho foi desenvolvido para identificar uma escala que pudesse ser aplicada em dois países sem a interferência de dados contábeis, que podem ser medidos de maneiras diferentes. Esta escala chamou a atenção da doutoranda pelo fato de englobar uma situação específica e um amplo campo do desempenho sem considerar dados numéricos reais das empresas, o que tornaria esses indicadores aplicáveis a estudos em PMEs.

Os autores Lages et al. (2005) consideraram cinco aspectos do desempenho de exportação: desempenho financeiro; desempenho estratégico; atingimento de objetivos; contribuição da unidade individual de exportação (produto-cliente-país) para as operações de exportação da empresa; e satisfação com o desempenho geral da unidade individual de exportação. $\mathrm{O}$ período de análise considerado foi um ano. Carneiro (2007) critica esse modelo por só medir o desempenho passado e não identificar medidas relativas aos dos concorrentes ou às operações domésticas. Mas a maneira de identificar o desempenho sem demandar resultados exclusivamente financeiros e a facilidade de entendimento chamou a atenção da autora da presente tese, que considerou ser viável sua aplicação em PMEs quando se estuda um momento específico.

Os trabalhos sobre PMEs utilizam, com frequência, a "Intensidade de Exportação (Vendas de exportação como um percentual do total de vendas) e Crescimento médio das exportações" como principais critérios de mensuração de desempenho. (COOPER; KLEINSCHMIDT, 1985). Para Aaby e Slater (1989), os critérios mais utilizados para desempenho exportador são percentual das vendas sobre o percentual das exportações.

Nos trabalhos sobre PMEs em grau de internacionalização mais complexos, percebe-se uma tendência em justificar que a corrente de network, conforme apresentada por Andersen e Buvik (2002), é a que justifica o aumento do envolvimento das PMEs no mercado externo e melhora o seu desempenho. (COVIELLO; McAULEY, 1999; HOLLENSTEIN, 2005). Os autores comentam que quanto mais intensiva a competição na economia global, aumentando o conhecimento da atividade econômica e da inovação, com o alto e crescente custo de produção de conhecimento e com a diminuição do ciclo de vida dos dos produtos, o network 
passa a ser bastante atrativo ou, até mesmo, necessário. Isso se traduz, para a PME, como uma oportunidade de acessar ativos complementares e de explorar economia de escala e escopo.

Modelos de mensuração de desempenho organizacional foram propostos por diversos autores e são utilizados pelas empresas. Grande parte desses modelos é bastante complexa e nem sempre utilizada pelas PMEs. O Tabelau de Bord é um desses modelos, mas é utilizado principalmente pelas empresas francesas onde o modelo foi criado. (EPSTEIN, MANZONI, 1998). O Balanced Scorecard, de Kaplan e Norton (1992), é um dos modelos mais utilizados, e mede o desempenho por meio de um conjunto de variáveis como: aspectos financeiros, clientes, processos internos e aprendizado. O objetivo desse modelo é vincular as medidas de desempenho à estratégia empresarial. Esses modelos não serão tratados nesta tese, pois o foco será em indicadores mais utilizados pelas PMEs e que refletem as estratégias de internacionalização. Ademais, para ter acesso aos dados exigidos pelos modelos, haveria a necessidade de pesquisas mais específicas e profundas em cada empresa.

Alguns autores identificaram formas de demonstrar a relação entre o GRI de internacionalização e o desempenho, que apesar de não terem sido utilizadas em estudos em empresas de pequeno e médio porte, podem ser úteis para se estudar essa relação nas PMEs. Esses modelos foram demonstrados em curva, e foram assim denominados: a curva invertida J e a curva U. Alguns modelos como por exemplo a curva S, são utilizados para estudar empresas MNCs como altíssimo GRI. (p. e. WINFRIED et al., 2007). Esses modelos baseiam-se na não linearidade do impacto do GRI no desempenho, ou seja, dependendo do GRI e do tempo de internacionalização, a empresa apresenta diferentes resultados.

A curva invertida J (GOMES; RAMASWAMY, 1999) identifica que a internacionalização poderia trazer mais benefícios para a empresa do que custo até o momento de excelência (ou ponto ótimo). Os autores acresentam que, após esse ponto, os custos envolvidos seriam ligeiramente maiores que os benefícios relacionados ao aumento dos investimentos. Geringer et al. (1989) argumentam que com isso o desempenho financeiro poderia aumentar no início do processo e diminuir em níveis mais elevados de internacionalização, quando os benefícios caem e os custos aumentam. Os autores Nohria e Ghoshal (1997) asseveram que quando as empresas tornam-se MNCs e adotam estruturas mais complexas, necessitam de esforços significativos para gerenciar as diferenças culturais, estimular o intercâmbio de conhecimento e inovação, aumentando os custos da empresa. 
Gomes e Ramaswamy (1999) lançaram mão de uma perspectiva da teoria econômica para explicar o modelo utilizando empresas Norte-Americanas e mensuraram os construtos da seguinte forma: a) Multinacionalidade: (nesta tese denominado de GRI) foi medida por meio de um índice combinando três dimensões: Percentual das vendas no exterior sobre vendas totais, percentual dos ativos no exterior sobre ativos totais, e número de países nos quais a empresa opera; b) Desempenho: este construto foi operacionalizado em termos financeiros e operacionais. O financeiro foi mensurado por Retorno sobre os Ativos (ROA) e o operacional pela média do custo operacional sobre vendas (OPSAL). De acordo com os autores, a mensuração do desempenho organizacional se deveu ao interesse de abordar o aspecto locacional, poisa MNC tem acesso a benefícios significantes no exterior como mão de obra e matéria-prima mais barata. Como variáveis de controle, os autores utilizaram: Tamanho da empresa (total das vendas), Setor, via uma variável dummy de 3 pontos. Os resultados sugerem que níveis moderados de internacionalização mostraram benefícios em termos de redução do custo operacional por unidade de venda e aumentou o retorno dos ativos. Já em altos níveis de internacionalização, o oposto é identificado.

Gomes e Ramaswamy (1999) comentam que a pesquisa da multilinearidade foi efetuada com grandes MNCs, mas se for efetuado um estudo similar em MNCs de menor porte o resultado pode não se mostrar da forma idêntica.

Para a curva U (RUIGROK; WAGNER, 2003), há também o ponto ótimo quando a empresa chega a até $50 \%$ da exportação sobre o total das vendas, a partir daí o desempenho começa a diminuir. No início da internacionalização o desempenho é mais alto, segundo os autores, pela vantagem das novas oportunidades do mercado estrangeiro, a partir daí o desempenho diminui, mas à medida que a empresa ganha experiência no exterior, ou seja, se envolve em novas redes de negócios, suas estratégias tornamse pró-ativas, e o desempenho volta a crescer. Para desenvolver este trabalho os autores se basearam na perspectiva comportamental da internacionalização analisando empresas Alemãs. Para os autores, o fato de pesquisar empresas localizadas em um país europeu poderá mudar os resultados, diferenciando-os dos estudos realizados com empresas Norte-Americanas, que resultaram na curva $\mathbf{J}$ invertida. 
Porter (1999), utilizando também de um diagrama de curva U, demonstrou que uma empresa, mesmo com pequenas parcelas de mercado, poderia obter ótimos resultados se optasse pela diferenciação.

No Brasil, Fleury et al. (2007) identificaram, em 118 grandes empresas, que a internacionalização garante um melhor desempenho. Os autores encontraram uma curva $\mathbf{J}$ invertida, ou seja, há uma relação positiva entre internacionalização e desempenho até um ponto ótimo, depois, quando a empresa se torna uma MNC com operações no exterior, o desempenho diminui. Para as empresas pesquisadas, "quando atingem 15\% nas vendas externas os resultados aumentam até $100 \%$ e quando a empresa parte para o IED, há um ponto de inflexão.” (FLEURY et al., 2007, p. 77).

Para muitos autores o desempenho não é um fator que muda com o tempo ou com o grau de investimento, como as curvas acima, mas, sim, o GRI tem tanto efeito positivo como negativo no desempenho das empresas. (p. e. HITT et al. 1997). O impacto positivo se reflete na habilidade de a empresa desenvolver economia de escala (PORTER, 1985), acesso a novas tecnologias. (BARTLETT; GHOSHAL, 1989). Já os efeitos negativos para as empresas que atuam no exterior com formas mais complexas se manifestam no aumento dos custos associados à internacionalização, como a coordenação e o controle de sistemas administrativos para gerenciar mercados culturalmente diferentes e diferentes recursos humanos. (KINDLEBERGER, 1974; GERINGER et al., 1989).

Para Lu e Beamish (2001; 2006), o desempenho é uma caixa preta, dadas as múltiplas motivações e objetivos que podem acompanhar uma estratégia de internacionalização. Mesmo assim, dois dos objetivos mais comuns atribuídos à expansão internacional são o crescimento das empresas e a melhora da rentabilidade. (McDOUGALL; OVIATT, 1996).

Os autores Lu e Beamish (2001) identificaram, em PMEs japonesas, como já mencionado no item GRI, por meio de um estudo longitudinal, que a exportação contribui positivamente para o crescimento da PME, mas negativamente para a lucratividade. Já o IED tem uma relação positiva com o crescimento das PMEs, mas uma curva $U$ em relação à lucratividade das PMEs. Quando as PMEs iniciam seus processos de internacionalização por meio de um IED, os autores constaram que existe um impacto negativo moderado na relação entre IED e crescimento da empresa, dando suporte à noção de "aprendendo vantagens com o novo", de 
acordo com Autio et al. (2000). Os autores utilizaram as variáveis retorno sobre os ativos (ROA) e retorno sobre as vendas (ROS) para mensurar desempenho.

Já em 2006, Lu e Beamish estenderam as medidas de desempenho além do ROA e de ROS para verificar a lucratividade da PME, utilizando a taxa de crescimento anual de vendas líquidas e o total de ativos de cada empresa para examinar o crescimento da empresa. Neste trabalho os autores identificaram que exportando tem um impacto positivo no crescimento das PMEs, com a exportação sendo medida via crescimento de vendas e crescimento de ativos, mas quando mensurado com a lucratividade da PME, o impacto da exportação foi negativo. Já para as PMEs com IED, identificou-se uma relação positiva com o crescimento da empresa, mas apresentando novamente uma curva $U$ em relação à lucratividade. Os testes estatísticos identificaram, na pesquisa dos autores em 2006, que quanto menor o número de países que a PME possui IED, menor será o ROS. Este resultado é assim interpretado pelos autores: o declínio em desempenho durante os estágios iniciais de IED confirma o passivo da estranheza. (HYMER, 1976). Em contrapartida, quando o número de países apresenta-se superior a cinco, há um aumento do ROS.

Contractor et al. (2003) procuraram evidências de que no estágio inicial de internacionalização as empresas tenderiam a ter um desempenho relativamente mais fraco, muitas vezes até com prejuízo, em razão dos custos de aprendizado iniciais, falta de experiência intercultural, e em mercados no exterior, escala relativamente baixa. Para o autor, à medida que a empresa avança na direção de maior comprometimento de recursos no exterior, é provável que os indicadores anteriormente utilizados para avaliar o desempenho de exportação não mais se mostrem adequados para avaliar o novo tipo de configuração das operações internacionais da empresa. Denis et al. (2002) constataram que além de o Grau de internacionalização não ter relação positiva direta com o desempenho, essas variáveis eram inversamente proporcionais, ou seja, quanto maior o IED, pior será o desempenho financeiro da empresa.

Contrariamente, Pangarkar (2008), estudando especificamente as PMEs japonesas, identificou a relação do Grau de internacionalização (GRI) com o desempenho. As variáveis de controle analisadas para verificar a relação foi o tamanho da empresa, a competência e a atratividade do país hospedeiro. Para desempenho o autor utilizou medidas de desempenho da organização 
em geral, pois medidas de desempenho da internacionalização já estavam embutidas no construto de GRI. Os indicadores foram avaliados por medidas de satisfação das operações de exportação e IED (mediante uma escala de Likert de cinco pontos, variando de discordo fortemente a concordo fortemente) e foram considerados: a) retorno sobre as vendas, b) crescimento das vendas, c) lucro externo sobre o \% do lucro total, d) crescimento dos lucros, e) retorno sobre os investimentos, f) experiência ou conhecimento, obtido como resultado do ingresso no mercado externo. A hipótese central do trabalho, de que um alto GRI apresentaria um melhor desempenho, se mostrou fortemente significativa.

Os trabalhos na área da estratégia não focam especificamente o desempenho da exportação, mas sim o desempenho organizacional, seguindo a perspectiva de Porter (1980), e também a RBV. Esses trabalhos (p. e. McGAHAN; PORTER, 1997; HAWAWINI et al., 2003) mensuraram desempenho por meio do indicador razão entre o lucro operacional, e o total e ativos (rentabilidade operacional) utilizam diversos fatores que podem impactar o desempenho, como por exemplo o setor no qual a empresa opera; ciclos e choques econômicos, que afetam todas as empresas em determinado ano; e características específicas e idiossincráticas da firma, que incluem diferenças entre posicionamento competitivo, capacidades e recursos, conhecida como o efeito da firma (empresa). Como resultado, esses trabalhos geralmente identificam que o efeito da firma é o mais impactante no desempenho, comprovando empiricamente a RBV.

Alguns trabalhos realizados no Brasil (p. e. BRITO; VASCONCELOS, 2003; BANDEIRADE-MELLO; MARCON, 2004) procuraram identificar o efeito do ano no desempenho, considerando o ambiente turbulento em decorrência de planos econômicos que as empresas brasileiras enfrentaram. Para Bandeira-de-Mello e Marcon (2004), em países emergentes, como o Brasil, onde as variáveis macroeconômicas estão fortemente baseadas na política monetária, com o constante controle da inflação, para determinar o desempenho das empresas é fundamental utilizar-se indicadores pelos quais o efeito dessas políticas pode ser melhor identificado. Para tal, faz-se necessário o uso de mais de uma variável para capturar, de forma abrangente, os efeitos de um ambiente turbulento na distribuição da performance, o que, de acordo com os autores (Ibid.,2004, p. 2), "poderia minimizar os efeitos do ano e maximizar os demais, como a indústria e a firma.” 
Bandeira-de-Mello e Marcon (2004) pesquisaram as empresas de capital aberto no Brasil. Para identificar o desempenho os autores utilizaram dados reais, disponíveis nos relatórios das empresas, considerando: a rentabilidade operacional; medidas de geração de valor para os proprietários das empresas, as quais são afetadas pela política monetária do governo; e também indicadores das expectativas do mercado sobre a empresa. Como resultado, os "efeitos da firma" apresentaram maior impacto sobre o desempenho.

Em trabalhos na área da estratégia, como os acima citados, as variáveis para mensurar desempenho também são diferentes, como acontece na área da internacionalização. Citaramse esses trabalhos para demonstrar que praticamente os mesmos fatores, nas duas áreas, são utilizados para mensurar desempenho, apesar de focarem áreas diferenciadas. Outras variáveis utilizadas na estratégia que também são utilizadas na internacionalização é a participação de mercado (CHANG; SINGH, 2000) e medidas da performance percebida pelos executivos. (POWELL, 1996).

No Quadro 11 apresentam-se as principais medidas de desempenho utilizada em estudos com PMEs internacionalizadas ou com possibilidade de adaptação à PME:

Quadro 11 - Medidas de desempenho para as PMEs

\begin{tabular}{|c|c|c|}
\hline Autor & Variáveis & Descrição \\
\hline $\begin{array}{l}\text { Knight e Kim (2009), Cavulsgil e } \\
\text { Zou (1994), Knight e Cavulsgil } \\
\text { (2004) }\end{array}$ & $\begin{array}{l}\text { Desempenho Internacional das } \\
\text { PMEs }\end{array}$ & $\begin{array}{l}\text { Os autores identificaram a variável } \\
\text { por meio do conjunto de: } \\
\text { Participação nno mercado } \\
\text { internacional, Crescimento das } \\
\text { vendas, } \\
\text { internacional e } \\
\text { exportação. }\end{array}$ \\
\hline Zou, Taylor e Osland (1998) & $\begin{array}{l}\text { Escala EXPERF - aspectos } \\
\text { financeiro, estratégico e de } \\
\text { satisfação }\end{array}$ & $\begin{array}{l}\text { Propuseram um modelo de } \\
\text { medição de desempenho que fosse } \\
\text { capaz de ser aplicado de forma } \\
\text { constante para empresas de } \\
\text { diferentes setores e provenientes } \\
\text { de diferentes nações e culturas, } \\
\text { podendo ter seus resultados } \\
\text { conceituados e generalizados. } \\
\text { Unifica os métodos comuns de } \\
\text { análise de desempenho e que } \\
\text { sugere que esta, em negócios no } \\
\text { exterior, de se } \\
\text { simultaneamente pelos aspectos } \\
\text { financeiro, estratégico e nível de } \\
\text { satisfação da empresa com a } \\
\text { operação, sendo estas as três } \\
\text { dimensões-chave da mensuração } \\
\text { dos resultados obtidos pela } \\
\text { empresa no processo de } \\
\text { internacionalizacão }\end{array}$ \\
\hline
\end{tabular}


conclusão

\begin{tabular}{|c|c|c|}
\hline Dimistratos (2002) & Internationalisation Ventures & $\begin{array}{l}\text { Vendas no exterior (exportação ou } \\
\text { produção no exterior) sobre o } \\
\text { número total de vendas da } \\
\text { empresa no último ano. } \\
\text { Percentual de mudança } \\
\text { (crescimento ou decréscimo) das } \\
\text { vendas nos últimos } 3 \text { anos. } \\
\text { O grau de satisfação dos } \\
\text { executivos com o desempenho no } \\
\text { negócio nos mercados externos. }\end{array}$ \\
\hline Lages et al. (2005) & The PERFEX Scorecard & $\begin{array}{l}\text { Por meio de escalas de } \\
\text { concordância de cinco pontos, os } \\
\text { autores solicitaram os seguintes } \\
\text { dados: } \\
\text { 1) Escala de desempenho } \\
\text { financeiro da exportação: } \\
\text { - ... tem sido muito lucrativa; } \\
\text {-... tem gerado um grande volume } \\
\text { de receitas; } \\
\text { _... atingiu rápido crescimento. } \\
\text { 2) Escala de desempenho } \\
\text { estratégico da exportação: } \\
\text {-... melhorou nossa } \\
\text { competitividade global; } \\
\text { - ... fortaleceu nossa posição } \\
\text { estratégica; } \\
\text { - ... aumentou significativamente. } \\
\text { nosso market share global } \\
\text { 3) Escala de atingimento dos } \\
\text { objetivos anuais da exportação: } \\
\text { - ... apresentou desempenho muito } \\
\text { satisfatório; } \\
\text { - ... tem sido muito bem-sucedida; } \\
\text { - ... atingiu plenamente nossas } \\
\text { expectativas. }\end{array}$ \\
\hline
\end{tabular}

Considerando que o foco desta tese são as formas mais complexas de internacionalização, os fatores que identificam desempenho neste estudo têm um olhar adicional, que é o impacto das operações no exterior no contexto geral da organização. Esses fatores não são considerados na grande parte dos trabalhos, principalmente quando se trata de PMEs.

\subsection{As PMEs Brasileiras, o GRI, as Competências e o Desempenho}

Neste item apresenta-se a PME e suas características. A seguir, a PME, no Brasil, é identificada com base em trabalhos específicos sobre este porte de empresa e os construtos desta tese. 


\subsubsection{O contexto da PME}

As PMEs são diferentes das grandes empresas nas suas atividades internacionais. Várias pesquisas demonstram a relação entre o tamanho da empresa e a internacionalização. (BAIRD et al., 1994; DHANARAJ; BEAMISH, 2003; BARNEY, 1991; CALOF, 1993; BECKER; PORTER, 1983; LEVITT, 1983). A premissa desses estudos é que empresas de pequeno e médio porte sofrem desvantagens quanto ao tamanho e possuem incentivos diferentes no que se refere à internacionalização.

As Pequenas e Médias Empresas (PMEs) são empresas consideradas inovadoras, visto que elas são mais flexíveis e ágeis para se adaptar às mudanças ocorridas no ambiente em que se encontram. Em geral, conseguem acompanhar rapidamente seus concorrentes, já que, segundo Souza e Bacci (1998 apud CÂNDIDO; ABREU, 2000), elas têm maior capacidade de inovação, diversificação e flexibilidade. Porém poucas estão dispostas a inovar, já que esta prática apresenta riscos e custos.

A competição também é estimulada pela existência das PMEs. Conforme Longenecker et al., 1998), quando os produtores estão reduzidos a poucas grandes empresas, o cliente fica à mercê deles. Estas empresas têm a liberdade de estabelecer preços elevados, conter desenvolvimentos tecnológicos, excluir novos concorrentes ou abusar da posição de poder que detêm. A existência contínua de PME em um sistema econômico é retrato da atuação eficiente destas empresas. Se elas fossem ineficientes e não oferecessem nenhuma contribuição ao país ou região em que se encontram, seriam rapidamente forçadas pelos concorrentes mais fortes a saírem do mercado.

A participação das Pequenas e Médias Empresas na exportação é significativa e importante para o desenvolvimento de vários países. Segundo Alaby (2003), nos Estados Unidos, de acordo com o Departamento de Comércio, empresas com menos de 19 empregados contribuem com cerca de $50 \%$ das exportações. Na Itália, o motor da economia é a formação dos consórcios e distritos industriais formados por esse segmento [...]. Na Itália, as empresas interagem por meio de redes industriais entre PMEs, levando em consideração as potencialidades dos recursos de cada região e um amplo apoio das políticas públicas, criando uma cadeia produtiva altamente funcional e uma cultura industrial que origina um fluxo 
endógeno de atualização tecnológica além de um ambiente de competitividade. (CHORINCAS et al., 2001).

Grandes empresas, principalmente as novas entrantes, adquirem ou se associam à PME no exterior para diminuir o tempo e os investimentos em aprendizado do mercado. Fornecedor local para multinacionais (MNEs) também está empurrando (pull) as PMEs para a internacionalização. Muitas PMEs estão iniciando suas operações no exterior por meio de networks, pois a cooperação com outras PMEs permite que as empresas se especializem no seu core-business, aumentando sua capacidade de competição. (UNIDO, 1999). Já no Brasil, o modelo exportador foi baseado na concentração dos grandes conglomerados empresariais, concentrando a atividade nas multinacionais e grandes empresas que representam aproximadamente $85 \%$ da pauta exportadora. (ALABY, 2003).

No Brasil, a internacionalização da grandes empresas está estimulando ou, em certos casos, forçando a internacionalização das PMEs. Como fornecedoras ou prestadoras de serviços, as PMEs embarcam nos processos de internacionalização. Além de criar a oportunidade de investimentos no exterior, esse network estimula as PMEs a buscar certificações internacionais e a torná-las mais ágeis e competitivas também no mercado doméstico. Um exemplo da prática do network na internacionalização das PMEs brasileiras é o da empresa Odebrecht. As PMEs são a maioria entre os fornecedores da Odebrecht no exterior; elas representam $90 \%$ dos fornecedores de serviços e $60 \%$ dos de produto. (O ESTADO, 2009).

Outro fator colocado como importante para o desempenho, por Dimitratos (2002) nas "Internationalisation Ventures", é o fator localização. O Autor denomina "Internationalisation Ventures" as PMEs que exportam e/ou possuem um Investimento Estrangeiro Direto (IED). As PMEs que operam em locais estrategicamente voltados para o mercado externo, como nas fronteiras da Grécia, apresentam melhor desempenho (Vantagem de Localização no país de origem) e são mais internacionalizadas. Para identificar a variável desempenho no estudo das empresas gregas, Dimitratos (2002) utilizou os seguintes critérios: a) Vendas no exterior (exportação ou produção no exterior) sobre o número total de vendas da empresa no último ano; b) Percentual de mudança (crescimento ou decréscimo) das vendas nos últimos 3 anos; c) Qual o grau de satisfação dos executivos com o desempenho no negócio nos mercados externos. 
A entrada no comércio mundial para as PMEs, que nem sempre possuem condições e conhecimentos necessários para a fixação de seus produtos no exterior com êxito, torna-se mais viável e propicia o sucesso, se apoiada por algum tipo de incentivo e de políticas governamentais favoráveis. Estes incentivos por parte do governo podem se dar por reduções de impostos ou isenção, ou por meio de programas de financiamentos às empresas que objetivam entrar no mercado internacional. Os mercados mundiais passaram a observar com mais atenção as PMEs nos últimos anos, pois, segundo Blank e Palmeira (2006), são elas as protagonistas do novo cenário mundial, havendo necessidade delas para o aumento da receita, a geração de emprego e de renda.

A liberalização do mercado pode acelerar os processos de internacionalização das empresas. A integração entre países, como o caso da União Europeia (UE) e o North American Free Trade Agreement (NAFTA), tem encorajado empresas a expandirem as operações geograficamente e tem se tornado crucial para a sobrevivência de grandes e PMEs. Conforme relatório da OECD (2007), o Euro reduz o risco da taxa de câmbio e os custos de transação entre os países da EU, suportando a expansão do comércio e dos negócios. Conforme Gonçalves (1994 apud Cezarino e Campomar, 2006), em países onde há um grande desequilíbrio entre as regiões, como é o caso do Brasil, as PMEs podem representar um importante papel na descentralização industrial.

\subsubsection{A PME brasileira}

Historicamente, no Brasil, fatores ambientais e motivacionais influenciaram o envolvimento das empresas com o mercado internacional. Os IEDs começam a fazer parte das políticas de incentivos governamentais a partir de 1990. Alguns pontos relevantes na economia que impactaram a internacionalização são assinalados no Quadro 12, a seguir. 
Quadro 12 - Perspectiva histórica dos fatores e os impactos na internacionalização das empresas brasileiras

\begin{tabular}{|c|c|c|}
\hline Fatores Ambientais & Fatores Motivacionais & Impactos na internacionalização \\
\hline $\begin{array}{l}\text { Década de 1960-70 } \\
\text { - Forte crescimento da economia } \\
\text { brasileira; (Milagre Econômico); } \\
\text { - Grande expansão do comércio } \\
\text { internacional; } \\
\text { - Política governamental de apoio às } \\
\text { exportações; } \\
\text { - Economia Fechada, protecionismo. }\end{array}$ & $\begin{array}{l}\text { Pedidos do exterior; } \\
\text { Incentivos Governamentais. }\end{array}$ & $\begin{array}{l}\text { Estímulo à internacionalização via } \\
\text { exportação. }\end{array}$ \\
\hline $\begin{array}{l}\text { Década de } 1980 \\
\text { - Recessão Internacional; } \\
\text { - Expansão do Japão e dos Tigres } \\
\text { Asiáticos; } \\
\text { - Década perdida, recessão no Brasil; } \\
\text { - Fechamento da economia. }\end{array}$ & $\begin{array}{l}\text { Os pedidos de exportação são } \\
\text { transferidos para a Ásia; } \\
\text { Escasseiam os incentivos à } \\
\text { exportação; } \\
\text { Falta competitividade aos produtos } \\
\text { brasileiros. }\end{array}$ & Redução das exportações. \\
\hline $\begin{array}{l}\text { De } 1990 \text { a } 1995 \\
\text { - Abertura de mercado, entrada de } \\
\text { concorrentes estrangeiros; } \\
\text { - Criação do MERCOSUL; } \\
\text {-Lei Kandir (1993). Lei } \\
\text { complementar n. 87, de } 13 \text { de } \\
\text { setembro de 1993, que isenta o IPI e } \\
\text { o ICMS das exportações de bens } \\
\text { primários e semielaborados. }\end{array}$ & $\begin{array}{l}\text { Aumenta a percepção do risco no } \\
\text { mercado interno; } \\
\text { Open mind para novos mercados. } \\
\text { Isenta de IPI e ICMS as exportações } \\
\text { de bens primários e semielaborados. }\end{array}$ & $\begin{array}{l}\text { Estímulo ao investimento estrangeiro } \\
\text { direto. } \\
\text { Estímulo à exportação da PME. }\end{array}$ \\
\hline $\begin{array}{l}\text { De } 1995 \text { a } 1998 \\
\text { - Expansão do mercado interno; } \\
\text { - Sobrevalorização da moeda } \\
\text { nacional, o Real. }\end{array}$ & $\begin{array}{l}\text { Aumenta a atratividade do mercado } \\
\text { doméstico; } \\
\text { Falta competitividade aos produtos } \\
\text { brasileiros. }\end{array}$ & $\begin{array}{l}\text { Diminuição das exportações; } \\
\text { Estímulo ao Investimento estrangeiro } \\
\text { direto. }\end{array}$ \\
\hline $\begin{array}{l}\text { De } 1998 \text { a } 2000 \\
\text { - Crise cambial em 1999; } \\
\text { - Desvalorização do Real; } \\
\text { - Foi adotado o regime de metas de } \\
\text { inflação com câmbio flexível. }\end{array}$ & $\begin{array}{l}\text { Cresce a competitividade dos } \\
\text { produtos brasileiros no exterior. }\end{array}$ & $\begin{array}{l}\text { Estímulo às exportações; } \\
\text { Diminuição dos Investimentos } \\
\text { estrangeiros diretos. }\end{array}$ \\
\hline $\begin{array}{l}\text { De } 2000 \text { a } 2008 \\
\text { - Ataque terrorista de } 11 \text { de setembro } \\
\text { de } 2001 \text { modifica as relações } \\
\text { políticas e comerciais entre os EUA e } \\
\text { o resto do mundo; } \\
\text { - Chega ao poder, no Brasil, } \\
\text { governantes de esquerda; } \\
\text { - O Brasil inicia uma fase de } \\
\text { estabilidade econômica, consegue } \\
\text { acumular mais reservas do que a } \\
\text { dívida externa, recebendo status de } \\
\text { credor; } \\
\text { - Crise e moratória Argentina. }\end{array}$ & $\begin{array}{l}\text { A explosão da demanda por matérias- } \\
\text { primas, especialmente na China, } \\
\text { elevou os preços das commodities a } \\
\text { níveis recordes. } \\
\text { A combinação notavelmente virtuosa } \\
\text { de baixas taxas de juros e abundante } \\
\text { liquidez no mundo, com a melhoria } \\
\text { dos balanços de pagamentos em } \\
\text { contas correntes dos países } \\
\text { emergentes, favoreceu o fluxo de } \\
\text { investimentos e aplicações } \\
\text { financeiras para estes países. } \\
\text { O maior crescimento da absorção } \\
\text { doméstica, combinado com a } \\
\text { desvalorização da taxa de câmbio até } \\
\text { meados de } 2008, \text { provocou uma } \\
\text { redução dos superávits na Balança } \\
\text { Comercial. }\end{array}$ & $\begin{array}{l}\text { Aumento das exportações do Brasil } \\
\text { para a China e implantação de } \\
\text { fábricas de empresas brasileiras no } \\
\text { exterior, especialmente na China. }\end{array}$ \\
\hline $\begin{array}{l}2008 / 2009 \\
\text { - A China aparece como a segunda } \\
\text { grande potência mundial; } \\
\text { - Forte desvalorização do real no } \\
\text { final de } 2008 \text {. }\end{array}$ & & $\begin{array}{l}\text { Significativa queda da relação } \\
\text { Dívida/PIB neste ano, quando } \\
\text { comparada à posição observada no } \\
\text { final de } 2007 . \\
\text { Empresas brasileiras se } \\
\text { internacionalizam para buscar } \\
\text { minimizar os riscos do câmbio }\end{array}$ \\
\hline
\end{tabular}

Fonte: Adaptado de Rocha (2003) até 2000 e, entre 2000 e 2009, o quadro foi completado pela autora focalizando eventos relevantes para o caso estudado 
Outra característica das PMEs brasileiras é a falta de recursos. Esta falta de recursos diferencia as PMEs brasileiras das PMEs de países desenvolvidos, que, mesmo com baixa qualidade gerencial e gestão informal, gozam de financiamentos sem muitas restrições. As PMEs brasileiras têm dificuldades na obtenção de financiamentos públicos. (CEZARINO; CAMPOMAR, 2006).

Mesmo considerando as dificuldades das PMEs brasileiras, o número de PMEs é muito maior que o das empresas de grande porte, como pode ser verificado na Tabela 3.

Tabela 3 - Número de empresas exportadoras segundo seu tamanho em 2008

\begin{tabular}{l|r|r|r|r|r|r}
\hline & \multicolumn{2}{|c|}{ TOTAL ANUAL } & \multicolumn{2}{c|}{ INDÚSTRIA } & \multicolumn{2}{c}{ COMÉRCIO/SERVIÇOS } \\
\hline & Quantidade & $\begin{array}{c}\text { Valor US\$ } \\
\text { FOB }\end{array}$ & Quantidade & $\begin{array}{c}\text { Valor US\$ } \\
\text { FOB }\end{array}$ & Quantidade & $\begin{array}{c}\text { Valor US\$ } \\
\text { FOB }\end{array}$ \\
\hline Total Geral & 23.032 & 197.942 .442 .909 & 15.198 & 154.887 .334 .273 & 7.223 & 42.710 .407 .812 \\
Microempresa & 5.054 & 267.259 .637 & 2.404 & 163.715 .071 & 2.650 & 103.544 .566 \\
Pequena & 6.066 & 2.042 .103 .284 & 3.759 & 1.364 .369 .676 & 2.307 & 677.733 .608 \\
Empresa & 5.793 & 8.899 .874 .080 & 4.841 & 7.426 .116 .078 & 952 & 1.473 .758 .002 \\
Média Empresa & 5.508 & 186.388 .505 .084 & 4.194 & 145.933 .133 .448 & 1.314 & 40.455 .371 .636 \\
Grande & & & & & & \\
Empresa & & & & & & \\
\hline
\end{tabular}

Fonte: MDIC (2008)

Apesar do alto valor exportado no ano de 2008, se comparado ao de 2007, observa-se que o desempenho das exportações foi bastante desigual, considerando-se o porte das empresas. $\mathrm{O}$ valor exportado pelas Microempresas teve uma queda de 48,31\% em relação ao ano de 2007, já para as Pequenas empresas esse decréscimo foi de 27,25\%, apesar de o número de empresas ter aumentado em 6,08\%. De acordo com o relatório da SECEX (2009), desagregando os números, verifica-se, no entanto, que parte desse resultado se deve à mudança de categoria de 332 empresas micro e pequenas para médio (324) e grande porte (8), ligadas principalmente aos setores do agronegócio, químico e de máquinas e equipamentos, fazendo diminuir, desta forma, a base de exportadores MPEs em 2008 na comparação com 2007.

Outro fator a influenciar o desempenho da categoria em 2008, de acordo com o mesmo relatório, foi a saída líquida de 467 MPEs da pauta exportadora em 2008 sobre 2007, consequência de o ingresso de 3.542 exportadores ter sido inferior a 4.009 empresas que deixaram de exportar. Este comportamento pode estar ligado ao eventual ambiente 
desfavorável de competitividade, situação esta que se agravou com a crise econômica mundial iniciada em setembro de 2008, e que teve como efeito a redução drástica da demanda externa. A SECEX (2009) registra que desde o início das publicações oficiais por porte de empresa, em 2002, as micro e pequenas empresas são maioria absoluta no comércio exterior brasileiro, tendo alcançado o pico em 2006, quando 12.218 empresas da categoria exportaram.

Já na média empresa o número aumentou de 5.793 para 5.811, mas mesmo assim o valor FOB em dólares exportado apresentou um decréscimo de 8,4\%. Diferentemente das PMEs, a grande empresa apresentou um aumento de $7,1 \%$ na quantidade de empresas e aumentou também o valor exportado em cerca de trinta e nove bilhões de dólares (26,3\%). A grande empresa é responsável por $94,2 \%$ do total do valor exportado em 2008, a média empresa por 4,6\% e a Micro e Pequena Empresa por 1,2\%. (SECEX, 2009).

A Agência Brasileira de Desenvolvimento Industrial (ABDI), a Secretaria de Tecnologia Industrial do Ministério de Desenvolvimento, Indústria e Comércio Exterior (MDIC) e a Delegação da Comissão Europeia (DCE) lançaram, em dezembro de 2009, o Projeto de Apoio à Inserção Internacional de Pequenas e Médias Empresas Brasileiras (PAIIPME). O PAIIPME é resultado do Ajuste Complementar ao Acordo-Quadro de Cooperação firmado entre a União Europeia e a República Federativa do Brasil, promulgado em 1995, e significa investimentos que irão promover o desenvolvimento e a inserção internacional de PMEs brasileiras, que passarão por processos de informatização, profissionalização, capacitação e qualificação de produção e serviços. Alguns editais deste projeto já estão abertos para promover a qualificação das PMEs e assim torná-las mais competitivas internacionalmente. (MDIC, 2010).

No que tange ao IED, o Brasil não publica dados por porte de empresa. Portanto, resta apresentar aqui o valor dos Investimentos Diretos Brasileiro no Exterior (IDBE). No ano de 2007 o valor total dos IDBE foi de US\$ 155.176 milhões; já no ano de 2008 foi de US\$ 170.397 milhões, representando um acréscimo de aproximadamente 9,8\%, conforme dados do BACEN, 2009. 


\subsubsection{O GRI, as competências e o desempenho da PME}

Um resumo dos três construtos que norteiam esta pesquisa será apresentado neste item. Buscou-se na literatura uma pesquisa que abordasse os três temas conjuntamente, mas nada foi encontrado, principalmente no que tange à PME. Há muitas pesquisas que demonstram o impacto do GRI com o desempenho da empresa e poucos são os trabalhos que abordam o impacto das competências no desempenho das PME internacionalizadas. (COVIELLO; McAULEY, 1999; KNIGHT, 2000; ZAHRA et al., 2000; KNIGHT; CAVUSGIL, 2004; RACELA et al., 2007; KNIGHT; KIM, 2009).

Os conceitos apresentados acima, de GRI, Competência e Desempenho, bem como trabalhos, nacionais e internacionais, que testaram esses conceitos não apresentam um framework que explique e/ou identifique a relação direta entre eles, mas os principais resultados isolados permitem encontrar evidências sobre o impacto direto ou indireto dos conceitos.

Internamente, as empresas se preparam para atuar no mercado externo desenvolvendo um conjunto de competências importantes na atuação interna, e as adaptam adotando um global mindset, implantando, assim, uma cultura de negócios internacionais. (KNIGHT; CAVUSGIL, 2004; KNIGHT; KIM, 2009). Mudanças na filosofia do negócio são necessárias para operar internacionalmente, identificando que nem todas as competências desenvolvidas na atuação do mercado interno serão suficientes ou até mesmo relevantes para atuação no mercado externo. Especialmente quando se trata de PME, sabe-se que há diferenças com as grandes MNCs, no que tange ao nível de recursos tangíveis.

Para autores como Fleury et al. (1981) e Kotabe e Czinkota (1992), o GRI consiste no grau de envolvimento ou comprometimento com as atividades internacionais a partir do comportamento empresarial resultante da crescente experiência adquirida nas atividades internacionais, incluindo a escolha de mercados e a acumulação de expertise dos procedimentos burocráticos da exportação; do comprometimento crescente de recursos da empresa com as atividades de exportação; e ainda de acordo com os recursos corporativos, tais como escala de produção, grau de diversificação ou economia de escopo, capacidade financeira, e capacidade gerencial. 
Knigt e Kim (2009) afirmam que, para o sucesso internacional, as PMEs devem desenvolver recursos distintos e específicos. Embora nestas empresas tendam a faltar substancialmente recursos financeiros e humanos, elas podem alavancar um conjunto de recursos intangíveis que facilitam o seu sucesso internacional. Os recursos consistem, em grande parte, do conhecimento, das habilidades e das competências empresariais globais que residem nos gerentes que trabalham nestas empresas.

Collis (1991) identificou as capacidades como sendo algo incorporado na cultura e nas rotinas da empresa, e à medida que resultem no desenvolvimento de uma competência essencial, essas capacidades podem proporcionar vantagens competitivas significativas para competir no mercado externo. O nível das vantagens comparativas em recursos resulta, além do posicionamento de vantagens competitivas, de um desempenho superior, afirma Hunt (2000). As grandes empresas MNCs imitarão facilmente os recursos tangíveis como plantas, equipamentos, matéria-prima das PMEs, mas dificilmente será imitado um processo de conhecimento intensivo que aumenta as competências nos negócios internacionais e nas rotinas da empresa. (DEV et al., 2002). Por esse motivo, alguns autores apontam a importância do desenvolvimento da mentalidade global dos executivos (COLLIS, 1991) e da rotinização das atividades organizacionais, onde as capacidades são integradas na memória organizacional (DEV et al., 2002) para possibilitar uma configuração única de recursos e de competências para a empresa.

Já para transformar essas competências em desempenho para a empresa, essas atividades organizacionais precisam criar valor para o cliente. Portanto, a competência da empresa reflete sua capacidade de executar várias tarefas produtivas que possam gerar valor por meio da transformação de entradas (inputs) em saídas (outputs). (NELSON; WINTER, 1982; TEECE et al., 1997). Posteriormente, as competências organizacionais serão a principal fonte de vantagens de desempenho da empresa. (GRANT, 1991). Para as PMEs, as competências da empresa são particularmente importantes para permitir sua entrada em novos mercados e, após o ingresso e a adaptação de novos conhecimentos e práticas, continuar sendo competitiva no novo mercado. (TEECE et al., 1997; DEV et al., 2002).

Esse conhecimento adquirido e a adaptação às rotinas da PME internacionalizada permitem um aumento do GRI, desenvolvendo ainda novas competências para que a PME possa continuar aumentando o seu GRI. (JOHANSON; VAHLNE, 1977; 1990). 
Estudos no Brasil e no exterior analisam o grau de internacionalização e sua influência em outras variáveis. Uma das variáveis mais estudadas e apresentadas pela literatura é o desempenho. (DUNNING, 1996; GOMES; RAMASWAMY, 1999; HASSEL et al., 2003). As empresas são constantemente confrontadas com a necessidade de escolhas estratégicas, como, por exemplo, a alocação de recursos entre o mercado doméstico e os negócios internacionais, ao perceberem que a exportação, por si, não é mais suficiente para melhorar o desempenho. (MAJOCCHI; ZUCCHELLA, 2003).

Internacionalização é um conceito multidimensional, e para capturar todos os aspectos deste conceito em termos de escopo e escala e desenvolver uma medida válida para a internacionalização da PME a variável desempenho tem sido uma parte consistente do conceito multidimensional. (RUZZIER et al., 2007).

Outros estudos identificaram a relação positiva entre níveis crescentes de comprometimento com a exportação e o desempenho das operações externas, que é avaliado pelo faturamento e pelo lucro das exportações. (CAVUSGIL; ZOU, 1994; DHANARAJ; BEAMISH, 2003; GENÇTÜRK e KOTABE, 2001). Para Leonidou e Katsikeas (1996), a continuidade e o maior envolvimento da firma na atividade exportadora podem ser associadas ao desempenho auferido pelos recursos empregados. Sullivan (1996) também identifica que o nível de internacionalização da firma explica significativamente as variâncias de indicadores de desempenho financeiro, mas com o foco na empresa como retorno sobre vendas e retorno sobre ativos.

Etemad (2004), num amplo levantamento bibliográfico, identificou que a implicação direta da teoria é que tamanho, idade, e experiência anterior da empresa ou do executivo devem ter uma direta e positiva relação com o grau de internacionalização.

A pesquisa de Pangarkar (2008) abordou os três principais construtos desta tese em PMEs, apesar de considerar alguns aspectos de maneira diferenciada. $\mathrm{O}$ autor identificou a relação do Grau de internacionalização (GRI) com o desempenho, mas utilizou as competências como uma variável de controle. A hipótese central do trabalho, de que um alto Grau de internacionalização apresentaria um melhor desempenho, se mostrou fortemente significativa ao nível de 0.05 de probabilidade, e as competências com o desempenho, em todas as análises 
de regressão, apresentaram coeficientes significantes ao nível de 0.01 de probabilidade. Assim, os autores concluíram que um alto GRI apresenta um melhor desempenho e que as competências influenciam o desempenho. Com esses resultados, os autores se questionaram sobre o que viriam antes, as competências ou a internacionalização.

No Brasil, não se encontrou trabalhos sobre a PME que abordassem os construtos desta tese. Verificou-se que Carvalho (2009), pesquisou a idade de entrada internacional, velocidade de internacionalização e seus efeitos sobre o crescimento no exterior de pequenas e médias empresas industriais do estado de São Paulo. Para a autora, as PMEs que começam a atuar mais cedo no exterior e que conseguem entrar em mercados de novos países mais rapidamente crescem mais suas vendas internacionais. No caso das PMEs industriais, a idade de entrada internacional é uma força moderadora, que atua negativamente sobre a relação positiva entre a velocidade de internacionalização e o crescimento no exterior. Assim, quanto menor a idade de entrada internacional, mais forte será a relação entre velocidade e crescimento internacionais.

A análise descritiva do trabalho de Carvalho (2009) apontou uma alta incidência de PMEs industriais cuja idade de entrada internacional as caracteriza como born globals: $16 \%$ tinham até três anos, e $42 \%$ até cinco anos quando começaram a exportar. Além disso, a ocorrência das mesmas apareceu não em setores intensivos em conhecimento, de alta intensidade tecnológica; a maior frequência de firmas desse tipo se concentrou em setores de baixa e média-baixa intensidade tecnológica, como no setor de bebidas e calçados, por exemplo. Outro ponto destacado pela análise descritiva da amostra é a alta incidência de PMEs industriais que adotam outros modos de entrada no exterior combinados à exportação direta: 40,6\%. Além disso, os dados mostram uma ampla cobertura geográfica do conjunto de 32 PMEs da amostra, cujos produtos são distribuídos em mercados (países) de todos os continentes do planeta.

No recente trabalho publicado no Journal of Small Business Management, Camisón e VillarLópez (2010) estudaram, nas PMEs de Valência, na Espanha, a relação entre a experiência internacional e o desempenho econômico utilizando os ativos intangíveis e financeiros, a estratégia competitiva e a intensidade internacional como variáveis mediadoras. Por meio da técnica de equações estruturais, o modelo foi organizado com a variável experiência internacional como uma variável exógena ou independente (ver capítulos 4 e 5) e cinco 
variáveis endógenas ou dependentes: ativos financeiros, ativos intangíveis exploráveis internacionalmente, intensidade internacional, estratégia de diferenciação e desempenho econômico. Como resultados os autores identificaram que o maior desempenho econômico, resultado do crescimento internacional, não irá resultar, por si só, em experiência internacional para as PMEs. Os autores identificaram que a experiência internacional só será transformada em excelentes resultados quando a empresa tirar proveito dessa aprendizagem para aumentar seu estoque de ativos intangíveis exploráveis internacionalmente ou quando transformá-los em estratégia competitiva de diferenciação. A evidência empírica consolida os ativos internacionalmente exploráveis e orientados para a estratégia competitiva de diferenciação como fatores determinantes da relação em estudo. Por outro lado, a intensidade internacional das empresas não parece ser um elemento mediador da relação entre a experiência internacional e o desempenho econômico.

Os resultados deste trabalho destacam a estreita relação entre a experiência internacional das PMEs e a sua dotação de recursos. Especificamente, os resultados indicam que a experiência internacional das PMEs é acompanhada por uma elevada dotação de ativos intangíveis, o mesmo não ocorrendo com os ativos financeiros. O estoque de recursos de tecnologia, comercial e recursos humanos que podem ser transferidos internacionalmente emerge como fator determinante da experiência internacional. Este resultado demonstra que há uma relação entre os ativos intangíveis que a empresa possui e a expansão internacional e também que o processo de internacionalização mostrou ser um meio de gerar este tipo de ativo.

Os ativos intangíveis também se consolidaram como fatores-chave da intensidade internacional assumida pela PME na pesquisa de Camisón e Villar-López (2010). Ativos intangíveis de propriedade da PME afetam significativamente a sua estratégia de internacionalização e, portanto, o compromisso que eles assumem durante o seu processo de expansão internacional. No entanto, os ativos financeiros não parecem ser determinantes da intensidade internacional. O fato das PMEs possuírem ativos intangíveis exploráveis internacionalmente aparecem como um fator determinante do desempenho econômico.

Os três construtos que foram esboçados e vinculados ao tema da pesquisa serão adiante tratados e correlacionados. No capítulo subsequente serão apresentados o modelo conceitual e as hipóteses. 


\section{ESTRUTURA CONCEITUAL E HIPÓTESES}

Neste capítulo são apresentados os critérios de seleção das variáveis que compõem o modelo conceitual, ou seja, Grau de Internacionalização, Competência e Desempenho, com a intenção de propor um modelo para ser validado empiricamente. Este modelo foi organizado a partir dos estudos internacionais já realizados e apresentados no referencial teórico e também por meio dos estudos de casos realizados, sendo as variáveis adaptadas ao contexto brasileiro e das PMEs. Em seguida, apresentam-se as hipóteses da pesquisa em telae, por fim, o desenho do modelo a ser testado.

Como mencionado no capítulo anterior, a maioria das teorias de internacionalização e dos trabalhos sobre grau de internacionalização e desempenho focam as MNCs. Além da importante adaptação ao contexto brasileiro, fez-se mister adaptar os indicadores à realidade da PME. Para tal adaptação utilizaram-se os trabalhos de PMEs brasileiras na exportação, apoiando-se nos autores que realizaram estudos sobre o tema e também em respostas de executivos de PMEs obtidas durante a etapa qualitativa desta tese. A realidade da PME francesa, estudada durante o doutorado sanduíche, também auxiliou no questionamento dos indicadores apresentados pelos trabalhos aplicados em MNCs.

Vários autores medem o grau de internacionalização (SULLIVAN, 1994) e desempenho (KAPLAN; NORTON, 1992; BANDEIRA-DE-MELLO; MARCON, 2004) em MNCs por meio de indicadores financeiros reais, ou seja, os números apresentados pelas empresas em seus balanços e publicados. (p. e. SULLIVAN, 1994; BARCELLOS; CYRINO, 2007; BANDEIRA-DE-MELO; MARCON, 2006). Estes indicadores financeiros reais, são difíceis de conseguir, pois não há obrigatoriedade de publicação de resultados e os executivos têm as informações como algo bastante sigiloso. Como resultado, muitos estudos sobre a internacionalização utilizaram medidas perceptuais. (CAVUSGIL; ZOU, 1994; KOH, 1991; AXINN, 1988; BROUTHERS; NAKOS, 2005; LAGES et al., 2005; HOLLENSTEIN, 2005; TODD, 2006; ARMARIO et al., 2008, ZOU et al., 1998). Para medir o desenvolvimento de competências utilizaram-se variáveis significantes para Knight e Kim (2009) pelo fato de o estudo destes autores ter sido desenvolvido em PMEs. 


\subsection{Os Indicadores de GRI, de Competência e de Desempenho para a Presente Pesquisa}

Para construir os indicadores de grau de internacionalização, de competência e de desempenho da pesquisa em questão consideraram-se:

- As teorias e os modelos apresentados no capítulo 2: diferentes autores foram utilizados para a construção dos indicadores pela adequação necessária à presente pesquisa. Os modelos considerados para a adequação são apresentados adiante neste capítulo.

- $\quad$ O objeto de pesquisa: as PMEs. Por ser uma categoria de empresa que não necessita divulgar seus dados e pelas peculiaridades das empresas deste porte, é exigido uma adequação dos modelos propostos, visto que, em sua maioria, tais modelos foram aplicados em grandes empresas ou MNCs.

- O país da aplicação: o Brasil. Faz-se necessário considerar a realidade do país em que a pesquisa será aplicada porque, como já demonstrado em diferentes pesquisas, essa variável influencia a internacionalização, seja por vantagens comparativas ou competitivas.

- $\quad$ Foco da pesquisa: formas mais complexas de internacionalização. Grande parte dos trabalhos sobre PMEs e o mercado externo focalizam a exportação. Diferentemente de outros estudos, neste trabalho a exportação será a fase inicial do processo de internacionalização, tendo como foco as formas mais complexas de internacionalização, ou seja, as PMEs com IED.

- Unidade de análise: verificou-se durante o levantamento bibliográfico que muitos trabalhos utilizam como unidade de análise um produto específico da empresa para um determinado país, muitas vezes com o objetivo de identificar melhores estratégias de comercialização. (CAVUSGIL; ZOU, 1994; ZOU et al., 1998; LAGES; MONTGOMERY, 2001; CARNEIRO, 2007). Entretanto, o ponto central desta tese não incide sobre um produto ou país, mas o sujeito de investigação é a empresa. Isto se faz necessário porque não há competências de um produto específico ou para um mercado específico e, sim, da organização, por conseguinte, este é o foco deste estudo. . 
Alguns critérios foram levados em conta para a elaboração dos indicadores deste trabalho, principalmente no que se refere a desempenho e grau de internacionalização, conforme já considerado em outros trabalhos (SULLIVAN, 1994; FORTE; SETTE JR., 2005; BARCELLOS; CYRINO, 2007), constando dentre eles:

- Abrangência do índice: os critérios de medidas devem considerar os diversos setores, as várias fases de internacionalização e os diversos fatores influenciadores do grau de internacionalização, como descrito do capítulo 2. Isto porque a internacionalização é um fenômeno multidimensional, como observado por Sullivan (1994).

- Facilidade da coleta de dados e confiabilidade das informações: tendo em conta que o objeto da pesquisa em tela são as PMEs brasileiras, e que não é possível conseguir informações secundárias sobre tais empresas, há necessidade de obtê-las por meio da aplicação de questionários, além de se ter que confiar na resposta dos dirigentes. Por esse motivo, os indicadores devem ser de fácil compreensão e devem possibilitar o menor número de respostas faltantes (missing datas).

- Simplicidade no entendimento e na interpretação: o resultado dos dados coletados deve ser de fácil compreensão para o entendimento do público a que se destina. (SULLIVAN, 1994).

- Comparabilidade entre empresas: para poder comparar empresas de diferentes setores e diferentes fases de internacionalização, os indicadores devem ser aplicados e respondidos de maneira idêntica e com os mesmos critérios de avaliação.

Nos próximos itens apresentam-se os critérios utilizados para compor os indicadores que serão analisados neste trabalho, ou seja, grau de internacionalização, competência e desempenho.

\subsubsection{Operação da variável "Grau de Internacionalização"}

Diversamente dos trabalhos que analisam a PME e o grau de internacionalização somente pelos números de exportação, de empregados no exterior, de países nos quais a empresa atua como exportadora, este trabalho busca analisar o GRI em que a PME brasileira se encontra, por meio de um conjunto de variáveis. Essa análise tem o objetivo de auxiliar a mensuração 
do grau de internacionalização, visto que em estudos aplicados em PMEs há dificuldades de se obter dados quantitativos específicos e resultados financeiros da empresa.

Devido a essa perspectiva estática da corrente comportamental e da visão oportunista da corrente econômica, nesta tese o GRI será identificado a partir de um conjunto de fatores que combinam as duas correntes, pois, desta forma, tendo em conta o contexto do estudo, o objetivo será melhor identificado. Considerando esse aspecto, para esta tese GRI é um conceito multidimensional, identificado pelo processo crescente de envolvimento em operações internacionais, que exige a adaptação da estratégia, dos recursos e da estrutura da organização. (WELCH; LUOSTARINEN, 1988; DUNNING, 1988; CALOF; BEAMISH, 1995).

Como a Teoria de Uppsala identifica que a internacionalização segue certas etapas, um único índice mediria um único estágio, como, por exemplo, vendas. Mesmo combinando com outros índices, como empregados no exterior, as empresas não seguem os mesmos estágios, o que torna questionável a combinação dos indicadores. (HASSEL et al., 2003). Assim, levar em consideração somente o grau de internacionalização por etapas tornaria o indicador muito eclético e mecanicista, pois a escolha de uma fase e não de outra pode envolver não somente uma decisão incremental de aprendizagem, mas também oportunidade de mercado, capacidade de gestão ou o network. (REID, 1983; SULLIVAN, 1994; CAVUSGIL; ZOU, 1994). Da mesma forma, Hassel et al. (2003) identificam que melhor que utilizar o grau de internacionalização como único dispositivo, ele deve ser abordado no contexto da suposição teórica na qual está baseada.

Para Dunning (1996), seguindo a ótica da teoria econômica da internacionalização, a múltipla localização de atividades de valor agregado é considerada um fator gerador linear de retornos positivos. Contudo, contrariando Dunning (1996), os resultados do trabalho de Gomes e Ramaswamy (1999) indicam que o efeito da proporção de vendas externas é curvilíneo, podendo ser positivo no início (número menor de vendas externas) e negativo quando o número de vendas externas aumenta. Variáveis como vendas externas, por exemplo, podem provocar distorção na análise dos efeitos da internacionalização sobre o desempenho da empresa, conforme menciona Hassel et al. (2003). 
Apesar das críticas ao modelo DOI de Sullivan (1994) e ao Índice de Transnacionalidade, a literatura aponta esses índices como possíveis de serem aplicados para mensurar o grau de internacionalização. Mas, em relação à PME, Trtnik (1999) questionou o Índice da UNCTAD (Transnacionalidade), por este não considerar as diferenças existentes entre as GRI das empresas que operam em um só país e aquelas que operam em vários países. Além disso, é preciso levar em conta o fato de as PMEs, em sua maioria, serem exportadoras e não possuírem ativos no exterior, e quando os possuem, estes são de pequena monta (em quantidade de subsidiárias), o que inviabilizaria a integração do número de subsidiárias no índice. No modelo DOI de Sullivan (1994), o autor mensura o percentual de subsidiária no exterior sobre o total de subsidiárias (OSTS).

Para grandes empresas MNCs, essa variável é relevante e também de fácil mensuração, já na PME brasileira, não teria muita relevância. Este argumento tem ainda mais relevo quando consideradas as diferentes teorias que abordam a internacionalização das MNCs (DUNNING, 1998; PENROSE, 1959), visto que as grandes empresas desenvolvem seus mercados internos utilizando o network das suas subsidiárias internacionais com o objetivo de baixar seus custos para o limite dos custos de transação e explorar suas vantagens específicas e locacionais. Por outro lado, essa medida para a PME pode negligenciar algumas dimensões mais importantes, como tempo de início da internacionalização, modo de operação e mercados selecionados. Essas medidas representam, para a MNC, mais decisões de rotina do que decisões estratégicas, mas para a PME são decisões que envolvem muitos recursos e são consideradas estratégicas. (RUZZIER et al., 2007).

Para possibilitar a mensuração da variável Grau de Internacionalização utilizaram-se critérios que pudessem retratar um fato já ocorrido (ex-post facto), mas considerando-os como um fenômeno dinâmico. (BONACCORSI; DALLI, 1990; ANDERSEN, 1993). O GRI desta pesquisa foi então elaborado por meio de uma medida multidimensional (HASSEL et al., 2003) utilizando-se indicadores tipo estruturais, de desempenho, atitudinais e de extensão empregados por Sullivan (1994), Dörrenbächer (2000) e Hassel et al. (2003), além de levar em conta as críticas de Ramaswamy (1996). Sentiu-se a necessidade de adaptar alguns indicadores propostos pelos autores acima à realidade da PME brasileira, conforme indicado por Reuber e Fisher (1997), que propuseram uma adaptação do DOI de Sullivan (1994) para a PME, o DOIsme (Degree Of Internationalization to SME), adaptação esta que foi igualmente identificada pelos estudos de caso da etapa qualitativa desta tese. 
Para formar a métrica do Grau de Internacionalização, consideraram-se as críticas de Hassel et al. (2003) e Sullivan (1994), que argumentam que a lógica para qualquer medida é o seu potencial para ajudar a explicar importantes causas e consequências da internacionalização e também deve ser observada dentro de um contexto de premissas teóricas utilizadas como base para o cálculo. Os referidos autores aceitam a combinação de indicadores para construir um índice agregado de internacionalização quando esses apresentarem uma covariância significativa entre as variáveis. Hassel et al. (2003) explicam a aceitação da combinação de indicadores com o argumento de que a proporção de ativos no exterior cresce, já que a redução das exportações não significa uma redução na internacionalização.

O objetivo com este construto não é o de comparar quais as PMEs mais internacionalizadas, mas sim verificar se quanto mais internacionalizadas as empresas estão novas competências elas desenvolvem e melhor será o seu desempenho. Tendo em vista a dinâmica do processo de internacionalização, este estudo não se limitará a uma dimensão, mas, sim, a um conjunto de variáveis que abordam os aspectos da internacionalização nas dimensões de estrutura, de desempenho, de atitudes e de extensão considerando tratar-se de PME e, ainda, do mercado específico brasileiro.

As quatro dimensões propostas por Sullivan (1994) e Dörrenbächer (2000) para caracterizar o GRI (dimensão estrutural, de desempenho, atitudinais e de extensão) são utilizadas nesta tese. Assim, as variáveis identificadas na literatura que puderam ser observadas nas PMEs brasileiras, e que são utilizadas neste trabalho, são apresentadas na Tabela 4, juntamente com o tipo de indicadores que caracterizam o GRI, bem como sua vinculação com as teorias da internacionalização anteriormente apresentadas e a indicação da variável no questionário aplicado (APÊNDICE A).

Tabela 4 - Variáveis iniciais aplicadas para GRI

\begin{tabular}{|c|c|c|c|}
\hline Aspectos da internac. da PME brasileira: & Indicadores & Aspectos teóricos & Questões \\
\hline - Vendas no exterior/Vendas total & Desempenho & Econômica & V6 \\
\hline $\begin{array}{l}\text { - Número de funcionários no exterior/número de } \\
\text { funcionários no Brasil }\end{array}$ & Estruturais & Econômica/comportamental & V7.2/7.1 \\
\hline - Número de países nos quais a empresa opera & Extensão & Econômica/comportamental & V3 \\
\hline - Modo de entrada no exterior & Estruturais & Comportamental & V1 \\
\hline $\begin{array}{l}\text { - Número de anos que a empresa exporta } \\
\text { diretamente }\end{array}$ & Extensão & Comportamental & $\mathrm{V} 2$ \\
\hline $\begin{array}{l}\text { - Número de executivos com experiência } \\
\text { internacional de estudo ou trabalho por mais de } \\
1 \text { ano. }\end{array}$ & Estruturais & Comportamental & V10.1 \\
\hline
\end{tabular}

Fonte: Adaptado com base na teoria e nos trabalhos apresentados no referencial teórico (2010) 
Levando em conta as discussões sobre a multidimensionalidade do construto e conhecendo os riscos do procedimento, não se agregaram os resultados num índice composto, como sugere Sullivan (1994), pois o que se pretende não é identificar qual empresa é mais internacionalizada e sim ter uma referência de indicadores que refletem o GRI. As variáveis foram adaptadas à realidade da PME brasileira e considerou-se também o número da amostra com vistas a gerar um indicador mais harmônico com os demais construtos e obter maior confiabilidade do modelo.

Para melhor compreensão das variáveis que foram utilizadas em cada aspecto, nos itens a seguir será apresentada a motivação da escolha.

\section{- Vendas no exterior sobre vendas totais (VEND)}

Como já demonstrado no referencial teórico (capítulo 2), o indicador mais utilizado para medir GRI é vendas no exterior como percentual do total de vendas (FSTS) (SULLIVAN, 1994). Tal indicador capta parcialmente a intensidade das atividades no estrangeiro, mas, como apontado por Sullivan (1994), por não ser um indicador dispensável, este foi combinado com outros indicadores para se tornar relevante. Esse indicador é utilizado em importantes índices como o da UNCTAD e DOI de Sullivan (HASSEL et al., 2001). Não se pretende medir com esse indicador o grau de extensão geográfica, como critica Ietto-Gillies (2001), pois para mensurar esse aspecto há o indicador país, apresentado adiante. Para Contractor et al. (2003), a participação das receitas internacionais na totalidade de receitas da empresa representa a profundidade da internacionalização que impacta no desempenho da PME. Considera-se, portanto, que quanto maior o valor dessa média, maior será o GRI da empresa.

\section{- Número de funcionários no exterior sobre o número de funcionários no país de origem (EMPR)}

Esse indicador não foi utilizado individualmente em outros trabalhos para medir o GRI, mas esse aparece como um dos indicadores de diversos índices compostos. (SULLIVAN, 1994; MOREIRA, 2009). Alguns autores julgam ser esse indicador uma medida de intensidade (IETTO-GILLIES, 2001), outros, como Hassel et al., (2001), uma medida estrutural. O indicador não é utilizado de maneira isolada, porque sozinho não poderá captar o grau de envolvimento internacional e, da mesma forma, poderia apresentar um viés ao se analisar empresas de segmentos de mão de obra intensiva que necessitam de mais funcionários. 
- Número de países para os quais a empresa exporta diretamente

Muitos trabalhos apresentam esse indicador como distância psíquica das subsidiárias no exterior, mas geralmente vinculam a distância geográfica e/ou lingüística, identificando a dispersão dos negócios. (RONEN; SHENKAR, 1985, SULLIVAN, 1994).

O conceito de distância psíquica é muito mais amplo, incluindo aspectos significantes de processos de tomada de decisão, dificuldades de negócios e diferenças culturais. (NORDSTRÖM; VALNE, 1992; HOFSTEDE, 1997). Para Ramaswamy et al., (1996), a simples contagem do número de países no qual a empresa possui operações ou vendas no exterior poderia oferecer uma medida mais provável.

Contractor et al., (2003), ao estudar o GRI, verificaram duas vertentes: a abrangência, ou seja, a dispersão geográfica da exportação ou número de países para onde o produto é exportado, e a profundidade, que, para os autores, é a participação das receitas internacionais na totalidade de receitas da empresa. Anteriormente, Madsen (1989), identificando a importância desses fatores no GRI, sugeriu que as empresas deveriam, como regra geral, buscar aumentar sua participação em mercados já atendidos em vez de aumentar o número de países atendidos. A sua pesquisa, por outro lado, identificou que as pequenas empresas apresentavam melhor desempenho caso ampliassem o número de países atendidos em vez de ampliar a participação em cada país. Alguns motivos podem ser encontrados na literatura para justificar esse resultado para a PME: os recursos escassos poderiam não permitir o aprofundamento, pela necessidade de a empresa ter que controlar os riscos que poderia assumir, e o número maior de países poderia gerar maior diversificação do risco.

Para este trabalho não se utilizou o conceito de distância psíquica pelo fato de ser difícil mensurar e quantificar as diferenças entre os países, como o faz Hofstede (1997). Da mesma forma, não se fez uso das zonas psíquicas, como o fizeram Sullivan (1994) e Ronen e Shenkar (1985), por considerar que a divisão das zonas não levava em conta as diferenças psíquicas e também pelo fato de essa divisão considerar o Brasil juntamente com Israel, Índia e Japão. Então, acatando a sugestão de Ramaswamy et al. (1996), considerou-se, para este trabalho, o número de países para onde a empresa exporta. Muitos trabalhos que estudam o conhecimento experiencial utilizam-se da simples contagem do número de países onde a empresa atua internacionalmente. (LU; BEAMISH, 2001; ERRAMILLI, 1991; RUZZIER et al., 2007). 
Os autores Thomas e Éden (2004), Delios e Beamish (1999), Lu e Beamish (2001) e Ramaswamy (1995) comentam que a dispersão das vendas externas pelos diversos mercados pode ser mais importante para determinar o Grau de internacionalização que o indicador vendas, pois possibilita alavancar o aprendizado, aumentando, consequentemente, o desempenho.

Para Contractor et al. (2003) e Hitt et al. (1997), a abrangência do GRI sobre o desempenho foi também representada pela dispersão geográfica da exportação, ou seja, pelo número de países para os quais o produto é exportado. Nesta tese, esta foi a dimensão utilizada (exportação), pois, desta forma, tanto as exportadoras como as empresas com operação no exterior teriam respondido essa questão. Verificou-se também que os países nos quais as empresas possuem IED são aqueles para os quais ela também exporta diretamente.

\section{- Modo de entrada da empresa no exterior}

Sabe-se que a maioria das PMEs somente exporta, mas igualmente se verifica que a cada ano os números dos Investimentos Brasileiros Diretos (IBD), como divulgado pelo BACEN no dia 22 de março de 2010, nos dois primeiros meses do ano, superam, de forma recorde para o período, os Investimentos Estrangeiros Diretos no Brasil (IED). IBD é a transferência de recursos financeiros da Matriz brasileira para a filial em outro país, já o IEDB é a transferência de dinheiro da matriz no exterior para a filial brasileira.

Este é um sinal de internacionalização das empresas brasileiras. Mesmo não tendo acesso a informação desses valores por porte de empresa, não se pode deixar de considerar, em trabalhos sobre empresas brasileiras, esse indicador. Como declarado pelo BACEN (2010), as empresas brasileiras estão se internacionalizando sempre mais.

Para operacionalizar essa variável e poder inseri-la como variável métrica, utilizou-se da reespecificação de variáveis por meio de variáveis dummy, ou seja, aquelas que podem assumir apenas dois valores. (MALHOTRA, 2001; HAIR JR. et al. 2009). De acordo com Malhotra (2001), a reespecificação de variáveis é a transformação de dados para criar novas variáveis ou modificar variáveis existentes de modo a torná-las mais consistentes com o objetivo do estudo. As variáveis dummy compreendem um importante processo de reespecificação. 
Nesse caso, a questão identificava o tipo de operação que a empresa possui. Para as empresas que atuam no exterior somente via exportação, atribui-se o valor 0 , e para as empresas que atuam no exterior de forma mais complexa, atribui-se o valor 1, utilizando o mesmo modelo de Rasheed (2005) e Erramili e Rao (1993).

\section{- Experiência de estudo ou trabalho no exterior}

Nos estudos em negócios internacionais o conhecimento é bastante explorado, principalmente o conhecimento experiencial. (SHARMA; JOHANSON, 1987; WIEDERSHEIM-PAUL et al., 1978; ERRAMILLI; RAO, 1993; CALOF; BEAMISH, 1995; BEAMISH, 1990). Segundo Etemad e Wright (1999), conhecimento experiencial específico de mercado desempenha um papel fundamental na explicação do processo de internacionalização das empresas.

Seguindo as críticas de Ramaswamy (1996) sobre a dificuldade de mensurar a experiência do executivo e qualificá-la, mas estando ciente da importância dessa variável para a PME, decidiu-se questionar a experiência prévia dos executivos. Pensou-se numa forma de a variável experiência estar mais bem qualificada (estudo e trabalho) e melhor especificada (por mais de um ano), como criticado por Ramaswamy (1996). Nesse aspecto, a avaliação focou os principais executivos da empresa. Foram considerados como principais executivos das empresas respondentes os gerentes, diretores e presidente (dono/proprietário). A experiência internacional anterior do executivo foi pesquisada por meio da experiência de trabalho e de estudo no exterior por, pelo menos, um ano. Hofstede (1997) considera que há mais introspecção da cultura nacional quando se permanece mais tempo em um determinado país. Esse tempo foi levado em conta para diferenciar experiências de turismo com aculturação.

Essa variável é medida pelo número de executivos principais da empresa que já estudaram ou trabalharam no exterior por mais de um ano.

\section{- Número de anos que a empresa atua com exportação}

De acordo com o modelo de Uppsala, o aumento do conhecimento e da experiência permite às empresas evoluírem em seus processos de internacionalização. A experiência internacional da empresa tem especialmente impacto na seleção de mercados internacionais e no modo de entrada. Esse conhecimento experiencial é também mensurado pelo número de anos que a empresa exporta diretamente. Optou-se pela identificação dos países pela exportação direta, 
considerando que se está medindo a mesma informação, ou seja, o tempo que a empresa exportadora e a empresa com operação no exterior exportam diretamente.

Como apresentado no referencial teórico desta tese (capítulo 2), há muitas outras variáveis que impactam na métrica de GRI, mas que por motivo de dimensão do questionário, quantidade de observações e/ou tempo de pesquisa disponível não foram consideradas. As variáveis que formam o GRI nesta tese foram testadas em trabalhos nacionais e internacionais e acredita-se que estas se refletem no GRI das PMEs Brasileiras.

Os trabalhos apresentados que analisam o GRI , na sua maioria, identificam o impacto direto no desempenho da empresa. Nesta tese, o GRI tem um impacto direto no desenvolvimento de novas competências e este, por sua vez, impactará no desempenho. O GRI impactará indiretamente em desempenho, pois este será mediado pelo desenvolvimento de novas competências.

\subsubsection{Operacionalização da variável "Competência"}

A RBV enfatiza que os recursos são essenciais para compreender o comportamento da empresa. $\mathrm{O}$ grande diferencial para a empresa internacionalizada é a capacidade de a empresa gerenciar esses recursos mediante processos organizacionais. (TEECE et al., 1997; HELFAT et al., 2007). Pode-se denominar essa capacidade de ativos difíceis de negociar e de copiar como, por exemplo, conhecimentos específicos de: desenvolvimento de produto, de marca, de mercado, de marketing. (TEECE et al., 1997). Essa capacidade dinâmica permite à empresa responder às novas condições de mercado, gerando novas competências que contribuem para o sucesso da empresa no mercado internacional. (TEECE; PISANO, 1994).

Por esse motivo, as competências, nesta tese, serão tratadas não somente como um recurso da empresa, mas também como a capacidade (habilidades) de gerenciar os recursos disponíveis na PME que criam valor para o cliente. A literatura identifica que, para a PME, a falta do necessário know- how administrativo ou gerencial restringe a oportunidade de esta se internacionalizar, reduzindo, consequentemente, seu desempenho. (WESTHEAD et al., 2004). 
Para identificar a variável "competências", utilizaram-se medidas que se mostraram significativas no estudo proposto por Knight e Kim (2009), como a International Business Competence (IBC), com as devidas adaptações identificadas no decorrer dos estudos e com os necessários ajustes indicados no pré-teste.

O questionário proposto por Knight e Kim (2009) encontrava-se em inglês, e ao se verificar que esta seria a forma mais eficaz de identificar as competências das PMEs brasileiras, elaborou-se o processo de tradução reversa, ou seja, inicialmente solicitou a uma professora de inglês (A) que fizesse a tradução para o português. Em seguida, solicitou-se que uma professora (B) de inglês realizasse a tradução da nova versão em português (realizada pela professora A) para o inglês novamente. A versão traduzida pela professora B foi então comparada com a versão original e, para os devidos ajustes da tradução, as professoras A e B se reuniram para identificar a melhor tradução.

Os executivos foram também questionados, durante os estudos de caso, sobre o conjunto de variáveis mais significativas utilizadas por Knight e Kim (2009). De forma bastante consistente, as questões foram criticadas e algumas até mesmo reelaboradas durante o préteste, quando se identificou que muitas delas se repetiam como conceito, dando a impressão, ao respondente, que algumas perguntas já haviam sido feitas anteriormente e outras não faziam sentido ou não eram compreendidas pelos entrevistados. Sendo assim, retiraram-se do conjunto do questionário (não sendo, pois, utilizadas no trabalho em tela) as perguntas que davam a sensação de repetição ou que se mostravam sem sentido, bem como as que não foram estatisticamente significativas no estudo de Knight e Kim (2009). Os resultados podem ser visualizados na Tabela 5 .

Tabela 5 - Variáveis iniciais aplicadas para competência

\begin{tabular}{l|c}
\hline \multicolumn{1}{c|}{ Variáveis Iniciais } & Questão \\
\hline ORIN - Orientação internacional - & V11.1 \\
\hline $\begin{array}{l}\text { Os gerentes na sua empresa tendem a ver o mundo, em vez de ver somente o Brasil como } \\
\text { mercado alvo? }\end{array}$ & V11.2 \\
\hline $\begin{array}{l}\text { A cultura organizacional que prevalece na sua empresa é conduzida para explorar novos } \\
\text { negócios no exterior }\end{array}$ & V11.3 \\
\hline $\begin{array}{l}\text { Os gerentes desenvolvem os recursos humanos e outros recursos para atingir os objetivos } \\
\text { no mercado internacional? }\end{array}$ & V15.1 \\
\hline HABMKT - Habilidades de Marketing Internacional - N. 15 & V15.2 \\
\hline O processo de planejamento de Marketing & V15.3 \\
\hline O controle e avaliação das atividades de Marketing & continua
\end{tabular}


conclusão

\begin{tabular}{l|c}
\hline $\begin{array}{l}\text { A habilidade para usar ferramentas de Marketing (design, publicidade) para diferenciar os } \\
\text { produtos }\end{array}$ & V15.4 \\
\hline INOVIN - Inovação Internacional - N. 11 & V11.4 \\
\hline Nossa empresa está avançada tecnologicamente nos mercados internacionais & V11.5 \\
\hline Nós inventamos muitas das tecnologias embutidas neste produto & V11.6 \\
\hline $\begin{array}{l}\text { No design e na manufatura deste produto nós empregamos alguns dos melhores } \\
\text { especialistas da indústria. }\end{array}$ & V11.7 \\
\hline ORIN - Orientação para o mercado internacional - N. 11 & V11.8 \\
\hline $\begin{array}{l}\text { Nossa empresa se preocupa com o cliente adaptando nossos produtos às necessidades dos } \\
\text { clientes }\end{array}$ & V11.9 \\
\hline $\begin{array}{l}\text { Nossos gerentes entendem como cada um pode contribuir para criar valor para o cliente no } \\
\text { mercado internacional. }\end{array}$ & V11.11 \\
\hline $\begin{array}{l}\text { Nossa empresa se preocupa e monitora as ações dos concorrentes no mercado internacional } \\
\text { Nossas funções do negócio (Mkt, vendas, manufatura, finanças) são integradas para atender } \\
\text { o mercado internacional? }\end{array}$ & \\
\hline
\end{tabular}

Fonte: Adaptado de Knight e Kim (2009)

As competências organizacionais não estão vinculadas a uma área ou a um departamento específico, podendo estar em qualquer função administrativa. Para desenvolver uma competência a empresa necessita de um processo sistemático de aprendizagem e inovação organizacional. (FLEURY; FLEURY, 2004). Considerando o posicionamento dos autores, para esta tese as competências analisadas são as da organização. Os indicadores deste trabalho refletem as competências em múltiplas áreas, incluindo o aprendizado do ambiente internacional e a adaptação da empresa com o novo ambiente via interação com o mercado externo, conforme trabalhado por Knight e Kim (2009). As dimensões do IBC são abaixo explicadas.

\section{a) Orientação internacional (ORINT)}

Durante as entrevistas com os executivos das PMEs brasileiras identificou-se que a necessidade de voltar o olhar da organização chegou ao momento crítico: "As empresas brasileiras foram acostumadas a serem compradas e agora nós temos que sair do ninho para vender." Empresas com uma forte orientação internacional tendem a apresentar competências específicas (McDOUGALL et al., 1994) que são difíceis de imitar (ETEMAD, 2004) e apresentam também um maior grau de internacionalização. (RUZZIER et al., 2007). Para as PMEs que apresentam recursos escassos, a visão empresarial e uma cultura organizacional pró-ativa para desenvolver recursos específicos são competências necessárias para atingir os objetivos da empresa no mercado externo (KNIGHT, 2000) e contribuir para o desempenho da empresa. (KNGHT; CAVUSGIL, 2004; KNIGHT; KIM, 2009). 
Nesse construto, as variáveis que o identificaram estavam ligadas aos gerentes, e a tendência a ver o mundo, à cultura organizacional voltada para novos mercados e para o desenvolvimento de Recursos Humanos com vistas a atingir os objetivos no mercado internacional. $\mathrm{O}$ respondente deveria indicar, numa escala Likert de 5 pontos, a total discordância (1) ou a total concordância (5).

\section{b) Habilidades de Marketing Internacional (HABMKT)}

“Apesar de conseguirmos apresentar produtos com inovação, nada adianta se não divulgarmos muito bem nossos produtos", disse o diretor do mercado externo. "Temos que desmistificar o estereótipo da empresa brasileira nos mercados internacionais e nos diferenciarmos das empresas concorrentes", complementou o proprietário de outra PME.

A habilidade em marketing internacional se mostrou relevante e necessária para a competitividade da PME brasileira no exterior. No IBC, essa competência foi identificada como a habilidade para criar valor para os clientes internacionais por meio da integração das atividades de marketing. Uma habilidade em marketing internacional superior à dos concorrentes possibilita as PMEs operar de forma mais efetiva, atendendo as expectativas dos clientes e, como consequïencia, melhorando o desempenho da empresa. (KNIGHT; CAVUSGIL, 2004).

Essa dimensão foi identificada pelas quatro variáveis já comentadas, abordando o planejamento, o controle e avaliação das atividades de marketing, habilidade de segmentar e identificar mercados e a habilidade para usar ferramentas de marketing para diferenciar produtos. Essas variáveis foram mensuradas comparando-as com os concorrentes, como sugerem Knight e Kim (2009), segundo uma escala Likert de 1 (pior que o meu concorrente) a 5 pontos (melhor que o meu concorrente).

\section{c) Inovação Internacional (INOVIN)}

A inovação pode ser o grande trunfo para a PME em mercados externos, pois pode gerar uma vantagem competitiva sustentável. É um processo complexo, exige competências gerenciais, o que não é facilmente copiado por outra empresa. (HOOLEY et al., 2005). Quando perguntado aos executivos o que tornava as empresas competitivas no exterior, a inovação 
apareceu como um fator chave. Neste caso, a inovação não se restringe à tecnologia, mas a muitos outros fatores, como o design e a "brasilidade" dos produtos das PMEs brasileiras.

Empresas sem a capacidade de inovação podem investir tempo e recursos estudando os mercados, mas não terão a habilidade necessária em traduzir esse conhecimento para o mercado. (KNIGHT; KIM, 2009). Corroborando os autores do IBC, os estudos de casos identificaram a capacidade de inovação como um fator muito importante para o sucesso e para um melhor desempenho das PMEs brasileiras.

As variáveis que formaram esse construto abordavam se a empresa era reconhecida pelos avanços tecnológicos, se a empresa havia inventado as muitas tecnologias que utilizava e se no design e na manufatura a empresa empregava alguns dos melhores especialistas. As respostas foram classificadas segundo a escala Likert de cinco pontos, variando de discordo totalmente a concordo totalmente.

\section{d) Orientação para o mercado internacional (ORMEI)}

Compreender o mercado externo e as necessidades dos clientes vai muito além da experiência e das informações do mercado externo. É necessário ter a capacidade de identificar e compreender as ações que geram valor para o cliente. (NAVI; SLATER, 1990). A orientação para o mercado internacional não está facilmente disponível e leva tempo para construir. (HOOLEY et al., 2005). "Quando decidimos internacionalizar a nossa empresa e atuar com lojas em Nova Iorque, não tínhamos o conhecimento das nuançass desse mercado, cometemos muito erros e tivemos que retornar. Entender o mercado, os clientes e o posicionamento dos concorrentes é fundamental para atuar no exterior", foi o comentário de um proprietário durante a entrevista.

"Antes de partir com nossa franquia para o exterior, tratamos de integrar as funções críticas do negócio. A comunicação entre as áreas precisa estar fluindo muito bem para que possamos atender os franqueados no mercado internacional", mencionou o Diretor do Mercado Internacional de outra empresa entrevistada. Para Fleury e Fleury (2004), as competências sociais, no campo da comunicação, são críticas para gerar interação e sinergia entre as áreas.

As variáveis que formam essa competência estão em concordância com o posicionamento de Narver e Slater (1990), que deram ênfase a três componentes comportamentais da orientação 
para o mercado: orientação para o cliente, orientação para os concorrentes e coordenação interfuncional.

Para esse construto, questionou-se sobre a preocupação da empresa com a adaptação dos produtos, a compreensão dos gerentes sobre a contribuição individual para criar valor para o cliente, a preocupação da empresa nas ações dos concorrentes e a integração das funções da empresa para atender às necessidades dos clientes. Todas as variáveis foram também mensuradas segundo uma escala Likert de 5 pontos variando entre (1) discordo totalmente e (5) concordo totalmente.

Alguns trabalhos internacionais apresentam o impacto individual dessa competência no desempenho da empresa. (PELHAN; WILSON, 1996; SLATER; NARVER, 1992; CADOGAN et al., 2002; RUZZIER, et al., 2007). Os resultados demonstram que em empresas com uma forte orientação para o mercado a competência individual poderá servir de fonte de informação para as inovações internacionais e para disseminar esses conhecimentos para a organização, contribuindo assim para um melhor desempenho.

O IBC foi escolhido como forma de identificar as competências que as PMEs desenvolveram com o GRI, pois retratam os recursos intangíveis da empresa que são importantes para as vantagens competitivas internacionais. Por meio de um conjunto de cultura empresarial e processos, o IBC apresenta variáveis de vantagens competitivas que são difíceis de serem imitadas rapidamente pelos concorrentes, como identificado em estudos de casos e por Fahy (2002). Considerando também o conceito do RBV apresentado no referencial teórico, a inimitabilidade está entre as características dos recursos da empresa que podem suportar vantagem competitiva sustentável, e as características pesquisadas da PME, nesta tese, englobam as capacidades de gerenciamento e de gestão, que são mais difíceis de serem imitadas.

Outro aspecto importante no IBC que foi considerado é a atenção dada ao conhecimento tácito (cultural, rotinas e processos e conhecimento dos executivos) e a capacidade da empresa em integrar o conhecimento de forma dinâmica para o sucesso das atividades internacionais. Esses fatores se apresentaram relevantes para a PME, tendo sido identificados em estudos de casos e também por Grant (1996) e por Johnson et al. (2006). 


\subsubsection{Operacionalização da variável "Desempenho da empresa"}

Levando em conta que apesar de muitos estudos apresentarem novas métricas de desempenho, mensurá-lo ainda é considerado uma dificuldade e um assunto não resolvido. (FUCHS, 2009). Diferentes abordagens são utilizadas pelos autores para mensurar o desempenho das empresas. (AABY; SLATER, 1989; ZOU; STAN, 1998; LAGES; MONTGOMERY, 2004; CAVUSGIL; ZOU, 1994).

Para Barney (2002), há na literatura uma pequena concordância sobre a melhor definição, mas efetivamente não há concordância sobre como medir o desempenho. Da mesma forma, Cameron (1986) considera que desempenho é principalmente um problema de construto e não de conceito. Diferentes empresas têm diferentes perspectivas de desempenho devido aos diferentes e específicos ambientes. Essas diferentes perspectivas de desempenho podem ser também influenciadas por diferentes fatores. Em vista disso, medir individualmente o desempenho tornaria o questionário impraticável, mas utilizar uma só variável para medi-lo tornaria o conceito simplista, não refletindo a complexidade do tema. (CAVUSGIL; ZOU, 1994; FUCHS, 2009).

Geralmente, as empresas tendem medir desempenho simultaneamente com objetivos como crescimento das vendas e lucratividade, ou aumento da participação do mercado global e aumento do retorno sobre investimentos. Às vezes esses objetivos se complementam, outras vezes não. (DESS; ROBINSON, 1984). Essa falta de complementaridade faz com que seja necessário considerar as medidas de desempenho como uma variável multidimensional. (SHOHAM, 1998).

Verificou-se na literatura (FIEGENBAUM et al., 1996) que há dimensões de referências que são utilizadas para compor os indicadores de desempenho, como as dimensões de referência interna, externa e temporal. A primeira é considerada pelas medidas de processos internos, tais como reduções de custo ou desenvolvimento de novos produtos, e também pelas medidas de resultados externos, tais como vendas ou lucratividade, que também podem significar resultados financeiros e de mercado. Já para a Dimensão de referência externa, a autoanálise das empresas é comparada com outros agentes, como, por exemplo, os competidores. Os autores também recomendam levar em consideração medidas sob o ponto de vista dos clientes e não apenas dos acionistas e dos executivos, bem como o atendimento a diversos outros tipos de stakeholders. Por fim, no referente à Dimensão de referência temporal onde as 
decisões estratégicas são fortemente afetadas pelo passado (até o momento) e pelo futuro (onde a empresa gostaria de chegar), deveriam ser consideradas medidas que indicassem como foi o desempenho passado e como se esperava que viesse a ser o desempenho futuro.

Tendo em conta esses fatores, verificou-se que a origem dos dados que compõem os indicadores de desempenho também são relevantes. Para Ginsberg (1984), a origem dos dados poderia ser classificada das seguintes formas: a) dados objetivos (fontes públicas secundárias), dados subjetivo-primários (relato de executivos ou avaliação por especialistas externos) e dados subjetivo-secundários (informações colhidas a partir de estudos de casos realizados anteriormente).

Mesmo conhecendo todos os vieses do levantamento desses dados apontados por Leonidou et al. (2002), e considerando o posicionamento de Fiegenbaum et al. (1996), os indicadores selecionados para esta pesquisa são voltados para a organização em geral (THACH; AXINN 1994), ou seja, via indicadores de dimensão de referência interna, com medidas de resultados externos, tais como indicadores financeiros e de mercado ou estratégicos. (CAVUSGIL; ZOU, 1994; SHOHAM, 1998, LAGES et al., 2005). As medidas financeiras são consideradas medidas mais orientadas para o curto prazo, e as medidas de mercado ou estratégicas, de medidas orientadas para o longo prazo. (LAGES et al., 2005).

Tem-se consciência que a avaliação objetiva dos resultados reais pode ser mais confiável, mas, levando-se em conta que não se está analisando um tipo de empresa, e sim um conjunto de diferentes empresas exportadoras, os números reais podem ocasionar problemas de medição contábeis diferentes. Ambas as partes interessadas e os gestores podem ter opiniões diferentes sobre quais medidas operacionais usar, e assim se torna muito difícil encontrar medidas financeiras para avaliar o desempenho das empresas. (MADSEN, 1989). Todas essas razões podem explicar por que as medidas subjetivas têm sido utilizadas para medir o desempenho.

Além disso, para a escolha dos indicadores de desempenho foram levados em consideração os comentários de Cameron (1986) acerca da formação do conceito e de seus indicadores, já apresentado na revisão bibliográfica, vinculando os indicadores aos objetivos da presente pesquisa e ao tipo de respondente, ou seja, o GRI influencia o desenvolvimento de 
competências que melhoram o desempenho, sendo esta pesquisa respondida por executivos de PMEs brasileiras.

Com isso, identificou-se que o exposto pelo executivo, ou seja, que os dados subjetivoprimários e multivariados seriam os mais indicados, como relatado por Bilkey (1982), Ginsberg (1984) e Shoham (1998) quando mencionaram que uma alternativa exequível para a coleta de informações sobre desempenho corresponde à percepção da lucratividade pelo corpo gerencial da empresa.

Considerando que as medidas de sucesso financeiro dependem do contexto de cada empresa (GREVE, 1998), utilizaram-se métricas de lucratividade financeiras mais genéricas e ainda métricas de produtividade, englobando também o mercado, para que o levantamento de dados pudesse ser feito de maneira mais uniforme nas diversas empresas pesquisadas. (LAGES et al., 2005).

Tendo em conta que as empresas pesquisadas estão em etapas diferentes de internacionalização, a incerteza nas etapas iniciais tende a ser grande e o comprometimento de recursos, pequeno. (CARNEIRO, 2007). Nas etapas mais complexas da internacionalização, a incerteza continua e o comprometimento de recursos deverá ser maior do que nas etapas iniciais. (PANGARKAR, 2008). Em consequência, qualquer previsão sobre o futuro pode se tornar mera especulação. Trabalhar com indicadores financeiros de desempenho futuro pode, portanto, não ser adequado. Indicadores de clientes/de mercado ou indicadores relacionados a objetivos estratégicos podem ser mais apropriados. (PANGARKAR, 2008).

Araújo (2005) observou que há uma preocupação, por parte dos pesquisadores da área internacional, com a dupla direção de causalidade entre produtividade e outros indicadores de desempenho e exportações. Por um lado, a firma torna-se exportadora devido a seus custos competitivos e maior capacidade de operar com margens de lucro menores. Por outro, a exposição a mercados internacionais mais competitivos que o doméstico permite que a empresa tenha acesso a insumos, padrões tecnológicos, consumidores mais exigentes, financiamentos internacionais, que possibilitam a dinamização de sua produtividade geral, com impacto no desempenho da organização como um todo. 
Por esse motivo, não faria sentido fazer perguntas aos executivos de empresas exportadoras sobre o desempenho das exportações e, para as empresas com operações mais complexas, acerca do desempenho destas e, após isto, juntar dois desempenhos diferentes para formar um único índice, pois se estaria juntando modos de internacionalização que demandam recursos diferenciados para a sua execução sem qualquer distinção. Além disso, a PME brasileira precisa identificar o aumento do GRI como uma alternativa de diluição de riscos e uma estratégia de crescimento que melhore o desempenho para a empresa como um todo, considerando que os recursos da PME, principalmente os financeiros, são escassos.

Sabe-se que diferentes trabalhos apresentaram perspectivas diferenciadas de desempenho internacional devido ao ambiente específico de atuação, o que pode ser justificado também por diferentes fatores. Thach e Axinn (1994) ponderam que não se deve assumir que a melhora no desempenho de exportação seja necessariamente melhora no desempenho da empresa e que isto é muitas vezes confundido pelos pesquisadores.

Considerando que as empresas utilizam medidas de desempenho diferentes, dependendo do contexto que atuam, os critérios serão identificados a partir da percepção do executivo, ou seja, por meio subjetivo. Como o ambiente analisado é a organização como um todo, tenta-se verificar qual o impacto da internacionalização sobre a empresa, pois as medidas de desempenho específicos de exportação, como as demonstradas no referencial teórico, não indicam se uma empresa tem explorado as oportunidades de exportação para melhorar o desempenho. (CAVUSGIL, 1984). Isto pode explicar por que os gestores, principalmente de PMEs, tendem a usar suas próprias percepções de desempenho, em vez de lançar mão de valores objetivos, a fim de formular as suas próprias decisões. (BOURGEOIS, 1980). Como o desenvolvimento de competências é analisado tendo a empresa como cenário, o desempenho também terá esse foco.

Nesta tese, o desempenho é identificado como a posição pela qual a empresa mensura seu próprio objetivo em duas vertentes: em termos financeiros, via aumento do retorno sobre Ativos (ROA), aumento da lucratividade geral da empresa e aumento da rentabilidade da empresa; e em termos do desempenho operacional, mensurado por meio do aumento de volumes de vendas total da empresa, do aumento da produtividade operacional e do aumento da participação do mercado global. Muitos estudos, quando abordam a influência do GRI do 
desempenho, analisam somente o da exportação. Aqui o desempenho será o da empresa em geral, pois se estuda a PME não somente exportadora, mas também a PME com operações internacionais mais complexas. Caso fossem seguidos os trabalhos que apresentam o desempenho da exportação, estar-se-ia aumentando o viés que o construto já apresenta.

Seguindo as sugestões de Lages et al. (2005), no que diz respeito aos fatores importantes para o desenvolvimento de um índice multidimensional, deve-se utilizar:

a) O Calendário: após internacionalização (exportação/operação no exterior)

b) Unidade de Análise: o desempenho em nível organizacional.

E de acordo com Gomes e Ramaswamy (1999), o desempenho será verificado em termos financeiros e operacionais, pois a empresa pode se internacionalizar não somente por motivos financeiros, mas em busca de outros recursos que possam melhorar sua produtividade.

Assim, como conceito, utiliza-se o desempenho da empresa, e como definição, a avaliação financeira e operacional, por meio do uso dem índices financeiros e de mercado como indicado pela literatura de negócios internacionais, que permitem inferir o crescimento da empresa após a internacionalização. Como indicado por Ramaswamy et al. (1996), os indicadores são analisados em índices diferentes para corroborar a técnica estatística de análise escolhida e pelo fato de os indicadores refletirem dimensões distintas.

Para mensurar a variável desempenho financeiro considerou-se a literatura de negócios internacionais que se utiliza de indicadores financeiros, como Aumento da Rentabilidade, da Lucratividade e do Retorno sobre os Ativos (ROA) da empresa. (BILKEY 1982; GRANT, 1987; MADSEN, 1989; CAVUSGIL; ZOU, 1994; SULLIVAN, 1994; ZOU et al., 1998; GOMES; RAMASWAMY, 1999).

Para medir o desempenho operacional também se lançou mão da literatura dos negócios internacionais, utilizando: aumento do volume de vendas; o aumento da participação do mercado e o aumento da produtividade operacional (COOPER; KLEINSCHMIDT, 1985; GRANT, 1987; MADSEN, 1989; ZOU et al., 1998; SHOHAM, 1998; GOMES; RAMASWAMY, 1999), questionando às empresas exportadoras acerca da concordância ou 
discordância com os indicadores, constantes da tabela abaixo, após o início da internacionalização. Ver na Tabela 6 os indicadores analisados.

Tabela 6 - Indicadores iniciais de desempenho financeiro da organização

\begin{tabular}{cllc}
\hline DESEMP & \multicolumn{1}{c}{ DESEMPENHO FINANCEIRO } & Indicadores & Questão \\
\hline Lucro & Aumento da Lucratividade geral da empresa & Financeiro & V13.1 \\
ROA & Aumento do Retorno sobre os Ativos & Financeiro & V12.6 \\
Rent & Aumento da Rentabilidade geral da empresa & Financeiro & V12.5 \\
\hline
\end{tabular}

Tanto o desempenho financeiro como o desempenho organizacional (Tabela 7) foram, em todas as análises estatísticas, considerados individualmente, podendo-se assim verificar a relação do GRI e das competências em cada desempenho.

Tabela 7 - Indicadores de desempenho operacional da organização

\begin{tabular}{cllc}
\hline ESMP & \multicolumn{1}{c}{ DESEMPENHO OPERACIONAL } & Indicadores & Questão \\
\hline Volum & Aumento do volumes de vendas da empresa & Operacionais & V12.4 \\
Rent & Aumento da produtividade operacional & Operacionais & V12.7 \\
Partici & Aumento da participação do mercado global & Operacionais /Mercado & V13.6 \\
\hline
\end{tabular}

Muitos dos índices utilizados tiveram que ser adaptados de sua forma original porque as PMEs, no Brasil, não publicam seus balanços, o que dificulta o levantamento de dados quantitativos diretos, ou seja, valores financeiros reais. Para buscar esses indicadores, tentouse captar a percepção do executivo acerca desses indicadores após o início da internacionalização. (ZOU et al., 1998; LAGES et al., 2005). Para as respostas elaboraram-se escalas tipo Likert, atribuindo 5 pontos para a total concordância e 1 ponto para total discordância, como pode ser visualizado no questionário apresentado no Apêndice A.

Infelizmente, a maioria dos estudos sobre PMEs depende da autoavaliação dos executivos respondentes, e para diminuir o viés deste construto faz-se necessário um maior número de indicadores para melhor avaliar a situação geral. (LAGES et al., 2005).

Para tentar minimizar este impacto sobre a autoavaliação utilizaram-se medidas financeiras, operacionais e de mercado/estratégicas (consideradas no desempenho operacional) por meio de uma abordagem pragmática, contendo indicadores estáticos e dinâmicos. Concordando com Lages e Lages (2004), que identificaram que as principais variáveis para mensurar o desempenho da empresa é volume de vendas, lucratividade, e market share, nesta tese 
acrescentou-se o aumento do ROA, para considerar os diferentes aportes de recursos dos diferentes modos de internacionalização, e a rentabilidade, com o propósito de investigar a lucratividade sobre o investimento total e o aumento da produtividade, visto que o desempenho pode também ser melhorado com o ganho de escala. Além disso, o ROA foi um dos indicadores mais utilizados, inclusive individualmente, para mensurar o desempenho. (SULLIVAN, 1994). Os itens acrescentados corroboram a opinião de vários autores, de que para minimizar o viés da percepção do respondente um conjunto maior de variáveis deveria ser usado para medir desempenho.

\section{- Aumento do Retorno sobre Ativos (ROA)}

O retorno sobre o ativo é considerado como um dos quocientes individuais mais importantes da análise de balanços, tendo em vista que ele demonstra o desempenho da empresa de uma forma global. A medida de retorno sobre o ativo representa o potencial de geração de lucros da empresa, isto é, o quanto a empresa obteve de lucro líquido em relação aos investimentos totais. A equação de ROA é dada da seguinte forma: ROA = (Lucro Líquido/Ativo Total). Este é um dos indicadores mais utilizados para medir desempenho, tanto em estratégia como na área dos negócios internacionais. (SULLIVAN, 1994).

Ao executivo foi perguntado se o retorno sobre os ativos cresceu após o início da operação no exterior, dando-lhe a possibilitando de identificar a alternativa que lhe parecia mais adequada, ou seja: (1) discordo totalmente e (5) concordo totalmente.

\section{- $\quad$ Lucratividade Líquida}

Lucratividade indica o percentual de ganho obtido sobre as vendas realizadas. A lucratividade esperada para micro e pequenas empresas é de 5\% a 10\% sobre as vendas. (SEBRAE, 2008).

Nesta questão, o objetivo foi identificar se a operação no exterior contribuiu para o aumento da lucratividade geral da empresa e, da mesma forma que na variável anterior, a resposta incidia entre 1 e 5 .

\section{- Aumento da rentabilidade geral da empresa}

Questionou-se também sobre o desempenho geral da empresa após o início da operação no exterior, isto é, se a rentabilidade da empresa aumentou ou não. Rentabilidade indica o percentual de remuneração do capital investido na empresa. A taxa de rentabilidade do 
investimento é calculada da seguinte forma: Lucro Líquido/Investimento total. A rentabilidade esperada para micro e pequenas empresas é de $2 \%$ a $4 \%$ ao mês sobre o investimento. (SEBRAE, 2008).

\section{- Aumento do volume de vendas geral da empresa}

Decidiu-se também aquilatar o aumento do volume produzido, pois um volume adicional adquirido no mercado externo pode ser útil para alcançar economias de escala, especialmente se o volume estava restrito ao mercado interno devido à saturação ou a outras questões, como o aumento dos concorrentes. Maiores volumes de venda podem permitir às PME a amortização dos custos de P \& D e destinar a alocação de recursos para essa função, que é fundamental para manter a competitividade. (KOBRIN, 1991; PANGARKAR, 2008).

\section{- Aumento da participação do mercado global}

Essa variável mensura o ambiente externo da organização. Sua medida quantifica, em termos percentuais, a quantidade do mercado dominado por uma empresa. Divide-se o número total de unidades que a empresa vendeu pelo total de unidades vendidas no segmento em que a empresa atua. $\mathrm{O}$ valor pode ser obtido ainda da divisão do valor total em vendas da empresa pelo valor total em vendas do segmento.

Para Cameron (1986), uma empresa não deveria focar sua energia apenas em uma dimensão do desempenho, tendo em vista que há conflito entre várias dimensões, podendo levar a uma disfunção. A existência de objetivos aparentemente paradoxais é o que move e dá mais energia às organizações. Assim sendo, a definição de desempenho deveria incluir, de alguma forma, um atendimento equilibrado entre indicadores aparentemente conflitantes.

\section{- $\quad$ Aumento da produtividade}

Um conceito mais amplo de produtividade inclui eficiência e eficácia, no qual eficiência é a medida do desempenho do processo de conversão das entradas em saídas, enquanto eficácia é a medida do grau em que as saídas satisfazem os requisitos, conforme apresentado por Carvalho e Laurindo (2003). Indagou-se dos executivos se após o início da operação no exterior a produtividade geral da empresa aumentou. 
Como visto em outros trabalhos apresentados nesta e em outras teses, como consistentemente apresentado por Carneiro (2007), o construto desempenho é bastante controverso e complexo. O objetivo nesta tese não foi desenvolver o modelo perfeito para ser aplicado universalmente, pelo contrário, o objetivo foi torná-lo mais simples, sem simplificar demais, fácil de ser respondido e que ao mesmo tempo pudesse indicar a realidade das Pequenas e Médias Empresas Brasileiras, apesar da subjetividade do respondente.

Como se pôde identificar nos indicadores apresentados, o modelo não aborda a totalidade das variáveis influenciadoras do GRI, de competência e de desempenho, mas também não tenta reproduzir uma realidade por meio de um único fator. $\mathrm{O}$ modelo utilizado nesta pesquisa é relativamente complexo, como sugere Madsen (1989), por utilizar variáveis que abordam o ambiente externo e interno das PMEs.

Como forma de tornar o modelo mais confiável, para analisar os dados coletados utilizaramse técnicas de equações estruturais, que consideram as relações complexas e integram um número razoável de fatores e de conjunto de fatores, como sugere Holzmüller e Stöttinger (1996).

Sendo assim, o Quadro 13 apresenta um resumo dos construtos desta tese, sua definição constitutiva e operacional.

Quadro 13 - Resumo das definições constitutivas e operacionais da presente tese

\begin{tabular}{|c|c|c|}
\hline CONSTRUTO & DEFINIÇÃO CONSTITUTIVA & DEFINIÇÃO OPERACIONAL \\
\hline GRI & $\begin{array}{l}\text { É um conceito multidimensional, } \\
\text { identificado pelo processo crescente de } \\
\text { envolvimento em operações } \\
\text { internacionais, que exige a adaptação da } \\
\text { estratégia, dos recursos e da estrutura da } \\
\text { organização. }\end{array}$ & $\begin{array}{l}\text { Vendas no exterior/vendas totais; } \\
\text { - Número de países para os quais a } \\
\text { empresa exporta; } \\
\text { - Quantidade de executivos que estudaram } \\
\text { ou trabalharam por mais de um ano no } \\
\text { exterior. } \\
\text { - Modo de operação no exterior: } \\
\text { exportação ou IED; } \\
\text { - Número de funcionários no } \\
\text { exterior/funcionários totais. }\end{array}$ \\
\hline COMPETÊNCIA & $\begin{array}{l}\text { Conjunto articulado de recursos e } \\
\text { capacidades para realizar atividades e } \\
\text { negócios nos mercados internacionais que } \\
\text { agreguem valor à organização. }\end{array}$ & $\begin{array}{l}\text { - Orientação Internacional; } \\
\text { - Habilidade de Marketing Internacional; } \\
\text { - Inovação Internacional; } \\
\text { - Orientação para o Mercado } \\
\text { Internacional. }\end{array}$ \\
\hline DESEMPENHO & $\begin{array}{l}\text { Resultados que uma empresa atinge após o } \\
\text { início da internacionalização sob o aspecto } \\
\text { financeiro e operacional. }\end{array}$ & $\begin{array}{l}\text { - Financeiro: ROA; Lucratividade geral; } \\
\text { Rentabilidade geral. } \\
\text { - Operacional: Volume de Vendas; } \\
\text { Produtividade Operacional; Participação } \\
\text { do mercado global. }\end{array}$ \\
\hline
\end{tabular}


Houve um cuidado especial na identificação das variáveis desta tese para não cometer um tipo de erro de especificação, como comentado por Hair Jr. et al. (2009), ou seja, a omissão de uma variável-chave, que acaba enviesando a importância das demais variáveis, e a inclusão de variáveis irrelevantes, que afetam o grau de parcimônia do modelo. Esses erros podem dificultar a interpretação dos resultados. Os referidos autores também fazem comentários acerca da dificuldade em controlar o desejo de se incluir todas as variáveis que são utilizadas em trabalhos semelhantes, pois as limitações estatísticas e de coleta de dados, inclusive a dificuldade da interpretação dos resultados, tornaria o modelo complexo demais. Modelos com mais de 20 variáveis já são considerados complexos pelos autores.

Levando-se em conta que a média desejável superior é de três indicadores por construto, indicada por Hair Jr. et al. (2009), o presente modelo foi desenvolvido buscando incluir indicadores significativos para a PME brasileira, conforme apresentado no referencial teórico e mais adiante nos estudos de casos.

Apesar de a literatura atribuir impacto positivo sobre os construtos, algumas variáveis não foram incluídas no modelo, ou pela dificuldade em se conseguir a informação ou pela variável não ser diretamente relacionada à PME e/ou ao Brasil, como, por exemplo, a taxa de câmbio de um determinado período, quantidade de infraestrutura no exterior, custo Brasil, carga tributária, entre outros. Como não se está fazendo um estudo comparativo entre países, a mesma taxa de câmbio influenciou em todas as PMEs brasileiras; $\mathrm{O}$ tamanho da empresa também não foi identificado no modelo como uma variável de controle, conforme outros trabalhos, pois como o foco do estudo já delimita o tamanho (PMEs), acredita-se não haver uma diferença significativa de recursos entre a Pequena e a Média empresa até 200 empregados; este fato é diferente quando se estuda a Grande empresa.

Como a técnica estatística considerada para a estimação do modelo foi a equação estrutural, não foi possível, apesar de se ter cogitado, a utilização de variáveis de controle, como o tipo de indústria, ano de fundação, entre outras, pois a técnica identifica que o número da amostra define o número ideal de variáveis no modelo ( $\mathrm{n}$ x 5, onde $\mathrm{n}$ é o número de variáveis), conforme Hair Jr. et al. (2009), e que neste estudo já se mostrou satisfatório. Como um primeiro estudo sobre as PMEs brasileiras, acredita-se que vale a análise mais geral da condição da internacionalização, deixando como sugestão para futuros trabalhos a inclusão de 
variáveis de controle para especificar ainda mais as condições da internacionalização das PMEs brasileiras.

Como as variáveis incorporadas ao modelo não são todas aquelas que poderiam influenciar os construtos, faz-se necessário considerar esse fator como uma limitação desta tese, devendo o resultado ser relativizado e contextualizado segundo essa limitação. (HAIR JR. et al., 2009). As variáveis apresentadas e utilizadas nesta tese combinam a experiência das pesquisas internacionais anteriores e das entrevistas em PMEs brasileiras para ajustá-las aos objetivos da pesquisa e da realidade da PME brasileira. Baseando-se nesses trabalhos, as hipóteses desta pesquisa são a seguir apresentadas.

\subsection{Hipóteses da Pesquisa}

Grande parte dos estudos que abordam a internacionalização das PMEs trata o tema por meio da exportação. Sabe-se que, na sua maioria, esta é a forma como as empresas iniciam seus processos de internacionalização e, também no Brasil, é a forma mais comum de internacionalização. De acordo com a OECD (1997), desde a década de 1980 o número de PMEs internacionalmente ativas cresceu de maneira considerável. É estimado que mais de um milhão de PMEs, cerca de 30\% das PMEs de manufatura nos países industrializados, estão internacionalizadas, respondendo por um terço do comércio mundial de mercadorias.

Sabe-se, ademais, que a maioria das PMEs brasileiras se internacionalizam por meio da exportação, mas não se pode negar que esse cenário vem sofrendo mudanças significativas e que as empresas estão iniciando a sua expansão internacional mediante formas mais complexas de internacionalização.

Inúmeras desvantagens são atribuídas às PMEs quando comparadas às grandes empresas que se internacionalizam. (WILLSON, 2000). A falta de poder de mercado para controlar preços, a dependência de pequenos clientes e o limitado e, até mesmo, inexistente acesso aos tomadores de decisões em nível regional e nacional aumentam a incerteza em avançar no grau de internacionalização, principalmente se comparada à grande empresa MNC. (ALDRICH; AUSTER, 1986; FUJITA, 1995; COVIELlO; McAULEY, 1999; KNIGHT, 2000; HOLLENSTEIN, 2005). 
Estudos atribuem à PME a deficiência, no que tange a recursos financeiros e recursos humanos, dificultando o acesso a informações de mercado, em coordenar esforços gerenciais e desenvolver uma estratégia adequada para a internacionalização. (SMALLBONE; WYER, 1995; ROTH, 1992; BIJMOLT; ZWART, 1994; HOLLENSTEIN, 2005).

Apesar das dificuldades encontradas pelas PMEs, e apresentadas em vários estudos nacionais e internacionais, os negócios internacionais das PMEs estão se expandindo para diversos países e correspondem a cerca de $60 \%$ do total das receitas provindas do exterior. (KNIGHT; CAVUSGIL, 2004). Alguns estudos identificaram que o avanço na internacionalização foi verificado em empresas Born globals, ou seja, aquelas que se internacionalizaram em até cinco anos, no máximo, desde sua criação. (McDOUGALL et al., 1994; OVIATT; McDOUGALL, 1995; BELL, 1995; KNIGHT; CAVUSGIL, 1996; COVIELLO; MUNRO, 1997). Os estudos não possuem um padrão de características para denominar Born Globals; há divergências quando os autores mencionam o número de anos que a empresa se internacionaliza, por exemplo: nasce internacionalizada, 3 anos após sua fundação ou 5 anos após sua fundação.

Pesquisas prévias atribuíram o mais alto grau de internacionalização às empresas que operam no setor de alta tecnologia e de setores chamados de conhecimento intensivo do que às empresas de setores tradicionais. (WIEDERSHEIM-PAUL et al., 1978; AMINE; CAVUSGIL, 1986; WAKELIN, 1998).

Sabe-se que a estratégia e as competências são fatores explicativos de desempenho organizacional, mas não há resposta de qual é o mais importante para alcançar o resultado desejado, pois ambos os conjuntos de fatores exerceriam importantes influências que não poderiam ser separadas, na prática, de forma tão fácil como apresentada na teoria, segundo afirmação de Schendel (1997), concordando com Henderson e Mitchell (1997) durante a introdução do caderno especial do Stategic Management Journal.

Para Schendel (1997), existem interações recíprocas entre as variáveis. Isto quer dizer que interações mútuas em múltiplos níveis de análise ocorreriam entre o ambiente e a empresa, as quais moldariam a estratégia e o desempenho, enquanto interações entre estratégia e desempenho, por sua vez, moldariam as capacitações organizacionais e o ambiente externo. $\mathrm{O}$ 
autor argumenta ainda que entender tais interações seria mais útil do que identificar os efeitos independentes.

Expandir para mercados externos pode representar, para a empresa, uma importante oportunidade de crescimento e geração de valor, mas implementar a estratégia de internacionalização envolve desafios adicionais aos enfrentados no mercado interno. Muitos desses desafios estão associados ao "passivo da estranheza" (Tradução da autora para para “liabilities of foreignness" HYMER, 1976; SETHI; JUDGE, 2009), ou seja, o conhecimento e a capacidade que uma PME desenvolveu por operar no seu mercado não foram suficientes para operar no novo mercado, e novos conhecimentos e capacidades deverão ser adquiridos ou desenvolvidos para atuar com sucesso no novo mercado. (McDOUGALL; OVIATT, 1996; SHAN; SONG, 1997). Expandir internacionalmente é a chave para promover o aprendizado organizacional. (PORTER, 1990; ZAHRA et al., 2000; FLEURY; FLEURY, 2004).

Na teoria da RBV, já apresentada, a empresa desenvolve certos recursos e capacidades que as diferenciam das demais e com isso pode explicar o melhor desempenho. (PENROSE, 1959; TEECE, 1997). Acredita-se que a RBV, por si só, não consegue identificar e explicar quais competências emergem dentro de uma empresa, pois as capacidades são ambíguas e os procedimentos são, muitas vezes, incorporados no intangível e ficam implícitos nas rotinas organizacionais e nos hábitos inconscientes dos gestores. (SCHREYÖGG; KLIESCH-EERL, 2007). As empresas devem ter acumulado alguns recursos e conhecimentos ao longo do tempo, e aplicando essa ideia às PMEs, que carecem de recursos principalmente financeiros, poucas conseguirão desenvolver competências para atuar no mercado externo ficando em seu país.

Considerando as contribuições de Prahalad e Hamel (1990), "as competências são formadas a partir de recursos e as estratégias são elaboradas a partir de grupos de recursos; a implementação da estratégia gera novas configurações de recursos e novas competências que, por sua vez, irão influenciar novamente a formulação da estratégia." (FLEURY; FLEURY, 2004, p. 32-33).

Sem competências adequadas, um maior grau de internacionalização não poderá conduzir a um maior desempenho, afirma Pangarkar (2008). Pode também ser importante para a PME saber o que vem antes, a internacionalização ou as competências. Os mesmos autores 
encontraram evidências de que a internacionalização contribui para o desenvolvimento das competências. Alguns autores que também evidenciaram o desenvolvimento de competências (GHOSHAL, 1987; GRANT, 1987) mencionam que a internacionalização proporciona muitas oportunidades de aprendizado e significativas mudanças organizacionais. (QIAN, 2002). Oviatt e McDougall (1994) reconhecem que para empresas com recursos escassos, como a PME, a internacionalização pode ser uma oportunidade para o crescimento da empresa ou para acessar recursos de criação de valor.

Para as PMEs é muito difícil dispor de uma vantagem de propriedade para então se internacionalizar, como prevê o modelo de paradigma eclético. (DUNNING, 2003). Portanto, nesta tese, o pressuposto é de que as PMEs dependem da aprendizagem de competências adquiridas no exterior (MATHEWS, 2006) para se tornaram mais competitivas e melhorar seu desempenho.

Acredita-se que quanto maior o envolvimento internacional da organização, mais experiência a organização desenvolveria - e esta experiência desenvolvendo novas competências organizacionais -, aumentando, assim, o seu desempenho.

Portanto, a hipótese central desta pesquisa é:

Hc: As competências organizacionais mediam positivamente a relação entre o GRI e o desempenho das PMEs.

Para melhor compreender a HC e para testá-la, dividiram-se as hipóteses de forma a identificar o impacto direto dos construtos em desempenho financeiro e operacional.

H1a: As competências organizacionais mediam positivamente a relação entre o GRI e o desempenho financeiro.

H1b: As competências organizacionais mediam positivamente a relação entre o GRI e o desempenho operacional.

É interessante notar que a lucratividade da empresa, à medida que as formas de internacionalização se tornam mais complexas, principalmente no início (pela falta de 
experiência), tende a diminuir. (RUIGROK; WAGNER, 2003). No entanto, é de se esperar que quanto maior a experiência acumulada pela empresa nos quesitos de experiência internacional dos executivos, maior a quantidade de país no qual a empresa opera, maior a quantidade de funcionários da empresa trabalhando nas subsidiárias, maior o tempo (em anos) que a empresa opera no exterior e, por fim, quanto maior percentual de vendas externas sobre vendas totais da empresa, melhor seria o desempenho financeiro e melhor ainda seria o seu desempenho operacional, conforme os autores Lages et al. (2005), sobre ganhos de mercado e escala. (PORTER, 1985). Ainda seguindo as considerações de Kindleberger (1974), a oportunidade de financiamentos no exterior para empresas com um maior grau de internacionalização poderia proporcionar uma vantagem para a empresa internacionalizada diferente da oferecida às empresas que atuam somente no mercado interno. É esta lógica que está sendo utilizada nestas hipóteses.

Como visto na revisão da literatura, grande parte dos estudos sobre GRI identificam sua influência no desempenho. Mas há muitas controvérsias sobre os resultados desses trabalhos. Assim, acredita-se, juntando os construtos, que haverá um desempenho financeiro e operacional superior quando o GRI evoluir e a empresa desenvolver mais competências. Dependendo dos objetivos estratégicos e objetivos globais, uma empresa irá evoluir no seu grau de internacionalização quando as opções estratégicas forem compatíveis com a disponibilidade de recursos e de competências. (DE CLERQ et al., 2005). Concordando com os autores, uma análise dos possíveis fatores que influenciam o desempenho internacional das PMEs deve considerar os recursos e as capacidades específicas disponíveis. 



\section{METODOLOGIA}

Neste capítulo apresentam-se a população e a amostra desta pesquisa, os procedimentos para a coleta de dados da fase qualitativa e da fase quantitativa, bem como os procedimentos para o tratamento dos dados.

No presente trabalho, utilizou-se do método misto, ou também conhecido como multimétodo (MALHOTRA, 2001), que combina as abordagens qualitativas e quantitativas. De acordo com Brewer e Hunter (1989 apud HOPPEN et al., 2000), consiste na utilização de mais de uma metodologia de pesquisa. A abordagem multimétodo enfoca o princípio de convergência, procedendo-se de modo que os resultados de um mesmo problema de pesquisa, com a utilização de métodos diferentes, sejam similares ou até idênticos. Hofstede (1997) aponta que o método quantitativo tem a vantagem da confiabilidade (independentes do sujeito que investiga) e da estabilidade temporal do instrumento, permitindo estudos longitudinais. A etapa qualitativa subsidiou a etapa quantitativa na formulação do questionário e, ao final, contribuiu para a interpretação dos resultados.

A concepção desta tese é a da pesquisa conclusivo-descritiva, que visa determinar em que grau certas variáveis estão correlacionadas e descrever as características do grupo de empresas pesquisadas. (MALHOTRA, 2001). Os dados foram obtidos por meio de uma survey, e os resultados foram descritos e analisados via um estudo transversal único (ou por levantamento de amostragem), ou seja, consistiu na extração de dados de uma amostra uma única vez. (Ibid., 2001).

O propósito deste trabalho é testar a conformidade de um modelo aos dados empíricos, por meio da formalização dos conceitos dos construtos GRI, competência e desempenho, que foram desenvolvidos a partir da base teórica apresentada.

Assim, visando confirmar os modelos de mensuração de cada um dos construtos, bem como as relações entre as variáveis de cada construto, utilizou-se uma equação de modelos estruturais para verificar empiricamente os dados coletados. Outras técnicas estatísticas foram usadas para complementar as análises (ANOVA) e tornar o teste das hipóteses mais explicativo (Sobre ANOVA ver APÊNDICE D). 
Considerando o objetivo da pesquisa, este é um estudo de natureza descritiva que, mediante uma survey, buscou estudar o comportamento de determinada população por meio de uma amostra considerável. (MALHOTRA, 2001; HAIR JR. et al., 2009). A partir da amostra selecionada, procurou-se identificar a incidência relativa, a distribuição e a relação entre as variáveis.

Como sugerem os autores apresentados na revisão teórica desta tese, um modelo teórico deve ser adaptado aos objetivos da pesquisa, mas seguindo as fronteiras teóricas. (SULLIVAN, 1994; RAMASWAMY, 1995).

Este estudo multimétodo tem como objeto o estudo das PMEs brasileiras internacionalizadas via exportação e Investimentos Diretos no Exterior (IDE). A escolha das empresas é justificada pela importância do processo de internacionalização no contexto competitivo atual e pelo conhecimento que será gerado para o grupo de pesquisadores do GINEBRA sobre as PMEs brasileiras. A escolha da região de estudo, ou seja, Brasil, deveu-se ao crescente número de PMEs que está passando por processos de internacionalização, e à importância, para o País, no concernente ao incremento do comércio internacional.

\subsection{Procedimentos de Campo - Primeira Fase: Abordagem Qualitativa}

A primeira fase desta pesquisa visa investigar a percepção das PMEs brasileiras em processo de internacionalização sobre o grau de internacionalização, as competências desenvolvidas e o desempenho das empresas.

A internacionalização tem sido estudada nos últimos 20 anos, sendo que para a PME a principal forma de internacionalização ainda é a exportação, mas as mudanças ocorridas no decorrer desses últimos 20 anos aportam à necessidade de identificar outros modos de internacionalização e, assim, verificar a evolução da internacionalização da PME brasileira.

Devido ao reduzido conhecimento sobre a internacionalização das PMEs além da exportação, a primeira fase deste estudo se caracteriza como exploratória no que se refere à estruturação do conhecimento. Nas situações em que o problema de pesquisa ainda é pouco compreendido 
(GHAURI; GRONHAUG, 2005) ou escassamente discutido (SELLTIZ et al., 1976), o desenho exploratório é apropriado.

Quanto ao escopo, a primeira fase da pesquisa emprega o estudo de caso. Esta modalidade analisa um número limitado de eventos ou condições e procura entender como os processos ocorrem e se inter-relacionam. (EMORY, 1980). O estudo de caso é considerado uma estratégia de pesquisa que procura compreender a dinâmica de determinado contexto (EISENHARDT, 1989), podendo envolver um único ou vários casos analisados e diversos níveis de análise. (YIN, 1984; MARSCHAN-PIEKKARI; WELCH, 2004).

Nesta fase foram realizados estudos de casos de PMEs brasileiras que se internacionalizaram de forma mais complexa e via exportação. Foi realizado também um levantamento de dados secundários disponíveis nos institutos de pesquisa, Organismos Governamentais e/ou sites com informações sobre PME brasileira e seus processos de internacionalização. O protocolo de entrevistas (APÊNDICE B) foi elaborado em forma de um check list para que a conversa não fosse totalmente direcionada, mas que não se perdesse nenhum tema importante. No momento das entrevistas utilizaram-se as variáveis do IBC que se mostraram significativas para Knight e Kim (2009), para testá-las com os executivos. Sabe-se que o protocolo de entrevistas não se apresenta de forma estruturada e/ou fechada, mas no caso deste estudo esta fase também serviu como um pré-teste para a etapa quantitativa, na qual procurou-se verificar se as variáveis eram adequadas para elaborar o questionário final do construto competência. De acordo com Malhotra (2001), mesmo que o entrevistador tente seguir um esboço predeterminado, as perguntas e a ordem de sua formulação acabam sendo influenciadas pelas respostas do entrevistado.

A dimensão temporal empregada na primeira fase deste estudo é transversal. Isto significa que a investigação ocorre uma única vez (EMORY, 1980) e as variáveis são medidas simultaneamente. (GHAURI; GRONHAUG, 2005). Dessa forma, não se procura analisar a evolução de parâmetros ao longo do tempo, mas entender o comportamento de determinados parâmetros em um período específico. O modo de comunicação da coleta de dados adotado nesta fase da pesquisa é o interrogativo. Mediante questionamento, formularam-se questões sobre os assuntos desejados e obtiveram-se respostas obtidas por meio de entrevista pessoal. 
No que diz respeito ao poder do pesquisador para alterar ou controlar as variáveis, esta fase do estudo se classifica como ex post facto. Esta modalidade é a mais comum nas pesquisas que abordam ciências sociais e negócios, sendo que o pesquisador não consegue controlar as variáveis porque os fatos já ocorrem ou porque elas realmente não podem ser controladas. (EMORY, 1980).

Portanto, os resultados dessa fase da pesquisa auxiliaram no ajuste das questões de investigação e no planejamento da fase quantitativa. A partir desses resultados, realizou-se uma nova revisão das teorias e foram incorporados novos autores que com vistas a corroborar os resultados apresentados na primeira fase.

Nesta fase da pesquisa adotou-se o critério da conveniência, que economiza recursos financeiros, tempo e esforços, mas pode comprometer as informações e a credibilidade. (MILES; HUBERMAN, 1994). Entretanto, alguns cuidados foram tomados: assegurou-se que a empresa se encontra em processo avançado de internacionalização e buscou-se também uma empresa exportadora de pequeno porte para verificar as diferenças mais significantes; que a empresa possuísse, no máximo, 200 funcionários no país de origem e que a empresa fosse brasileira de origem. Uma das empresas entrevistadas possui, atualmente, mais de 200 funcionários, mas quando iniciou seu processo de internacionalização possuía somente 180 funcionários diretos. O descrito acima está em conformidade com Simon (2003), que sugeriu o uso de tal procedimento quando se tratar de empresas que se internacionalizaram antes de participar de grandes grupos.

A partir desses dados, buscou-se a colaboração de empresas conhecidas pela pesquisadora para efetuar os estudos de casos e, no final, 3 empresas permitiram que a entrevista fosse realizada. Portanto, o critério de escolha da PME entrevistada foi o de acessibilidade, considerada por Malhotra (2001) como amostragem por conveniência, ou seja, uma técnica de amostragem não-probabilística que visa obter uma amostra de elementos convenientes, selecionados pelo entrevistador.

Os dados primários desta primeira fase do estudo foram coletados por meio de entrevistas pessoais, realizadas com os profissionais que possuem conhecimento suficiente sobre o processo de internacionalização da empresa pesquisada. Após revisão bibliográfica e 
identificação dos construtos que compõem este estudo, formularam-se as questões do protocolo.

Este instrumento teve como objetivo, além de melhor estruturação do questionário, conhecer o processo de internacionalização de empresas brasileiras, identificando os atributos e as características que podem diferenciar a amostra deste estudo dos encontrados na revisão teórica. O levantamento de experiência com executivos e das empresas em processos de internacionalização se caracterizam por ser uma forma de coleta de dados que se dá em função dos objetivos da pesquisa e para possibilitar a adquisição de conhecimento sobre o tema, com vistas a identificar as variáveis importantes que influenciam no desempenho da PME. De acordo com Malhotra (2001), a diversidade de experiências possibilita descobrir motivações, atitudes e sensações subjacentes sobre um tópico, ou seja, a se ter uma visão ampla do tema e com diferentes pontos de vista sobre o problema. O autor ainda identifica que a principal utilidade das entrevistas é a pesquisa exploratória, que propicia a análise pessoal e o entendimento, gerando variáveis importantes para o desenvolvimento e continuidade da pesquisa.

Outra questão referente à entrevista em profundidade é o número de executivos a serem entrevistados. De acordo com alguns autores, como Dillon et al. (1994), Rossi e Slongo (1998) e Malhotra (2001), não há um número definido de entrevistas a serem feitas, o que deve orientar esta etapa é a qualidade das informações.

Antes mesmo de realizar as entrevistas no Brasil, realizaram-se três entrevistas (total de 5 horas) durante o período de doutorado sanduíche na França. Durante estas, além de testar as variáveis procurou-se conhecer outra realidade de PME internacionalizada.

Nas entrevistas realizadas na França as variáveis se mostraram adequadas e de fácil compreensão dos respondentes, mas foi necessário fazer alguns ajustes em cada uma das entrevistas para melhorar o instrumento. Os ajustes iniciais tiveram como propósito melhorar o entendimento de desempenho. Quando questionado diretamente sobre o desempenho da empresa após a internacionalização, os executivos somente respondiam melhorou ou piorou. Quando questionado acerca das expectativas futuras, os executivos respondiam "espero que melhore", por exemplo. Assim, adequaram-se as questões de desempenho. Já para as questões de competência, os executivos consideraram-nas bastante cansativas, pois havia muitas 
perguntas repetitivas. As entrevistas na França não serão aqui apresentadas, visto que o objetivo principal de sua aplicação foi verificar a aplicabilidade deste estudo e dos construtos.

No Brasil, as 3 entrevistas totalizaram cerca de 3 horas e esta fase foi muito importante para conhecer a realidade da PME brasileira internacionalizada e também testar as possíveis variáveis que formariam o modelo desta tese, ou seja, as variáveis observáveis que formaram os construtos de GRI, competência e de desempenho.

Tem-se consciência que para se ter uma visão mais ampla do cenário da internacionalização das PMEs brasileiras os executivos de muitas outras empresas deveriam ter sido entrevistados, mas o ponto de corte foi o tempo disponível para partir para a etapa quantitativa, que demandaria um período também considerável e a disponibilidade dos respondentes. Uma empresa de chocolates de Minas Gerais, que se internacionalizou por franquia e lojas próprias, foi contatada, mas a entrevista dependeria da vinda do diretor a São Paulo, como combinado com a doutoranda, mas até o momento isso ainda não ocorreu.

A preparação para a entrevista envolve a observação de alguns pontos, dentre os quais podem ser destacados: a análise do problema de pesquisa, a ciência de quais informações precisam ser obtidas do entrevistado e a identificação de quem poderá fornecer as informações desejadas (GHAURI; GRONHAUG, 2005), além das informações secundárias sobre a empresa, a fim de diminuir o tempo de entrevista e melhor utilizar o tempo para perguntas mais objetivas e que não estão disponíveis em fontes secundárias.

Considerando os aspectos acima abordados, a autora desta tese procedeu da seguinte maneira: a) explicou ao respondente tanto os objetivos da pesquisa e os potenciais benefícios que cada parte poderá auferir a partir dos resultados finais do estudo, com destaque para as possíveis contribuições acadêmicas e práticas, como os conceitos que englobam esta tese. b) Utilizou-se um roteiro semiestruturado, conforme apresentado no Apêndice B desta tese, para conduzir e assegurar a obtenção das informações essenciais ao estudo do caso; c) registrou-se o conteúdo da entrevista por meio de gravação, com concordância do entrevistado, para otimizar a discussão dos temas e assegurar que todas as informações relevantes fossem assimiladas; d) as entrevistas foram conduzidas com uma pessoa em cada empresa, sendo dois diretores gerais (sócios) e um diretor de mercado externo. 
Os dados que auxiliaram a elaboração do questionário serão apresentados nos resultados qualitativos do capítulo 5 e também as informações dos mesmos executivos que auxiliaram no pré-teste do questionário.

\subsection{Procedimentos de Campo - Segunda Fase: Abordagem Quantitativa}

O estudo quantitativo se caracteriza pela natureza numérica dos seus resultados e requer planejamento na elaboração das escalas de resposta do instrumento de coleta de dados. (VELDE et al., 2004). A segunda fase tem o mesmo foco da primeira, ou seja, verificar se o grau de internacionalização desenvolve mais competências organizacionais e melhora o desempenho da PME. Esta fase do estudo também se configura pela dimensão temporal transversal, ou seja, o levantamento de dados ocorre em um único momento, representando um determinado período. (EMORY, 1980).

\subsubsection{Definição da população e da amostra}

A população consiste no conjunto total de elementos sobre os quais se deseja fazer inferências. (COOPER; SCHINDLER, 2003). O foco inicial desta pesquisa era investigar somente as empresas que possuíam IED no exterior. Mas, após contatos com vários órgãos como a Agência Brasileira de Promoção de Exportações e Investimento (APEX), o Centro de Estudos do Comércio Exterior (FUNCEX), a Secretaria de Comércio Exterior do Brasil (SECEX) e o Banco Central do Brasil (BACEN), verificou-se que não seria possível manter esse foco. Pelo Decreto-lei n. 5.844, do Banco Central do Brasil, os dados sobre as empresas que possuem IED, bem como das pessoas físicas com investimento no exterior são sigilosos. Portanto, não existe qualquer tipo de lista oficial das empresas com IDE no exterior, sendo necessário constituir um banco de dados a partir de outras fontes. Esse fato também ocorre em outros países, como comentam Fujita (1995) e Hollestein (2005), e a solução encontrada por outros pesquisadores que realizaram estudos com esse mesmo foco foi o banco de dados de empresas exportadoras, mesmo sabendo que o fato da empresa ter IDE no exterior não necessariamente a classifica como exportadora. 
Assim, para formar a população deste estudo consideraram-se os seguintes critérios:

- Mínimo de 5 funcionários, para garantir a mínima gestão organizacional, e máximo de 200 funcionários (sem considerar previamente o número de funcionários no exterior). $\mathrm{O}$ número de funcionários foi definido como um dos critérios, pois é a forma mais comum e mais fácil de identificar uma empresa de pequeno e médio porte. Já o número máximo de funcionários seu deu pela disponibilidade da base de dados. As PMEs brasileiras são classificadas pelo MDIC (200 funcionários) e de modo diferente pelo SEBRAE (499 funcionários) e a relação das empresas exportadoras por porte só foi conseguida pelos dados do MDIC via FUNCEX, como será a seguir explicado.

- Exportaram ininterruptamente durante os 3 últimos anos (exportadores experientes, não oportunistas, conforme Madsen, 1989). Buscou-se, mediante este critério, dispor de empresas mais experientes e com a exportação fazendo parte da sua estratégia de vendas.

- Não foram consideradas nesta pesquisa as empresas prestadoras de serviço de comércio exterior, como Trading Companies e Comerciais Exportadoras, isto é, empresas que somente exportavam comodities e empresas sem fins lucrativos. Por outro lado, foram consideradas as empresas construtoras e de TI, pois estas produzem algum bem e possuem um mínimo de estrutura organizacional e produtiva.

- Foram selecionadas empresas cujo capital fosse, no mínimo, misto, ou seja, com participação no capital da empresa brasileira. Esse quesito foi levado em conta para evitar a influência total de grupos estrangeiros no controle das empresas, influenciando com isso, ou até mesmo facilitando, o processo de internacionalização, e também pelo fato de esse estudo focalizar-se em empresas brasileiras, com vistas a buscar um conhecimento do perfil dessas empresas nesse mercado específico.

- Respondente preferencialmente Diretor Executivo (dono), Diretor de Exportação ou de mercado externo, Diretor de Marketing, Diretor de Recursos Humanos. O nome do contato pretendido não estava disponível na base de dados recebida. Para poder direcionar o questionário à pessoa responsável pela gestão da internacionalização da empresa utilizou-se o serviço do Call Center para identificá-lo pelo nome, telefone e email; em muitos casos, o Call Center conversava com a própria pessoa de interesse. 
Nesta pesquisa, quando abordado o tema das Pequenas e Médias Empresas (PMEs), utilizouse, para o Brasil, a classificação pelo número de empregados. Segundo o SEBRAE (2007), a estratificação das empresas segundo tamanho combina dois critérios que são geralmente utilizados em estudos empresariais, que são o número de empregados e o valor de faturamento. Optar pela classificação do número de empregados é mais adequado em estudos empresariais no Brasil, pois a informação anual do Ministério do Trabalho e Emprego é a única estatística disponível para todo o universo de pessoas jurídicas ativas no País (Relação Anual de Informações Sociais - RAIS). Em relação ao valor de faturamento, a informação, na maioria dos casos, fica sujeita a restrições de sigilo comercial ou estatístico.

No Brasil, existem duas entidades que classificam as empresas, o SEBRAE e o MDIC. De acordo com o SEBRAE, as PMEs são empresas de até 499 empregados, conforme Tabela 8.

\begin{tabular}{ll}
\multicolumn{1}{c}{ Tabela 8 - Critério para a classificação das empresas no Brasil pelo SEBRAE } \\
\hline \multicolumn{1}{c}{ Tipo de Empresa } & Pessoas Ocupadas \\
\hline Microempresa & até 20 \\
Pequena Empresa & De 20 a 99 \\
Média Empresa & De 100 a 499 \\
\hline
\end{tabular}
Fonte: SEBRAE (2008)

Já para o MDIC, as PMEs são empresas com até 200 empregados, conforme demonstra a Tabela 9.

Tabela 9 - Critério para a classificação das empresas no Brasil pelo MDIC

\begin{tabular}{l|l|l|l|l}
\hline \multirow{2}{*}{ Porte } & \multicolumn{2}{c|}{ Indústria } & \multicolumn{2}{c}{ Comércio e Serviços } \\
\cline { 2 - 5 } & $\mathbf{N}^{\circ}$ Empregados & \multicolumn{1}{c}{ Valor Exportado } & $\mathbf{N}^{\circ}$ Empregados & \multicolumn{1}{c}{ Valor Exportado } \\
\hline Microempresa & Até 10 & Até US\$ 400 mil & Até 5 & Até US\$ 200 mil \\
Pequena Empresa & Entre 11 e 40 & Até US\$ 3,5 milhões & Entre 6 e 30 & Até US\$ 1,5 milhão \\
Média Empresa & Entre 41 e 200 & Até US\$ 20 milhões & Entre 31 e 80 & Até US\$ 7 milhões \\
Grande Empresa & $>200$ & $>$ US\$ 20 Milhões & $>80$ & $>$ US\$ 7 Milhões \\
\hline
\end{tabular}

Fonte: MDIC (2010)

Inicialmente tentou-se o apoio do SEBRAE para a aplicação da presente pesquisa. Muitos contatos foram efetuados sem sucesso. Da Fundação Centro de Estudos do Comércio Exterior (FUNCEX), uma entidade privada criada com a finalidade de desenvolver o comércio exterior brasileiro, recebeu-se o banco de dados que tem origem nos dados da Secretaria de Comércio Exterior. 
Verificou-se, por meio de estudos internacionais, que em outros países não há, da mesma forma que no Brasil, um único critério para definir PME. Por questão de disponibilidade de banco de dados, utilizou-se o critério do MDIC para esta tese. Assim sendo, consideraram-se as empresas que atendiam aos quesitos já apresentados e que se encontravam na base de dados da SECEX, disponibilizada para a autora em maio de 2009, que totalizavam 6.750 empresas.

Após o recebimento do banco de dados da FUNCEX, verificou-se que muitas das empresas que constavam no documento eram empresas estrangeiras e brasileiras de grande porte ou pertenciam a grandes grupos. A identificação das empresas não-elegíveis para a pesquisa foi realizada inicialmente em pesquisa do código da Classificação Nacional das Atividades Econômicas (CNAE) do Instituto Brasileiro de Geografia e Estatística (IBGE, 2009) e também pelo site das próprias empresas e pelo site do MDIC, Catálogo de Exportadores Brasileiros da Confederação Nacional das Indústrias - CNI, disponível em www.brazil4export.com. Este último site foi inclusive sugerido pela SECEX, para a melhor identificação das empresas da listagem, visto que o órgão não filtrava as informações no contexto que a pesquisa necessitava. Os filtros que a FUNCEX realizou foram: a) Número de empregados, e b) exportaram nos últimos 3 anos (2008, 2007, 2006). Pesquisaram-se também, na internet e na base de dados do CNI, as empresas cuja origem não se tinha certeza, e após constatação, principalmente da origem da empresa, retirava-a da lista. Por fim, questões específicas do questionário ajudaram a identificar as empresas não-elegíveis dentre as respondentes. Procedeu-se da mesma forma com todas as empresas citadas e pesquisadas que não faziam parte do foco da presente pesquisa, tais como: Trading companies; empresas de serviço; galerias de arte, igrejas, centros espíritas, ONGs, obras missionárias, entre outras. O intuito foi poder identificar um grupo de empresas de forma mais homogênea, conforme sugerido por Madsen (1996). O contrário, ou seja, a não seleção do grupo de respondentes poderia aumentar o viés desta pesquisa, considerando que empresas de serviços focam principalmente oportunidades e possuem estratégias diferenciadas de exportação. Essa constatação vem de experiência prévia da doutoranda em consultorias realizadas em trading companies. Já as empresas produtoras de comodities aportam características específicas quanto à exportação, visto que estas são mais influenciadas por fatores incontroláveis como o clima, a região de produção e/ou vantagens comparativas do país. A internacionalização de forma mais complexa, nestes casos, também é mais difícil por um aspecto logístico, ou seja, 
abrir uma empresa na China somente para receber o navio de soja. Nesse setor, o usual é que a empresa brasileira tenha representantes no exterior. É mais comum a empresa abrir escritórios próprios no exterior à medida que a empresa deixa de ser produtora de comodities e passa a industrializar mais o produto.

As MNCs ou grandes grupos representaram cerca de $36 \%$ das empresas extraídas e as tradings companies e prestadoras de serviços de comércio exterior ou galerias de arte, por exemplo, representaram cerca de 32\% das empresas retiradas. Por fim, mais 660 empresas foram consideradas não-elegíveis por serem entidades sem fins lucrativos, como igrejas, seitas religiosas, empresas em nome de pessoas físicas que não foram identificadas e, foram ainda retiradas 149 empresas com menos de 5 funcionários. Esta fase exigiu da doutorando uma grande dedicação, tendo em vista que foi analisada empresa por empresa e extraídas da base de dados somente aquelas que se identificavam, em seus sites, que não faziam parte do foco da pesquisa. Essa fase foi realizada com auxílio de dois acadêmicos do curso de comércio exterior e que trabalham em empresa júnior. As empresas que continuavam gerando dúvidas sobre as suas atividades foram mantidas no banco de dados. Ao final dessa análise, restaram 2.138 empresas para serem pesquisadas.

Em seguida, contratou-se um Call Center para entrar em contato com as 2.138 empresas que restaram. Inicialmente, o objetivo da tese era pesquisar somente as PMEs com operação no exterior, mas no decorrer da pesquisa muitas dificuldades foram encontradas que indicavam que seria muito difícil operacionalizá-la, como, por exemplo:a fase de pesquisa na França já apresentou um número muito restrito das empresas pesquisadas; as pesquisas internacionais que abordam o mesmo tema (HOLLENSTEIN, 2005; KALANTARIDIS, 2004; FUJITA, 1995; RASHEED, 2005; IBEH, 2004, entre outros) também indicavam problemas com os dados; a legislação que protege o sigilo dos dados das empresas que possuem investimentos no exterior pelo BACEN; e durante a pesquisa das não-elegíveis também se confirmou que não havia muitas PMEs em fase de internacionalização mais complexa, o que tornaria muito difícil obter um número de respondentes que pudesse se adequar à técnica estatística identificada (equações estruturais), conforme sugerido por Hair Jr. et al. (2009), a ser mais adiante explicada. Com isso, decidiu-se que além das PMEs com operação no exterior, a pesquisa também englobaria as empresas exportadoras que atendessem aos critérios já mencionados acima. 
Mesmo diante de vários indícios de que seria difícil focar a pesquisa na PME em fase de internacionalização mais complexa, e tendo expandido a amostra da pesquisa, decidiu-se contratar um Call Center para tentar identificar o modo de internacionalização das PMEs pesquisadas e também verificar a pessoa específica para encaminhar o questionário final da presente pesquisa. O Call Center aproveitava a ligação para informar que a empresa receberia o questionário, apresentava a pesquisa e solicitava colaboração ao respondente. Muitas vezes o atendente era direcionado a falar com a pessoa responsável pelo departamento de comércio exterior ou com algum diretor ou gerente. A doutoranda preparou um esboço para os atendentes apresentarem, e realizou também um pré-teste com os atendentes.

Para operacionalizar a contratação do Call Center, a doutoranda pesquisou em diversas fontes: contatou um grande banco nacional que utiliza muito esse serviço e o terceiriza, via internet, e por indicação de conhecidos. Os dois serviços de Call Center utilizados pelo banco contatado fizeram a cotação, mas o preço cobrado inviabilizaria qualquer pesquisa acadêmica. Depois de muitos contatos e muita negociação definiu-se o serviço a ser contratado. Este serviço é cobrado pelo tempo de execução, pelo número de atendentes, pela quantidade de ligações e, ainda, pelo tempo de duração médio das chamadas.

Das 2.138 empresas contatadas pelo Call Center, 53 empresas não exportavam mais em 2009, 380 empresas não atenderam à ligação (o Call Center justificou esse número de empresas inacessíveis, pois o Centro de Proteção ao Consumidor (PROCON) autoriza às pessoas físicas e jurídicas o bloqueio de ligações via Call Center, ou trocas de telefone, ou até mesmo o fechamento das empresas).

Após explicar a pesquisa, 15 empresas informaram não serem pequenas ou médias empresas, sendo caracterizadas como grandes empresas ou MNCs. Por fim, 25 empresas não aceitaram participar da pesquisa.

O Call Center, na metade das ligações efetuadas, entrou em contato com a doutoranda para verificar se a pesquisa estava adequada às expectativas, porquanto foi observado que das 1.000 primeiras empresas contatadas somente 15 possuíam alguma operação no exterior. Algumas gravações das ligações foram ouvidas pela doutoranda para identificar a existência de possíveis erros de comunicação. Como nenhum problema foi detectado, chegou-se à 
conclusão que as exportações ainda continuam sendo a forma mais praticada de internacionalização pelas PMEs brasileiras. Ao final das ligações, cuja duração foi de 28 dias, o Call Center verificou que das 1.665 empresas contatadas, e consideradas válidas para o presente estudo, apenas $6 \%$ possuíam operações mais complexas no exterior (99 empresas) e que as demais (94\%) somente exportavam.

Após a entrega dos resultados do Call Center, 1.665 questionários foram encaminhados às empresas a serem pesquisadas. Os e-mails foram enviados ao endereço eletrônico que os atendentes do Call Center solicitaram, sendo tais endereços, na sua maioria, dos responsáveis pelo departamento de comércio exterior ou pelo departamento comercial.

O envio do questionário obedeceu duas etapas: na primeira, no dia 05 de novembro, 230 questionários foram encaminhados via e-mail, e o respondente poderia acessá-lo pelo link do sistema de pesquisa survey monkey, adiante explicado. Desses, 18 e-mails retornaram por endereço inexistente ou caixa postal cheia. Nesta primeira etapa, 20 questionários foram recebidos sem detecção de qualquer problema com as respostas. Após 10 dias do envio da primeira etapa, os demais e-mails foram enviados (1.435). Na segunda etapa, que teve início no dia 15 de novembro, mais 52 e-mails retornaram pelos mesmos motivos antes mencionados. No dia 12 de dezembro mais 58 questionários haviam sido respondidos e encaminhados ao sistema.

Para estimular a devolução do questionário, constou da apresentação deste que se o respondente devolvesse o questionário estaria concorrendo ao sorteio, a ser realizado no dia 21 de dezembro, de um I-pod da marca Apple.

No dia 08 de dezembro foram enviados, para as mesmas 1.595 empresas iniciais, um novo email, contendo agora não somente o link da pesquisa, mas também o questionário, em Word, anexado. Esse procedimento foi necessário porque na segunda etapa de encaminhamento dos questionários duas empresas responderam ao e-mail informando que não conseguiam acessar o link, e mais uma empresa comunicou que não costuma acessar links desconhecidos e que, portanto, para responder ao questionário seria necessário encaminhá-lo anexado ao e-mail ou por fax. Com esse procedimento, mais 10 questionários foram devolvidos por e-mail. 
Como no dia 15 de dezembro verificou-se que somente 83 empresas haviam respondido ao questionário, decidiu-se então, por meio dos contatos apresentados pelo Call Center, telefonar para as empresas. Buscou-se, inicialmente, contatar as PMEs com operações mais complexas no exterior e em seguida as empresas exportadoras. Até o dia 20 de dezembro, das pessoas contatadas 50 se comprometeram a responder à pesquisa. Muitos alegaram desconhecer o recebimento do e-mail e outros usaram como pretexto a falta de tempo. Após o contato com cada pessoa, novo e-mail era encaminhado. Desse modo, o resultado foi mais efetivo.

Notou-se, após o uso desses procedimentos, que muitas pessoas são um pouco avessas às opções via internet e também que muitas empresas bloqueiam sites diferentes ao acesso interno, bem como ligações de Call Center. Acredita-se que tais comportamentos tomados pelas empresas têm o propósito de evitar acessos indesejados, tirando o foco do trabalho, e também de controlar o acesso aos dados internos da empresa por pessoas não autorizadas.

No dia 22 de dezembro, 120 respostas haviam sido conseguidas. Ao analisar as respostas confirmatórias acerca do perfil das empresas respondentes, constatou-se que duas empresas possuíam uma receita total acima de 250 milhões, apesar de não ter sido considerado o faturamento como ponto de corte do tamanho da PME, esse valor, portanto, poderia enviesar os resultados; uma empresa tinha mais de 200 funcionários diretos no Brasil e duas eram de capital estrangeiro. Em vista disso, o questionário dessas 5 empresas foi descartado. Um outro questionário foi também descartado por conter apenas uma questão respondida.

O I-pod foi sorteado e o ganhador comunicado por e-mail. Este agradeceu e informou que o Ipod seria sorteado mais uma vez entre os funcionários da empresa (Empresa de Produtos Químicos, Curitiba - PR).

Dos questionários recebidos e validados, 44 empresas possuíam operações mais complexas no exterior e 70 exportavam diretamente. Como o natal se aproximava, e também as férias coletivas, a pesquisa foi concluída.

Para a pesquisa em tela tem-se uma taxa efetiva de respostas de 7,17\%, assim calculada: 114/ $(1.665-18-52-6)=7,17 \%$. 
Convém repetir que o Call Center constatou que das 1.665 empresas listadas, 6\% possuíam operação no exterior (99 empresas) e que as demais (94\%) somente exportavam. Com base nestes dados, conclui-se que o percentual das empresas respondentes com operação no exterior corresponde a $44,4 \%$.

\subsubsection{Coleta de dados}

A fase quantitativa apresenta um formato diferenciado da etapa qualitativa em termos de coleta dos dados. Nesta fase, coletaram-se os dados por meio de uma survey, via questionário encaminhado aos respondentes.

O questionário é um instrumento de coleta de dados estruturado e que necessita ter validade, confiabilidade e eficiência, por meio de perguntas claras que viabilizem a mensuração daquilo que o pesquisador deseja medir. (VELDE et al., 2004; MALHOTRA, 2001). Após o levantamento bibliográfico e análise dos principais trabalhos sobre a internacionalização das empresas ou especificamente da PME, a etapa qualitativa serviu para auxiliar a doutoranda na compreensão dos fatos da PME brasileira, visto que a maioria dos trabalhos existentes foi desenvolvido em países Norte-Americanos ou Europeus, e também para testar as variáveis que se pretendia aplicar no questionário, visto que as variáveis do construto competência surgiram de um questionário já aplicado e que estava em inglês. Segundo Malhotra (2001, p. 282), o questionário estruturado é composto por “[...] perguntas que preespecificam o conjunto de respostas alternativas e o formato da resposta."

O questionário foi inicialmente elaborado no papel, testado e em seguida transformado em um questionário on line. A decisão de disponibilizar o questionário on line surgiu da leitura de outras teses (DIB, 2008) e da experiência prévia da doutoranda com pesquisas on line. Em outras pesquisas realizadas, verificou-se que o acesso ao questionário é mais fácil, que não há necessidade de gravar o arquivo nem cuidar do preenchimento para evitar a desconfiguração, além de ser um modo mais rápido de se obter resposta, como pôde ser verificado durante a fase do pré-teste, adiante explicado. Outro motivo que definiu a aplicação do questionário on line foi o tempo hábil para realizar a pesquisa. Questionários on line são mais práticos e mais rápidos de serem encaminhados e de receber a resposta se comparado ao questionário enviado em papel, pelo correio. 
Foi então elaborado um e-mail com uma carta apresentando a pesquisa, bem como a orientadora e a doutoranda, para que o respondente pudesse sanar eventuais dúvidas (Apêndice C), juntamente com o link de acesso ao questionário. Mediante o clique nesse link, o respondente acessava diretamente a primeira página de apresentação do questionário, e à medida que finalizava cada página de resposta clicava em prosseguir, passando, assim, para outra página do questionário. Ao final do preenchimento, clicava em finalizar e o sistema se encarregava de enviar diretamente ao banco de dados da pesquisa. $\mathrm{Na}$ carta de apresentação havia também a menção da garantia de anonimato e também que o respondente receberia cópia dos resultados, além da participação do sorteio do I-pod para aqueles que deixassem o seu e-mail. Do total, $62 \%$ dos respondentes indicaram o seu e-mail para participar do sorteio.

O questionário foi composto por quatro principais abordagens: um diagnóstico da empresa, o grau de internacionalização, as competências e questões sobre o desempenho. Inicialmente, as questões foram divididas em blocos conforme os construtos, e para evitar o direcionamento das respostas, misturaram-se as questões organizando-as pelas escalas semelhantes, como sugerido por Rossiter (2000) e como identificado durante um dos pré-testes.

Optou-se, na grande parte das perguntas, por escalas tipo Likert de intensidade de concordância de 5 pontos. Outras questões eram do tipo de razão/de relação (como o número de empregados ou receita).

\subsubsection{Pré-teste}

Antes da aplicação definitiva do questionário, realizou-se o pré-teste. Durante as entrevistas, além de buscar as informações necessárias para compor os estudos de caso, procurou-se investigar o grau de compreensão do respondente a cada questão e identificar possíveis falhas ou repetição, sendo esta fase considerada já parte do pré-teste para a escolha das variáveis encontradas na literatura. Nesta fase, algumas dificuldades de compreensão e repetições foram identificadas, sendo a ordem das perguntas alteradas para melhorar a sequência da entrevista e para um melhor fluxo de informações.

De acordo com Malhotra (2001, p. 290), “[...] o pré-teste se refere ao teste do questionário em uma pequena amostra de entrevistados, com o objetivo de identificar e eliminar problemas 
potenciais." Diversas modalidades de pré-teste são possíveis. Uma delas consiste em realizar o pré-teste com pessoas que possuem características semelhantes àquelas que responderão o questionário definitivo. (COOPER; SCHINDLER, 2003). Outra modalidade de pré-teste envolve a aplicação do questionário para um número maior de participantes, com a finalidade de verificar se os resultados se comportam conforme o esperado em termos de média, variância e relações entre os itens, para assegurar a consistência do instrumento. (SCHWAB, 2005). Uma terceira modalidade refere-se ao pré-teste do pesquisador, situação em que colegas professores e pesquisadores realizam um teste informal do instrumento. (COOPER; SCHINDLER, 2003).

Após a definição do questionário, efetuou-se uma primeira fase de pré-teste com o questionário em papel, como proposto por Cooper e Schindler (2003). O questionário foi enviado inicialmente a um diretor de uma grande empresa brasileira com vasta experiência no mercado internacional, que dedicou uma hora do seu tempo para discuti-lo. Esse diretor fez muitas considerações sobre os termos técnicos e ou acadêmicos que estavam sendo utilizados no questionário e que poderia criar dificuldade para os respondentes, ou o respondente, por desconhecimento, responderia qualquer coisa ou não responderia. Os termos foram então reformulados e, logo após, o questionário foi enviado para três doutorandos, com temas de pesquisa sobre a internacionalização, e para mais três professores com vasto conhecimento em pesquisa quantitativa sobre o tema de internacionalização e desempenho. Após a primeira avaliação, o questionário foi enviado para três PMEs entrevistadas na etapa qualitativa. Os executivos dessas empresas responderam ao questionário e mencionaram não ter encontrado qualquer dificuldade para respondê-lo. Em seguida, o questionário foi transformado em formato on line, no sistema survey monkey, que foi contratado para disponibilizá-lo,, sendo os dados então coletados por um período de seis meses. Logo após a estruturação do questionário on line, um novo pré-teste foi realizado novamente com o executivo de grande empresa, que concordou com a facilidade e com a agilidade do meio de coleta de dados, com os doutorandos, que sugeriram algumas modificações de formato, e com os executivos das PMEs entrevistadas, que responderam sem qualquer problema ao questionário on line.

Durante o pré-teste foram feitas revisões de redação de algumas perguntas para deixar o objetivo mais claro. Foi constatado que poderia haver confusão entre a informação local e a internacional. Por esse motivo, foi mencionado, nas questões referentes ao mercado internacional, o termo adequado, como, por exemplo, em marketing $=$ marketing 
internacional. Termos específicos foram complementados com explicações, tais como: orientação interfuncional significa que as áreas de Marketing, vendas, manufatura, finanças, etc, são integradas. Os respondentes levavam cerca de 20 minutos para responder ao questionário em papel e 15 minutos para a forma on line. A versão final do questionário é apresentada no Apêndice A.

\subsection{Tratamento e Análise dos Dados}

Os dados coletados via questionário foram organizados, codificados e processados com o auxílio do software estatístico SPSSTM (Statistical Package for the Social Sciences) e o $\operatorname{AMOS}^{\mathrm{TM}}$ versão 4.0. Inicialmente, foi efetuada a estatística exploratória para cada construto, com a finalidade de melhor compreender os dados, sendo observado o tipo de distribuição das variáveis, a relação de linearidade entre elas e as medidas aleatórias de erros. (VELDE et al., 2004).

Para modelar e testar as hipóteses utilizou-se como técnica principal a modelagem de equações estruturais (Ver Glossário). O modelo de equações estruturais fornece sistemas simultâneos de equações, permitindo testes em modelos complexos considerando as medidas de erros. É um método estatístico desenvolvido a partir da análise das estruturas de covariância, e combina técnicas de regressões múltiplas, e análise fatorial com um conjunto simultâneo de regressões estruturais lineares entre os fatores - representadas pelo modelo de fatores. O objetivo da utilização da técnica de equações estruturais foi identificar a relação causal simultânea dos construtos GRI, competência e desempenho estudados nesta tese.

\subsection{Uma Introdução à Técnica Estatística utilizada nesta Tese}

Neste item será apresentada uma introdução sobre a técnica estatística utilizada nesta tese. As equações estruturais, não obstante seu emprego em diversos trabalhos, ainda são de uso bastante restrito se comparado a outras técnicas como a regressão, por exemplo. As equações estruturais são utilizadas nesta tese com o objetivo de identificar as relações entre as variáveis e os construtos, bem como a relação entre os construtos. 


\subsubsection{Equações estruturais}

Como afirmado acima, o teste estatístico que será realizado nesta tese será a técnica de Modelagem por Equações Estruturais (SEM - Structural Equation Modeling).

Hair Jr. et al. (2009) afirmam que um dos principais objetivos desta técnica é expandir a habilidade explanatória do pesquisador e a eficiência estatística. Enquanto outras técnicas, como a regressão múltipla e análise fatorial, examinam uma só relação por vez entre as variáveis dependentes e independentes, as equações estruturais, mediante um conjunto de técnicas de regressão múltipla e da análise fatorial, permitem a estimação de relações simultâneas entre múltiplas variáveis independentes e múltiplas variáveis dependentes. (SCHUMACKER; LOMAX, 1996). Essa técnica permite investigar o quanto as variáveis independentes ou exógenas explicam a variável dependente (endógenas). (MARUYAMA, 1998).

Variável dependente são aquelas que medem o efeito presumido, ou resposta, a uma mudança nas variáveis independentes, que por sua vez são a causa presumida de qualquer mudança na variável dependente e que são manipuladas pelo pesquisador e cujos efeitos são medidos e comparados. (MALHOTRA, 2001; HAIR et al., 2009).

Acredita-se, por exemplo, neste trabalho, que o maior GRI desenvolve mais competências, e com mais competência haverá uma melhora no desempenho da empresa, por conseguinte, competência é uma variável dependente e independente no mesmo modelo. Essa análise direta, a SEM permite avaliar. Com isso, a SEM identifica a estrutura de inter-relações expressas em uma série de equações, descrevendo todas as relações entre os construtos envolvidos na análise. Os construtos desta tese são o GRI, a competência e o desempenho, que são considerados fatores latentes, ou seja, não são observados diretamente e, sim, são formados por uma série de diversos indicadores.

Como visto no levantamento bibliográfico já apresentado, os construtos desta tese são considerados complexos e multifacetados, não devendo, por esse motivo, ser analisados diretamente, não sendo possível informar a sua medida precisa. Esses construtos são então considerados como variáveis latentes, que, de acordo com Hair Jr. et al. (2009), podem ser medidos por uma ou mais variáveis, e que em combinação com as respostas dadas às várias questões fornecem uma medida razoavelmente precisa do construto. 
A análise fatorial é caracterizada pela mensuração dos construtos (GRI, Competência e Desempenho) por intermédio de variáveis observáveis, que também são denominadas de indicadores refletidos, ou seja, o indicador reflete o comportamento do construto. Com isso é presumida uma relação causal entre a variável latente e os indicadores refletidos.

Os principais resultados que podem ser esperados por meio desta técnica estatística são:

a) Uma estimativa da dimensão dos efeitos entre as variáveis, tanto no concernente ao impacto de uma variável sobre a outra como em relação à influência direta de uma variável posicionada entre duas outras (interveniente ou mediadora), como é o caso do construto competência nesta tese. (MARUYAMA, 1998).

b) A possibilidade de testar se o modelo é consistente com os dados observados, ou seja, se o modelo e os dados são consistentes, pode-se dizer que este é plausível, mas não se pode afirmar que é correto. (KLEM, 1995).

Nas Ciências Sociais, a utilização desta técnica é relativamente nova, pois não se pode assumir que há perfeita confiabilidade do modelo. Mas, de acordo com Maruyama (1998), para resolver esse problema faz-se uso de variáveis latentes e/ou de erros no modelo teórico. Com isso, pode-se explicar a quantidade de variância não explicada pelas variáveis exógenas especificadas.

A especificação do erro de mensuração nas equações estruturais nas variáveis endógenas e exógenas permite a geração de parâmetros com estimativas mais aprimoradas. A partir daí, pode-se perceber os benefícios da utilização desta técnica, que, como apontado por Hair Jr. et al. (2009), são:

Melhoramento da estimação estatística: realizada por meio da confiabilidade, que é um indicador da extensão em que todos os indicadores de um construto latente medem a mesma coisa, significando que é internamente consistente com base em quão altamente relacionados são os indicadores,apesar de uma alta confiabilidade não expressar necessariamente a precisão da medição do construto. Por esse motivo envolve também uma avaliação de validade. 
- $\quad$ Especificação de erros de mensuração: como já apresentado, nas Ciências Sociais não se pode medir com perfeição um conceito, por isso considera-se que sempre haverá algum grau de erro de mensuração. Nesta pesquisa esse fato é relevante, visto que os executivos respondentes passarão suas percepções a respeito dos construtos, e que por falta de tempo ou acesso, apenas um executivo por empresa será questionado, podendo assim gerar exageros ou reduções nas variáveis medidas, principalmente quando se aborda o construto desempenho. Considera-se, pois, que as respostas possuem algum erro de mensuração. Com isso a SEM pode avaliar a contribuição de cada item na representação de seu construto associado, medir sua confiabilidade, incorporando-a à estimação entre os construtos.

- Representação de conceitos teóricos: os erros não acontecem somente por respostas imprecisas, mas também por se estar utilizando conceitos teóricos complexos e multifacetados. Procuram-se, na teoria e na prática, as melhores questões para formar esse construto, tendo em mente que os respondentes poderão divergir nas opiniões de questões idênticas, mas considerando que um conjunto de respostas é que representará esse conceito e não uma única variável. Assim, conhecendo o problema, incorpora-se a confiabilidade à estimação estatística para melhorar o modelo de dependência.

Para o autor (HAIR JR. et al., 2009), o erro mais crítico no desenvolvimento de modelos a partir de base teórica é a omissão de uma ou mais variáveis independentes. Esse erro é conhecido como erro de especificação do modelo. Para o autor, todos os modelos de equações estruturais contêm, de alguma forma, esse erro, ou pela exclusão de alguma variável ou de algum construto importante. A técnica SEM leva em consideração esses erros na identificação das estimativas das relações entre os construtos. Para Hair Jr. et al. (2009), a SEM é um método de análise confirmatória, guiado mais pela teoria do que por resultados empíricos, para testar hipótese. Contudo, o atendimento da hipótese não significa que o modelo retrata corretamente a realidade, mas sim que o modelo testado não foi refutado e pode ser submetido a outros testes para sua validação.

\subsubsection{O modelo de mensuração inicial}

Neste modelo (Figura 2) estão incluídas todas as variáveis identificadas na teoria e nos estudos de caso para compor cada construto. Estão incluídas oito variáveis latentes, das quais cinco variáveis, no modelo estrutural 1a, são exógenas (GRI) e três variáveis são endógenas 
(competência, desempenho financeiro e desempenho operacional). O construto competência é também uma variável exógena, mas como em uma parte do modelo ela se caracteriza como variável endógena, como regra, ela será considerada endógena. (KLEIN, 1995).

No total foram inicialmente selecionadas 26 variáveis observáveis. A média dos indicadores deste modelo é de 3,23 indicadores por construto, não havendo construto com menos de 3 indicadores, com o máximo sendo de 6 indicadores. Hair Jr. et al., (2009) sugerem o uso de mais de três indicadores por construto como adequado para a identificação estatística. Já para Rigdon (1998), um modelo não deve conter mais de 20 variáveis, pois um número grande de medidores dificulta a obtenção de bons ajustes. O modelo inicial desta pesquisa é apresentado na Figura 3.

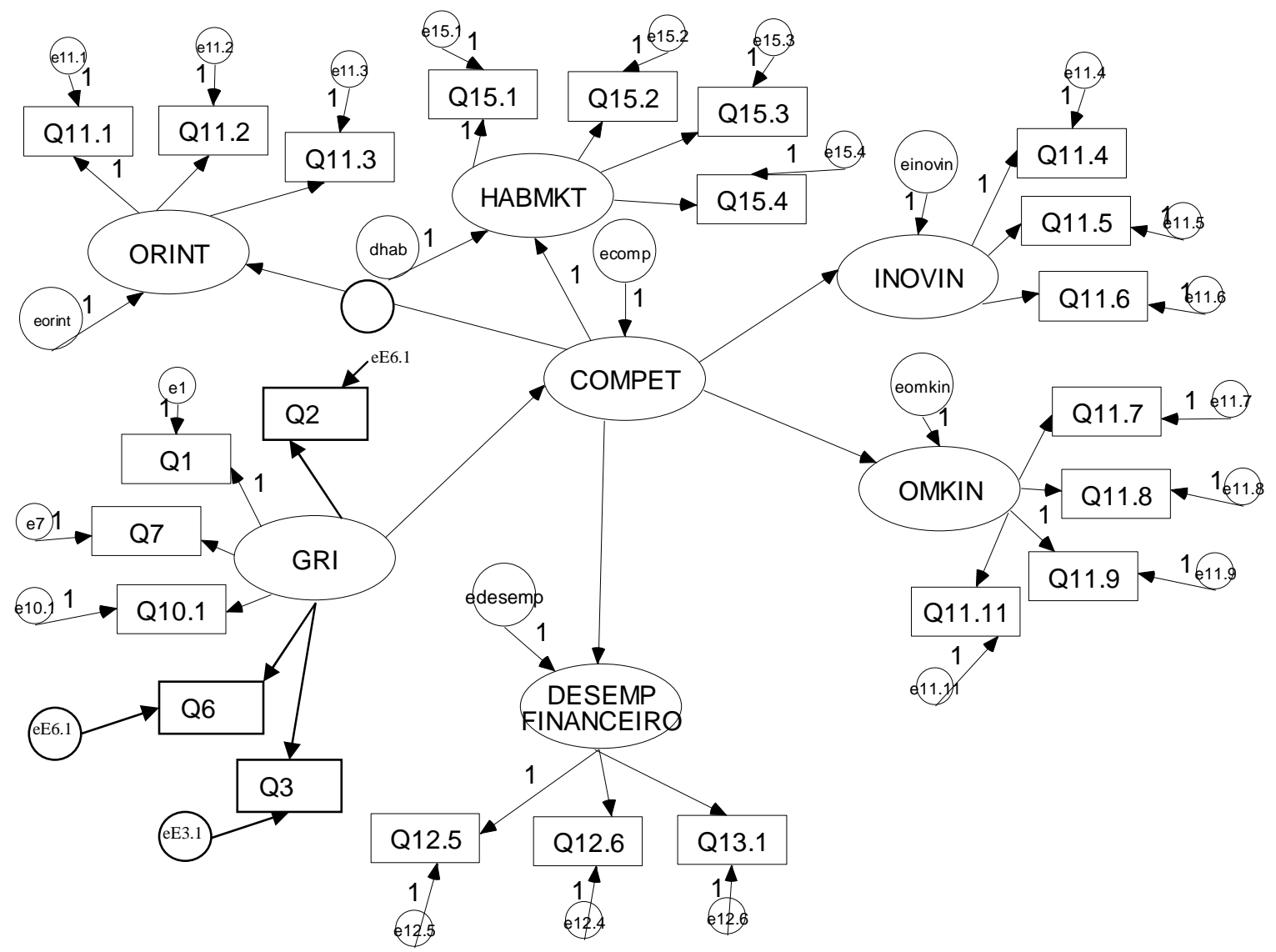

Figura 3 - Modelo inicial

Fonte: dados da pesquisa (2010) 
Os desenhos do modelo reconhecidos pelo software AMOS utilizados são conceituados da seguinte forma: os retângulos representam as variáveis observadas; as elipses representam as variáveis latentes ou os erros; uma seta reta com uma única ponta indica o caminho ou a relação de causa entre as duas variáveis. Para a representação causal a seta é da esquerda para a direita, e quando a relação é reflexiva a seta é da direita para a esquerda.

O GRI e Desempenho são construtos de primeira ordem com uma representação reflexiva. Já Competência é um construto de segunda ordem com uma representação reflexiva, tanto na segunda como na primeira ordem. Construtos de segunda ordem correspondem a construtos que influenciam suas variáveis e são influenciadas por um construto principal. Os construtos iniciais são denominados de construtos de primeira ordem, ao passo que o outro construto, que está associado aos construtos de primeira ordem, é chamado de construto de segunda ordem. A relação entre os construtos se dá por uma representação causal.

O desempenho operacional não está demonstrado no modelo inicial, porquanto se supõe que esse construto foi mensurado separadamente, considerando que o restante do modelo continuaria idêntico.

Não somente o modelo de mensuração inicial foi testado nesta tese, mas também foram avaliados modelos concorrentes. Sabendo que o teste estatístico associado aos modelos de equações estruturais é um teste de aproximação ou de medidas de ajustes (fit measures), é interessante demonstrar que o grau das medidas de ajustes do modelo inicial deve ser comparado com modelos alternativos ou concorrentes, como sugerem Hair Jr. et al. (2009) e como utilizou Carneiro (2007) em sua tese de doutorado. Pode-se assim identificar os diferentes tipos de efeitos de um construto sobre o outro e/ou de variáveis sobre os construtos.

As associações estruturais entre todas as variáveis do modelo são estimadas e comparadas com aquelas verificadas na amostra. O modelo estará mais ajustado ou consistente quanto menor a discrepância entre esses valores, ou seja, quanto mais as premissas e relações estimadas pelas relações do modelo se aproximarem das relações apresentadas pelos dados amostrais. 
Como todo modelo de regressão, existem parâmetros desconhecidos e que precisam ser estimados a partir da amostra observada. Mas quando se utiliza as equações estruturais, o problema de estimação é mais complexo que em outras técnicas devido à presença de variáveis latentes, ou seja, as variáveis não observáveis diretamente. (MINGOTI, 2005). De acordo com Hair Jr. et al., (2009), os métodos estatísticos mais comumente utilizados na estimação de parâmetros são os da máxima verossimilhança (MLE), mínimos quadrados ordinários e mínimos quadrados parciais. Nesta tese, a estimação de máxima verossimilhança foi utilizada. Esta estimação MLE é um procedimento que melhora, por iterações, as estimativas de parâmetros para minimizar uma função de ajuste especificada. A MLE é mais eficiente e sem vieses quando a suposição de normalidade multivariada é atendida.

Alguns trabalhos na área dos negócios internacionais utilizaram a técnica de equações estruturais para comprovar seus resultados. Lages e Montgomery (2001) elaboraram um modelo estrutural composto por variáveis latentes para analisar o impacto de programas de auxílio às exportações no crescimento do desempenho da empresa, medido pelo lucro, valor e volume das exportações; Dhanaraj e Beamish (2003) apresentaram um modelo estrutural em que os construtos são variáveis latentes, como o desempenho das exportações, que foi mensurado pelo lucro, pela parcela do mercado e pelo crescimento da empresa. Carneiro (2007) modelou o desempenho econômico da exportação como uma estrutura reflexiva multidimensional de primeira ordem, divididos em três dimensões constituintes e cada uma delas indicada por diversas variáveis. Albuquerque (2008) testou seus construtos de desempenho, políticas públicas, capacidades dinâmicas, recursos, entre outros, em variáveis reflexivas e causais, mas ao final dos testes estatísticos o autor constatou que o melhor ajuste seria dado pelas relações reflexivas. 


\section{RESULTADOS}

Neste capítulo apresentam-se os resultados obtidos neste estudo. Inicialmente, realiza-se uma apresentação das características das PMEs no Brasil, sua mensuração e o contexto em que estão inseridas. No item subsequente, três estudos de casos de PMEs brasileiras são expostos, com intuito de evidenciar os resultados obtidos na etapa qualitativa, seguido do perfil das empresas pesquisadas na fase quantitativa da tese, analisando as empresas exportadoras e as empresas que possuem IDE. Por fim, são apresentados os modelos estatísticos indicando a se as hipóteses desta tese foram ou não confirmadas.

A primeira empresa entrevistada possui lojas próprias no exterior e franquias, e já teve parcerias com empresas chinesas para a produção dos produtos e posterior exportação para o Brasil. No entanto, em decorrência das mudanças cambiais e da necessidade de atender o público brasileiro mais de perto, e de forma mais proativa, deixou de fabricar na China e passou a produzir no Brasil. É uma empresa familiar.

A segunda empresa entrevistada se internacionalizou somente via franquias. É também uma empresa familiar, e no início do processo de internacionalização possuía 180 funcionários. Por esse motivo, decidiu-se por sua manutenção na pesquisa.

A terceira empresa, considerada pequena, é somente exportadora, atuando basicamente nos países do MERCOSUL. Decidiu-se consultar uma empresa desse tipo para verificar as diferenças potenciais entre elas.

Na segunda parte dos resultados apresenta-se o perfil das empresas pesquisadas, realizando as análises estatísticas passo a passo para testar as hipóteses.

\subsection{Estudos de Casos das PMEs Brasileiras}

Como resultado da etapa qualitativa desta tese, apresenta-se neste item as empresas entrevistadas e os principais resultados. As entrevistas não foram apresentada na sua totalidade porque continha outros temas além da internacionalização, temas estes que não 
foram tratados na análise dos dados. Focaram-se aqui apenas os trechos das entrevistas que abordavam a internacionalização.

\section{a) Empresa Morana de Bijuterias}

Respondente: Jae Ho Lee - Proprietário

Fundada em 2002 pelo Sr. Jae Ho Lee, a empresa de bijuterias Morana possui atualmente 140 unidades franqueadas pelo Brasil, uma no Porto (Portugal), em Nova York (EUA) e Bogotá (Colômbia). Entre 2003 e 2008, o faturamento da Morana cresceu 11 vezes, e no mesmo período o número de pontos de venda aumentou menos de seis vezes. Para o ano de 2009, foram abertas, segundo mencionado pelo executivo, 62 novas lojas, havendo assim a expectativa de terminar o ano com mais de 200 lojas. "Gostaria de frisar que todas estão muito bem, e não tenho repasse de loja."

A empresa possui cerca de 200 funcionários diretos no Brasil. Um dos atrativos da marca é o mix de produtos que disponibiliza aos seus consumidores. Sua equipe de criação tem parcerias com fornecedores no Brasil e no exterior. Além de lojas, a Morana disponibiliza seus produtos em quiosques em shoppings centers.

Quando questionado sobre os motivos que o levaram a se internacionalizar, o Sr. Lee respondeu: "Vejo muitas pequenas empresas do meu setor, internacionalizando em resposta a oportunidades que surgem no dia a dia, e também pela vaidade dos sócios. No nosso processo de internacionalização, o nosso plano inicial era começar pelos países mais próximos do Brasil, onde a referência do Brasil é mais forte. Nova York, confesso, foi um erro. Como muitos pequenos empreendedores cometem no meu setor, deixando-se cair em tentações das oportunidades que surgem no nosso dia a dia. Hoje, vejo que erramos e já estamos corrigindo. Não tínhamos o conhecimento suficiente das nuanças desse mercado $e$ tivemos que retornar. Entender o mercado, os clientes e o posicionamento dos concorrentes é fundamental para atuar no exterior."

Para a PME atuar com sucesso no exterior é fundamental que antes da decisão de processo de internacionalização a empresa, no Brasil, esteja 100\% sintonizada, "redonda", como comenta o executivo. "Se a organização toda não comprar a ideia, não dará certo!". Depois da 
efetivação da internacionalização, é essencial, na visão do Sr. Lee, que se envie ao exterior os melhores profissionais que a empresa dispõe para controlar as operações. "Isto significa abrir mão dele aqui no Brasil. Custa caro”, complementa.

A internacionalização ofereceu aos sócios-proprietários da Morana duas lições: 1) a força da marca Brasil. Quanto a este aspecto o executivo fez o seguinte comentário: "Estamos associando à nossa marca a palavra BRASIL. Pelo menos no segmento de moda, o que eles compram e desejam é o lifestyle brasileiro.” 2) expandir pelos países da America Latina: “o Brasil é referência forte para esses países, e também pela estrutura de distribuição de renda existente nestes países, muito similares às do Brasil."

O executivo comentou, ademais, que os fornecedores da sua matéria-prima são do Brasil e do Exterior, e dependendo da época e da cotação da moeda a empresa importa parte da mercadoria da China. Por ter parentes naquele mercado, o processo fica mais facilitado, às vezes compensando mais do que produzir no Brasil. No início do negócio, a importação chegava a $100 \%$ da mercadoria vendida. Mas atualmente, pela necessidade de resposta mais rápida, o desenvolvimento das bijuterias tem se realizado no Brasil.

A estratégia que adotaram para abastecer a rede de franquias é tendo novidades semanais: “costumamos não repetir o mesmo modelo, mesmo que tenha tido uma excelente venda. Dentro dessa estratégia, é quase impossível desenvolvermos internamente todos os produtos." A empresa conta com uma equipe interna de quatro profissionais que criam e desenvolvem uma parte do mix. "O restante aproveitamos a estrutura de $P \& D$ dos nossos fornecedores, estamos muito alinhados com os fornecedores. Eles já conhecem profundamente a linha que trabalhamos e eles desenvolvem coleções exclusivas para a rede."

Quando o assunto foi desempenho financeiro de lojas próprias e de lojas franqueadas, o executivo respondeu: "A nossa experiência nos mostrou que as lojas próprias não têm o mesmo desempenho de uma loja franqueada. Temos exemplos de lojas próprias em "UTI", repassadas para um franqueado, que começa a dar altos lucros. Sei que sem dinheiro não começamos nada, mas sem um bom operador não teremos sustentabilidade do negócio." Para o Sr. Lee existem muitos detalhes na operação do dia a dia que um gerente, mesmo que muito bem treinado, não consegue captar, e complementa: “Tem a ver com compromisso [...] lembra 
daquela história de galinha x porco? galinha doa ovos todos os dias, mas o porco se sacrifica fornecendo a própria carne."

Um aspecto bastante discutido durante a entrevista foi sobre desafios. Para o entrevistado, os desafios são diários e não se pode ter controle sobre eles, mas para superá-los o executivo investe em preparo pessoal e busca ter uma visão mais ampla do seu negócio e da sua vida. $\mathrm{O}$ Sr. Lee complementa: "É engraçado falar isso, mas o meu maior desafio está sendo agora. Sou mais empreendedor do que executivo. Agora, com o crescimento da internacionalização e da empresa, vejo que demandam série de competências que nunca precisei para chegar até aqui." Quando a empresa somente exportava algumas bijuterias, as preocupações eram menores, mas com o aumento da internacionalização por meio de lojas no exterior os desafios são outros, menciona o entrevistado.

O executivo faz uma metáfora do desafio da internacionalização com uma corrida "Vejo o desafio de internacionalização como uma corrida de maratona: exige estratégia, fôlego e paciência. Já, aqui no Brasil, para nós, é uma corrida de 100m."

E sobre as perspectivas para os três próximos anos, o executivo disse: "Nós estamos muito animados com perspectivas para os próximos anos. Além do otimismo do crescimento do mercado brasileiro para os próximos anos, os setores onde atuamos, como varejo, gestão de marca e franchising, estão "bombando". Nunca o varejo foi tão valorizado na história. Muitas indústrias estão indo para o varejo. E franchising vive o seu melhor momento. Hoje percebo profissionalismo dos franqueadores e dos franqueados. Somando todos esses fatores, esperamos atingir a marca de 600 pontos de vendas em 2012. O nosso foco é o mercado."

\section{b) Empresa Carmen Stefan Ltda.}

Respondente: Diretor de Marketing Internacional

A empresa Carmen Steffans, fabricante de calçados, localizada em Franca, Estado de São Paulo, foi fundada em 1993, possui atualmente 500 funcionários diretos. Em junho de 2009 contava com 140 lojas franqueadas no Brasil e 20 no exterior, localizadas na América do Sul, por onde iniciaram o processo de internacionalização, e na Europa. A expansão internacional se deu em 2002, na cidade de Punta Del Leste, no Uruguai, quando possuía 180 funcionários 
diretos, e em 2004 já com 250 funcionários diretos, abriu a primeira franquia em Portugal, na Europa.

Os próximos planos é o investimento da marca nos EUA e depois em Tóquio, no Japão. O produto é focado no público A e B, e a empresa tem como meta consolidar-se como primeira grife genuinamente brasileira de consagração mundial.

Quando questionado sobre o fator impulsionador para a empresa atuar no exterior, o executivo respondeu, prontamente, que a qualidade e beleza do produto e as estratégias da empresa voltadas para o mercado externo impulsionaram a internacionalização. Mas, para efetivar tal processo, o executivo citou, que o atributo essencial, que a empresa precisou desenvolver, para atuar no exterior, foi "ter um departamento expert no segmento com pessoas qualificadas e preparadas para expandir e aproveitar as oportunidades. As empresas brasileiras foram acostumadas a serem compradas e agora nós temos que sair do ninho para vender."

Quando o assunto foi desempenho, o executivo respondeu que o que garante o melhor resultado para a sua empresa na internacionalização é o design, expertise em posicionamento e construção de marca e ainda uma estrutura produtiva bastante organizada. Segundo o executivo: "Antes de partir com a nossa franquia para o exterior tratamos de integrar as funções críticas do negócio. A comunicação entre as áreas precisa estar fluindo muito bem para que possamos atender os franqueados no mercado internacional." A melhor forma de verificar o desempenho da empresa, apontou o executivo, é via mercado.

Por se tratar de moda, o Brasil não é visto como um mercado que desenvolve tendências, e por esse motivo a empresa precisou desenvolver habilidades para criar valor ao cliente no exterior, mencionou o entrevistado: "realizamos pesquisas de tendências de moda globais e juntamos com uma pitada de brasilidade única." O Produto é o grande diferencial da empresa no exterior, "temos que desmistificar o estereótipo da empresa brasileira nos mercados internacionais e nos diferenciarmos das empresas concorrentes."

Para se manter competitiva no mercado externo com as franquias o executivo responde que é necessário, em ordem de importância, focar: a. Design dos produtos; b. Local dos pontos de vendas; c. Marketing e propaganda; d. Inovação. "Para o franchising esses pontos devem 
estar completamente formatados e integrados para que possamos atender ao franqueado. O fato de sermos uma empresa internacionalizada agrega mais valor nas vendas e na marca."

\section{c) Empresa Nardelli Eletrodomésticos}

Respondente: Sócio-proprietário Sr. Eder Nardelli

A empresa Nardelli de fornos e fogões se localiza em Rio do Oeste, interior do Estado de Santa Catarina. Foi criada em 1987 e produz fornos e fogões elétricos. Fabrica atualmente 550 fornos por dia e tem capacidade para produzir 850 fornos, atendendo o Brasil, com foco de atuação na região Sul, e exporta para o MERCOSUL.

A tecnologia utilizada na Nardelli Eletrodomésticos é resultado de um trabalho conjunto, dos colaboradores da própria empresa e das parcerias. "A matéria-prima para os queimadores dos fogões, por exemplo, é de uma empresa italiana. É o que existe de mais sofisticado no mercado e contribui para a eficiência energética. Toda a tubulação interna nós desenvolvemos na empresa e aperfeiçoamos com fornecedores, estamos sempre em busca da eficiência", enfatiza o Sr. Eder.

Atualmente, a Nardelli conta com 60 funcionários, em média, que há qualquer momento param de fazer um modelo e iniciam outro, é uma produção no sistema Kanban, que transfere para o "chão de fábrica" a responsabilidade pela programação diária da produção, além de ser visual e simples.

Segundo o diretor da empresa, Eder Nardelli, é preciso entender o momento para conseguir adequar o que a empresa tem planejado para essa nova realidade. "Buscamos nos aperfeiçoar sempre, para garantir, assim, qualidade e segurança para o consumidor dos produtos Nardelli", finaliza.

Quando questionado sobre o fator que impulsionou a empresa a iniciar a exportar, o diretor comentou: "O Mercosul é um mercado que soma as possibilidades de venda da empresa, aproveitando-se ainda a questão de isenções tributárias em virtude dos acordos do bloco. 
Assim, pela facilidade de distância, língua e proximidade de costumes culinários tem-se o objetivo de buscar as vendas no exterior, principalmente no âmbito do MERCOSUL."

Anteriormente à empresa de eletrodomésticos, a Nardelli fabricava móveis e já exportava. Com esse conhecimento da sistemática do comércio exterior brasileiro (burocracia), a empresa continuou exportando para o MERCOSUL.

O Diretor comenta que o prazo de entrega rápido, auxiliado pelo curtíssimo tempo de trânsito rodoviário da mercadoria para os países do Mercosul, além do desenvolvimento de variações nos produtos para que cada cliente tenha um produto exclusivo no mercado, contribuem para o diferencial da empresa. "Apesar de conseguirmos apresentar um produto com inovação, nada adianta se não divulgarmos bem nossos produtos."

O sucesso da empresa veio com a oferta, ao cliente, da possibilidade de produto private label, além de produtos com especificações distintas para cada cliente, ainda que na mesma plataforma de produtos. "Buscamos diferenciar o produto ao cliente, adequar a cada necessidade sem perder escala para podermos atender também no melhor preço."

E para se manterem competitivos no mercado externo, o diretor aponta que as estratégias são:

a) Design dos produtos: "Busca de produtos exclusivos e atualmente desenvolvendo produtos visando à redução de custos, para buscar alguma compensação pela valorização do R\$ além de necessidade constante de combater produtos chineses."

b) Local dos pontos de vendas: "Venda a distribuidores, visando concentrar energias."

c) Marketing e propaganda: "Deixamos para o cliente no exterior direcionar as estratégias de marketing, não temos conhecimento suficiente para identificar a melhor campanha."

d) Inovação: "Como o maior mercado é o Paraguai, e o poder de compra do consumidor local é baixo, tem-se buscado a inovação do sentido de redução de custos."

Quanto às principais vantagens competitivas da empresa que geram valor ao cliente no exterior o Sr. Eder respondeu que "Em nível de mercado produtor brasileiro um dos diferenciais é o private label e a possibilidade de variações do produto, embora com os produtos chineses estas características também sejam comuns." "Nossa empresa não utiliza 
as linhas de financiamento do governo, a exportação é considerada mais um mercado como o nacional, mas não temos a intenção de aumentar."

Observa-se, por meio das declarações dos respondentes, a quantidade de variáveis que influenciam a internacionalização das PMEs brasileiras. Enquanto a empresa de calçados que iniciou seu processo de internacionalização em pequenos passos, para países geográfica e culturalmente próximos, cresceu e tem a intenção de expandir internacionalmente cada vez mais, a empresa de bijuterias acabou buscando oportunidades em mercados distantes, como Nova Iorque, e se arrependeu. Já a pequena empresa exportadora não pensa nem em aumentar as suas exportações, que dirá o seu modo de atuação no exterior. Esta última encara a exportação apenas como um processo burocrático.

No Quadro 14 apresenta-se os pontos relevantes das entrevistas e que serviram de auxílio para o desenvolvimento desta tese.

Quadro 14 - Síntese dos pontos relevantes das entrevistas

\begin{tabular}{|c|c|}
\hline \multicolumn{2}{|r|}{ Pontos Relevantes das Entrevistas } \\
\hline GRI & $\begin{array}{l}\text { - iniciar por países geograficamente mais próximos do Brasil; } \\
\text { - erros cometidos por cair nas tentações das oportunidades; } \\
\text { - necessidade de dispor dos melhores profissionais para dar } \\
\text { andamento ao processo de internacionalização; } \\
\text { - crescimento acelerado para se igualar aos concorrentes; } \\
\text { - aumentar em termos de número de países. }\end{array}$ \\
\hline COMPETÊNCIA & $\begin{array}{l}\text { - } \text { necessidade de conhecimento das nuanças do mercado: } \\
\text { compreensão do mercado, dos clientes e dos concorrentes; } \\
\text { - comunicação e processo precisam estar fluindo muito bem; } \\
\text { - necessidades de competências individuais específicas para } \\
\text { atender o mercado interno; } \\
\text { - } \text { qualidade do Produto e design; } \\
\text { - empresa orientada para o mercado internacional; } \\
\text { - pessoas qualificadas. }\end{array}$ \\
\hline DESEMPENHO & $\begin{array}{l}\text { - aprendizado: A Força da marca Brasil; a força do Brasil nos } \\
\text { países mais próximos; } \\
\text { - resultado financeiro depende do empreendedor; } \\
\text { - conquistar mais mercado; } \\
\text { - produtividade organizada. }\end{array}$ \\
\hline DESAFIOS & $\begin{array}{l}\text { - deixar de ser empreendedor para ser executivo à medida que o } \\
\text { GRI aumenta; } \\
\text { - pouco tempo para se igualar aos concorrentes internacionais; } \\
\text { - crescer; } \\
\text { - concorrência internacional. }\end{array}$ \\
\hline
\end{tabular}

Verificou-se que as empresas com IDE deram muita importância às competências da organização para se manterem competitivas no exterior. Seja pelo design ou pela orientação 
para o mercado, os executivos percebem que há necessidade de dispor de pessoas qualificadas para atender o mercado externo. Nesse sentido, os comentários corroboram as variáveis utilizadas para identificar as competências da organização como mediadora do aumento do GRI e do desempenho.

Os dados acima apresentados serviram para, principalmente, auxiliar na elaboração do questionário, na identificação de correspondência das variáveis que formaram os construtos GRI e desempenho, e na formação das variáveis de competência que foram extraídas do questionário de Knight e Kim (2009). Acredita-se ter sido importante essa etapa da pesquisa para adequar as variáveis que formaram o construto à realidade das empresas brasileiras, sendo que os executivos consideraram que as variáveis inicialmente identificadas eram correspondentes aos construtos que se deseja analisar via equações estruturais na etapa quantitativa.

\subsection{Resultados da Etapa Quantitativa}

Os resultados da etapa quantitativa serão apresentados em duas etapas. Na primeira parte expõe-se o perfil das empresas pesquisadas para uma melhor avaliação de tais empresas. As Empresas com operação no exterior e as empresas exportadoras são apresentadas separadamente. $\mathrm{Na}$ segunda parte são descritas as relações estatísticas observadas entre as variáveis, acompanhadas de uma análise de cada relação. Nas análises do modelo de equações estruturais, as empresas são apresentadas conjuntamente, pois a técnica estatística não permite a análise de uma amostra pequena.

\subsection{1 $O$ perfil das empresas pesquisadas e dados gerais da internacionalização}

A amostra dessa pesquisa é constituída de 70 empresas exportadoras e 44 empresas com IDE. A apresentação do perfil das empresas pesquisadas, como afirmado acima, será realizada separadamente, ou seja, as exportadoras, denominadas nas tabelas de "exporta", e as empresas com operação no exterior, denominadas de "opera”.

Das empresas exportadoras respondentes, 36\% exportam indiretamente, e das empresas que operam no exterior, $18,2 \%$ exportam indiretamente. Percebe-se, com este dado inicial, que as 
empresas com IDE se utilizam menos de empresas atravessadoras para chegar ao cliente final no exterior. Na prática, dependendo do setor, da quantidade destinada à exportação e do país de destino, uma trading company se faz necessário. Por outro lado, esse dado também pode sinalizar um conhecimento maior por parte das empresas que já operam no exterior. Como já comentado no início desta tese, as empresas que tivessem escritórios próprios e/ou centros de pesquisa no exterior seriam denominadas de empresas com formas mais complexa de internacionalização. Verifica-se que das empresas com operação no exterior, $54 \%$ possuem escritórios próprios e $11 \%$ possuem fábrica no exterior, mas nenhuma empresa respondente possui centro de pesquisa no exterior. Outro dado interessante desta apresentação do perfil é a comparação do número de empresas exportadoras que possuem representantes exclusivos no exterior (34\%) com o das empresas com IDE (29\%). Analisando, juntamente com o dado anterior, o número de empresas com operação no exterior que possuem escritórios próprios no exterior pode-se inferir que elas trocaram o representante (terceirizado) para uma representação própria. Os demais tipos de operação e o percentual das empresas encontram-se na Tabela 10.

Tabela 10 - Tipo de operação

\begin{tabular}{l|c|c|c|c}
\multicolumn{1}{c|}{ Operações } & $\begin{array}{c}\text { \# } \\
\text { Exporta }\end{array}$ & $\begin{array}{c}\text { Exporta } \\
\text { \% }\end{array}$ & \# Opera & $\begin{array}{c}\text { Opera } \\
\mathbf{\%}\end{array}$ \\
\hline Exportação indireta & 25 & $36 \%$ & 8 & $18,2 \%$ \\
Exportação direta & 70 & $100 \%$ & 44 & $100 \%$ \\
Representante exclusivo no exterior & 24 & $34 \%$ & 13 & $29 \%$ \\
Escritórios de comercialização próprios & - & - & 24 & $54 \%$ \\
Centros de distribuição próprios & - & - & 10 & $23 \%$ \\
Franquia, licenciamento no exterior & - & - & 8 & $18 \%$ \\
Lojas próprias no exterior & - & - & 6 & $14 \%$ \\
Produção terceirizada no exterior & - & - & 4 & $9 \%$ \\
Joint-Venture/Parcerias no exterior & - & - & 7 & $16 \%$ \\
Produção própria no exterior & - & - & 5 & $11 \%$ \\
Centro de Pesquisa & - & - & - & - \\
\hline Total de respondentes & $\mathbf{7 0}$ & $\mathbf{1 0 0 \%}$ & $\mathbf{4 4}$ & $\mathbf{1 0 0 \%}$ \\
\hline
\end{tabular}

Fonte: Dados da pesquisa (2010)

As empresas respondentes estão localizadas, na sua maioria, em São Paulo, tanto as exportadoras como as com operação no exterior (32\%). Em seguida, vem o Estado de Santa Catarina, representado por $23 \%$ das empresas exportadoras e $16 \%$ das empresas com operação no exterior. Pode-se perceber, na Tabela 11, a seguir, que o Sudeste do Brasil representa a maioria dos respondentes, ou seja, $44 \%$ das empresas exportadoras e $46 \%$ das empresas com 
operação no exterior, sendo seguido pela região Sul do Brasil, com, respectivamente, $44 \%$ e $36 \%$ das empresas exportadoras e com operação no exterior.

Tabela 11 - Estado ou região da localização da matriz

\begin{tabular}{l|r|r|r|r}
\hline Estado ou Região da Localização da Matriz & $\begin{array}{c}\# \\
\text { Exporta }\end{array}$ & $\begin{array}{c}\text { Exporta } \\
\mathbf{\%}\end{array}$ & $\begin{array}{c}\# \\
\text { Opera }\end{array}$ & $\begin{array}{c}\text { Opera* } \\
\mathbf{\%}\end{array}$ \\
\hline Região Norte & 4 & $6 \%$ & 3 & $7 \%$ \\
Região Nordeste & 3 & $4 \%$ & 5 & $11 \%$ \\
Região Centro-Oeste & 1 & $1 \%$ & 0 & - \\
Rio de Janeiro & 4 & $6 \%$ & 3 & $7 \%$ \\
Santa Catarina & 16 & $23 \%$ & 7 & $16 \%$ \\
São Paulo & 22 & $32 \%$ & 14 & $32 \%$ \\
Paraná & 10 & $15 \%$ & 7 & $16 \%$ \\
Rio Grande do Sul & 4 & $6 \%$ & 2 & $4 \%$ \\
Minas Gerais & 4 & $6 \%$ & 3 & $7 \%$ \\
\hline Total de respondentes & $\mathbf{6 8}$ & $\mathbf{9 7 \%}$ & $\mathbf{4 4}$ & $\mathbf{1 0 0}$ \\
\hline
\end{tabular}

* A soma dos percentuais pode ser diferente de $100 \%$ devido a erros de arredondamento.

Fonte: Dados da pesquisa (2010)

Segundo dados da SECEX, no ano de 2008 as Pequenas e as Médias empresas estavam localizadas, respectivamente: no Sudeste $(60,8 \%$ e 58,7\%), no Sul (27,5\% e 29,9\%), no Nordeste $(5,3 \%$ e $5,3 \%)$, no Norte $(3,7 \%$ e $3,7 \%)$ e no Centro-Oeste $(2,6 \%$ e $2,4 \%)$. Na presente pesquisa, a população foi baseada nos dados da SECEX, mas foram consideradas somente as empresas que exportaram nos últimos 3 anos sem interrupção, sem considerar as empresas de serviço de comércio exterior. O intuito de apresentar os dados da SECEX é verificar que mesmo com as diferenças de população das pesquisas, o resultado não apresentou modificações consideráveis. Na presente pesquisa, o Sudeste aparece em primeiro lugar, seguido da Região Sul, vindo em terceiro lugar a Região Norte (na pesquisa da SECEX aparece em 4을 lugar), seguida da Região Nordeste (3ำ lugar SECEX) e, por fim, a CentroOeste.

Nas PMEs exportadoras pesquisadas, o percentual de receitas de vendas no exterior sobre percentual de receitas das vendas totais é, na sua maioria, baixo: a faixa de 1 a 5\% representa $21 \%$ dos respondentes. Já para as PMEs com operação no exterior, a faixa dos $6 \%$ a $10 \%$ representa a maior parte dos respondentes (27\%). Quando se analisam os dados constantes da parte final da Tabela 12, a seguir, verifica-se que 14\% das PMEs exportadoras exportam mais de $61 \%$, enquanto as PMEs com operação no exterior exportam somente $9 \%$. 
Tabela 12 - Vendas no exterior

\begin{tabular}{l|r|r|r|r}
\hline $\begin{array}{l}\text { \% de vendas no exterior/ vendas totais } \\
\text { (a) }\end{array}$ & $\begin{array}{c}\text { Exporta } \\
\#\end{array}$ & $\begin{array}{c}\text { Exporta } \\
\text { \% (b) }\end{array}$ & $\begin{array}{c}\text { Opera } \\
\#\end{array}$ & $\begin{array}{c}\text { Opera } \\
\text { \%(b) }\end{array}$ \\
\hline Menos de 1\% & 3 & $4 \%$ & 0 & $0 \%$ \\
1 a 5\% & 15 & $21 \%$ & 7 & $16 \%$ \\
6 a 10\% & 11 & $16 \%$ & 12 & $27 \%$ \\
11 a $15 \%$ & 7 & $10 \%$ & 4 & $9 \%$ \\
16 a $20 \%$ & 10 & $14 \%$ & 3 & $7 \%$ \\
21 a $25 \%$ & 0 & $0 \%$ & 1 & $2 \%$ \\
26 a 30\% & 4 & $6 \%$ & 5 & $11 \%$ \\
31 a 35\% & 2 & $3 \%$ & 2 & $5 \%$ \\
36 a $40 \%$ & 1 & $1 \%$ & 1 & $2 \%$ \\
41 a $45 \%$ & 1 & $1 \%$ & 4 & $9 \%$ \\
46 a 50\% & 2 & $3 \%$ & 0 & $0 \%$ \\
51 a 55\% & 1 & $1 \%$ & 0 & $0 \%$ \\
56 a $60 \%$ & 3 & $4 \%$ & 1 & $2 \%$ \\
Mais de $61 \%$ & 10 & $14 \%$ & 4 & $9 \%$ \\
\hline Total de respondentes & $\mathbf{7 0}$ & $\mathbf{1 0 0 \%}$ & $\mathbf{4 4}$ & $\mathbf{1 0 0 \%}$ \\
\hline
\end{tabular}

(a) As faixas foram elaboradas pela doutoranda para melhor visualização do perfil.

(b) A soma dos percentuais pode ser diferente de $100 \%$ devido a erros de arredondamento.

Fonte: dados da pesquisa (2010)

O resultado das PMEs com operação no exterior pode estar vinculado a outras formas de receber o produto no exterior, ou pela própria fábrica no exterior, que representou $11 \%$ das formas utilizadas pelas empresas pesquisadas, ou via importação provinda de outro país (fábricas terceirizadas - 9\%) ou ainda pela parceria/joint venture (16\%) (Tabela 10).

Os países para os quais as PMEs exportam e nos quais as PMEs operam são listados na Tabela 13, a seguir. Percebe-se que as empresas exportadoras exportam para um número maior de países comparativamente às empresas que têm operação no exterior. As empresas exportadoras, tirando os EUA, exportam, na sua maioria, para países da América do Sul, como o Chile, a Argentina e o Paraguai. As empresas com operação no exterior também selecionaram, em sua maioria, os EUA como destino das suas mercadorias, mas em seguida, diferentemente das exportadoras, elas exportam para países da União Européia, como a Itália, Alemanha, Espanha e Portugal, e somente depois destes é que aparece o primeiro país da América do Sul. 
Tabela 13 - Número de empresas que selecionaram cada país na exportação

\begin{tabular}{|c|c|c|c|c|c|c|c|}
\hline País & Exporta & País & Opera & País & Exporta & País & Opera \\
\hline EUA & 23 & EUA & 23 & Dubai & 1 & Grécia & 1 \\
\hline Chile & 18 & Itália & 11 & Egito & 1 & Hong Kong & 1 \\
\hline Argentina & 17 & Alemanha & 10 & Filipinas & 1 & Ilhas Canárias & 1 \\
\hline Paraguai & 15 & Espanha & 10 & Guatemala & 1 & Irã & 1 \\
\hline Canadá & 10 & Portugal & 10 & Grécia & 1 & Panamá & 1 \\
\hline Equador & 10 & Argentina & 9 & Holanda & 1 & Polinésia França & 1 \\
\hline Alemanha & 9 & França & 9 & Hong Kong & 1 & Quênia & 1 \\
\hline Peru & 9 & México & 9 & Indonésia & 1 & Rússia & 1 \\
\hline Portugal & 9 & Chile & 6 & Kuwait & 1 & Suécia & 1 \\
\hline R Dominicana & 9 & Inglaterra & 6 & Líbia & 1 & Suíca & 1 \\
\hline Bolívia & 8 & Paraguai & 6 & Malásia & 1 & Suriname & 1 \\
\hline Uruguai & 8 & Angola & 5 & Marrocos & 1 & Tanzânia & 1 \\
\hline Inglaterra & 7 & R Dominicana & 5 & Nigéria & 1 & Turquia & 1 \\
\hline Itália & 7 & Uruguai & 5 & Polônia & 1 & Uganda & 1 \\
\hline México & 7 & Bolívia & 4 & Porto Rico & 1 & Venezuela & 1 \\
\hline Espanha & 6 & Colômbia & 4 & Romênia & 1 & & \\
\hline França & 6 & Japão & 4 & Rússia & 1 & & \\
\hline Venezuela & 6 & Austrália & 3 & Síria & 1 & & \\
\hline Colômbia & 5 & Canadá & 3 & Suíca & 1 & & \\
\hline África do Sul & 4 & China & 3 & Suriname & 1 & & \\
\hline Jordânia & 4 & Equador & 3 & Tailândia & 1 & & \\
\hline Angola & 3 & Peru & 3 & Vietnã & 1 & & \\
\hline Arábia Saudita & 3 & África & 2 & $* *$ & & $* *$ & \\
\hline Austrália & 3 & África do Sul & 2 & América do Sul & - & América do Sul & 2 \\
\hline Japão & 3 & Costa Rica & 2 & América Latina & 2 & América Latina & 5 \\
\hline China & 2 & El Salvador & 2 & $\mathrm{eu}$ & 2 & eu & 4 \\
\hline Emirados Árabes & 2 & Honduras & 2 & Europa Lest & 3 & Europa Lest & 1 \\
\hline Panamá & 2 & Jordânia & 2 & Ásia & 1 & Ásia & 2 \\
\hline Tailândia & 2 & Arábia Saudita & 1 & Mercosul & 10 & Mercosul & 2 \\
\hline Bahrain & 1 & Bahrain & 1 & América Central & 1 & América Central & 1 \\
\hline Cabo verde & 1 & Caribe & 1 & Oriente Médio & 2 & Oriente Médio & 3 \\
\hline Costa do Marfim & 1 & Emirados Árabes & 1 & Vários & 2 & Vários & 5 \\
\hline Cuba & 1 & Guatemala & 1 & & & & \\
\hline
\end{tabular}

Obs: **Em alguns casos, o respondente indicou uma região ou mercado comum em vez de apenas um país de destino e, assim, manteve-se a resposta original.

Fonte: Dados da pesquisa (2010)

Ainda de acordo com a Tabela 13, verifica-se que 10 empresas exportadoras e 2 com operação no exterior indicaram o MERCOSUL como destino das suas exportações. Percebese, assim, que as empresas exportadoras atuam geograficamente mais próximas ao Brasil do que as empresas com operação no exterior. As empresas com IDE indicaram que suas fábricas próprias estão localizadas no Japão, na Holanda, na China, na França, no Chile, em Honduras e na República Dominicana. Já aquelas que possuem contrato de terceirização para a fabricação, apontaram como locais de sua atividade a China (5), México (1), Israel (1) e Itália (1). No estudo de caso da empresa de bijuterias Morana, verificou-se que, inicialmente, a empresa terceirizava sua produção para uma empresa (da família) na China. Em uma das entrevistas realizadas na França, a forma de internacionalização se dava via terceirização da 
produção. Este fato tem chamado a atenção dos governantes dos países, principalmente na França, pois caracteriza a "desindustrialização", ou seja, uma empresa deixa de produzir no país e contrata uma empresa no exterior para realizar a produção em busca de custos menores, passando muitas vezes a importar o próprio produto para ser distribuído em seu país de origem.

$\mathrm{Na}$ Tabela 14, quando se compara o número de funcionários das empresas no Brasil, constatase que $44 \%$ das empresas exportadoras e $36 \%$ das PMEs com operação no exterior possuem de 50 a 100 empregados. Quando questionadas sobre o número de funcionários no exterior, 7 (10\%) PMEs exportadoras responderam possuir empregados no exterior, sendo que 4 possuem de 1 a 5 empregados e 3 possuem de 6 a 10. Já para as empresas com operação no exterior, o número subiu para 41 empresas $(93 \%)$ que possuem funcionários no exterior. $\mathrm{O}$ número de empregados também serviu para controlar o perfil do respondente, já que empresas com mais de 200 funcionários não fariam parte da presente pesquisa.

Tabela 14 - Número de funcionários no Brasil e no exterior

\begin{tabular}{|c|c|c|c|c|c|c|c|c|c|}
\hline $\begin{array}{l}\text { Número } \\
\text { funcionários } \\
\text { no Brasil (a) }\end{array}$ & $\begin{array}{c}\text { Expor } \\
\text { t \# }\end{array}$ & $\begin{array}{c}\text { Export } \\
\%\end{array}$ & $\begin{array}{c}\text { Opera } \\
\#\end{array}$ & $\begin{array}{c}\text { Opera } \\
\%\end{array}$ & $\begin{array}{l}\text { Número } \\
\text { funcionários } \\
\text { no Exterior } \\
\text { (a) }\end{array}$ & $\begin{array}{c}\text { Expor } \\
\text { t \# }\end{array}$ & $\begin{array}{c}\text { Export } \\
\%\end{array}$ & $\begin{array}{c}\text { OPera } \\
\#\end{array}$ & $\begin{array}{c}\text { Opera } \\
\%\end{array}$ \\
\hline Nenhum & - & - & - & - & Nenhum & 63 & $90 \%$ & 3 & $7 \%$ \\
\hline De 1 a 5 & - & - & - & - & De 1 a 5 & 4 & $6 \%$ & 23 & $52 \%$ \\
\hline De 6 a 10 & 3 & $4 \%$ & - & & De 6 a 10 & 3 & $4 \%$ & 11 & $25 \%$ \\
\hline De 11 a 20 & 4 & $6 \%$ & - & & De 11 a 20 & - & - & 4 & $9 \%$ \\
\hline De 21 a 49 & 8 & $11 \%$ & 5 & $11 \%$ & De 21 a 49 & - & - & 3 & $7 \%$ \\
\hline Entre 50 e 100 & 31 & $44 \%$ & 16 & $36 \%$ & $\begin{array}{l}\text { Entre } 50 \text { e } 100 \\
\text { Entre } 100 \mathrm{e}\end{array}$ & - & - & - & - \\
\hline Entre 100 e 150 & 15 & $21 \%$ & 14 & $32 \%$ & $\begin{array}{l}150 \\
\text { Entre } 150 \mathrm{e}\end{array}$ & - & - & - & - \\
\hline Entre 150 e 200 & 9 & $13 \%$ & 9 & $20 \%$ & 200 & - & - & - & - \\
\hline Total & 70 & $100 \%$ & 44 & $100 \%$ & Total & 70 & $100 \%$ & 44 & $100 \%$ \\
\hline
\end{tabular}

(a) A soma dos percentuais pode ser diferente de $100 \%$ devido a erros de arredondamento.

(b) As faixas foram elaboradas pela doutoranda para melhor visualização do perfil.

Fonte: Dados da pesquisa (2009)

As PMEs exportadoras tiveram sua fundação principalmente na década de 1980 (36\%), enquanto que as empresas com operação no exterior foram fundadas, em sua maioria, na década de 1990 (34\%), como pode ser verificado na Tabela 15, a seguir. 
Tabela 15 - Ano de fundação e de início da exportação das empresas pesquisadas

\begin{tabular}{l|c|c|c|c|c|c|c|c}
\hline \multicolumn{5}{c}{ Ano de Fundação } & \multicolumn{2}{c}{ Ano de início da Exportação Direta } \\
\hline & $\begin{array}{c}\text { Export } \\
\#\end{array}$ & $\begin{array}{c}\text { Export } \\
\%\end{array}$ & $\begin{array}{c}\text { Opera } \\
\#\end{array}$ & $\begin{array}{c}\text { Opera } \\
\%\end{array}$ & $\begin{array}{c}\text { Export } \\
\#\end{array}$ & $\begin{array}{c}\text { Export } \\
\text { \% }\end{array}$ & $\begin{array}{c}\text { Opera } \\
\#\end{array}$ & $\begin{array}{c}\text { Opera } \\
\text { \% }\end{array}$ \\
\hline antes de 1960 & 9 & $13 \%$ & 4 & $9 \%$ & - & - & - & \\
década de 1960 & 5 & $7 \%$ & 2 & $5 \%$ & 1 & $1 \%$ & 1 & $2 \%$ \\
década de 1970 & 3 & $4 \%$ & 4 & $9 \%$ & 1 & $1 \%$ & 5 & $11 \%$ \\
década de 1980 & 25 & $36 \%$ & 12 & $27 \%$ & 6 & $8 \%$ & 8 & $18 \%$ \\
década de 1990 & 18 & $26 \%$ & 15 & $34 \%$ & 19 & $27 \%$ & 6 & $14 \%$ \\
2000 a 2003 & 6 & $8 \%$ & 6 & $14 \%$ & 32 & $45 \%$ & 14 & $32 \%$ \\
2004 a 2006 & 3 & $4 \%$ & 1 & $2 \%$ & 11 & $16 \%$ & 10 & $23 \%$ \\
\hline Total & $\mathbf{6 9}$ & $\mathbf{9 8 \%}$ & $\mathbf{4 4}$ & $\mathbf{1 0 0 \%}$ & $\mathbf{7 0}$ & $\mathbf{1 0 0 \%}$ & $\mathbf{4 4}$ & $\mathbf{1 0 0 \%}$ \\
\hline
\end{tabular}

* soma dos percentuais pode ser diferente de $100 \%$ devido a erros de arredondamento.

Fonte: Dados da pesquisa (2009)

Ao se comparar o ano de fundação com o ano de início das exportações diretas, verifica-se que as empresas com operação no exterior iniciaram mais cedo a exportar. Percebe-se, ademais, que o início dos anos 2000 foi o período em que a maioria das empresas pesquisadas iniciou a exportação. Das empresas com operação no exterior, somente uma indicou ter iniciado uma joint venture no exterior na década de 1980 e outra um escritório no exterior. A maioria das empresas com operação no exterior (34\%) iniciou sua operação no exterior no ano de 2006.

No ano de 2001, houve a primeira empresa, das respondentes, a mencionar a abertura de uma fábrica no exterior. Pode-se notar que há certa linearidade com os dados (Quadro 12), que apresenta as fases da economia brasileira. Na década de 1960 e 1970 houve um incentivo governamental para as empresas brasileiras iniciarem a exportação. Após 10 anos, o número de empresas exportadoras aumentou, mas não foi muito significativo se comparado ao número de empresas que foram fundadas, e isto pode ser explicado se se considerar que na década de 1980 o Brasil estava bastante fechado, com os olhos para dentro. Já na década de 1990 essa realidade muda com a abertura comercial do Governo Collor de Mello e a criação do MERCOSUL, quando $27 \%$ das empresas exportadoras respondentes iniciam suas exportações. Já as empresas com operação no exterior não apresentam a mesma realidade: o número aumentou em 18\% na década de 1980 e $14 \%$ na década de 1990. 
No início do ano 2000 a China começa a despontar no comércio mundial, as exportações são destinadas àquele mercado e as empresas brasileiras começam a se internacionalizar de forma mais complexa. Só no ano 2002, $23 \%$ das empresas com operação no exterior, que responderam ao questionário, iniciaram alguma operação mais complexa no exterior.

A principal atividade das empresas exportadoras da pesquisa é o ramo madeireiro/mobiliário (17\%), e para aquelas com operação no exterior, o ramo do têxtil/calçado/moda representou $20 \%$ dos respondentes. As demais atividades da pesquisa podem ser visualizadas na Tabela 16.

Tabela 16 - Ramo de atividade das empresas pesquisadas

\begin{tabular}{lrr|rr}
\hline Principal Atividade da Empresa & $\begin{array}{c}\text { Export } \\
\#\end{array}$ & $\begin{array}{c}\text { Export } \\
\text { \% }\end{array}$ & $\begin{array}{c}\text { Opera } \\
\#\end{array}$ & $\begin{array}{c}\text { Opera } \\
\mathbf{\%}\end{array}$ \\
\hline Alimentos/Bebidas & 8 & $11 \%$ & 6 & $14 \%$ \\
Construção & 2 & $3 \%$ & 1 & $2 \%$ \\
Farmacêutico & 0 & $0 \%$ & 1 & $2 \%$ \\
Madeireira/mobiliário & 12 & $17 \%$ & 3 & $7 \%$ \\
Máquinas/equipamentos & 6 & $9 \%$ & 7 & $16 \%$ \\
Metalurgia/Produtos de metal & 6 & $9 \%$ & 3 & $7 \%$ \\
Mineração & 3 & $4 \%$ & 2 & $5 \%$ \\
Papel/Celulose & 0 & $0 \%$ & 0 & $0 \%$ \\
Perfumaria/Cosméticos & 0 & $0 \%$ & 1 & $2 \%$ \\
Químicos & 2 & $3 \%$ & 0 & $0 \%$ \\
Serviços & 0 & $0 \%$ & 0 & $0 \%$ \\
Tecnologia & 6 & $9 \%$ & 4 & $9 \%$ \\
Têxtil/Calçados/Moda & 10 & $14 \%$ & 9 & $20 \%$ \\
Veículos/Autopeças & 6 & $8 \%$ & 3 & $7 \%$ \\
Outro & 9 & $13 \%$ & 4 & $9 \%$ \\
\hline Total & $\mathbf{7 0}$ & $\mathbf{1 0 0 \%}$ & $\mathbf{4 4}$ & $\mathbf{1 0 0 \%}$ \\
* soma dos percentuais pode ser diferente de 100\% devido a erros de arredondamento. & \\
Fonte: Dados da pesquisa (2010) & \multicolumn{4}{|c}{}
\end{tabular}

Aproveitou-se ainda essa questão para fazer um controle dos respondentes. Empresas de serviços de comércio exterior e empresas produtoras de commodities não fariam parte da amostra.

A receita líquida das empresas também foi uma informação usada como controle dos respondentes, visto que para ser considerada uma PME no Brasil (MDIC, 2009) a receita líquida não deverá ultrapassar R \$ 250 milhões. Pode-se perceber na Tabela 17, a seguir, que a maioria das exportadoras tem uma receita líquida de 1 a 10 milhões de reais, enquanto que a maioria das empresas com operação ficou entre R \$ 1 milhão até R\$ 20 milhões. 
Tabela 17 - Receita líquida das empresas

\begin{tabular}{lcccc}
\hline \multicolumn{1}{c}{ Receita Líquida } & $\begin{array}{c}\text { Opera } \\
\text { \% }\end{array}$ & $\begin{array}{c}\# \\
\text { Opera }\end{array}$ & $\begin{array}{c}\text { Export } \\
\text { \% }\end{array}$ & $\begin{array}{c}\# \\
\text { Export }\end{array}$ \\
\hline menos de R \$ 1 milhão & $4,5 \%$ & 2 & $21,2 \%$ & 14 \\
entre R \$ 1 milhão e R \$ 10 milhões & $22,7 \%$ & 10 & $34,8 \%$ & 23 \\
entre R 10 milhões e R \$ 20 milhões & $22,7 \%$ & 10 & $12,1 \%$ & 8 \\
entre R \$ 20 milhões e R \$ 30 milhões & $9,1 \%$ & 4 & $13,6 \%$ & 9 \\
entre R \$ 30 milhões e R \$ 40 milhões & $2,3 \%$ & 1 & $4,5 \%$ & 3 \\
entre R 40 milhões e R \$ 50 milhões & $4,5 \%$ & 2 & $7,6 \%$ & 5 \\
entre R \$ 50 milhões e R \$ 100 milhões & $15,9 \%$ & 7 & $3,0 \%$ & 2 \\
entre R 100 milhões e R \$ 200 milhões & $11,4 \%$ & 5 & $1,5 \%$ & 1 \\
entre R \$ 200 milhões e R \$ 250 milhões & $6,8 \%$ & 3 & $1,5 \%$ & 1 \\
Mais de R \$ 250 milhões & - & - & - & - \\
\hline Total dos Respondentes & $\mathbf{1 0 0 \%}$ & $\mathbf{4 4}$ & $\mathbf{9 4 \%}$ & $\mathbf{6 6}$ \\
\hline Fonte: Dados da pesquisa (2009) & & & &
\end{tabular}

Durante os estudos de caso realizados na França e no Brasil, muito se conversou sobre os auxílios às exportações e à internacionalização. Tanto na França como no Brasil os respondentes informaram não terem sido ajudados, que todos os esforços para a internacionalização foram da equipe interna da empresa. Em vista disso, resolveu-se verificar, em um número maior de respondentes, se a PMEs recebeu algum auxílio no processo de internacionalização. Numa escala Likert de 5 pontos, os respondentes deveriam indicar, dentre as alternativas apresentadas, quem auxiliou muito ou nada auxiliou. O ranking foi organizado na Tabela 18, a seguir, pela maior pontuação indicada pelas PMEs com operação no exterior. Assim, verifica-se que, em primeiro lugar, novos funcionários foram contratados pelas empresas para auxiliar no processo de internacionalização, tanto para as empresas com operação no exterior $(4,11)$ quanto para as empresas exportadoras $(3,89)$. Em seguida, aparecem os funcionários da própria empresa, que auxiliam ambas as categorias de empresas (3,77 e 3,70, respectivamente), vindo em terceiro lugar os clientes ou fornecedores, com 3,64 e 3,60, respectivamente. Já as parcerias que as empresas possuem com uma empresa estrangeira não tiveram a mesma ordem de pontuação: ficou em 4o lugar para as empresas com operação no exterior e em 8- para as exportadoras. Ficaram em 5 lugar para as empresas com operação no exterior e também em 5으 para empresas exportadora as alternativas parceria com empresas brasileiras e auditores/bancos/consultores, respectivamente. 
Tabela 18 - Auxílio para a internacionalização às empresas pesquisadas

\begin{tabular}{|c|c|c|c|c|}
\hline Auxílio & $\begin{array}{l}\text { Média } \\
\text { Opera }\end{array}$ & Rank & $\begin{array}{l}\text { Média } \\
\text { Exporta }\end{array}$ & Rank \\
\hline Novos funcionários com as novas competências requisitadas & 4,11 & $11^{\circ}$ & 3,89 & 1 은 \\
\hline Os funcionários da própria empresa & 3,77 & $2^{\circ}-$ & 3,70 & $2-$ \\
\hline Clientes ou fornecedores & 3,64 & 3 o & 3,60 & 3 o \\
\hline A parceria que temos com uma empresa estrangeira & 3,02 & $4^{\mathrm{o}}$ & 1,88 & $8-$ \\
\hline A parceria que temos com uma empresa brasileira & 2,82 & 5 o & 2,21 & 4 - \\
\hline Auditores/Bancos/ Consultores & 2,34 & 6o & 2,21 & 5 o \\
\hline SEBRAE/APEX & 2,18 & $7^{\mathrm{o}}$ & 1,97 & $6^{-}$ \\
\hline Governo Federal & 1,98 & $8-$ & 1,76 & $9-$ \\
\hline Universidades & 1,98 & $9-$ & 1,50 & $11^{\mathrm{o}}$ \\
\hline Associação Comercial/Câmaras de Comércio e Indústria & 1,82 & $10^{\circ}$ & 1,92 & $7 \stackrel{o}{-}$ \\
\hline Outros empresários (sem relação comercial) & 1,76 & $11^{\circ}$ & 1,67 & $10^{\circ}$ \\
\hline
\end{tabular}

Fonte: Dados da pesquisa (2009)

Quando questionado sobre as dificuldades encontradas na exportação ou na operação no exterior, as empresas, além de indicarem o grau de dificuldade, mencionaram, em "outras questões", aquelas que dificultam a atuação da empresa no exterior, diferentemente das indicadas pela doutoranda. Nos questionários das empresas com operação no exterior encontrou-se resposta do seguinte tipo: "Apesar de a moda brasileira estar em alta, ainda há certo preconceito. E as grifes tradicionais levam vantagem." Já para as empresas exportadoras, os respondentes mencionaram: "Imagem ruim do Brasil no exterior; Câmbio irreal; Atualmente a taxa cambial dólar/real; Alta carga tributária, juros alto. O real está supervalorizado; Custos logísticos; No início o fato de ser uma empresa brasileira foi um problema, hoje não; Para os nossos produtos (biquínis) o fato de ser uma empresa brasileira só ajuda. O pão de queijo é um produto brasileiro e nossos clientes no exterior também são." Como se pode perceber pelos comentários das exportadoras, a principal reclamação é quanto à política cambial brasileira. $\mathrm{O}$ fato de ser uma empresa brasileira às vezes atrapalha, mas outras vezes auxiliam a venda do produto.

Como pode ser verificado no ranking da Tabela 19, a seguir, para as empresas com operação no exterior a principal dificuldade reside nos custos para iniciar a operação; já para os exportadores, cujo risco da operação é o da variação cambial no Brasil, as normas cambiais foram a principal dificuldade identificada. 
Tabela 19 - Dificuldades da operação/exportação

\begin{tabular}{|c|c|c|c|c|c|c|}
\hline Principais dificuldades & $\begin{array}{l}\text { Média } \\
\text { Opera }\end{array}$ & \# & Rank & $\begin{array}{l}\text { Média } \\
\text { Export }\end{array}$ & \# & Rank \\
\hline $\begin{array}{lcccc}\text { Os custos para abrir a operação } & \text { no } \\
\text { exterior/iniciar a exportar }\end{array}$ & 4,02 & 44 & 1 운 & 3,08 & 66 & 60 \\
\hline Normas cambiais brasileiras & 3,86 & 43 & 2 o & 4,34 & 67 & 1 o \\
\hline A falta de apoio financeiro do governo brasileiro & 3,82 & 44 & 3 운 & 3,43 & 67 & $4^{\circ}$ \\
\hline Adequar a empresa à legislação local & 3,73 & 44 & $4^{\circ}$ & 2,80 & 66 & $7^{\mathrm{o}}$ \\
\hline $\begin{array}{l}\text { Manter o mesmo padrão de qualidade da } \\
\text { empresa no Brasil }\end{array}$ & 3,72 & 43 & 5 o & 3,52 & 67 & $3-$ \\
\hline Lidar com os funcionários estrangeiros & 3,70 & 43 & $6-$ & 2,55 & 40 & 9 - \\
\hline Os Concorrentes internacionais & 3,55 & 44 & $7-$ & 3,96 & 68 & $2-$ \\
\hline $\begin{array}{l}\text { Transferir as competências da matriz para a } \\
\text { operação/exportação no exterior }\end{array}$ & 3,52 & 44 & 8 - & 3,18 & 67 & 50 \\
\hline Adaptar-se à cultura do país & 3,25 & 44 & 9 o & 2,52 & 67 & $8-$ \\
\hline O idioma & 2,82 & 44 & $10^{\circ}$ & 2,18 & 67 & 11 운 \\
\hline O fato de ser uma empresa brasileira & 2,39 & 44 & $11^{\circ}$ & 2,40 & 67 & $10^{\circ}$ \\
\hline
\end{tabular}

Fonte: Dados da pesquisa (2009)

Para as empresas com operação no exterior, a intenção mais indicada para os próximos três anos é formar parcerias ou joint ventures com empresas no exterior, já para os exportadores é ter uma fábrica própria no exterior. Pode-se perceber, por meio desse resultado (Tabela 20), que o fator cambial realmente representa um risco para o exportador, e para minimizar esse risco a saída é realmente produzir no país do cliente. Lojas próprias e franquias foram selecionadas pelas empresas com operação no exterior em percentuais iguais a $29 \%$ e $21 \%$, respectivamente, mas, para os exportadores, essas intenções representaram somente $0 \%$ e $7 \%$. Na opinião da autora, há necessidade de não se ficar à mercê das políticas econômicas do Brasil, tendo em vista que as empresas externaram ter a intenção de direcionar, de alguma forma, seus investimentos para algum tipo de produção no exterior. Contudo, pelo que se pode depreender da Tabela 20, a seguir, as empresas têm mais intenções em produzir no exterior do que atender o mercado externo com suas lojas ou marcas próprias, Assim sendo, muitas empresas parecem querer produzir no exterior para atender o mercado interno (Brasil) ou, do exterior, exportar diretamente para outros mercados. 
Tabela 20 - Intenção em investimento para os três próximos anos

\begin{tabular}{l|c|c|c|c}
\hline \multicolumn{1}{c}{ Intenção de investir em 3 anos* } & $\begin{array}{c}\boldsymbol{\%} \\
\text { Opera }\end{array}$ & $\begin{array}{c}\# \\
\text { Opera }\end{array}$ & $\begin{array}{c}\text { \% } \\
\text { Exporta }\end{array}$ & $\begin{array}{c}\# \\
\text { Exporta }\end{array}$ \\
\hline Joint-Venture/Parcerias & $50 \%$ & 21 & $36 \%$ & 16 \\
Fábrica própria & $31 \%$ & 13 & $48 \%$ & 21 \\
Fábrica terceirizada & $7 \%$ & 3 & $20 \%$ & 9 \\
Escritórios & $26 \%$ & 11 & $9 \%$ & 4 \\
Centro de Distribuição & $17 \%$ & 7 & $16 \%$ & 7 \\
Lojas próprias & $29 \%$ & 12 & $0 \%$ & 0 \\
Franquia & $21 \%$ & 9 & $7 \%$ & 3 \\
Centro de Pesquisa & $9 \%$ & 4 & $9 \%$ & 4 \\
Total dos respondentes & $\mathbf{9 5 \%}$ & $\mathbf{4 2}$ & $\mathbf{6 3 \%}$ & 44 \\
\hline
\end{tabular}

* Mais de uma alternativa por respondente

Fonte: Dados da pesquisa (2009)

A Tabela 21 confirma as expectativas da Tabela 20. Para as empresas com operação no exterior, questionou-se acerca das vantagens de se ter um IDE. A maioria dos respondentes indicou que a vantagem é entrar ou desenvolver novos mercados, seguida de manter os mercados que já atuam. Em terceiro lugar, a intenção em ter um IDE é exportar para outros países.

Para as empresas que possuem operação no exterior, questionou-se sobre as vantagens do IDE. A Tabela 21 mostra o ranking das vantagens para as empresas respondentes.

Tabela 21 - Vantagens em ter uma operação no exterior

\begin{tabular}{lcc}
\hline Vantagens & Média & Ranking \\
\hline Entrar/desenvolver novos mercados & 4,43 & 1 o \\
Manter/desenvolver mercados que a empresa já exporta & 4,25 & 2 o \\
Exportar para outros países & 4,23 & $3-$ \\
Estar no mercado do principal cliente & 4,20 & $4-$ \\
Estar onde os competidores atuam & 3,95 & $5-$ \\
Evitar as barreiras comerciais & 3,91 & $6-$ \\
Diminuir o risco de taxas de câmbio & 3,98 & $7-$ \\
Ser fornecedora da nossa própria empresa no exterior & 3,80 & $8-$ \\
A carga tributária menor, subsídios & 3,41 & 9 o \\
A disponibilidade de fornecedores & 3,34 & $10^{\mathbf{o}}$ \\
O custo de transporte & 3,31 & $11^{\mathbf{o}}$ \\
A disponibilidade de mão de obra & 3,07 & $12^{\mathbf{o}}$ \\
O custo dos salários & 2,86 & 13 o \\
A burocracia & 2,77 & $14^{\mathbf{o}}$ \\
A regulamentação do mercado de trabalho & 2,73 & $15^{\mathbf{o}}$ \\
A regulamentação ambiental & 2,49 & $16^{\mathbf{o}}$ \\
A disponibilidade de recursos naturais & 2,45 & 17 o \\
\hline
\end{tabular}

Fonte: Dados da pesquisa (2009) 
Como se pode perceber pela exposição do perfil dos respondentes há diferenças de percepção entre os exportadores e as empresas com operação no exterior.

No Quadro 15 apresenta-se uma síntese dos resultados identificados no perfil das empresas entrevistadas e nos dados diversos da internacionalização.

Quadro 15 - Síntese do perfil e dos resultados da internacionalização da PME entrevistada

\begin{tabular}{|c|c|}
\hline \multicolumn{2}{|c|}{ As empresas brasileiras: } \\
\hline Na sua maioria & $\begin{array}{c}\text { Principais diferenças entre as exportadoras e as } \\
\text { empresas com IDE* }\end{array}$ \\
\hline $\begin{array}{l}\text { - Estão localizadas no Sudeste do Brasil; } \\
\text { Exportam e Operam principalmente com os EUA } \\
\text { - Continuam sendo exportadoras, com sinais de } \\
\text { aumento do GRI quanto ao modo de entrada. } \\
\text { - Foram fundadas entre as décadas de } 1980 \text { e } \\
1990 \text {, sendo que as exportadoras são as que } \\
\text { iniciaram mais cedo. } \\
\text { - Iniciaram a expoção principalmente no início } \\
\text { dos anos } 2000 \text {. } \\
\text { - Exportam de } 5 \% \text { a } 10 \% \text { das vendas totais } \\
\text { - Contrataram novos funcionários para atuar com } \\
\text { a exportação e nos processos de } \\
\text { internacionalização } \\
\text { Possuem entre } 50 \text { a } 100 \text { empregados no Brasil e } 1 \\
\text { a } 5 \text { funcionários no exterior. }\end{array}$ & $\begin{array}{l}\text { - Enquanto as empreas com IDE tem a intenção de, na } \\
\text { sua maioria, formar Joint ventures, as exportadoras } \\
\text { querem abrir suas próprias fábricas; } \\
\text { - As PMEs com IDE indicaram ter parcerias com } \\
\text { empresas no exterior que auxiliam a internacionalização, } \\
\text { já as empresas exportadoras identificaram a parceria com } \\
\text { uma empresa nacional. } \\
\text { As empresas exportadoras são, em sua maioria, do setor } \\
\text { madeireiro/mobiliário. As IDE, são do setor da moda. } \\
\text { As empresas exportadoras têm uma receita líquida de até } \\
10 \text { milhões de reais, já as IDE, entre R\$ } 1 \text { e R\$ } 20 \\
\text { milhões de Reais } \\
\text { - Enquanto que para as PMEs com IDE a grande } \\
\text { dificuldade está nos custos para abrir uma operação no } \\
\text { exterior, para as exportadoras a maior dificuldade está } \\
\text { nas normas cambiais brasileiras }\end{array}$ \\
\hline
\end{tabular}

*As diferenças aqui comentadas são somente por diferenças numérica simples, não há teste de significância dessas diferenças pois não há uma quantidade adequada de respondentes para cada grupo e o grupo de exportação é $60 \%$ maior que o número de respondentes com IDE

Fonte: Dados da pesquisa, 2010.

\subsection{Modelo Analítico Final}

Neste item apresentam-se os passos realizados para elaborar o modelo analítico final resultante da técnica de equação estrutural que foi aplicada para testar as Hipóteses. Inicialmente, apresenta-se o passo a passo das técnicas utilizadas, em seguida, apresentam-se os resultados desses passos, ou seja, os testes propriamente ditos, e por fim os modelos finais e os resultados das hipóteses já comentadas.

\subsubsection{Passos seguidos para o uso da modelagem de equações estruturais}

1. Baseando-se na teoria, na experiência prévia, na etapa qualitativa e nos objetivos da pesquisa distinguiram-se quais variáveis independentes (exógenas) preveem cada variável dependente (endógenas), especificando cada uma das relações. Essas relações 
foram mostradas na Figura 3, na apresentação do modelo inicial. Um modelo de equações estruturais apresenta tantos modelos de mensuração quanto as relações existente entre os construtos (variáveis latentes do modelo). As variáveis latentes são aquelas que não podem ser mediadas diretamente, pois os constructos abordados nesta tese são considerados de natureza complexa, exigindo um conjunto de variáveis para identificá-los. O modelo de mensuração é composto pelo conjunto de variáveis latentes, pelos indicadores de mensuração das variáveis latentes, ou seja, as variáveis observáveis, e pelas variáveis latentes que expressam os erros de mensuração dos indicadores. $\mathrm{Na}$ área de ciências sociais, muitas teorias e modelos são formulados em termos de conceitos teóricos que não são diretamente observáveis ou mensuráveis, mas que podem ser avaliados de forma bastante razoável por indicadores (MELHADO, 2004; KLEM, 1995). Com isto, geralmente surgem dois problemas básicos que a modelagem de equações estruturais procura amenizar: a) $\mathrm{O}$ que a medida observada (indicador) realmente está medindo; b) Como inferir relações causais complexas entre as variáveis que não são observáveis diretamente. Assim , a Modelagem de Equações Estruturais é composta por duas partes: i) Modelo estrutural (análogo ao modelo de regressão): relaciona as variáveis latentes, como por exemplo ao avaliar o impacto de GRI sobre o desempenho por meio da competência; ii) Modelo de mensuração (análogo ao modelo de análise fatorial): avalia como uma variável latente pode ser mensurada através de um conjunto de indicadores, por exemplo, o desempenho financeiro através de Rent, ROA e Lucro.

2. Neste trabalho foram avaliadas diversas características das 114 empresas por meio da aplicação de um questionário. Alguns respondentes podem deixar de responder algumas questões, muitas vezes por não terem um posicionamento a respeito ou não querer realmente passar a informação. Nesses casos, é necessário tratar os dados ausentes (missing data). Nesta tese, ao examinar a base de dados completa e os dados ausentes, verificou-se que se tratava de dados ausentes totalmente aleatórios, ou seja, se o padrão de dados perdidos para uma variável se relaciona com outras variáveis, mas não com os seus próprios valores. Para um nível baixo de dados ausentes aleatórios (-10\%) pode-se utilizar o método de imputação pela média dos demais respondentes para substituir os dados faltantes. Nesta tese, não se realizou uma análise específica por dado ausente como efetuada em Carneiro (2007); a substituição foi feita pela imputação pelas médias 
de todos os respondentes para substituir esses valores faltantes, considerando ser de no máximo 9 (7,9\%) os valores ausentes em cada questão.

3. Para a identificação das variáveis observáveis baseou-se em trabalhos publicados e apresentados no capítulo 3 desta tese, e que em seguida foram também abordadas na etapa qualitativa da pesquisa com os executivos entrevistados. Para a identificação das relações existentes entre as variáveis observáveis e as variáveis latentes, foi realizada uma análise fatorial exploratória, onde se observou o número de fatores formados e o conjunto de variáveis em cada fator, bem como as cargas fatoriais. Para que a carga fatorial seja considerada significativa ou minimamente aceitável, conforme menciona Hair Jr.et al. (2009), os valores devem apresentar cargas $\pm 0,30$ a $\pm 0,40$. Contudo, são geralmente consideradas necessárias para a significância prática valores maiores que \pm 0,50. Cargas fatoriais com valores abaixo de 0,50 são consideradas como não tendo explicação suficiente e são, então, eliminadas.

4. Após definidas as variáveis mais bem explicadas em cada fator (através da análise fatorial exploratória - item 3), foi realizada a análise fatorial confirmatória (que é um caso particular dos modelos de equações estruturais) para verificar se as variáveis observáveis selecionadas realmente são significativas para mensurar os constructos de GRI, competência e desempenho - essa etapa foi realizada para confirmar a significância do grupo de fatores que formaram os construtos após a eliminação das variáveis que resultaram em uma carga fatorial baixa. Além disso, calculou-se o Alfa de Cronbach para verificar a consistência interna dessas mesmas variáveis observáveis para cada um dos constructos.

5. Identificabilidade do modelo de Análise Fatorial Confirmatória: esse passo é necessário para estimar os parâmetros das equações estruturais, pois garantem uma solução única para os parâmetros dos modelos. De modo a interpretar os efeitos dos fatores em seus indicadores, uma escala de mensuração dos fatores deve ser fixada. A forma mais usual consiste na fixação em uma unidade da carga fatorial de um dos Indicadores, geralmente fixado por 1. Dessa forma, sua unidade de mensuração corresponde exatamente à escala da variável observacional com a qual apresenta coeficiente de regressão unitária, subtraída do erro de mensuração desse indicador. A seleção da variável que melhor representa o constructo é recomendada. Para fixar os parâmetros dos construtos, a análise fatorial exploratória foi considerada, sendo que a maior carga fatorial para cada construto foi a escolhida para ser fixada. No modelo de AFC, os parâmetros a serem estimados são: as cargas que relacionam indicadores a variáveis 
latentes, as variâncias de erro de mensuração dos indicadores, variância não explicada nas variáveis latentes exógenas e, as variâncias e covariâncias das variáveis latentes.

6. Verifica-se a validade, ou seja, a adequação dos indicadores selecionados para medir os construtos. Isso se faz necessário para verificar se cada indicador está realmente medindo o que deve medir ou está relacionado ao conceito desse fator (SANCHES, 2005). Um exemplo desta validade nesta tese foi o de identificar se a experiência do executivo no exterior está relacionada ao grau de internacionalização. A validade está associada à maior carga fatorial do construto assim, melhor será a validade do indicador de mensuração.

7. Normalidade das variáveis observáveis: nos modelos de equações estruturais, em geral, supõe-se que os indicadores dos constructos seguem uma distribuição normal. Para constatar se os indicadores utilizados nesta tese satisfazem essa suposição, verificou-se as medidas de assimetria e excessos de curtose. As medidas de assimetria são as medidas do grau de assimetria de uma distribuição. Valores do coeficiente de assimetria fora do intervalo -1 a +1 indicam uma distribuição substancialmente assimétrica. Já medida de curtose é a medida da elevação ou do achatamento de uma distribuição quando comparada com uma distribuição normal. Um valor positivo do excesso de curtose indica uma distribuição relativamente elevada, e um valor negativo indica uma distribuição relativamente achatada (Hair Jr. et al, 2009)

8. Estimação dos parâmetros do modelo: O procedimento mais comum segundo Hair Jr. et al. (2009) é o da estimação de máxima verossimilhança (MV) - supondo distribuição normal para as variáveis, pois ela fornece resultados válidos com tamanhos amostrais pequenos, mas o mínimo recomendado é de uma amostra de 100 a 150. Já para amostras superiores a 400 o método é muito sensível detectando muitas diferenças piorando as medidas de ajustes. Esta tese parece atender razoavelmente às exigências de tamanho mínimo, embora não seja ideal (total de observações válidas: 114). No que concerne a quantidade de dados amostrais, não há um consenso sobre o número exato de observações (ou respondentes) necessários para formar o modelo, muitos autores comentam que vai depender da complexidade do modelo proposto. Klem (1995) e Maruyama (1998) sugerem de 200 a 300 casos para cada modelo, já Hair Jr. et al. (2009) sugere de 5 a 10 respondentes por parâmetro como mínimo, o ideal seria 15 respondentes. 
9. Após a estimação de todos os modelos de análise fatorial confirmatória seguindo as etapas 3, 5 a 8, iniciou-se a estimação dos modelos mais complexos de equações estruturais em que, além da mensuração dos constructos através dos itens do questionário, o interesse era relacionar os constructos GRI, competência e desempenho.

10. Verificou-se também os dados outliers, ou seja, aqueles valores extremos substancialmente distintos do padrão geral de características das demais observações da amostra (Hair Jr. et al., 2009).

11. Verificou-se as medidas de ajustes:

Tabela 22 - Principais medidas de ajuste e sua utilização

\begin{tabular}{|c|c|c|}
\hline \multirow{2}{*}{ Índice } & Escala de Variação & Aplicação \\
\hline & Valor de Ajuste & Propriedades \\
\hline \multirow{2}{*}{$\begin{array}{l}\text { Qui-Quadrado } \\
\left(\mathrm{x}^{2}\right)\end{array}$} & $\begin{array}{l}\text { Valor da distribuiçãa qui- } \\
\text { quadrada em função } \alpha \text { e } \\
\qquad \mathrm{gl}\end{array}$ & $\begin{array}{l}\text { - Único critério que apresenta teste estatístico } \\
\text { - Não significância estatística sugere que o modelo não será } \\
\text { rejeitado } \\
\text { - o gl da distribuição é igual ao número de gl do modelo }\end{array}$ \\
\hline & $\begin{array}{c}\text { p-valor do teste }>\alpha \text { (nível } \\
\text { de significância) }\end{array}$ & $\begin{array}{l}\text { - Sensível ao tamanho da amostra; o valor é superestimado } \\
\text { para grandes amostras e subestimado para pequenas. } \\
\text { - Premissa de distribuição multivariada normal } \\
\text { - Estima parâmetros amostrais }\end{array}$ \\
\hline \multirow[b]{2}{*}{$\begin{array}{l}\text { CFI } \\
\text { (comparative fit } \\
\text { index) }\end{array}$} & $0-1$ & $\begin{array}{l}\text { - É um modelo comparativo } \\
\text { - Mensura o nível de melhoria da centralidade obtida por um } \\
\text { novo modelo embrionário de um anterior }\end{array}$ \\
\hline & $\begin{array}{c}\text { CFI }>0,90 \text { (mais próximo } \\
\text { de } 1 \text { ) }\end{array}$ & $\begin{array}{l}\text { - Utiliza uma distribuição } x^{2} \text { não-centralizada } \\
\text { - Modelo de comparação referencial é menos restritivo } \\
\text { - Sensível ao tamanho da amostra } \\
\text { - Entre os indicadores de não-centralidade, é o menos } \\
\text { enviesado para amostras Pequenas } \\
\text { - Estima parâmetros populacionais }\end{array}$ \\
\hline \multirow{3}{*}{$\begin{array}{l}\text { RMSEA (root } \\
\text { mean square } \\
\text { error of } \\
\text { approximation) }\end{array}$} & $0-1$ & $\begin{array}{l}\text { - Adota uma distribuição } x^{2} \text { não-centralizada para estimar o } \\
\text { grau de não-adequação ou má-especificação do modelo } \\
\text { - Estima uma distribuição } x^{2} \text { não-centralizada, em que o valor } \\
\text { do parâmetro não-centralizado é comparado com o valor da } \\
\text { distribuição centralizada. }\end{array}$ \\
\hline & \multirow[b]{2}{*}{$\mathrm{RMSEA} \leq 0,05$} & $\begin{array}{l}\text { - Valor é ajustado segundo os graus de liberdade do modelo } \\
\text { - Ajusta o valor da estatística } \mathrm{x}^{2} \text { segundo o tamanho da } \\
\text { amostra }\end{array}$ \\
\hline & & $\begin{array}{l}\text { - Robusto à violação da distribuição normal } \\
\text { - Sensível ao tamanho da amostra } \\
\text { - Expressa a variância dos dados que não é explicada pelo } \\
\text { modelo } \\
\text { - Avalia o nível de não-adequação aos parâmetros } \\
\text { populacionais } \\
\text { - Obtido a partir da distribuição } x^{2} \text {, permite a obtenção de } \\
\text { intervalo de confiança }\end{array}$ \\
\hline \multirow[t]{2}{*}{$\begin{array}{l}\mathrm{RMR} \text { (root } \\
\text { mean square } \\
\text { residual) }\end{array}$} & $0-1$ & $\begin{array}{l}\text { - valor médio dos resíduos quadrados } \\
\text { - determinado, apenas, a partir dos elementos da matriz de } \\
\text { covariância residual } \\
\text { - compara diferentes modelos que utilizam os mesmos dados } \\
\text { - expressa a variância dos dados que não é explicada pelo } \\
\text { modelo }\end{array}$ \\
\hline & $<0,05$ - Próximo de 0 & $\begin{array}{l}\text { - pequenos resíduos ocasionam baixo indicador } \\
\text { - sensível ao desvio de normalidade } \\
\text { - estima parâmetros amostrais }\end{array}$ \\
\hline
\end{tabular}


conclusão

\begin{tabular}{|c|c|c|c|}
\hline $\begin{array}{l}\text { AIC (Akaike } \\
\text { information }\end{array}$ & \multirow{4}{*}{$\begin{array}{l}\text { Comparação } \\
\text { entre modelos } \\
=\mathrm{O} \text { modelo } \\
\text { com menor } \\
\text { valor desses } \\
\text { índices deve } \\
\text { ser escolhido. }\end{array}$} & $<0$ & $\begin{array}{l}\text { - Corresponde à estatística qui-quadrada ajustada pelos gl } \\
\text { - Compara modelos alternativos gerados pelo pesquisador, } \\
\text { que apresentam números diferentes de fatores (modelos não- } \\
\text { hierárquicos) }\end{array}$ \\
\hline & & $\begin{array}{c}\text { Próximo } \\
\text { a zero }\end{array}$ & $\begin{array}{l}\text { Robusto à violação da distribuição normal } \\
\text { Requer amostras grandes } \\
\text { Estima parâmetros populacionais }\end{array}$ \\
\hline BIC & & & \\
\hline BCC & & & \\
\hline
\end{tabular}

Fonte: Adaptada de Melhado (2004) e Albuquerque (2008)

12. Modelos alternativos foram testados para validar a hipótese central de pesquisa pela natureza e direção das relações entre uma dada ordem de construtos. Modelos estruturais alternativos podem variar em termos do número de variáveis exógenas e endógenas, ou do número de relações causais especificadas, bem como do tipo de efeito. Ao final de cada conjunto de modelos alternativos, indicaram-se as medidas de ajustes de comparação dos modelos (AIC, BCC e BIC) para verificar o modelo que melhor explica a relação.

\subsubsection{Os resultados analíticos da equação estrutural}

O objetivo desta equação é relacionar GRI (grau de internacionalização), COMPET (competência) e DESEMP (desempenho), que são variáveis não-observáveis diretamente, ou seja, variáveis latentes, que podem ser mensuradas por algumas questões (variáveis observáveis ou indicadores). Além disso, a competência é um construto de segunda ordem, ou seja, é mensurada por outras variáveis latentes - inovação (INOV), habilidade em marketing (HMKT), orientação internacional (ORINT) e orientação para mercado internacional (OMKIN) - e, estas, por sua vez, são mensuradas por questões.

Para identificar as variáveis que melhor explicariam os construtos e para fixar o parâmetro das variáveis latentes foi realizada uma análise fatorial exploratória (AFE) com todas as questões a serem analisadas e, em seguida, observaram-se as cargas fatoriais de cada uma das variáveis 
nos fatores formados. Verificou-se que algumas variáveis não apresentavam uma carga fatorial satisfatória, por esse motivo, estas foram retiradas na análise. Esse procedimento se faz necessário para a obtenção de uma melhor combinação linear entre as variáveis. A variável com maior carga fatorial para determinado fator foi a escolhida para ser fixada e garantir a identificabilidade do modelo.

As cargas fatoriais do modelo de AFE inicial são apresentadas na Tabela 23, na qual pode-se notar que sete fatores foram selecionados (pela porcentagem da variabilidade explicada de pelo menos 70\%; Para Hair Jr. et al. (2009), uma solução que explique 60\% da variância total é satisfatória).

Nota-se na Tabela 23 que as variáveis relacionadas ao grau de internacionalização (Modo, Idade, País, Vendas, Func e ExpExc) não estão todas em um único fator, porém, Modo, Funcionários no exterior/Funcionários Total (Func) e a Experiência do Executivo no Exterior (ExpExc) possuem cargas fatoriais altas no mesmo fator e, portanto, decidiu-se pela eliminação das três variáveis para refazer a AFE e verificar os novos resultados.

Tabela 23 - Cargas fatoriais para o modelo de AFE inicial

\begin{tabular}{|c|c|c|c|c|c|c|c|}
\hline \multirow{2}{*}{ Variável } & \multicolumn{7}{|c|}{ Fator } \\
\hline & 1 & 2 & 3 & 4 & 5 & 6 & 7 \\
\hline \multicolumn{8}{|l|}{ GRI } \\
\hline Modo & 0,095 & $-0,003$ & 0,057 & 0,197 & 0,051 & 0,674 & $-0,074$ \\
\hline Idade & $-0,080$ & 0,015 & 0,034 & 0,026 & 0,035 & $-0,038$ & $\mathbf{0 , 8 6 7}$ \\
\hline País & 0,104 & 0,117 & $-0,452$ & 0,178 & 0,496 & 0,214 & 0,370 \\
\hline Vendas & 0,335 & $-0,115$ & 0,465 & $-0,099$ & 0,091 & $-0,101$ & 0,450 \\
\hline Func & 0,015 & 0,104 & 0,201 & $-0,046$ & $-0,063$ & 0,699 & $-0,175$ \\
\hline ExpExc & $-0,065$ & 0,024 & $-0,042$ & 0,114 & 0,217 & 0,722 & 0,225 \\
\hline \multicolumn{8}{|c|}{ Orientação Internacional } \\
\hline Q11.1 & 0,441 & 0,182 & $\mathbf{0 , 5 0 7}$ & 0,020 & 0,100 & 0,298 & 0,117 \\
\hline Q11.2 & 0,366 & 0,357 & 0,571 & 0,226 & 0,114 & 0,184 & 0,202 \\
\hline Q11.3 & 0,242 & 0,277 & $\mathbf{0 , 7 0 2}$ & 0,244 & 0,021 & 0,308 & 0,002 \\
\hline \multicolumn{8}{|c|}{ Habilidade de Marketing Internacional } \\
\hline Q15.1 & 0,116 & $\mathbf{0 , 8 7 8}$ & 0,022 & 0,162 & 0,064 & 0,003 & 0,042 \\
\hline Q15.2 & 0,068 & 0,768 & 0,194 & 0,134 & 0,271 & $-0,022$ & 0,160 \\
\hline Q15.3 & 0,158 & $\mathbf{0 , 7 5 0}$ & 0,216 & 0,275 & 0,127 & 0,065 & $-0,008$ \\
\hline Q15.4 & 0,151 & 0,789 & 0,096 & 0,055 & 0,202 & 0,173 & $-0,203$ \\
\hline \multicolumn{8}{|c|}{ Inovação Internacional } \\
\hline Q11.4 & 0,161 & 0,136 & 0,249 & 0,697 & 0,381 & 0,156 & 0,014 \\
\hline Q11.5 & 0,069 & 0,202 & $-0,008$ & 0,771 & 0,017 & 0,188 & 0,032 \\
\hline Q11.6 & 0,063 & 0,357 & 0,171 & 0,587 & 0,056 & $-0,001$ & $-0,015$ \\
\hline
\end{tabular}




\begin{tabular}{|c|c|c|c|c|c|c|c|}
\hline \multicolumn{8}{|c|}{ Orientação para o mercado internacional } \\
\hline Q11.7 & 0,122 & $-0,038$ & 0,526 & 0,498 & 0,177 & $-0,025$ & 0,027 \\
\hline Q11.8 & 0,313 & 0,246 & 0,723 & 0,197 & 0,177 & 0,095 & 0,009 \\
\hline Q11.9 & 0,016 & 0,197 & 0,386 & 0,023 & 0,776 & 0,085 & 0,045 \\
\hline Q11.10 & 0,103 & 0,279 & 0,042 & 0,165 & 0,773 & 0,070 & 0,025 \\
\hline Q11.11 & 0,037 & 0,340 & 0,568 & 0,293 & 0,476 & $-0,005$ & $-0,156$ \\
\hline \multicolumn{8}{|c|}{ Desempenho Operacional } \\
\hline Volum & $\mathbf{0 , 8 3 9}$ & $-0,008$ & 0,058 & 0,264 & $-0,001$ & $-0,034$ & $-0,133$ \\
\hline Prodt & 0,689 & 0,037 & 0,120 & 0,282 & 0,009 & $-0,077$ & $-0,127$ \\
\hline Partic & $\mathbf{0 , 5 3 0}$ & 0,195 & 0,290 & 0,483 & $-0,044$ & 0,153 & $-0,017$ \\
\hline \multicolumn{8}{|c|}{ Desempenho Financeiro } \\
\hline Rent & $\mathbf{0 , 8 3 0}$ & 0,156 & 0,153 & 0,053 & 0,051 & 0,028 & 0,018 \\
\hline ROA & 0,716 & 0,127 & 0,138 & $-0,121$ & 0,338 & $-0,070$ & 0,184 \\
\hline Lucro & 0,609 & 0,188 & 0,163 & $-0,122$ & $-0,047$ & 0,270 & 0,087 \\
\hline
\end{tabular}

Fonte: Dados da Pesquisa, 2010

Na Tabela 24 apresentam-se os resultados da nova fatoração do modelo retirando as variáveis indicadas como de baixa carga fatorial (Tabela 23) relacionadas ao GRI. Pode-se observar que, neste caso, seis fatores foram selecionados, porém algumas questões relacionadas à orientação para o mercado internacional não se apresentam em um mesmo fator com cargas fatoriais altas, como seria esperado.

Tabela 24 - Cargas fatoriais para o modelo de AFE sem idade, país e vendas

\begin{tabular}{|c|c|c|c|c|c|c|}
\hline \multirow{2}{*}{ Variável } & \multicolumn{6}{|c|}{ Fator } \\
\hline & 1 & 2 & 3 & 4 & 5 & 6 \\
\hline \multicolumn{7}{|l|}{ GRI } \\
\hline Modo & 0,097 & 0,077 & 0,030 & 0,213 & $-0,011$ & 0,699 \\
\hline Func & $-0,029$ & 0,298 & 0,113 & $-0,042$ & $-0,156$ & 0,661 \\
\hline ExpExc & $-0,032$ & $-0,054$ & 0,016 & 0,082 & 0,339 & 0,771 \\
\hline \multicolumn{7}{|c|}{ Orientação Internacional } \\
\hline Q11.1 & 0,401 & 0,618 & 0,125 & $-0,017$ & 0,140 & 0,224 \\
\hline Q11.2 & 0,317 & 0,677 & 0,309 & 0,190 & 0,138 & 0,111 \\
\hline Q11.3 & 0,193 & $\mathbf{0 , 7 6 8}$ & 0,224 & 0,233 & 0,046 & 0,233 \\
\hline \multicolumn{7}{|c|}{ Marketing Internacional } \\
\hline Q15.1 & 0,117 & 0,067 & $\mathbf{0 , 8 8 3}$ & 0,142 & 0,057 & 0,014 \\
\hline Q15.2 & 0,070 & 0,189 & 0,766 & 0,133 & 0,306 & $-0,011$ \\
\hline Q15.3 & 0,147 & 0,238 & 0,756 & 0,277 & 0,111 & 0,068 \\
\hline Q15.4 & 0,122 & 0,189 & $\mathbf{0 , 7 9 3}$ & 0,052 & 0,135 & 0,147 \\
\hline \multicolumn{7}{|c|}{ Inovação Internacional } \\
\hline Q11.4 & 0,153 & 0,256 & 0,141 & $\mathbf{0 , 7 0 0}$ & 0,372 & 0,161 \\
\hline Q11.5 & 0,074 & 0,065 & 0,195 & 0,718 & 0,014 & 0,194 \\
\hline Q11.6 & 0,070 & 0,157 & 0,365 & $\mathbf{0 , 5 9 1}$ & 0,040 & 0,017 \\
\hline \multicolumn{7}{|c|}{ Orientação para o mercado internacional } \\
\hline Q11.7 & 0,102 & 0,486 & $-0,051$ & 0,527 & 0,180 & $-0,048$ \\
\hline Q11.8 & 0,266 & 0,772 & 0,199 & 0,206 & 0,178 & 0,017 \\
\hline Q11.9 & $-0,022$ & 0,397 & 0,191 & 0,061 & 0,757 & 0,042 \\
\hline Q11.10 & 0,122 & 0,035 & 0,287 & 0,186 & 0,779 & 0,084 \\
\hline Q11.11 & 0,006 & $\mathbf{0 , 5 3 7}$ & 0,339 & 0,357 & 0,421 & $-0,041$ \\
\hline
\end{tabular}




\begin{tabular}{|c|c|c|c|c|c|c|}
\hline \multicolumn{7}{|c|}{ Desempenho Operacional } \\
\hline Volum & $\mathbf{0 , 8 3 9}$ & 0,069 & 0,021 & 0,280 & $-0,052$ & $-0,010$ \\
\hline Prodt & 0,701 & 0,079 & 0,069 & 0,319 & $-0,032$ & $-0,041$ \\
\hline Partic & $\mathbf{0 , 5 1 0}$ & 0,403 & 0,170 & 0,443 & $-0,075$ & 0,112 \\
\hline \multicolumn{7}{|c|}{ Desempenho Financeiro } \\
\hline Rent & $\mathbf{0 , 8 2 5}$ & 0,226 & 0,140 & 0,029 & 0,065 & 0,013 \\
\hline ROA & $\mathbf{0 , 7 0 7}$ & 0,188 & 0,109 & $-0,140$ & 0,389 & $-0,084$ \\
\hline Lucro & $\mathbf{0 , 5 8 2}$ & 0,287 & 0,149 & $-0,179$ & 0,003 & 0,228 \\
\hline
\end{tabular}

Fonte: Dados da pesquisa, 2010

Assim sendo, após algumas tentativas de extração de variáveis relacionadas à Orientação para o mercado internacional, decidiu-se retirar a questão 11.10, que foi a variável que reestruturou o conjunto de variáveis para o construto analisado. Os resultados são apresentados na Tabela 25 , a seguir.

Por meio da Tabela 25, a seguir, nota-se que novamente seis fatores foram selecionados, e estes explicam aproximadamente $70 \%$ da variabilidade dos dados. No fator 6 , as questões relacionadas ao grau de internacionalização são identificadas e apresentam-se com cargas fatoriais altas; no fator 5, estão as relacionadas à inovação internacional; no fator 4, as relacionadas ao desempenho operacional; no fator 3 , as relacionadas ao desempenho financeiro; no fator 2, as relacionadas às habilidades de marketing internacional; e, no fator 1 , as relacionadas tanto à orientação internacional quanto à orientação para o mercado internacional. Como a fatoração indicou as variáveis orientação para o mercado internacional e a orientação internacional num único fator, verificou-se que em Knight e Kim (2009) as duas variáveis tiveram a maior relação com competência e os autores somaram as duas orientações, o que gerou o indicador mais forte do construto competência.

Após verificar que a fatoração organizou o conjunto de indicadores, que os construtos ainda assim explicavam $70 \%$ da variabilidade dos dados, e que em cada construto havia, pelo menos, três critérios, partiu-se para a organização do modelo final.

As cargas fatoriais resultantes da melhor fatoração foram utilizadas para fixar os parâmetros nas análises fatoriais confirmatórias e nos modelos de equações estruturais realizados adiante, conforme apresentado na Tabela 25. 
Tabela 25 - Cargas fatoriais para o modelo de AFE final (sem idade, país, vendas e Q11.10)

\begin{tabular}{|c|c|c|c|c|c|c|}
\hline \multirow{2}{*}{ Variável } & \multicolumn{6}{|c|}{ Fator } \\
\hline & 1 & 2 & 3 & 4 & 5 & 6 \\
\hline \multicolumn{7}{|l|}{ GRI } \\
\hline Modo & 0,090 & 0,047 & $-0,068$ & 0,187 & 0,104 & 0,774 \\
\hline Func & 0,131 & 0,085 & 0,047 & $-0,010$ & $-0,047$ & 0,752 \\
\hline ExpExc & $-0,015$ & 0,032 & 0,303 & $-0,424$ & 0,401 & 0,545 \\
\hline \multicolumn{7}{|c|}{ Orientação Internacional } \\
\hline Q11.1 & $\mathbf{0 , 5 0 2}$ & 0,107 & 0,502 & 0,172 & 0,035 & 0,256 \\
\hline Q11.2 & 0,597 & 0,297 & 0,375 & 0,199 & 0,191 & 0,157 \\
\hline Q11.3 & 0,652 & 0,205 & 0,240 & 0,193 & 0,184 & 0,336 \\
\hline \multicolumn{7}{|c|}{ Habilidade de Marketing Internacional } \\
\hline Q15.1 & 0,073 & $\mathbf{0 , 8 8 7}$ & 0,074 & 0,109 & 0,101 & 0,031 \\
\hline Q15.2 & 0,298 & 0,790 & 0,122 & $-0,029$ & 0,120 & $-0,036$ \\
\hline Q15.3 & 0,260 & 0,765 & 0,092 & 0,156 & 0,220 & 0,094 \\
\hline Q15.4 & 0,175 & 0,793 & 0,188 & 0,014 & 0,069 & 0,146 \\
\hline \multicolumn{7}{|c|}{ Inovação Internacional } \\
\hline Q11.4 & 0,427 & 0,183 & 0,117 & 0,089 & 0,748 & 0,044 \\
\hline Q11.5 & 0,067 & 0,198 & 0,042 & 0,090 & 0,828 & 0,073 \\
\hline Q11.6 & 0,232 & 0,384 & $-0,146$ & 0,279 & 0,461 & 0,058 \\
\hline \multicolumn{7}{|c|}{ Orientação para o Mercado Internacional } \\
\hline Q11.7 & $\mathbf{0 , 5 8 1}$ & $-0,027$ & 0,014 & 0,190 & 0,439 & $-0,029$ \\
\hline Q11.8 & 0,760 & 0,202 & 0,239 & 0,264 & 0,086 & 0,130 \\
\hline Q11.9 & 0,691 & 0,254 & 0,175 & $-0,256$ & 0,083 & $-0,033$ \\
\hline Q11.11 & 0,756 & 0,388 & $-0,094$ & 0,134 & 0,144 & 0,055 \\
\hline \multicolumn{7}{|c|}{ Desempenho Operacional } \\
\hline Volum & 0,058 & 0,037 & 0,405 & $\mathbf{0 , 7 7 1}$ & 0,153 & 0,032 \\
\hline Prodt & 0,135 & 0,099 & 0,199 & 0,775 & 0,082 & 0,062 \\
\hline Partic & 0,327 & 0,165 & 0,265 & 0,545 & 0,348 & 0,180 \\
\hline \multicolumn{7}{|c|}{ Desempenho Financeiro } \\
\hline Rent & 0,152 & 0,139 & 0,658 & 0,527 & 0,054 & $-0,005$ \\
\hline ROA & 0,243 & 0,131 & 0,724 & 0,234 & $-0,022$ & $-0,192$ \\
\hline Lucro & 0,071 & 0,111 & 0,759 & 0,126 & 0,061 & 0,133 \\
\hline
\end{tabular}

Fonte: Dados da pesquisa, 2010

Verificou-se, então, a confiabilidade do questionário aplicado. Para isso, calculou-se o Alfa de Crombach para os grupos de questões relacionadas a cada variável latente (Tabela 26). Como não se tem um ponto de corte para considerar o coeficiente alfa como indicativo de alta confiabilidade do questionário, utilizaram-se algumas regras apresentadas por diversos autores. Kline (2005) identificou que os coeficientes em torno de 0,90 são considerados "excelentes", em torno de 0,80 são "muito bons" e valores em torno de 0,70 são "adequados". Para Hair Jr. et al. (2009), a média de confiabilidade pode variar de 0 a 1 , sendo que os valores de 0,60 a 0,70 são considerados como limite inferior de aceitabilidade. Já para Malhotra (2005), um valor de 0,60 ou menos geralmente indica confiabilidade insatisfatória da consistência interna.

De acordo com Hair Jr. et al. (2009), uma elevada confiabilidade de construto indica a existência de consistência interna, o que significa que todas as medidas representam 
consistentemente o mesmo construto latente. $\mathrm{O}$ coeficiente alfa é usado com frequência em parceria com modelos SEM.

Os resultados do teste de confiabilidade do questionário da presente pesquisa, para as variáveis latentes de primeira ordem "Desempenho financeiro e operacional" e para a variável de segunda ordem "Competência" são adequados ou muito bons, pois apresentaram um Alfa de Crombach de, no mínimo, 0,73, como pode ser visualizado individualmente na Tabela 26.

Tabela 26 - Confiabilidade das questões que mensuram as variáveis latentes

\begin{tabular}{c|c|c}
\hline Variável Latente & Questões & Alfa de Cronbach \\
INOV & $11.4,11.5 \mathrm{e} 11.6$ & 0,733 \\
HMKT & $15.1,15.2,15.3 \mathrm{e} 15.4$ & 0,880 \\
ORINT & $11.7,11.8,11.9 \mathrm{e} 11.11$ & 0,798 \\
OMKIN & $11.1,11.2 \mathrm{e} 11.3$ & 0,856 \\
DESEMP FINANCEIRO & Rent, ROA e Lucro & 0,770 \\
DESEMP OPERACIONAL & Volum, Prodt e Partic & 0,791 \\
\hline
\end{tabular}

Fonte: Dados da pesquisa (2010)

Já o construto reflexivo GRI, foi mensurado por modo de entrada, por tempo que realiza as exportações no exterior, pela quantidade de países em que a empresa atua, pelo \% de receita de vendas no exterior/vendas totais, pela proporção de funcionários no exterior e pelo número de executivos principais com experiência prévia no exterior. Como estas variáveis não possuem resultados de escalas tipo Likert e não possuem respostas fechadas em sua maioria, realizou-se uma análise fatorial confirmatória para determinar quais as variáveis são realmente significativas para mensurar GRI. O modelo inicial está apresentado na Figura 4, e os resultados dos testes de significância dos parâmetros do modelo estão na Tabela 27.

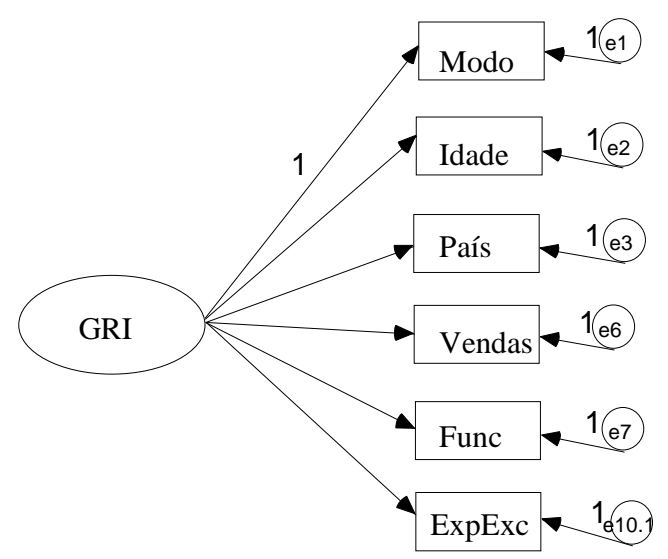

Figura 4 - Diagrama de caminho: análise fatorial confirmatória - GRI Fone: dados da pesquisa (2010) 
Como se pode perceber pela observação da Figura 4, GRI é um construto de representação reflexiva de primeira ordem. Isto quer dizer que o construto GRI não é observado diretamente, mas é refletido por variáveis, e estas, sim, são observadas. Esta observação é o reflexo das questões solicitadas aos respondentes. Por ser um fator reflexivo, os erros foram também considerados na análise. A fixação da variável modo foi realizada para garantir a identificabilidade do modelo.

Na Tabela 27, a seguir, os testes de significância do modelo de análise fatorial foram realizados para esta variável. Verifica-se, por meio desta etapa, as variáveis observáveis que não se mostraram significativas já na etapa exploratória e se confirmaram na etapa confirmatória. Segundo Hair Jr. et al. (2009), a técnica da análise fatorial confirmatória informa o quão bem as especificações dos fatores combinam com a realidade. Mediante a teoria de mensuração, especificaram-se as relações das variáveis medidas que representam um construto latente que não é diretamente medido, neste caso, o GRI.

Pelo fato dos construtos terem sido definidos a partir da literatura, dos exemplos de trabalhos empíricos publicados e da etapa qualitativa, utilizou-se inicialmente a análise fatorial exploratória e após a Análise Fatorial Confirmatória (CFA) para confirmar as variáveis que comporiam os construtos.

A validade do construto é o grau segundo o qual um conjunto de itens medidos realmente reflete o construto latente que esses itens devem medir, e para isso os itens (variáveis) devem ser no mínimo significantes, como mencionado por Hair Jr. et al. (2009). O nível de significância mínima para ser mantido como variável que possa garantir a robustez do modelo é de $5 \%$.

Percebe-se pela Tabela 27, a seguir, que as variáveis Idade (Tempo de experiência com exportação), País (Quantidade de países que a empresa exporta diretamente) e Vendas (percentual da receita de vendas/receitas totais) não se mostraram significativas. Como alternativa para preservar o modelo, tais variáveis foram retiradas uma a uma para verificar se a significância seria alterada pela saída de uma ou outra variável. Esta fase da pesquisa é chamada de exploratória, visto que se identificam as variáveis que poderão representar o melhor modelo. As mesmas variáveis foram também retiradas durante a etapa exploratória. 
Tabela 27 - Testes de significância: análise fatorial confirmatória inicial para GRI

\begin{tabular}{ccccccc}
\hline \multicolumn{2}{c}{ Relação } & & Estimativa & Erro-padrão & $\begin{array}{c}\text { Estatística } \\
\text { de teste }\end{array}$ & P-valor \\
\hline Modo & $<--$ & GRI & 1,000 & & & \\
Idade & $<--$ & GRI & 1,503 & 3,271 & 0,460 & 0,646 \\
País & $<--$ & GRI & 1,440 & 0,815 & 1,766 & 0,077 \\
Vendas & $<--$ & GRI & 0,310 & 1,302 & 0,238 & 0,812 \\
Func & $<--$ & GRI & 0,202 & 0,064 & 3,168 & 0,002 \\
ExpExc & $<--$ & GRI & 0,897 & 0,283 & 3,174 & 0,002 \\
\hline
\end{tabular}

Fonte: dados da pesquisa (2010)

Portanto, verificou-se que as variáveis que se relacionavam com o construto GRI, indicados pela técnica estatística da análise fatorial confirmatória, quais sejam, a proporção de funcionários no exterior/funcionários totais (FUNC) e o número de executivos com experiência no exterior (ExcExp), são estatisticamente significativas. Vale ressaltar que o parâmetro referente ao modo de entrada foi fixado para garantir a identificabilidade do modelo. O modelo final e a significância das variáveis para GRI é demonstrado na Tabela 28.

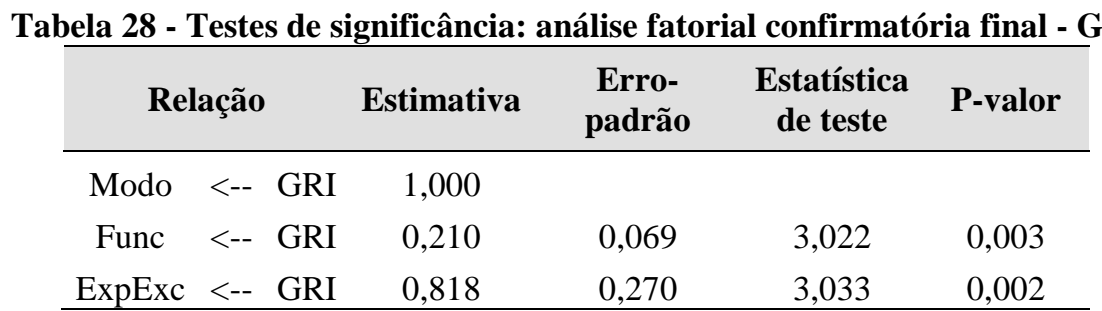

Fonte: Dados da pesquisa (2010)

Mediante esses testes, verificou-se que as variáveis que demonstraram maior combinação com a realidade que se pretende pesquisar (HAIR JR. et al., 2009; DUNNING, 1996) foram os funcionários das PMEs no exterior, a experiência internacional do executivo e a estratégia de internacionalização (que foi fixada).

Embora os demais construtos estejam relacionados a questões cujas possíveis respostas são escalas do tipo Likert, e já tenha sido calculada a confiabilidade por meio do Alfa de Crombach, também realizou-se uma análise fatorial confirmatória para determinar quais variáveis são realmente significativas para mensurar cada um dos construtos. O modelo inicial para desempenho financeiro está apresentado na Figura 5, a seguir, e os resultados dos testes de significância dos parâmetros do modelo estão na Tabela 29. 


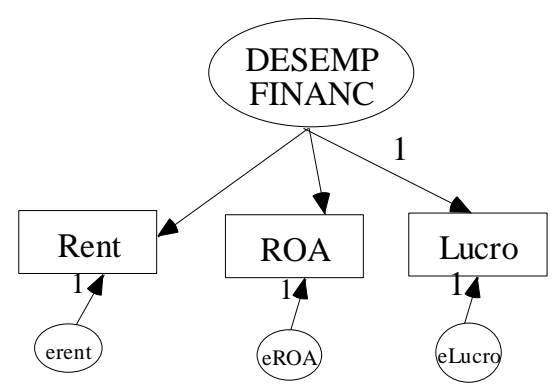

Figura 5 - Diagrama de caminho: análise fatorial confirmatória inicial - desempenho financeiro Fonte: Dados da pesquisa (2010)

Pela Tabela 29, observa-se que todos os parâmetros são estatisticamente significativos a um nível de significância de 5\%. Vale ainda ressaltar que o parâmetro referente à questão 13.1 foi fixado para garantir a identificabilidade(?) do modelo, seguindo os resultados das cargas fatoriais da Tabela 25 .

Tabela 29 - Testes de significância do modelo de análise fatorial confirmatória inicial/final para desempenho financeiro

\begin{tabular}{ccccccc}
\hline & & Relação & Estimativa & $\begin{array}{c}\text { Erro- } \\
\text { padrão }\end{array}$ & $\begin{array}{c}\text { Estatística } \\
\text { de teste }\end{array}$ & P-valor \\
\hline Rent & $<--$ & DESEMP FINANCEIRO & 1,645 & 0,310 & 5,299 & 0,000 \\
ROA & $<--$ & DESEMP FINANCEIRO & 1,412 & 0,250 & 5,639 & 0,000 \\
Lucro & $<--$ & DESEMP FINANCEIRO & 1,000 & & & \\
\hline
\end{tabular}

Fonte: Dados da pesquisa (2010)

Na Figura 6, apresenta-se o modelo inicial para desempenho operacional, e os resultados dos testes de significância dos parâmetros do modelo encontram-se na Tabela 30.

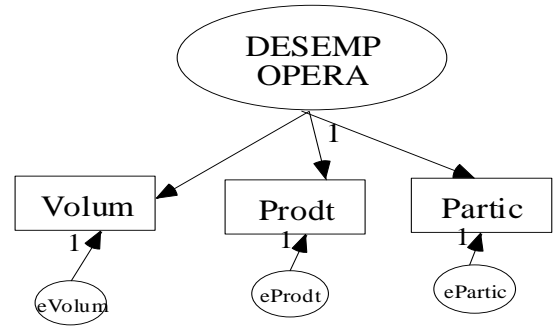

Figura 6 - Diagrama de caminho do modelo de análise fatorial confirmatória inicial para desempenho operacional

Fonte: Dados da pesquisa (2010) 
Na Tabela 30 observa-se que todos os parâmetros são estatisticamente significativos a um nível de significância de 5\%. Outro aspecto que merece ser ressaltado é que o parâmetro referente à questão Produtividade (Prodt) foi fixado para garantir a identificabilidade do modelo, seguindo igualmente os resultados das cargas fatoriais da Tabela 25.

Tabela 30 - Testes de significância do modelo de análise fatorial confirmatória inicial/final para desempenho operacional

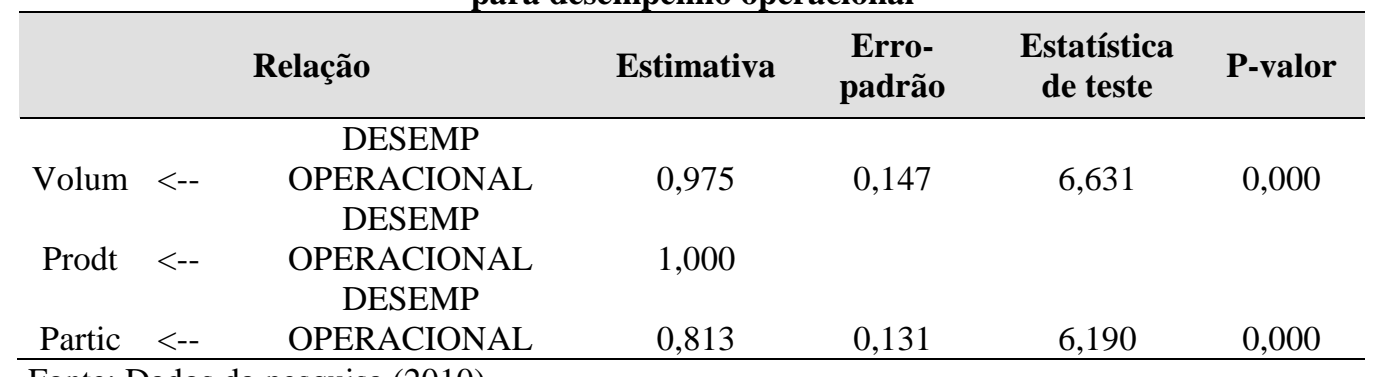

Fonte: Dados da pesquisa (2010)

Na Figura 7 consta o modelo inicial para inovação internacional e na Tabela 31 são exibidos os resultados dos testes de significância dos parâmetros do modelo.

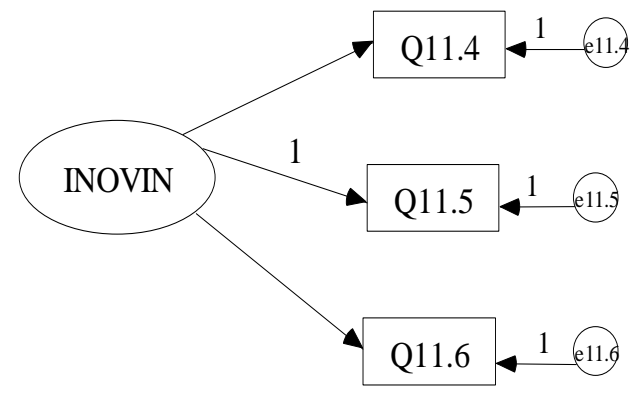

Figura 7 - Diagrama de caminho do modelo de análise fatorial confirmatória inicial para inovação internacional

Fonte: Dados da pesquisa (2010)

Observa-se, na Tabela 31, a seguir, que todos os parâmetros são estatisticamente significativos a um nível de significância de 5\%. Vale ainda observar que o parâmetro referente à questão 11.5 foi fixado para garantir a identificabilidade do modelo, seguindo também os resultados das cargas fatoriais da Tabela 25. 
Tabela 31 - Testes de significância do modelo de análise fatorial confirmatória inicial/final para inovação internacional

\begin{tabular}{|c|c|c|c|c|c|c|}
\hline \multicolumn{3}{|c|}{ Relação } & \multirow{2}{*}{$\begin{array}{c}\text { Estimativa } \\
1,118\end{array}$} & \multirow{2}{*}{$\begin{array}{c}\begin{array}{c}\text { Erro- } \\
\text { padrão }\end{array} \\
0,233\end{array}$} & \multirow{2}{*}{$\begin{array}{c}\begin{array}{c}\text { Estatística } \\
\text { de teste }\end{array} \\
4,803\end{array}$} & \multirow{2}{*}{$\begin{array}{c}\text { P-valor } \\
0,000\end{array}$} \\
\hline Q11.4 & $<--$ & INOVIN & & & & \\
\hline Q11.5 & $<--$ & INOVIN & 1,000 & & & \\
\hline Q11.6 & $<--$ & INOVIN & 0,572 & 0,126 & 4,541 & 0,000 \\
\hline
\end{tabular}

Fonte: Dados da pesquisa (2010)

Na Figura 8 mostra-se o modelo inicial para habilidade em marketing internacional e na Tabela 32 os resultados dos testes de significância dos parâmetros do modelo.

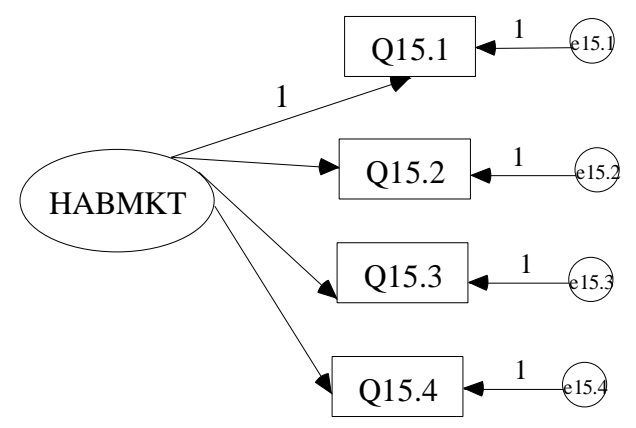

Figura 8 - Diagrama de caminho do modelo de análise fatorial confirmatória inicial para habilidade em marketing internacional

Fonte: Dados da pesquisa (2010)

Constata-se, pela análise da Tabela 32, que todos os parâmetros são estatisticamente significativos a um nível de significância de 5\%. Vale mencionar, outrossim, que o parâmetro referente à questão 15.1 foi fixado para garantir a identificabilidade do modelo, seguindo os resultados das cargas fatoriais da Tabela 25, apresentada anteriormente.

Tabela 32 - Testes de significância do modelo de análise fatorial confirmatória inicial/final para habilidade em marketing internacional

\begin{tabular}{ccccccc}
\hline & \multicolumn{7}{c}{ Relação } & Estimativa & $\begin{array}{c}\text { Erro- } \\
\text { padrão }\end{array}$ & $\begin{array}{c}\text { Estatística } \\
\text { de teste }\end{array}$ & P-valor \\
\hline Q15.1 & $<--$ & HABMKT & 1,000 & & & \\
Q15.2 & $<--$ & HABMKT & 0,942 & 0,091 & 10,333 & 0,000 \\
Q15.3 & $<--$ & HABMKT & 1,125 & 0,117 & 9,591 & 0,000 \\
Q15.4 & $<--$ & HABMKT & 1,009 & 0,111 & 9,097 & 0,000 \\
\hline
\end{tabular}

Fonte: Dados da pesquisa (2010) 
Verificou-se, na Tabela 25, anteriormante apresentada. que como as questões relacionadas à orientação internacional e à orientação para o mercado internacional apresentaram cargas fatoriais altas no mesmo fator, decidiu-se, então, juntá-las num único construto, que será denominado de ORIENTAÇÃO.

Apresenta-se na Figura 9 o modelo inicial para orientação e na Tabela 33 os resultados dos testes de significância dos parâmetros do modelo.

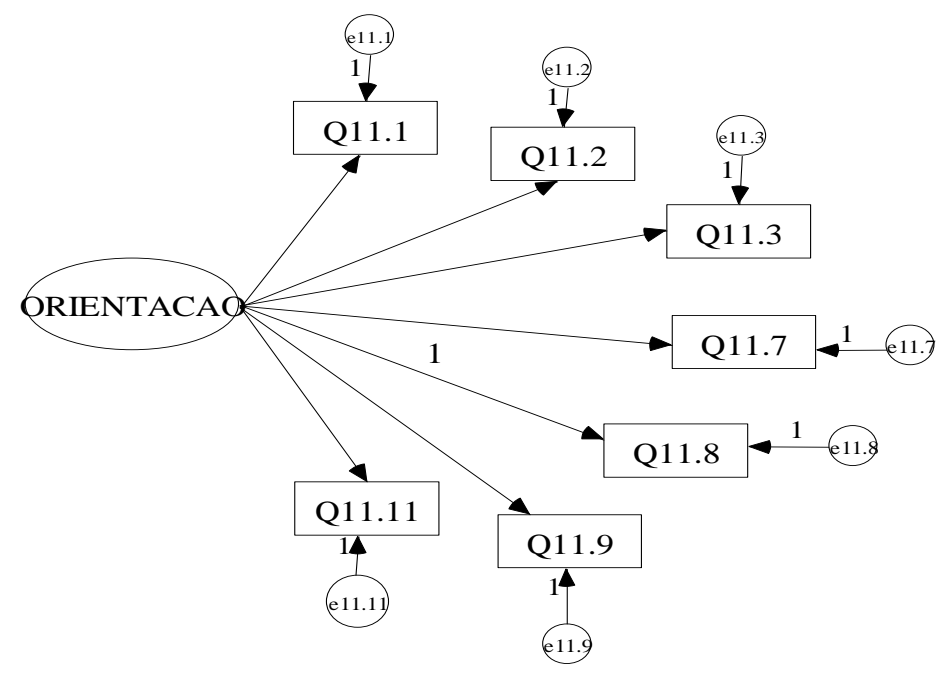

Figura 9 - Diagrama de caminho do modelo de análise fatorial confirmatória inicial para Orientação Fonte: Dados da pesquisa (2010)

De modo similar ao apresentado nas tabelas anteriores, também na Tabela 33 constata-se que todos os parâmetros são estatisticamente significativos a um nível de significância de 5\%. Vale destacar uma vez mais que o parâmetro referente à questão 11.8 foi fixado para garantir a identificabilidade do modelo, seguindo os resultados das cargas fatoriais da Tabela 25.

Tabela 33 - Testes de significância do modelo de análise fatorial confirmatória inicial/final para orientação

\begin{tabular}{ccccccc}
\hline & Relação & Estimativa & $\begin{array}{c}\text { Erro- } \\
\text { padrão }\end{array}$ & $\begin{array}{c}\text { Estatística } \\
\text { de teste }\end{array}$ & P-valor \\
\hline Q11.1 & $<--$ & ORIENTACAO & 0,845 & 0,102 & 8,244 & 0,000 \\
Q11.2 & $<--$ & ORIENTACAO & 0,981 & 0,100 & 9,823 & 0,000 \\
Q11.3 & $<--$ & ORIENTACAO & 1,142 & 0,105 & 10,893 & 0,000 \\
Q11.7 & $<--$ & ORIENTACAO & 0,606 & 0,108 & 5,630 & 0,000 \\
Q11.8 & $<--$ & ORIENTACAO & 1,000 & & & \\
Q11.9 & $<--$ & ORIENTACAO & 0,663 & 0,113 & 5,867 & 0,000 \\
Q11.11 & $<--$ & ORIENTACAO & 0,824 & 0,103 & 8,010 & 0,000 \\
\hline Fonte: Dados da pesquisa $(2010)$ & & & &
\end{tabular}

Fonte: Dados da pesquisa (2010) 
Definidas as variáveis que serão utilizadas para mensurar o grau de internacionalização (GRI), faz-se necessário iniciar os ajustes dos modelos de equações estruturais para verificar se as relações supostas nesta tese são de fato estatisticamente significativas, e com isso testar as hipóteses da presente tese.

\subsubsection{Teste das hipóteses desta tese}

As relações entre o GRI, competência e desempenho são, nesta fase, identificadas. A Hipótese Central é o foco desta análise:

Hc: O maior grau de internacionalização impacta positivamente o desenvolvimento de competências que têm uma relação positiva e direta com o desempenho financeiro e operacional da PME brasileira.

Para relacionar a hipótese desta tese com a técnica estatística utilizada e auxiliar na compreensão da Hc foi necessário fazer a adaptação da sua apresentação. Assim sendo, as hipóteses derivadas da Hc são:

H1a: As competências organizacionais mediam direta e positivamente a relação entre o GRI e o desempenho financeiro.

H1b: As competências organizacionais mediam direta e positivamente a relação entre o GRI e o desempenho operacional.

A hipótese inicial a ser testada é a H1a, ou seja, a relação entre o GRI e o desempenho financeiro, mediada pelas competências.

Na Figura 10, a seguir, apresenta-se o diagrama de caminho inicial para o 1o modelo ajustado(1a). 


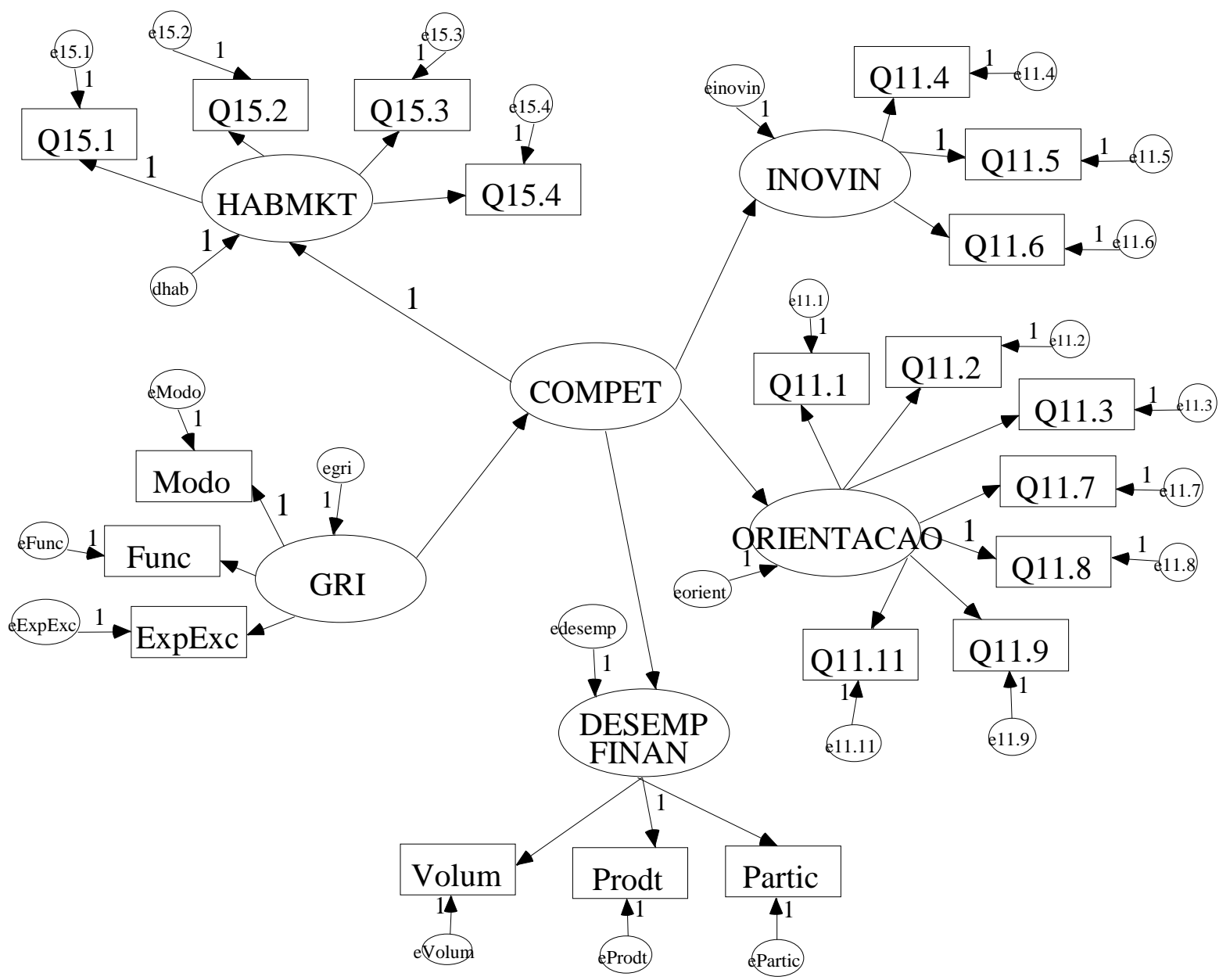

Figura 10 - Diagrama de caminho do modelo inicial 1a.

Fonte: dados da pesquisa (2010)

Por meio do diagrama apresentado na Figura 10 pode-se, com facilidade, escrever as equações dos modelos de mensuração (relacionando cada item com sua variável latente) e do modelo estrutural (relaciona as variáveis latentes entre si). Assim, têm-se os modelos de mensuração expostos na Tabela 34.

Tabela 34 - Modelos de mensuração

\begin{tabular}{|c|c|}
\hline Variáveis & Modelos \\
\hline GRI & $\begin{array}{c}\mathrm{Q}_{\mathrm{i}}=\mathrm{a}_{\mathrm{i}} \mathrm{GRI}+\mathrm{e}_{\mathrm{i}} \\
\mathrm{i}=\text { modo, Func e ExpExc }\end{array}$ \\
\hline ORIENTACAO & $\begin{array}{c}\mathrm{Q}_{\mathrm{j}}=\mathrm{a}_{\mathrm{j}} \text { ORINTACAO+ } \mathrm{e}_{\mathrm{j}} \\
\mathrm{j}=11.1,11.2,11.3,11.7,11.8,11.9 \text { e } 11.11\end{array}$ \\
\hline HABMKT & $\begin{array}{c}\mathrm{Q}_{\mathrm{k}}=\mathrm{a}_{\mathrm{k}} \mathrm{HABMKT}+\mathrm{e}_{\mathrm{k}} \\
\mathrm{k}=15.1,15.2,15.3 \text { e } 15.4\end{array}$ \\
\hline INOVIN & $\begin{array}{c}\mathrm{Q}_{\mathrm{l}}=\mathrm{a}_{\mathrm{l}} \text { INOVIN }+\mathrm{e}_{1} \\
\mathrm{l}=11.4,11.5 \text { e } 11.6\end{array}$ \\
\hline DESEMP FINANCEIRO & $\begin{array}{c}\mathrm{Q}_{\mathrm{r}}=\mathrm{a}_{\mathrm{r}} \text { DESEMP FINANCEIRO+e }_{\mathrm{r}} \\
\mathrm{r}=\text { Rent, ROA e Lucro }\end{array}$ \\
\hline
\end{tabular}


O Modelo Estrutural é apresentado da seguinte forma:

- ORIENTACAO $=b_{1}$ COMPET $+\mathrm{e}_{\text {orint }}$

- $\mathrm{HABMKT}=\mathrm{b}_{2} \mathrm{COMPET}+\mathrm{e}_{\mathrm{hab}}$

- $\quad$ INOVIN $=b_{3}$ COMPET $+e_{\text {inovin }}$

- $\quad$ COMPET $=b_{4}$ GRI $+e_{\text {comp }}$

- DESEMP FINANCEIRO $=\mathrm{b}_{5} \mathrm{COMPET}+\mathrm{e}_{\text {desemp }}$

em que: $b_{s}$ são os coeficientes das equações estruturais e $e_{s}$ são os erros estruturais.

Antes de estimar os efeitos (parâmetros) do modelo, como já comentado, é necessário verificar a identificabilidade do modelo, ou seja, se o modelo apresenta soluções únicas para as equações apresentadas.

O modelo proposto para o problema estudado consiste de um modelo de análise fatorial confirmatória de segunda ordem, em que os fatores de primeira ordem são as três variáveis latentes relacionadas à competência (INOV, HABMKT, ORIENTAÇÃO) e o fator de segunda ordem é a competência (COMPET). Para este tipo de modelo, Kline (2005) sugere as seguintes regras de identificabilidade:

a) Deverá haver pelo menos 3 fatores de primeira ordem;

b) Cada fator de primeira ordem deve ter pelo menos 2 indicadores (que neste caso são os itens do questionário correspondentes a cada variável latente);

c) Deve-se fixar o coeficiente de um indicador de cada fator de primeira ordem como 1;

d) Deve-se fixar um dos coeficientes de efeito do fator de segunda ordem sobre um fator de primeira ordem como 1 .

Pode-se observar que as regras (a) e (b) estão satisfeitas. E para que (c) e (d) também sejam satisfeitas, basta fixar $\mathrm{a}_{1}=\mathrm{a}_{11.1}=\mathrm{a}_{15.1}=\mathrm{a}_{11.4}=\mathrm{a}_{11.9}=\mathrm{a}_{12.5}=\mathrm{b}_{2}=1$. Assim, tem-se que o modelo proposto é identificável.

Para garantir a identificabilidade do modelo, calcula-se inicialmente o número de graus de liberdade do modelo. Os graus de liberdade (gl) são calculados da seguinte maneira: 


$$
g l=\frac{(p+q)(p+q+1)}{2}-t
$$

em que: $\mathrm{p}$ e q são o número de variáveis observadas relacionadas às variáveis latentes endógenas e exógenas, respectivamente, e t é o número de parâmetros livres do modelo (coeficientes que acompanham as variáveis latentes nas equações estruturais e de mensuração, variâncias e covariâncias das variáveis latentes exógenas e variâncias dos erros de mensuração e dos erros das equações estruturais).

Assim, o modelo inicial 1a proposto consta com:

a) 17 variáveis observadas relacionadas às variáveis latentes endógenas (variáveis que recebem influência de outras variáveis latentes) e 3 variáveis observadas relacionadas à variável latente exógena GRI (variável que não recebe influência de outra variável latente), então, $p=17$ e $q=3$;

b) 15 coeficientes que acompanham as variáveis latentes nas equações de mensuração (isto porque 5 coeficientes foram fixados como 1), 4 coeficientes que acompanham as variáveis latentes nas equações estruturais (lembrando que 1 coeficiente foi fixado como 1 também neste caso), 1 variância da variável latente exógena GRI, 20 variâncias dos erros de mensuração e 5 variâncias dos erros das equações estruturais, o que leva a $t=$ 45 .

Logo, $\quad \frac{(p+q)(p+q+1)}{2}=\frac{20 \times 21}{2}=210$ (número de elementos distintos na matriz de covariância amostral). Então:

$$
\mathrm{gl}=210-45=165
$$

Neste momento é necessário escolher o método de estimação a ser utilizado. Como o modelo possui variáveis ordinais (escala Likert de 5 pontos), em geral tem-se uma violação da suposição de normalidade multivariada das variáveis observadas e, portanto, o ideal é utilizar o método de mínimos quadrados ponderados, WLS (ou Asymptotically distribution-free, 
ADF, no AMOS), com a matriz de correlação polychoric como matriz de pesos (JÖRESKOG, 2004). Porém, este método tem 3 restrições importantes, de acordo com Byrne (2001):

(a) necessidade de amostras muito grandes $\left(N>\frac{(p+q)(p+q+1)}{2}\right)$;

(b) número limitado de variáveis observadas $(\mathrm{p}+\mathrm{q}<25)$;

(c) a forte suposição de que por trás de cada variável categórica observada há uma variável latente contínua equivalente e, além disso, que essas variáveis latentes contínuas têm distribuição normal multivariada.

Como a suposição (c) é extremamente forte e pode ser inapropriada em alguns contextos, alguns autores afirmam que faz mais sentido tratar as variáveis categóricas como variáveis contínuas e corrigir a estatística de teste, como, por exemplo, a estatística corrigida de Satorra-Bentler, do que utilizar um método diferente de estimação. (BYRNE, 2001).

Um estudo de simulação realizado por Hu et al. (1992), no qual se avaliou o comportamento de seis estatísticas de teste com um estudo de análise fatorial confirmatória de Monte Carlo para três tipos de violação de condições teóricas (violações de distribuição, de independência e de exigências de tamanhos amostrais grandes), mostrou que o teste de ADF foi muito ruim para amostras pequenas e médias, sendo satisfatório somente para amostras maiores que 5000. Além disso, observou-se que os testes utilizando o método de máxima verossimilhança (MV) foram satisfatórios para amostras com tamanho em torno de 500 para a maioria das condições estudadas.

Olsson et al. (2000) também compararam o método de WLS com os métodos de MV e GLS (mínimos quadrados generalizados) sob diferentes condições e constataram que, ao contrário dos textos que recomendam o método de WLS para dados não-normais, nas simulações este método mostrou-se inferior, até mesmo com amostras de tamanho 1000, e nenhum dos casos se mostrou melhor que os métodos de MV e de GLS. Outros estudos igualmente sugerem que o método de WLS leva a estatísticas de ajuste similares à estimação de MV e sem diferenças na interpretação. (GARSON, 2007). 
Algumas suposições do modelo devem ser verificadas antes de se iniciar a análise do modelo efetivamente. Na Tabela 35, a seguir, apresentam-se as medidas de assimetria e excesso de curtose das variáveis observadas e suas respectivas razões críticas (CR). Nota-se, por meio da referida tabela, que a maioria dos coeficientes de assimetria e excesso de curtose são estatisticamente não significativos $(|\mathrm{CR}|<2,00)$, ou seja, estas variáveis apresentam assimetria e excesso de curtose nula (equivalentes à distribuição Normal).

\begin{tabular}{|c|c|c|c|c|c|c|}
\hline Variável & Mínimo & Máximo & Assimetria & CR & $\begin{array}{c}\text { Excesso } \\
\text { de } \\
\text { Curtose }\end{array}$ & CR \\
\hline Modo & 0 & 1 & 0,468 & 2,042 & $-1,781$ & $-3,881$ \\
\hline Func & 0 & 1 & 4,841 & 21,102 & 30,872 & 67,283 \\
\hline ExpExc & 0 & 2 & 0,755 & $\mathbf{3 , 2 9 0}$ & $-0,927$ & $-2,021$ \\
\hline Q11.1 & 1 & 5 & $-0,350$ & $-1,527$ & $-0,811$ & $-1,767$ \\
\hline Q11.2 & 1 & 5 & $-0,241$ & $-1,051$ & $-0,879$ & $-1,916$ \\
\hline Q11.3 & 1 & 5 & 0,033 & 0,143 & $-0,753$ & $-1,642$ \\
\hline Q15.1 & 1 & 5 & $-0,391$ & $-1,705$ & 0,233 & 0,509 \\
\hline Q15.2 & 1 & 4 & $-0,190$ & $-0,827$ & $-0,583$ & $-1,270$ \\
\hline Q15.3 & 1 & 5 & $-0,201$ & $-0,878$ & $-0,421$ & $-0,917$ \\
\hline Q15.4 & 1 & 5 & $-0,052$ & $-0,227$ & $-0,408$ & $-0,889$ \\
\hline Q11.4 & 1 & 5 & $-0,067$ & $-0,290$ & $-1,023$ & $-2,229$ \\
\hline Q11.5 & 1 & 5 & $-0,005$ & $-0,024$ & $-1,007$ & $-2,194$ \\
\hline Q11.6 & 1 & 5 & $-0,425$ & $-1,852$ & $-0,404$ & $-0,880$ \\
\hline Q11.7 & 1 & 5 & $-0,620$ & $-2,701$ & $-0,402$ & $-0,877$ \\
\hline Q11.8 & 1 & 5 & $-0,343$ & $-1,495$ & $-0,297$ & $-0,647$ \\
\hline Q11.9 & 1 & 5 & $-0,048$ & $-0,209$ & $-0,802$ & $-1,748$ \\
\hline Q11.11 & 1 & 5 & $-0,118$ & $-0,516$ & $-0,240$ & $-0,524$ \\
\hline Rent & 1 & 5 & $-0,198$ & $-0,862$ & $-0,821$ & $-1,790$ \\
\hline ROA & 1 & 5 & 0,140 & 0,612 & $-0,906$ & $-1,974$ \\
\hline Lucro & 1 & 5 & 0,166 & 0,725 & $-0,445$ & $-0,971$ \\
\hline
\end{tabular}

Opta-se, então, por utilizar o método de máxima verossimilhança para estimação dos parâmetros do modelo inicial 1a proposto (Figura 10 - Modelo 1a).

Na Tabela 36, a seguir, apresentam-se os testes de significância dos parâmetros do modelo, e conclui-se que todos são estatisticamente significativos a um nível de significância de 5\%, pois todos os p-valores são menores que 0,05. Pode-se identificar que o grau de internacionalização tem um impacto positivo de 0,604 sobre a competência, e esta, por sua 
vez, tem um impacto de 0,777 sobre o desempenho financeiro, indicando que quanto maior o grau de internacionalização da empresa, maior a sua competência, e ainda que quanto maior for a competência, melhor o desempenho financeiro. Além disso, pode-se dizer que o grau de internacionalização tem um impacto de 0,469 no desempenho financeiro, via competência.

Tabela 36 - Testes de significância do modelo inicial/final 1

\begin{tabular}{|c|c|c|c|c|c|c|}
\hline \multicolumn{3}{|c|}{ Relação } & \multirow{2}{*}{$\begin{array}{c}\text { Estimativa } \\
0,604\end{array}$} & \multirow{2}{*}{$\begin{array}{c}\begin{array}{c}\text { Erro- } \\
\text { padrão }\end{array} \\
0,230\end{array}$} & \multirow{2}{*}{$\begin{array}{c}\begin{array}{c}\text { Estatística } \\
\text { de teste }\end{array} \\
2,629\end{array}$} & \multirow{2}{*}{$\begin{array}{c}\text { P-valor } \\
0,009\end{array}$} \\
\hline $\begin{array}{l}\text { COMPET } \\
\text { DESEMP }\end{array}$ & $<--$ & GRI & & & & \\
\hline FINANCEIRO & $<--$ & COMPET & 0,777 & 0,198 & 3,922 & 0,000 \\
\hline ORIENTACAO & $<--$ & COMPET & 1,750 & 0,328 & 5,340 & 0,000 \\
\hline HABMKT & $<--$ & COMPET & 1,000 & & & \\
\hline INOVIN & $<--$ & COMPET & 1,234 & 0,282 & 4,377 & 0,000 \\
\hline Modo & $<--$ & GRI & 1,000 & & & \\
\hline Func & $<--$ & GRI & 0,222 & 0,064 & 3,489 & 0,000 \\
\hline ExpExc & $<--$ & GRI & 0,833 & 0,244 & 3,421 & 0,001 \\
\hline Q11.1 & $<--$ & ORIENTACAO & 0,845 & 0,105 & 8,037 & 0,000 \\
\hline Q11.2 & $<--$ & ORIENTACAO & 1,014 & 0,101 & 9,998 & 0,000 \\
\hline Q11.3 & $<--$ & ORIENTACAO & 1,137 & 0,108 & 10,530 & 0,000 \\
\hline Q11.7 & $<--$ & ORIENTACAO & 0,636 & 0,109 & 5,846 & 0,000 \\
\hline Q11.8 & $<--$ & ORIENTACAO & 1,000 & & & \\
\hline Q11.9 & $<--$ & ORIENTACAO & 0,694 & 0,114 & 6,075 & 0,000 \\
\hline Q11.11 & $<--$ & ORIENTACAO & 0,862 & 0,104 & 8,295 & 0,000 \\
\hline Q15.1 & $<--$ & HABMKT & 1,000 & & & \\
\hline Q15.2 & $<--$ & HABMKT & 0,966 & 0,098 & 9,837 & 0,000 \\
\hline Q15.3 & $<--$ & HABMKT & 1,216 & 0,124 & 9,780 & 0,000 \\
\hline Q15.4 & $<--$ & HABMKT & 1,072 & 0,118 & 9,101 & 0,000 \\
\hline Q11.4 & $<--$ & INOVIN & 1,285 & 0,190 & 6,781 & 0,000 \\
\hline Q11.5 & $<--$ & INOVIN & 1,000 & & & \\
\hline Q11.6 & $<--$ & $\begin{array}{l}\text { INOVIN } \\
\text { DESEMP }\end{array}$ & 0,622 & 0,131 & 4,729 & 0,000 \\
\hline Rent & $<-$ & $\begin{array}{l}\text { FINANCEIRO } \\
\text { DESEMP }\end{array}$ & 1,555 & 0,259 & 6,013 & 0,000 \\
\hline ROA & $<--$ & $\begin{array}{l}\text { FINANCEIRO } \\
\text { DESEMP }\end{array}$ & 1,399 & 0,239 & 5,849 & 0,000 \\
\hline Lucro & $<--$ & FINANCEIRO & 1,000 & & & \\
\hline
\end{tabular}

Fonte: Dados da pesquisa (2010)

Uma vez ajustado o modelo, é preciso verificar se este está bem ajustado aos dados. Isto é feito por meio de algumas medidas de ajuste (fit measures). 
O teste qui-quadrado é o teste de ajuste mais comum, em que a hipótese testada é de que o modelo está bem ajustado aos dados. Portanto, realizando testes de hipóteses com 5\% de significância, tem-se que p-valores acima de 0,05 indicarão um modelo bem ajustado. Para o modelo 1a, obteve-se uma estatística qui-quadrado de 298,134, com um p-valor<0,001. Temse, portanto, evidências de que o modelo não está bem ajustado aos dados.

É importante ressaltar, contudo, que esse teste deve ser utilizado com muita cautela, pois ele precisa de algumas condições:

1) As variáveis observadas devem ter curtoses próximas às da distribuição normal.

2) O tamanho da amostra deve ser suficientemente grande (o número de observações deve ser pelo menos 10 vezes maior que o número de variáveis).

Sendo assim, o resultado obtido deve ser utilizado com muita cautela, e outras medidas de ajuste alternativas devem ser empregadas para verificar a qualidade do ajuste do modelo.

Uma medida que é considerada como uma das mais informativas é a raiz do erro quadrático médio de aproximação (RMSEA - root mean square error of approximation), que leva em conta o erro de aproximação na população e tenta responder à seguinte questão: "Quão bem o modelo, com parâmetros desconhecidos, mas eficientemente escolhidos, ajustam a matriz de covariância populacional?". Para o modelo 1a proposto, o resultado foi RMSEA $=0,085$, com um intervalo de confiança de $90 \%$ dado por $(0,069 ; 0,100)$. Sabe-se que valores abaixo de 0,05 são considerados como indicativos de bom ajuste, e realizando o teste para verificar se o RMSEA realmente está abaixo deste valor, obteve-se um p-valor de $<0,001$, o que indica que o modelo não estaria tão bem ajustado. Porém, Huntley e Perry (2003) sugerem a seguinte regra de decisão: valores menores que 0,05 indicam um bom ajuste; valores entre 0,08 e 0,10 indicam um ajuste razoável; valores acima de 0,10 indicam um ajuste pobre. Segundo Huntley e Perry (2003), esta medida de ajuste tem sido reconhecida recentemente como um dos critérios mais informativos para ser utilizado na modelagem de estrutura de covariância. Portanto, utilizando esta medida, e seguindo a sugestão de Huntley e Perry (2003), conclui-se que o modelo 1a apresenta-se razoavelmente ajustado aos dados.

Outra medida que pode ser utilizada é o índice de ajuste comparativo (CFI), que preconiza que quanto mais próximo de 1, mais aceitável é o modelo. Em geral, utiliza-se 0,80 ou 0,90 
como ponto de corte para considerar os modelos aceitáveis. O modelo 1a apresenta CFI = 0,874 e, assim, o modelo é considerado aceitável.

Por fim, será analisada a raiz do quadrado médio residual (RMR). Como ela é a raiz do quadrado médio dos elementos abaixo da diagonal da matriz de resíduos, um RMR próximo de zero indica um bom ajuste. Para o modelo 1a, obteve-se um RMR $=0,077$, Por este resultado, pode-se também dizer que o modelo está bem ajustado. Portanto, de um modo geral, pode-se inferir que o modelo 1a está bem ajustado aos dados.

Para verificar se essa relação realmente justifica a confirmação da H1a, modelos concorrentes foram testados para cada situação. Como já apresentado anteriormente, procurar-se á verificar se outras relações entre os construtos explicam mais ou não.

Parte-se, por conseguinte, para a apresentação dos resultados do segundo modelo que tem como objetivo verificar se o grau de internacionalização (GRI) tem influência direta sobre o desempenho financeiro (DESEMP FINANCEIRO), sem considerar as competências. Traduzindo o diagrama apresentado na Figura 11, tem-se que as PMEs se internacionalizariam sem a importância que se deu no modelo 1a à competência, portanto, quanto maior for o GRI, mais o impacto direto terá no DESEMP FINANC.

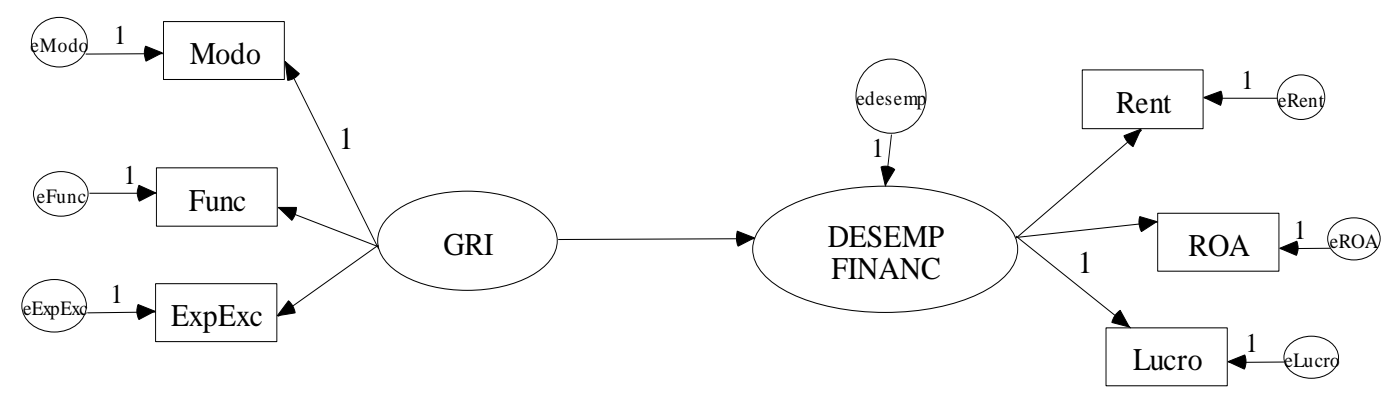

Figura 11 - Diagrama de caminho do modelo inicial 2 a Fonte: Dados da pesquisa (2010)

De acordo com a Figura 11, descrevem-se as equações dos modelos de mensuração e estrutural conforme Tabela 37, a seguir. 
Tabela 37 - Modelos de mensuração

\begin{tabular}{|c|c|}
\hline Variáveis & Modelos de Mensuração \\
\hline GRI & $\begin{array}{c}\mathrm{Q}_{\mathrm{i}}=\mathrm{a}_{\mathrm{i}} \text { GRI+e } \mathrm{e}_{\mathrm{i}} \\
\mathrm{i}=\operatorname{modo}, \text { Func e ExpExc }\end{array}$ \\
\hline DESEMP FINANCEIRO & $\begin{array}{c}\mathrm{Q}_{\mathrm{r}}=\mathrm{a}_{\mathrm{r}} \text { DESEMP FINANCEIRO }_{\mathrm{r}} \\
\mathrm{r}=\text { Rent, ROA e Lucro }\end{array}$ \\
\hline
\end{tabular}

*em que: $a_{i}$ e $a_{r}$ são os coeficientes das equações de mensuração para cada variável latente e, $e_{i}$ e $e_{r}$ seus respectivos erros de mensuração.

Fonte: Dados da pesquisa (2010)

Assim, o Modelo Estrutural é:

- $\quad$ DESEMP FINANCEIRO $=b_{1}$ GRI $+e_{\text {desemp }}$

em que: $b_{1}$ é o coeficiente da equação estrutural e $e_{\text {desemp }}$ são os erros estruturais.

No caso do modelo de equação estrutural (modelo 2a), o processo de verificação de identificabilidade é realizado em duas etapas:

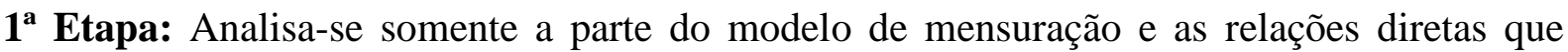
haviam entre as variáveis latentes são substituídas por correlações. Assim, fica-se com o diagrama apresentado na Figura 12, apresentada adiante.

Verifica-se se as duas regras estão satisfeitas, uma necessária e outra suficiente.

a) Regra 1.1 (Regra 2 indicadores):

(i) os erros de mensuração devem ser não-correlacionados;

(ii) as variáveis latentes devem ser correlacionadas;

(iii) um coeficiente associado a cada variável latente deve ser fixado como 1.

Se estas condições estiverem satisfeitas, dois indicadores por variável latente serão suficientes para a identificabilidade do modelo de mensuração.

Pode-se observar que para o modelo de mensuração da Figura 12, as três condições da regra de dois indicadores estão satisfeitas. Ainda é necessário verificar se a regra está satisfeita. 
b) Regra 1.2 (Regra t):

o número de parâmetros livres no modelo $(\mathrm{t})$ deve ser menor ou igual ao número de elementos distintos na matriz de covariância amostral $\left(\frac{(p+q)(p+q+1)}{2}\right)$.

Assim, para o modelo de mensuração do modelo 2a proposto apresenta-se:

a) 6 variáveis observadas relacionadas às variáveis latentes exógenas (GRI e DESEMP FINANCEIRO), então, $p=0$ e $q=6$;

b) 4 coeficientes que acompanham as variáveis latentes nas equações de mensuração (isto porque 2 coeficientes foram fixados como 1), 2 variâncias das variáveis latentes exógenas, 6 variâncias dos erros de mensuração e 1 covariância entre as variáveis latentes, o que leva a $\mathrm{t}=13$.

Logo, $\frac{(p+q)(p+q+1)}{2}=\frac{6 \times 7}{2}=21 \mathrm{e}$, portanto, a condição está satisfeita. Assim, o modelo de mensuração do modelo 2 a é identificável.

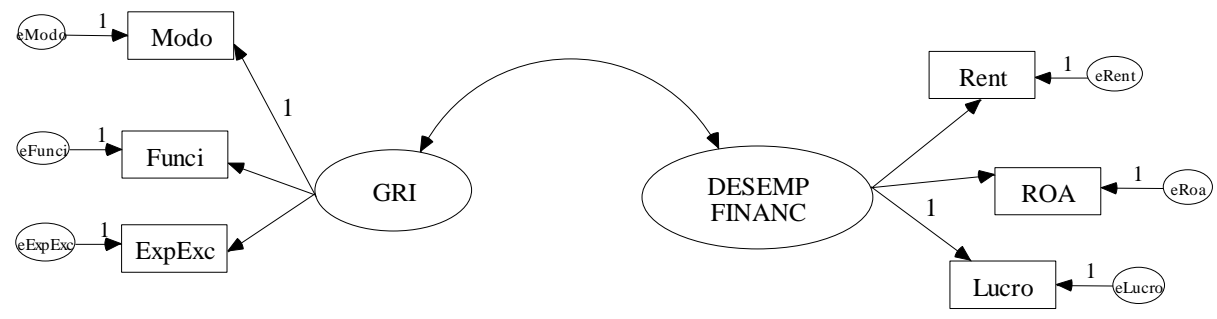

Figura 12 - Diagrama de caminho do modelo de mensuração - Modelo 2a - Identificabilidade Fonte: dados da pesquisa (2010)

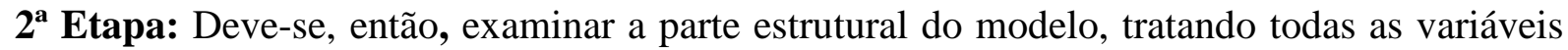
latentes como observadas (Figura 12). Neste caso, também será preciso verificar se uma condição necessária e outra suficiente estão satisfeitas. 
a) Regra 2.1 (Regra B Nula): não há influências entre as variáveis endógenas.

b) Regra 2.2 (Regra t): mesma regra já apresentada anteriormente.

Para o modelo apresentado na Figura 13, nota-se que a regra 2.1 é satisfeita, pois só há uma variável latente endógena (DESEMP FINANCEIRO) e, portanto, é impossível que haja relação entre variáveis latentes endógenas. Quanto à regra 2.2, verifica-se que:

a) O modelo 2a apresenta uma variável endógena e uma exógena, ou seja, $\mathrm{p}=\mathrm{q}=1$.

b) $\mathrm{O}$ modelo $2 \mathrm{a}$ apresenta um coeficiente relacionando DESEMP FINANCEIRO e GRI e uma variância do erro, neste caso $\mathrm{t}=2$.

Logo, $\frac{(p+q)(p+q+1)}{2}=\frac{2 \times 3}{2}=3$ e, portanto, a condição está satisfeita. Assim, o modelo estrutural do modelo 2a é identificável, então, o modelo de equações estruturais completo é identificável.

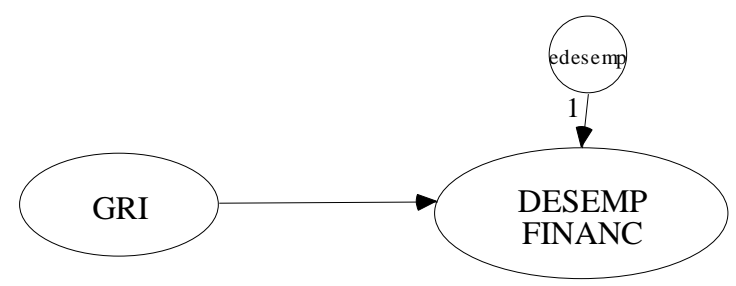

Figura 13 - Diagrama de caminho do modelo estrutural - Modelo 2a - Identificabilidade Fonte: Dados da Pesquisa (2010)

Verificou-se anteriormente, na Tabela 34, que os coeficientes de assimetria e excesso de curtose das variáveis que mensuram DESEMP FINANCEIRO são estatisticamente não significativos $(|\mathrm{CR}|<2,00)$, ou seja, estas variáveis apresentam assimetria e excesso de curtose nula (equivalentes à distribuição Normal). Porém, o mesmo não acontece com as variáveis relacionadas ao GRI.

Também já foi apresentado que o ideal no caso de violação da suposição de normalidade é o uso do método de estimação de mínimos quadrados ponderados, WLS (ou Asymptotically distribution-free, ADF, no AMOS), e ainda que neste método verificam-se três restrições importantes: 
(a) necessidade de amostras muito grandes $\left(N>\frac{(p+q)(p+q+1)}{2}\right)$;

(b) número limitado de variáveis observadas $(\mathrm{p}+\mathrm{q}<25)$;

(c) a forte suposição de que por trás de cada variável categórica observada há uma variável latente contínua equivalente e, além disso, que essas variáveis latentes contínuas têm distribuição normal multivariada.

Para testar o modelo 2a, as restrições (a) e (b) são superadas, porém a suposição (c) continua sendo muito forte. Portanto, decidiu-se ajustar o modelo 2 utilizando os métodos de máxima verossimilhança (MV) e de mínimos quadrados ponderados (WLS) e então compararam-se os resultados obtidos.

Na Tabela 38 apresentam-se os testes de significância dos parâmetros do modelo estimados por ambos os métodos citados anteriormente, e conclui-se que todos os parâmetros das variáveis para mensurar GRI e DESEMP FINANCEIRO são estatisticamente significativos a um nível de significância de $5 \%$, pois todos os p-valores são menores que 0,05 . Porém, notase que o impacto do grau de internacionalização sobre o desempenho financeiro não é estatisticamente significativo ( $\mathrm{p}$-valor $=0,328$ pelo método de MV e p-valor $=0,519$ pelo método WLS).

Tabela 38 - Testes de significância do modelo inicial/final 2a

\begin{tabular}{|c|c|c|c|c|c|c|c|c|c|c|}
\hline \multirow{2}{*}{\multicolumn{3}{|c|}{ Relação }} & \multicolumn{4}{|c|}{ Método MV } & \multicolumn{4}{|c|}{ Método WLS } \\
\hline & & & Estimativa & $\begin{array}{c}\text { Erro- } \\
\text { padrão }\end{array}$ & $\begin{array}{c}\text { Estatística } \\
\text { de teste }\end{array}$ & P-valor & Estimativa & $\begin{array}{c}\text { Erro- } \\
\text { padrão }\end{array}$ & $\begin{array}{l}\text { Estatística } \\
\text { de teste }\end{array}$ & P-valor \\
\hline $\begin{array}{c}\text { DESEMP } \\
\text { FINANCEIRO }\end{array}$ & $<--$ & GRI & 0,242 & 0,247 & 0,978 & 0,328 & 0,164 & 0,255 & 0,645 & 0,519 \\
\hline Modo & $<-$ & GRI & 1,000 & & & & 1,000 & & & \\
\hline Func & $<-$ & GRI & 0,213 & 0,069 & 3,067 & 0,002 & 0,207 & 0,056 & 3,723 & 0,000 \\
\hline ExpExc & $<-$ & $\begin{array}{c}\text { GRI } \\
\text { DESEMP }\end{array}$ & 0,815 & 0,265 & 3,077 & 0,002 & 1,188 & 0,359 & 3,315 & 0,001 \\
\hline Rent & $<-$ & $\begin{array}{l}\text { FINANCEIRO } \\
\text { DESEMP }\end{array}$ & 1,641 & 0,308 & 5,332 & 0,000 & 1,620 & 0,255 & 6,344 & 0,000 \\
\hline ROA & $<--$ & $\begin{array}{l}\text { FINANCEIRO } \\
\text { DESEMP }\end{array}$ & 1,398 & 0,247 & 5,656 & 0,000 & 1,533 & 0,209 & 7,323 & 0,000 \\
\hline Lucro & $<--$ & FINANCEIRO & 1,000 & & & & 1,000 & & & \\
\hline
\end{tabular}

Fonte: Dados da pesquisa (2010)

Agora, é necessário verificar, por meio das medidas de ajuste consideradas para o modelo $2 \mathrm{a}$ (Figura 13), se o modelo está bem ajustado aos dados. Pelo teste qui-quadrado, tem-se que o modelo está bem ajustado aos dados por ambos os métodos de estimação (P-valor $=0,210$ pelo método de MV e, p-valor = 0,092 pelo WLS). Além disso, sabe-se que a raiz do erro 
quadrático médio de aproximação (RMSEA) deve apresentar valores abaixo de 0,05 para que o modelo seja considerado bem ajustado. Para o modelo 2, obteve-se RMSEA=0,056 com o método de MV (e 0,079 para o método de WLS), com um intervalo de confiança de 90\% dado por $(0,000 ; 0,132)$ para o método de MV (e $(0,000 ; 0,149)$ pelo outro método). Realizando o teste para verificar se o RMSEA está realmente abaixo de 0,05 , não se rejeita a hipótese, o que indica que o modelo está bem ajustado por ambos os métodos.

Analisando o índice de ajuste comparativo (CFI) e a raiz do quadrado médio residual (RMR), também pode-se considerar que o modelo está bem ajustado aos dados, já que eles apresentaram valores bem próximos a 1 e a 0 , respectivamente.

Portanto, de um modo geral, de acordo com a Tabela 39, pode-se dizer que o modelo 2a está bem ajustado aos dados.

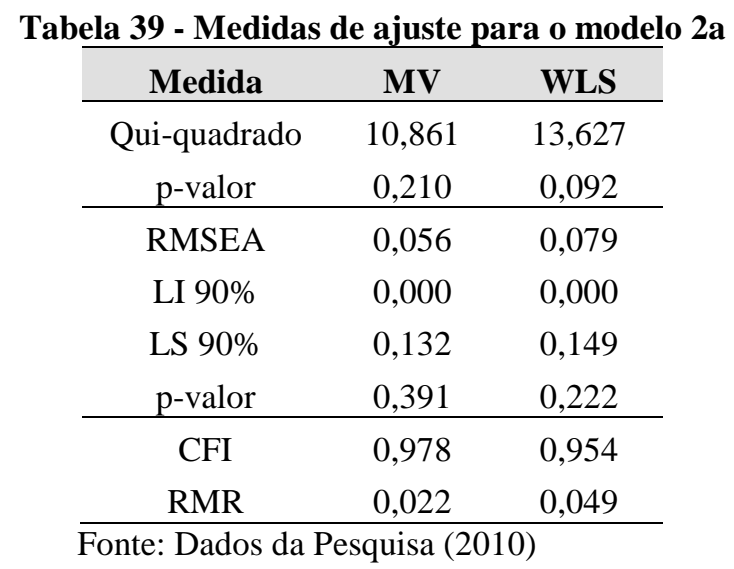

Com esse resultado, apesar dos dados se mostrarem ajustados, o impacto do GRI, desconsiderando o desenvolvimento de competências internacionais para melhorar o desempenho financeiro, não se mostrou significativo. Portanto, leia-se que somente o aumento do GRI não explica um melhor desempenho financeiro nas PMEs estudadas.

Considerando esse resultado, outro modelo concorrente (Figura 14) foi verificado. Neste, voltou-se a identificar as competências como variável analisada, mas agora não na posição de mediadora e sim na posição exógena. O objetivo é verificar se a competência (COMPET) tem influência sobre grau de internacionalização (GRI), e se este, por sua vez, tem influência direta sobre o desempenho financeiro (DESEMP FINANCEIRO) A suposição neste modelo concorrente é que a PME, antes de aumentar o GRI, deveria desenvolver as competências 
necessárias para que o desempenho financeiro apresentasse um resultado positivo. Verificase, então, na Figura 14, que o fluxo causal foi alterado, isto é, a mediação neste modelo é impactada pelo GRI e não mais pela competência, como sugere o modelo 1a.

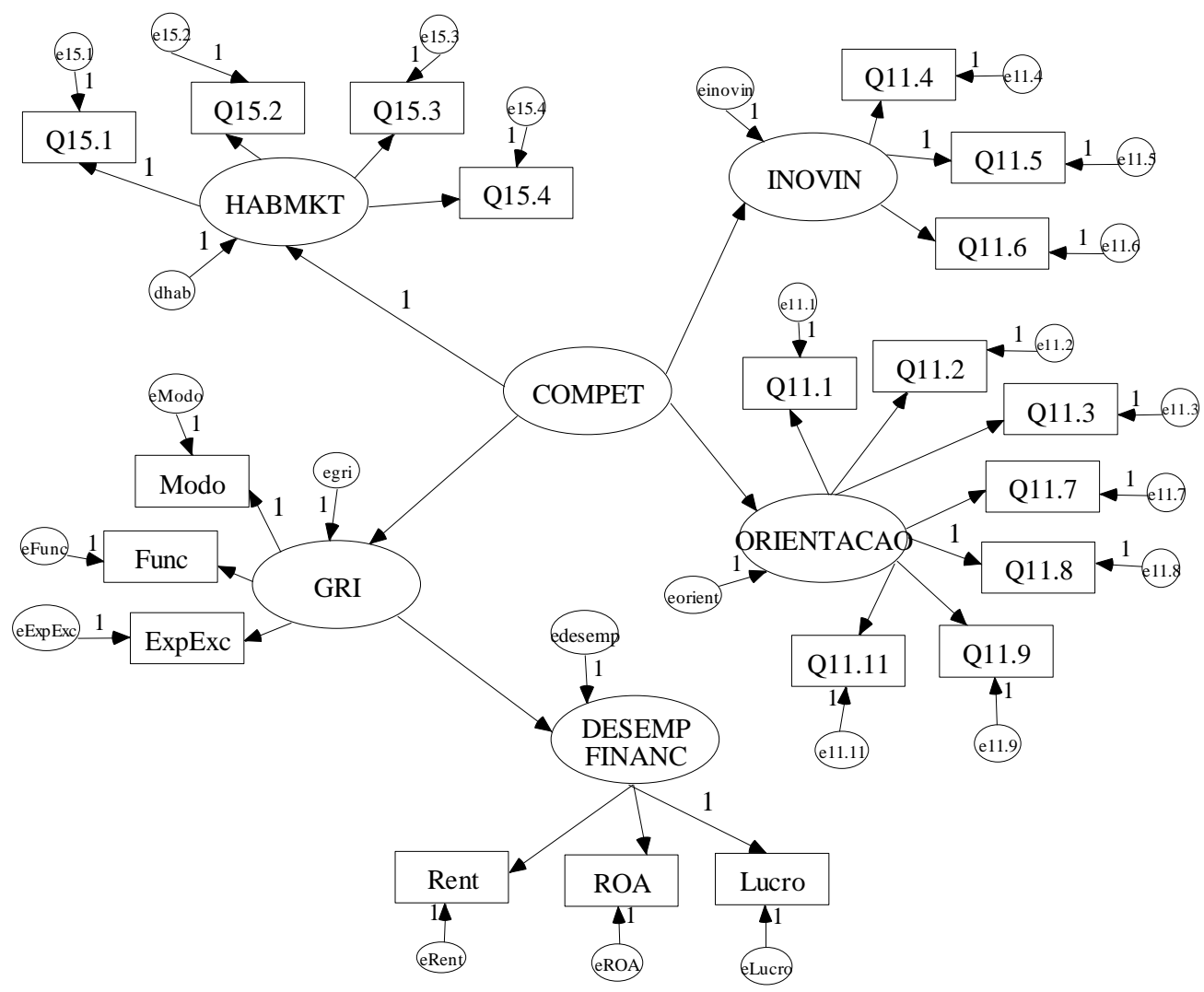

Figura 14 - Diagrama de caminho do modelo inicial 3a Fonte: Dados da Pesquisa (2010)

Nota-se que o modelo 3 a apresentado na Figura 14 é similar ao modelo 1a (Figura 10), sendo que agora a competência é uma variável latente exógena e GRI e DESEMP FINANCEIRO são endógenas, e o desempenho deste modelo sofre influência direta de COMPET e GRI, respectivamente. Como os modelos são similares, todos os comentários feitos anteriormente sobre a suposição de normalidade, método de estimação e identificabilidade do modelo se estendem para este modelo.

Portanto, na Tabela 40 apresentam-se os testes de significância dos parâmetros do modelo 3a e conclui-se que todos são estatisticamente significativos a um nível de significância de 5\%, pois todos os p-valores são menores que 0,05 . Além disso, pode-se dizer que a competência 
tem um impacto positivo de 0,344 sobre o grau de internacionalização, e este, por seu turno, tem um impacto de 0,684 sobre o desempenho financeiro, indicando que quanto maior a competência da empresa, maior o seu grau de internacionalização e também que quanto maior o grau de internacionalização, melhor o desempenho financeiro.

Tabela 40 - Testes de significância do modelo inicial/final 3a

\begin{tabular}{|c|c|c|c|c|c|c|}
\hline \multicolumn{3}{|c|}{ Relação } & \multirow{2}{*}{$\begin{array}{c}\text { Estimativa } \\
0,344\end{array}$} & \multirow{2}{*}{$\begin{array}{c}\begin{array}{c}\text { Erro- } \\
\text { padrão }\end{array} \\
0,103\end{array}$} & \multirow{2}{*}{$\begin{array}{c}\text { Estatística } \\
\text { de teste }\end{array}$} & \multirow{2}{*}{$\begin{array}{c}\text { P-valor } \\
0,001\end{array}$} \\
\hline $\begin{array}{c}\text { GRI } \\
\text { DESEMP }\end{array}$ & $<-$ & COMPET & & & & \\
\hline FINANCEIRO & $<--$ & GRI & 0,684 & 0,309 & 2,216 & 0,027 \\
\hline ORIENTACAO & $<--$ & COMPET & 1,560 & 0,300 & 5,201 & 0,000 \\
\hline HABMKT & $<-$ & COMPET & 1,000 & & & \\
\hline INOVIN & $<-$ & COMPET & 1,286 & 0,283 & 4,545 & 0,000 \\
\hline Modo & $<-$ & GRI & 1,000 & & & \\
\hline Func & $<-$ & GRI & 0,233 & 0,067 & 3,491 & 0,000 \\
\hline ExpExc & $<-$ & GRI & 0,871 & 0,260 & 3,356 & 0,001 \\
\hline Q11.1 & $<-$ & ORIENTACAO & 0,837 & 0,106 & 7,908 & 0,000 \\
\hline Q11.2 & $<-$ & ORIENTACAO & 1,004 & 0,102 & 9,802 & 0,000 \\
\hline Q11.3 & $<-$ & ORIENTACAO & 1,147 & 0,108 & 10,604 & 0,000 \\
\hline Q11.7 & $<-$ & ORIENTACAO & 0,635 & 0,109 & 5,823 & 0,000 \\
\hline Q11.8 & $<-$ & ORIENTACAO & 1,000 & & & \\
\hline Q11.9 & $<-$ & ORIENTACAO & 0,697 & 0,114 & 6,088 & 0,000 \\
\hline Q11.11 & $<-$ & ORIENTACAO & 0,871 & 0,104 & 8,380 & 0,000 \\
\hline Q15.1 & $<-$ & HABMKT & 1,000 & & & \\
\hline Q15.2 & $<-$ & HABMKT & 0,966 & 0,099 & 9,797 & 0,000 \\
\hline Q15.3 & $<--$ & HABMKT & 1,221 & 0,125 & 9,795 & 0,000 \\
\hline Q15.4 & $<-$ & HABMKT & 1,075 & 0,118 & 9,091 & 0,000 \\
\hline Q11.4 & $<-$ & INOVIN & 1,254 & 0,181 & 6,919 & 0,000 \\
\hline Q11.5 & $<-$ & INOVIN & 1,000 & & & \\
\hline Q11.6 & $<-$ & INOVIN & 0,633 & 0,131 & 4,830 & 0,000 \\
\hline Rent & $<-$ & DESEMP FINANCEIRO & 1,613 & 0,292 & 5,519 & 0,000 \\
\hline ROA & $<-$ & DESEMP FINANCEIRO & 1,381 & 0,242 & 5,706 & 0,000 \\
\hline Lucro & $<-$ & DESEMP FINANCEIRO & 1,000 & & & \\
\hline
\end{tabular}

Fonte: Dados da pesquisa (2010)

Ajustado o modelo, o passo seguinte é verificar se o modelo está bem ajustado aos dados por meio de algumas medidas de ajuste.

A estatística qui-quadrado para este modelo é de 323,026, com um p-valor $<0,001$, ou seja, por meio deste teste têm-se evidências de que o modelo não está bem ajustado aos dados. Mas, 
como afirmado anteriormente, outras medidas alternativas devem ser avaliados, pois a estatística qui-quadrado é boa sob algumas condições específicas.

A raiz do erro quadrático médio de aproximação (RMSEA) do modelo 3a foi de 0,092, com um intervalo de confiança de $90 \%$ dado por $(0,077 ; 0,107)$. Além disso, o teste para verificar se o RMSEA realmente está abaixo de 0,05 apresentou um p-valor de $<0,001$, o que indica que o modelo não estaria tão bem ajustado. Porém, utilizando a regra de decisão de Huntley e Perry (2003), tem-se que o modelo 3a está razoavelmente ajustado aos dados.

Pelo índice de ajuste comparativo $(\mathrm{CFI}=0,850)$ e pela raiz do quadrado médio residual $(\mathrm{RMR}=0,117)$ também pode-se considerar que o modelo está razoavelmente ajustado aos dados, já que eles apresentaram valores próximos a 1 e a 0 , respectivamente.

Portanto, de um modo geral, pode-se dizer que o modelo 3a está bem ajustado aos dados.

Assim sendo, H1a foi considerada válida (modelo 1a), pois o modelo 2a não se mostrou significativo e o modelo 3a, apesar de ter se apresentado valores significativos de medição entre a competência e o desempenho financeiro, os valores de ajustes do modelo não se apresentaram tão adequados quanto no modelo 1a.

Comparando-se então os modelos 1a e 3a quanto aos índices de ajustes, têm-se os resultados conforme apresentados na Tabela 41.

Tabela 41 - Resumos dos ajustes do Modelo 1a e do Modelo 3a

\begin{tabular}{c|c|c|c|c}
\hline Modelo & $\mathrm{x}^{2}$ & RMSEA & CFI & SRMR \\
\hline 1a & $<0,001$ & 0,085 & 0,874 & 0,077 \\
3a & $<0,001$ & 0,092 & 0,850 & 0,117 \\
\hline \multicolumn{7}{l}{ Fonte: Dados da pesquisa (2010) }
\end{tabular}

Para compreender melhor os dados da Tabela 41, acima, é necessário relembrar que para que o ajuste CFI se mostre adequado o valor deverá ser o mais próximo de 1, já para o RMR o valor deverá ser $<0,005$. Portanto, verifica-se que o modelo 1a está mais ajustado que o modelo 3a. 
Existem algumas medidas de ajuste que não são utilizadas para avaliar a qualidade do ajuste de um único modelo, sendo úteis para comparação de modelos. A mais conhecida dessas medidas é o Critério da Informação de Akaike (AIC), existindo também duas medidas derivadas do AIC: o Critério da Informação de Bayes (BIC), que indica uma maior penalidade para a complexidade do modelo e que tende a escolher modelos mais parcimoniosos, e o Critério de Browne-Cudeck (BCC). Com base nessas medidas, deve-se escolher o modelo com o menor valor de AIC, BCC ou BIC.

Assim sendo, essas medidas serão utilizadas para comparar os modelos 1a e 3a, que são concorrentes (Tabela 42). Observa-se que as medidas constantes da referida tabela são bem parecidas para ambos os modelos, mas nossa escolha deveria incidir sobre o modelo 1a, em que o GRI tem um impacto de 0,604 sobre competência e esta, por sua vez, tem impacto de 0,777 em desempenho financeiro.

Tabela 42 - Medidas de ajuste para comparação de modelos

\begin{tabular}{cccc}
\hline Modelo & AIC & BCC & BIC \\
\hline $1^{\text {a }}$ & 388,134 & 408,677 & 646,071 \\
$3^{\text {a }}$ & 413,026 & 433,570 & 670,963 \\
\hline \multicolumn{4}{l}{ Fonte: Dados da pesquisa (2010) }
\end{tabular}

Outra consideração que aporta à conclusão de que o modelo 1a está mais adequado, justificando melhor as relações entre os construtos, é a estimativa que explica o quanto cada construto impacta ou explica suas relações. Os valores do modelo 1a e do modelo 3a são reapresentados na Tabela 43, para melhor compreensão:

Tabela 43 - Dados totais de relação Modelos 1a e 3a

\begin{tabular}{|c|c|c|c|c|}
\hline Modelo & Relação & Estimativa & Sig (P-valor) & Est. total \\
\hline $1 \mathrm{a}$ & COMPET <-- GRI & 0,604 & 0,009 & \multirow[b]{2}{*}{0,469} \\
\hline $1 \mathrm{a}$ & $\begin{array}{c}\text { DESEMP } \\
\text { FINANC <-- COMPET }\end{array}$ & 0,777 & 0,000 & \\
\hline $3^{a}$ & GRI <-- COMPET & 0,344 & 0,001 & \multirow[b]{2}{*}{0,235} \\
\hline $3^{a}$ & $\begin{array}{c}\text { DESEMP } \\
\text { FINANC <-- GRI }\end{array}$ & 0,684 & 0,027 & \\
\hline
\end{tabular}

Fonte: Dados da pesquisa (2010) 
Como pode ser verificado na Tabela 43, acima, os valores que explicam a relação entre os construtos do modelo 1a apresentam um melhor impacto, assim sendo, considera-se a H1a positiva.

No que concerne a H1a, os dados se mostraram significativos a um nível de 0,05 e o modelo está ajustado aos dados, como demonstrado na Figura 15. No Anexo 01 é apresentado o diagrama completo. Como resultado para a H1a tem-se que:

\section{H1a: As competências organizacionais mediam direta e positivamente a relação entre o} GRI e o desempenho financeiro.

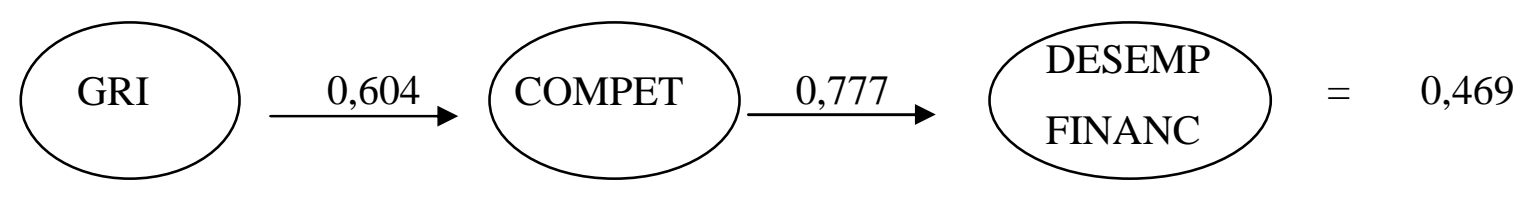

Figura 15 - Modelo 1a - H1a

Fonte: Dados da Pesquisa (2010)

Verificou-se, então, que a H1a foi confirmada e que o modelo foi explicado em 0,469.

Analisada a H1a, parte-se para a análise da H1b:

H1b: As competências organizacionais mediam direta e positivamente a relação entre o GRI e o desempenho operacional.

A hipótese H1b tem como objetivo avaliar os impactos estudados nos modelos 1a, 2a e 3a sobre o DESEMPENHO OPERACIONAL das PMEs em vez do desempenho financeiro. A seguir, apresentam-se, resumidamente, os resultados obtidos para os modelos análogos aos mostrados anteriormente.

Vale lembrar que para o desempenho operacional utilizou medidas operacionais e de mercado como: Volum (aumento do volume de vendas), Prodt (aumento da produtividade operacional geral da empresa) e Partic (aumento da participação do mercado global). 
Na Figura 16, a seguir, apresenta-se o diagrama de caminho do modelo Inicial 1b, no qual se verifica o impacto do grau de internacionalização no desempenho operacional, por meio da competência. Este modelo é similar ao modelo 1a (Figura 10) e, portanto, ele é identificável. Porém, é preciso avaliar se as variáveis que mensuram o desempenho operacional possuem coeficientes de assimetria e de excesso de curtose nulos.

Já foi mencionado que para um modelo com essa estrutura não é possível estimar os parâmetros pelo método WLS devido ao reduzido tamanho amostral, e ainda foi constatado que este método nem sempre apresenta bons resultados, apresentando, em muitos casos, resultados similares aos obtidos pelo método de MV. Sendo assim, optou-se por utilizar o método de máxima verossimilhança para estimação dos parâmetros do modelo inicial $1 \mathrm{~b}$ proposto, conforme demonstra a Figura 16.

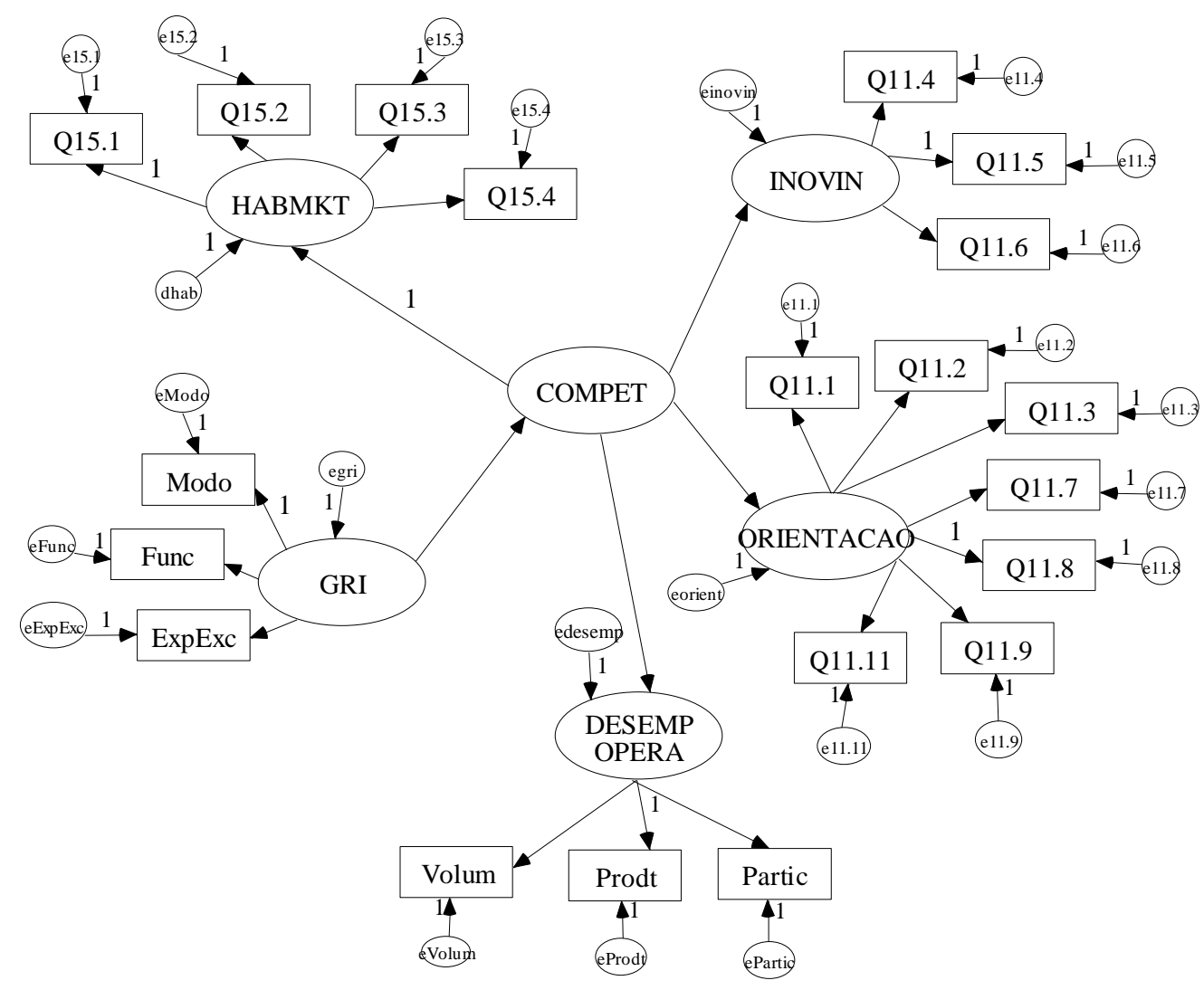

Figura 16 - Diagrama de caminho do modelo inicial 1b Fonte: dados da Pesquisa (2010)

$\mathrm{Na}$ Tabela 44, a seguir, apresentam-se as medidas de assimetria e excesso de curtose das variáveis observadas relacionadas ao desempenho operacional e suas respectivas razões críticas (CR). Por meio da Tabela 44, nota-se que dois coeficientes de assimetria são 
estatisticamente significativos $(|\mathrm{CR}|>2,00)$, ou seja, estas variáveis apresentam assimetria não-nula.

Tabela 44 - Medidas de assimetria e curtose - desempenho operacional

\begin{tabular}{c|c|c|c|c|c|c}
\hline Variável & Mínimo & Máximo & Assimetria & CR & $\begin{array}{c}\text { Excesso } \\
\text { de } \\
\text { Curtose }\end{array}$ & CR \\
\hline Volum & 2 & 5 & $-0,518$ & $\mathbf{- 2 , 2 5 6}$ & $-0,389$ & $-0,848$ \\
Prodt & 1 & 5 & $-0,644$ & $\mathbf{- 2 , 8 0 8}$ & $-0,359$ & $-0,783$ \\
Partic & 1 & 5 & $-0,424$ & $-1,848$ & $-0,407$ & $-0,886$ \\
\hline \multicolumn{7}{l}{ Fonte: Dados da pesquisa (2010) }
\end{tabular}

Fonte: Dados da pesquisa (2010)

Na Tabela 45 estão expostos os testes de significância dos parâmetros do modelo. Pela análise dos resultados dessa tabela pode-se concluir que todos são estatisticamente significativos a um nível de significância de 5\%, pois todos os p-valores são menores que 0,05. Além disso, é possível dizer que o grau de internacionalização tem um impacto positivo de 0,623 sobre a competência e esta, por sua vez, tem um impacto de 1,033 sobre o desempenho operacional, indicando que quanto maior o grau de internacionalização da empresa, maior a sua competência, e também que quanto maior a competência, melhor o desempenho operacional. Além disso, pode-se afirmar que o grau de internacionalização tem um impacto de 0,643 no desempenho operacional, via competência.

Tabela 45 - Testes de significância do modelo inicial/final 1b-

\begin{tabular}{ccc|c|c|c|c}
\hline & Relação & & Estimativa & $\begin{array}{c}\text { Erro- } \\
\text { padrão }\end{array}$ & $\begin{array}{c}\text { Estatística } \\
\text { de teste }\end{array}$ & P-valor \\
\hline COMPET & $<--$ & GRI & 0,623 & 0,231 & 2,695 & 0,007 \\
DESEMP OPERAC & $<--$ & COMPET & 1,033 & 0,231 & 4,473 & 0,000 \\
ORIENTACAO & $<--$ & COMPET & 1,630 & 0,299 & 5,455 & 0,000 \\
HABMKT & $<--$ & COMPET & 1,000 & & & \\
INOVIN & $<--$ & COMPET & 1,323 & 0,290 & 4,560 & 0,000 \\
Modo & $<--$ & GRI & 1,000 & & & 0,001 \\
Func & $<--$ & GRI & 0,210 & 0,060 & 3,481 & 0,001 \\
ExpExc & $<--$ & GRI & 0,804 & 0,235 & 3,417 & 0,000 \\
Q11.1 & $<--$ & ORIENTACAO & 0,837 & 0,104 & 8,017 & 0,000 \\
Q11.2 & $<--$ & ORIENTACAO & 1,000 & 0,101 & 9,924 & 0,000 \\
Q11.3 & $<--$ & ORIENTACAO & 1,141 & 0,106 & 10,721 & 0,000 \\
Q11.7 & $<--$ & ORIENTACAO & 0,634 & 0,108 & 5,871 & 0,000 \\
Q11.8 & $<--$ & ORIENTACAO & 1,000 & & & 0,000 \\
Q11.9 & $<--$ & ORIENTACAO & 0,678 & 0,114 & 5,956 & 0,365 \\
Q11.11 & $<--$ & ORIENTACAO & 0,861 & 0,103 & 8,365 & 0,000 \\
Q15.1 & $<--$ & HABMKT & 1,000 & & & 0,000 \\
Q15.2 & $<--$ & HABMKT & 0,962 & 0,098 & 9,813 & 0,000 \\
Q15.3 & $<--$ & HABMKT & 1,218 & 0,124 & 9,826 & continua \\
Q15.4 & $<--$ & HABMKT & 1,069 & 0,118 & 9,092 &
\end{tabular}




\begin{tabular}{|c|c|c|c|c|c|c|}
\hline Q11.4 & $<--$ & INOVIN & 1,254 & 0,180 & 6,986 & $\begin{array}{c}\text { conclusão } \\
0,000\end{array}$ \\
\hline Q11.5 & $<-$ & INOVIN & 1,000 & & & \\
\hline Q11.6 & $<-$ & $\begin{array}{l}\text { INOVIN } \\
\text { DESEMP }\end{array}$ & 0,637 & 0,131 & 4,852 & 0,000 \\
\hline Volum & $<-$ & $\begin{array}{c}\text { OPERACIONAL } \\
\text { DESEMP }\end{array}$ & 0,903 & 0,128 & 7,074 & 0,000 \\
\hline Prodt & $<-$ & $\begin{array}{l}\text { OPERACIONAL } \\
\text { DESEMP }\end{array}$ & 1,000 & & & \\
\hline Partic & $<-$ & OPERACIONAL & 0,992 & 0,145 & 6,860 & 0,000 \\
\hline
\end{tabular}

Fonte: Dados da pesquisa (2010)

É preciso verificar agora se o modelo está bem ajustado aos dados. A estatística qui-quadrado deste modelo é de 326,911, com um p-valo<0,001, ou seja, com base neste medida conclui-se que o modelo não está bem ajustado aos dados. Por outro lado, a raiz do erro quadrático médio de aproximação (RMSEA) do modelo $1 \mathrm{~b}$ foi de 0,093, com um intervalo de confiança de $90 \%$ dado por $(0,078 ; 0,108)$. Além disso, o teste para verificar se o RMSEA está realmente abaixo de 0,05 , pois apresentou um p-valor de $<0,001$, indica que o modelo não estaria tão bem ajustado. Porém, utilizando a regra de decisão de Huntley e Perry (2003), verifica-se que o modelo 1 b está razoavelmente ajustado aos dados. Analisando o índice de ajuste comparativo $(\mathrm{CFI}=0,853)$ e a raiz do quadrado médio residual $(\mathrm{RMR}=0,081)$, também se considera que o modelo está bem ajustado aos dados, já que estes apresentaram valores próximos a 1 e a 0 , respectivamente. Tendo efetuado os vários teste de ajustes, verifica-se que, de modo geral, o modelo 1 b está bem ajustado aos dados.

Na Figura 17 apresenta-se o diagrama de caminho do modelo $2 b$, no qual se verifica o impacto direto do grau de internacionalização no desempenho operacional. Este modelo é similar ao modelo 2 a e, portanto, ele é identificável e as equações dos modelos são praticamente as mesmas.

Tal como realizado no modelo 2a, os parâmetros do modelo foram estimados por dois métodos: MV e WLS, sendo os resultados apresentados na Tabela 46. Com base nesta tabela, verificou-se que todos os parâmetros das variáveis usados para mensurar GRI e DESEMP OPERACIONAL são estatisticamente significativos a um nível de significância de 5\%, pois todos os p-valores são menores que 0,05. Porém, nota-se que o impacto do grau de internacionalização sobre o desempenho operacional não é estatisticamente significativo (pvalor = 0,087 pelo método de MV e p-valor = 0,075 pelo método WLS). 


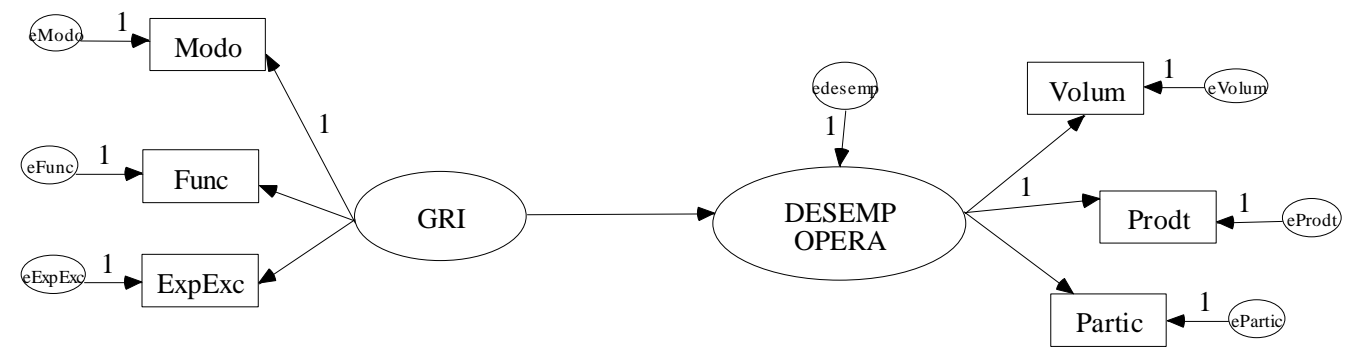

Figura 17 - Diagrama de caminho do modelo 2b

Fonte: Dados da pesquisa (2010)

Tabela 46 - Testes de significância do modelo 2b

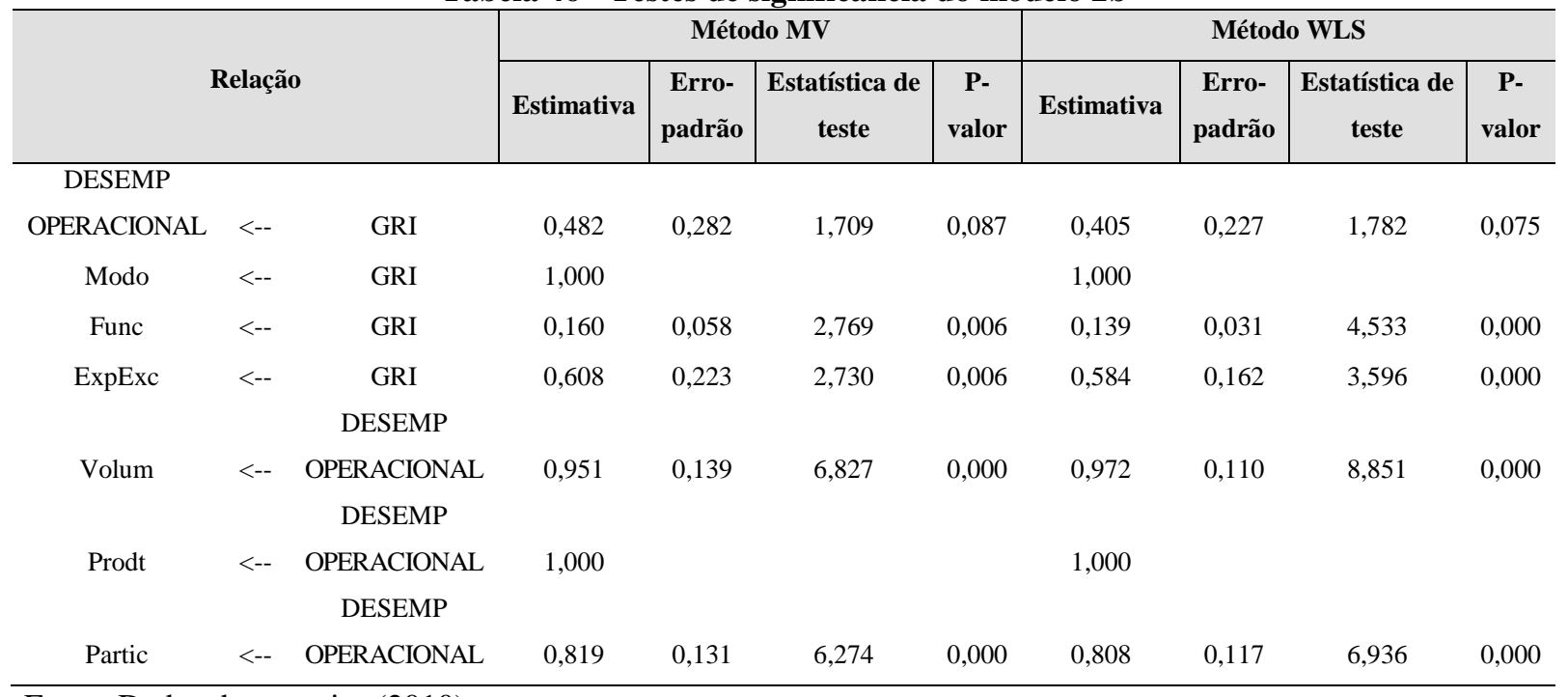

Fonte: Dados da pesquisa (2010)

Verifica-se, então, se o modelo está bem ajustado aos dados por meio de medidas de ajuste consideradas para o modelo 2 b (Tabela 46). Pelo teste qui-quadrado, tem-se que o modelo está bem ajustado aos dados por ambos os métodos de estimação ( $\mathrm{P}$-valor $=$ 0,176 pelo método de MV e, p-valor = 0,113 pelo WLS). A raiz do erro quadrático médio de aproximação (RMSEA) deve apresentar valores abaixo de 0,05 para que o modelo seja considerado bem ajustado. $\mathrm{O}$ modelo $2 \mathrm{~b}$ apresentou um RMSEA $=0,062 \mathrm{com}$ o método de MV (e 0,074 para o método de WLS), com um intervalo de confiança de $90 \%$ dado por $(0,000 ; 0,136)$ para o método de MV e $(0,000 ; 0,145)$ pelo outro método. Realizando o teste para verificar se o RMSEA realmente está abaixo de 0,05, não se rejeita a hipótese, o que indica que o modelo está bem ajustado por ambos os métodos. Analisando o índice de ajuste comparativo (CFI) e a raiz do quadrado médio residual (RMR), também se pode considerar 
que o modelo está bem ajustado aos dados, já que eles apresentaram valores bem próximos a 1 e a 0 , respectivamente. Portanto, de um modo geral, pode-se afirmar que o modelo $2 b$ está bem ajustado aos dados, conforme Tabela 47.

\begin{tabular}{ccc}
\multicolumn{3}{c}{ Tabela 47 - Medidas de ajuste para o modelo 2b } \\
\hline Medida & MV & WLS \\
\hline Qui-quadrado & 11,481 & 12,979 \\
p-valor & 0,176 & 0,113 \\
\hline RMSEA & 0,062 & 0,074 \\
LI 90\% & 0,000 & 0,000 \\
LS 90\% & 0,136 & 0,145 \\
p-valor & 0,348 & 0,256 \\
\hline CFI & 0,976 & 0,958 \\
RMR & 0,028 & 0,044
\end{tabular}

Fonte: Dados da pesquisa (2010)

Considerando a falta de significância dos dados, pode-se inferir que para o desempenho organizacional as competências também se fazem importantes, ou seja, para que haja um desempenho organizacional significativo quando a PME aumenta o GRI, a empresa necessita desenvolver competências organizacionais.

Finalmente, o último modelo concorrente analisado (Figura 18) para a confirmação ou não da H1b tem como objetivo verificar se a competência (COMPET) tem influência sobre grau de internacionalização (GRI) e se este, por sua vez, tem influência direta sobre o desempenho operacional (DESEMP OPERACIONAL). Ou seja, o objetivo é verificar se a competência impacta no desempenho operacional por meio do grau de internacionalização. 


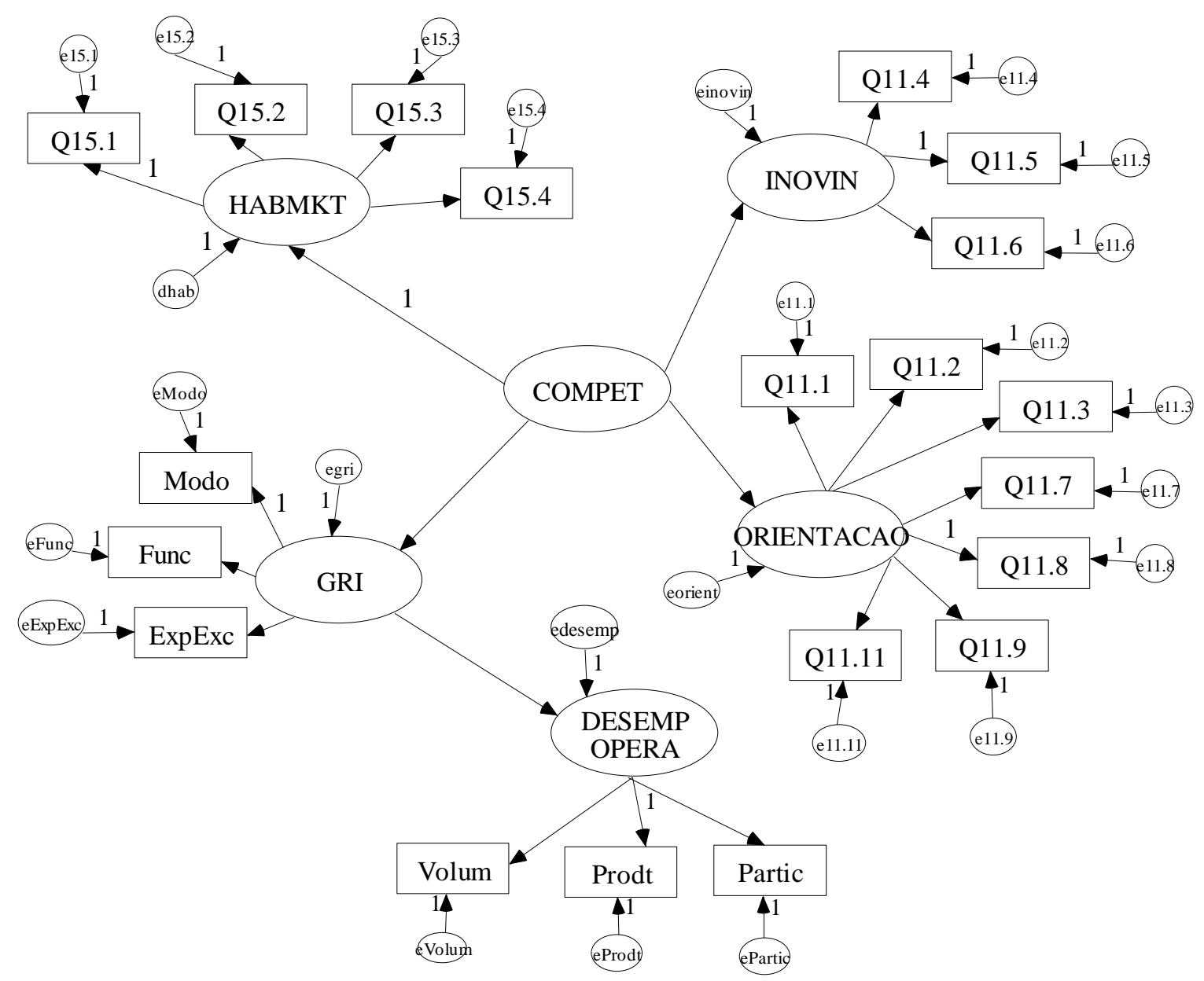

Figura 18 - Diagrama de caminho do modelo $3 b$ Fonte: Dados da pesquisa (2010)

Na Tabela 48, a seguir, mostram-se os testes de significância dos parâmetros do modelo 3b, e pelos resultados conclui-se que todos são estatisticamente significativos a um nível de significância de 5\%, porquanto todos os p-valores são menores que 0,05. Além disso, verifica-se que a competência tem um impacto positivo de 0,378 sobre o grau de internacionalização, e que este, por seu turno, tem um impacto de 0,971 sobre o desempenho operacional, indicando que quanto maior a competência da empresa, maior o seu grau de internacionalização e que quanto maior o grau de internacionalização, melhor o desempenho operacional. 
Tabela 48 - Testes de significância do modelo 3b

\begin{tabular}{|c|c|c|c|c|c|c|}
\hline \multicolumn{3}{|c|}{ Relação } & \multirow{2}{*}{$\begin{array}{c}\text { Estimativa } \\
0,378\end{array}$} & \multirow{2}{*}{$\begin{array}{c}\begin{array}{c}\text { Erro- } \\
\text { padrão }\end{array} \\
0,107\end{array}$} & \multirow{2}{*}{$\begin{array}{c}\begin{array}{c}\text { Estatística } \\
\text { de teste }\end{array} \\
3,519\end{array}$} & \multirow{2}{*}{$\begin{array}{c}\text { P-valor } \\
0,000\end{array}$} \\
\hline $\begin{array}{c}\text { GRI } \\
\text { DESEMP }\end{array}$ & $<-$ & COMPET & & & & \\
\hline OPERACIONAL & $<-$ & GRI & 0,971 & 0,362 & 2,682 & 0,007 \\
\hline ORIENTACAO & $<-$ & COMPET & 1,551 & 0,297 & 5,218 & 0,000 \\
\hline HABMKT & $<-$ & COMPET & 1,000 & & & \\
\hline INOVIN & $<-$ & COMPET & 1,300 & 0,285 & 4,562 & 0,000 \\
\hline Modo & $<-$ & GRI & 1,000 & & & \\
\hline Func & $<-$ & GRI & 0,203 & 0,058 & 3,520 & 0,000 \\
\hline ExpExc & $<-$ & GRI & 0,742 & 0,224 & 3,305 & 0,001 \\
\hline Q11.1 & $<-$ & ORIENTACAO & 0,836 & 0,106 & 7,908 & 0,000 \\
\hline Q11.2 & $<-$ & ORIENTACAO & 1,002 & 0,102 & 9,794 & 0,000 \\
\hline Q11.3 & $<-$ & ORIENTACAO & 1,148 & 0,108 & 10,624 & 0,000 \\
\hline Q11.7 & $<-$ & ORIENTACAO & 0,635 & 0,109 & 5,833 & 0,000 \\
\hline Q11.8 & $<-$ & ORIENTACAO & 1,000 & & & \\
\hline Q11.9 & $<-$ & ORIENTACAO & 0,695 & 0,114 & 6,070 & 0,000 \\
\hline Q11.11 & $<-$ & ORIENTACAO & 0,871 & 0,104 & 8,391 & 0,000 \\
\hline Q15.1 & $<-$ & HABMKT & 1,000 & & & \\
\hline Q15.2 & $<-$ & HABMKT & 0,965 & 0,098 & 9,799 & 0,000 \\
\hline Q15.3 & $<-$ & HABMKT & 1,221 & 0,125 & 9,802 & 0,000 \\
\hline Q15.4 & $<-$ & HABMKT & 1,073 & 0,118 & 9,089 & 0,000 \\
\hline Q11.4 & $<-$ & INOVIN & 1,251 & 0,180 & 6,944 & 0,000 \\
\hline Q11.5 & $<-$ & INOVIN & 1,000 & & & \\
\hline Q11.6 & $<-$ & $\begin{array}{l}\text { INOVIN } \\
\text { DESEMP }\end{array}$ & 0,635 & 0,131 & 4,845 & 0,000 \\
\hline Volum & $<-$ & $\begin{array}{l}\text { OPERACIONAL } \\
\text { DESEMP }\end{array}$ & 0,932 & 0,133 & 7,033 & 0,000 \\
\hline Prodt & $<-$ & $\begin{array}{l}\text { OPERACIONAL } \\
\text { DESEMP }\end{array}$ & 1,000 & & & \\
\hline Partic & $<-$ & OPERACIONAL & 0,839 & 0,131 & 6,406 & 0,000 \\
\hline
\end{tabular}

Fonte: Dados da pesquisa (2010)

Ajustado o modelo, verifica-se, então, o ajuste dos dados do modelo. A estatística quiquadrado para este modelo é de 350,875, com um p-valor $<0,001$, ou seja, por meio deste teste têm-se evidências de que o modelo não está bem ajustado aos dados. Mas, como já frisado anteriormente, outras medidas alternativas devem ser avaliadas, pois a estatística quiquadrado é vantajosa sob certas condições específicas.

A raiz do erro quadrático médio de aproximação (RMSEA) do modelo $3 b$ foi de 0,100 , com um intervalo de confiança de $90 \%$ dado por $(0,085 ; 0,114)$. Além disso, o teste para verificar se o RMSEA realmente está abaixo de 0,05 apresentou um p-valor de $<0,001$, o que indica 
que o modelo não estaria tão bem ajustado. Porém, utilizando a regra de decisão de Huntley e Perry (2003), o modelo 3 b apresentou-se razoavelmente ajustado aos dados.

Analisando o índice de ajuste comparativo $(\mathrm{CFI}=0,831)$ e a raiz do quadrado médio residual $(\mathrm{RMR}=0,120)$, também se pode considerar que o modelo está razoavelmente ajustado aos dados, já que eles apresentaram valores próximos a 1 e a 0 , respectivamente. Portanto, de um modo geral, conclui-se que o modelo 3 b está bem ajustado aos dados.

Tenta-se ainda verificar as medidas de comparação de modelos citadas anteriormente para os modelos 1 b e 3b, que são concorrentes (Tabela 49). Por meio da análise da tabela que contém essas medidas observa-se que elas são bem parecidas para ambos os modelos, mas a opção, aqui, seria pelo modelo $1 \mathrm{~b}$, em que o GRI tem um impacto sobre a competência, e esta, por sua vez, tem impacto sobre o desempenho organizacional.

Tabela 49 - Medidas de ajuste para comparação de modelos

\begin{tabular}{c|c|c|c}
\hline Modelo & AIC & BCC & BIC \\
\hline 1b & 416,911 & 437,455 & 674,848 \\
2b & 440,875 & 461,419 & 698,812 \\
\hline
\end{tabular}

Fonte: Dados da pesquisa (2010)

Assim, H1b foi considerada válida (modelo 1b), pois o modelo $2 b$ não se mostrou significativo, e o modelo $3 \mathrm{~b}$, apesar de ter se demonstrado ser significativa a relação mediadora de GRI entre a competência e o desempenho financeiro, os valores de ajustes do modelo não se apresentaram tão adequados quanto no modelo 1 b.

Comparando-se então o modelo $1 \mathrm{~b}$ e $3 \mathrm{~b}$ no concernente aos índices de ajustes, obtêm-se os resultados expostos na Tabela 50 .

Tabela 50 - Resumos dos ajustes do Modelo $1 \mathrm{~b}$ e do Modelo 2b

\begin{tabular}{c|c|c|c|c}
\hline Modelo & $\mathrm{x}^{2}$ & RMSEA & CFI & RMR \\
\hline $\mathrm{1b}$ & $<0,001$ & 0,093 & 0,853 & 0,081 \\
$\mathrm{3b}$ & $<0,001$ & 0,100 & 0,831 & 0,120 \\
\hline
\end{tabular}

Fonte: Dados da pesquisa (2010) 
Para compreender melhor os dados da Tabela 50, acima, é necessário relembrar que para que o ajuste CFI se mostre adequado seu valor deverá ser o mais próximo de 1, já para o RMR o valor deverá ser $<0,005$. Portanto, pode-se verificar pelos dados da Tabela 50 que o modelo 1 b está mais ajustado que o modelo $3 b$.

Outra consideração que conduz à conclusão de que o modelo $1 \mathrm{~b}$ está mais adequado e explicando melhor as relações entre os construtos é a estimativa que explica o quanto cada construto impacta ou explica suas relações. Os valores do modelo $1 \mathrm{~b}$ e do modelo $3 \mathrm{~b}$ são reapresentados na Tabela 51, para melhor compreensão:

\begin{tabular}{c|ccccc}
\multicolumn{6}{c}{ Tabela 51 - Dados totais de relação Modelos 1b e 3b } \\
\hline Modelo & Relação & Estimativa & Sig (P-valor) & Est. Total \\
\hline $1 \mathrm{~b}$ & COMPET <-- GRI & 0,623 & 0,007 & \multirow{2}{*}{0,643} \\
$\mathrm{1b}$ & DESEMP & 1,033 & 0,000 & \\
$\mathrm{3b}$ & OPERA<-- COMPET & 0,378 & 0,000 & \multirow{2}{*}{0,367} \\
$\mathrm{Hb}$ & GRI <-- COMPET & DESEMP & 0,971 & 0,007 & \\
\hline
\end{tabular}

Fonte: Dados da pesquisa (2010)

Como pode ser verificado na Tabela 51, os valores que explicam a relação entre os construtos do modelo $1 \mathrm{~b}$ apresentam um melhor impacto, assim, considera-se a H1b positiva. No Anexo 02 apresenta-se o diagrama completo. A relação final resumida é demonstrada na Figura 19.

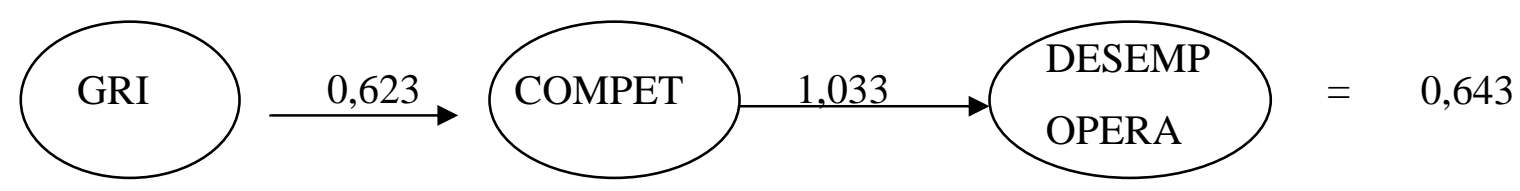

Figura 19 - Relação final entre os construtos H2

Fonte: dados da pesquisa (2010)

Pelos resultados acima apresentados, chega-se à conclusão que o modelo 1a e o modelo 1 b são os que melhor explicam a relação entre GRI e desempenho, ou seja, os modelos que são medidos pelas competências. 



\section{DISCUSSÃO DOS RESULTADOS}

Os resultados desta tese respondem à questão da pesquisa, que afirma que quanto maior o GRI, mais competências a PME desenvolve e melhor será o seu desempenho financeiro e operacional. As competências mediaram positivamente o GRI e o desempenho financeiro e operacional, comprovando as hipóteses.

Enfatiza-se que a análise das relações que condicionaram o GRI das PMEs brasileiras e o desempenho, mediados pela competência, foram fundamentadas no modelo de equações estruturais, privilegiando a análise em nível da empresa.

Das 6.750 empresas que faziam parte do Banco de dados da SECEX (2009),aplicou-se a survey em 1589 PMEs (com até 200 funcionários) e, por meio de telefone e e-mail, foram obtidos 114 respondentes, sendo que destes 44 PMEs possuem investimento direto no exterior e 70 PMEs são exportadoras.

Pelo número de respondentes $(7,17 \%)$ não se pode extrapolar os resultados para todas as PMEs brasileiras, mas acredita-se que o resultado encontrado pode servir de estímulo para que outras PMEs brasileiras passem a observar o mercado internacional como uma alternativa de aprendizado e estratégica, não só para os seus produtos, mas também para os seus investimentos.

Muitos autores (HYMER, 1976; SETHI; JUDGE, 2009; PORTER, 1990; ZAHRA et al., 2000; FLEURY; FLEURY, 2004; GHOSHAK, 1987; GRANT, 1987; QIAN, 2002; CAMISÓN; VILLAR-LÓPEZ, 2010) consideram que o aumento do GRI possibilita à empresa o desenvolvimento de novas competências que permitem melhorar o desempenho, corroborando os resultados desta tese. Já outros autores, diferentemente dos resultados aqui propostos, identificam que as competências é que possibilitam o aumento do GRI. (p.e. RUZZIER et al., 2007). Há ainda alguns autores, como Schendel (1997), que consideram que a interação entre o GRI e as competências seria recíproca, e outros, como, por exemplo, Pangarkar (2008), não sabem o que vem antes, a internacionalização ou as competências.

Penrose (1959) afirma que o crescimento da empresa está diretamente ligado à aquisição de conhecimento e que, conforme a empresa cresce, ela aprende a utilizar os recursos humanos 
de modo mais eficiente. Neste sentido, a opinião do Sr. Lee, proprietário da Morana Bijuterias, apresentada no estudo de caso, comprova o que diz a autora acima citada, quando menciona que a empresa precisa disponibilizar os melhores profissionais para a internacionalização e abrir mão deles na matriz brasileira, o que custa caro e torna a decisão da internacionalização ainda mais difícil. A preocupação do Sr. Lee confirma a opinião de Knigt e Cavusgil (2004), quando estes sustentam que as capacitações das pessoas poderiam colocar um limite na expansão da empresa.

O aumento do GRI, mediado pelo desenvolvimento das habilidades em lidar com o mercado internacional (KNIGHT e KIM, 2009), assegura competências internacionais, que podem distinguir as PMEs com alto GRI das PMEs que operam localmente. (PENROSE, 1959; TEECE, 1997). Tais competências são um composto de habilidades, de conhecimento e de experiências em marketing internacional, orientação internacional e em inovação que são reflexos de um conjunto de competências individuais que devem ser incorporadas na rotina das PMEs e transformadas em competências organizacionais.

No início do processo de internacionalização, o desempenho da PME poderá declinar tendo em vista o passivo de estranheza e poderá pagar com seus lucros o preço da iniciação da expansão internacional. (RUIGROK; WAGNER, 2003). O desempenho irá aumentar à medida que as vantagens de propriedade forem exploradas em um maior grau de internacionalização, e em que novos recursos sejam desenvolvidos em mercados internacionais. (HITT et al., 1997). À medida que o grau de internacionalização aumenta, diminui o "passivo de estranheza" por meio da experiência acumulada, fazendo com que o desempenho da PME cresça. (HYMER, 1976). Para auxiliar a análise dos resultados nesta tese verificou-se, por meio de uma análise de variância, o comportamento do desempenho em PMEs exportadoras e com IDE de baixo, médio e alto GRI (Ver Apêndice D). Porém, os resultados encontrados nesta tese permitem inferir que para as PMEs brasileiras respondentes o desempenho financeiro apresenta um decréscimo quando as PMEs exportadoras chegam ao nível médio de GRI, já quando as PMEs exportadoras atingem o nível máximo de GRI, o desempenho financeiro também atinge o seu nível máximo. Por outro lado, quando as PMEs iniciam o seu IDE, o desempenho financeiro cai ao seu nível mais baixo, e quando as PMEs com IDE atingem o seu nível médio de GRI, o seu desempenho também cresce, atingindo 
novamente seu nível máximo. Contudo, assim que a PME aumenta o seu GRI, o desempenho volta a cair.

Como na perspectiva do processo de internacionalização por etapas (JOHANSON; VAHLNE, 1990) explica que a empresa se internacionaliza à medida que acumula as competências necessárias.

Para as empresas exportadoras, o desempenho operacional se comportou de forma idêntica ao desempenho financeiro. Diferentemente, porém, é o comportamento do desempenho operacional para as PMEs com IDE. A partir do momento em que a PME inicia o investimento direto no exterior, o desempenho operacional se mantém praticamente linear durante o aumento do GRI, não apresentando quedas no decorrer do aumento do GRI. Com esse resultado, parece haver uma curva U entre o aumento do GRI das PMEs exportadoras e IDE com o desempenho financeiro. Já para o desempenho organizacional, a curva U parece ser identificada somente para as empresas exportadoras. Para as empresas com IDE, há indícios de linearidade.

A possibilidade de reversão do desempenho pode ser particularmente difícil para a PME, uma vez que esta pode não ter os recursos de gestão necessários, bem como a experiência para coordenar a internacionalização de forma eficiente. (QIAN, 2002). Por esse motivo, o desenvolvimento de competências com o aumento do GRI pode ser o grande diferencial para a PME melhorar o desempenho e aproveitar os benefícios do aumento do GRI. Dunning (1973) e Oviatt e McDougall (1994) concordam que quanto mais fortes forem as capacidades da PMEs, maior será sua vantagem competitiva e, consequentemente, melhor será o seu desempenho. Vernon (1966) complementa que empresas com uma forte vantagem de propriedade (capacidades) podem estar numa posição melhor para barganhar taxas governamentais nos países hospedeiros ou ter outras concessões, aumentando a capacidade de atrair parceiros e ainda aumentar o desempenho. A RBV reconhece que a internacionalização pode fornecer um meio para as empresas criarem recursos internos, mas não aceita que as deficiências de recursos podem conduzir a esse tipo de comportamento. (TEECE; PISANO, 1994; GRANT, 1996).

A teoria dos custos de transação sugere que a internacionalização desafia a gestão e pode levar a um aumento no custo de coordenação e de comunicação. Grande parte da literatura, 
entretanto, concorda com os benefícios da internacionalização, ou seja, que esta compensa o aumento dos custos e, portanto, deve impactar positivamente o desempenho da empresa (GHOSHAL, 1987). Sabe-se, porém, que a internacionalização pode ter um efeito negativo no desempenho, pois pode elevar os custos de transação, bem como os custos de coordenação (BUCKLEY; CASSON, 1976; GERINGER et al., 1989; THOMAS; ÉDEN, 2004), mas com o aumento da experiência internacional, as PMEs adquirem maior confiança na sua capacidade de avaliar as necessidades do cliente, para estimar custos e retornos e para avaliar o verdadeiro valor econômico dos mercados internacionais. (DAVISON, 1980; SUH et al., 2007).

Apesar dos modelos mediados pela competência e os mediados pelo GRI terem, ambos, se mostrado significativos, verifica-se uma diferença tanto nos resultados de ajuste como nos resultados de relação entre os construtos. Com isso, pode-se inferir que o desempenho financeiro e operacional é melhor explicado pelas novas competências desenvolvidas após o aumento do grau de internacionalização.

É interessante notar que quando se procurou verificar se o aumento do GRI influenciava diretamente o desempenho das PMEs, o resultado não se mostrou significativo. Esse resultado permite concluir que sem que a empresa desenvolva competências não haverá um aumento do desempenho financeiro ou operacional para as PMEs internacionalizadas.

$\mathrm{O}$ aprendizado adquirido pela experiência internacional permite à PME aperfeiçoar suas competências internacionais, permitindo, ao mesmo tempo, à empresa aumentar o seu grau de internacionalização a favor da continuação do processo de aprendizagem e assim, tornar o processo contínuo, ou seja, a empresa se internacionaliza, gera o aprendizado necessário, o que lhe possibilita evoluir ainda mais no grau de internacionalização (CAMISÓN; VILLARLÓPEZ, 2010). Sabe-se que para comprovar essa causalidade seria necessário um estudo longitunial, mas este estudo apresenta uma nova abordagem explorando uma variável que media a relação entre o GRI e o desempenho.

\section{a) Resultados para o GRI}

Dos seis indicadores iniciais para GRI, somente três atenderam adequadamente aos critérios de significância estabelecidos (5\%). Dois desses critérios são relacionados com pessoas, ou 
seja, a experiência do executivo e os empregados no exterior se mostraram significativos para o construto. Este resultado possibilita inferir acerca da importância da gestão de pessoas para a internacionalização das PMEs brasileiras. Verifica-se, então, que executivos mais expostos a culturas estrangeiras, via estudo ou trabalho, e os empregados das PMEs no exterior, provavelmente possibilitam às PMEs acumular conhecimento experiencial sobre as características do mercado internacional, o que torna possível o aumento do GRI. Este resultado corrobora os resultados de outras pesquisas de internacionalização de PMEs, que identificaram que fatores pessoais dos executivos e funcionários das PMEs podem influenciar fortemente o processo de internacionalização. (DICHTL et al., 1990; IETTO-GILLIES, 1998; IBEH; YOUNG, 2001; McDONALD et al., 2003; MAJOCCHI, 2005; ETEMAD,2004; RUZZIER et al., 2007).

O número de executivos com experiência de estudo ou trabalho no exterior por um período maior ou igual a um ano foi o indicador que se mostrou mais relacionado ao GRI $(0,833$, pvalor 0,001 ). O modo de internacionalização foi fixado em 1 e o número de funcionários no exterior explica 0,222 com um nível de significância de 5\% (Ver diagrama final nos ANEXOS 1 e 2).

\section{b) Os resultados para competência}

Os resultados sugerem que a competência da empresa nos negócios internacionais também é um construto multidimensional que gera novas e específicas competências internas nas PMEs, como a cultura empresarial e as capacidades em lidar com uma cultura diferente. Estas competências se mostraram fundamentais para a atuação internacional das PMEs e também poderão ser importantes para os negócios da empresa no mercado interno (KNIGT; KIM, 2009).

Embora tenda a faltar recursos financeiros e humanos na PME (ROTH, 1992; BIJMOLT; ZWART, 1994; HOLLESTEIN, 2005; CAMISÓN; VILLAR-LÓPEZ, 2010), as competências para os negócios internacionais, identificadas neste trabalho, parecem alavancar um conjunto de recursos intangíveis que são importantes para o sucesso da empresa como um todo. Esses recursos foram identificados pela habilidade em marketing internacional, em inovação e pela orientação internacional. Este resultado sugere que as pessoas da organização necessitam ser preparadas para enfrentar os negócios no exterior, e que isso deve ser feito no decorrer do aumento do GRI. 
Devido à dimensão territorial brasileira e a expressiva quantidade de consumidores locais, que falam o mesmo idioma e possuem, apesar de suas diferenças, costumes similares, as PMEs brasileiras acabam se acomodando na atuação nacional. (ROCHA, 2003). Essa acomodação dificulta o desenvolvimento de novas competências internacionais que, como mostrado neste trabalho, permitem aumentar o desempenho organizacional.

Os três construtos que formaram o construto competência se mostraram significativos ao nível de 5\%, apresentando todos eles uma alta estimativa para explicar o construto maior que formaram, ou seja, competência. Apesar de Knight e Kim (2009) terem utilizado técnicas estatísticas diferentes, eles chegaram à conclusão que juntando a orientação internacional e a orientação para o mercado internacional poderiam explicar melhor a competência. Nesta tese os dois indicadores foram juntados durante a análise fatorial exploratória para assim explicar melhor o construto competência, confirmando o resultado dos autores.

Apesar de os resultados aqui demonstrados terem apresentado um efeito geral positivo sobre os resultados financeiros e operacionais das PMEs, podem redundar em um efeito negativo sobre os resultados quando a empresa precisar investir para melhorar essas competências devido ao aumento do grau de internacionalização.

Embora haja, sem dúvida, outras competências para as PME internacionais, os resultados aqui encontrados indicam que a habilidade em marketing internacional, a inovação e a orientação internacional desenvolvem novas competências nas PMEs entrevistadas, que auxiliam em um melhor desempenho organizacional.

\section{c) Resultados para desempenho}

Os resultados do desempenho financeiro e do desempenho operacional resultaram positivos pelo aumento do grau de internacionalização. Contudo, essa relação só se demonstrou significativa pelo desenvolvimento de competências.

A relação entre GRI, competências e o desempenho operacional foi melhor explicada quando se comparou a relação dos mesmos construtos com o desempenho financeiro. Este resultado, como indicado por Lages et al. (2005) e Porter (1985), sugere que pelo aumento do GRI e do desenvolvimento de novas competências as PMEs conseguem ganhar mais em produção e 
escala do que financeiramente. Mas para a PME brasileira que está iniciando sua trajetória internacional (a maioria se internacionalizou no início dos anos 2000), a demonstração de ganho de mercado, de volume de vendas e de produtividade, pode ser, num primeiro momento, mais importante que o ganho financeiro. Com o aumento da experiência internacional e o aumento do desempenho operacional, o desempenho financeiro também tende a crescer.

Analisando a Hipótese Central definida nesta tese verifica-se, de acordo com os resultados estatísticos das equações estruturais aqui apresentadas, que:

O GRI impacta positivamente no desenvolvimento de competências, que por sua vez impacta positivamente o desempenho organizacional. Como argumentou Sullivan (1994), não se pode prever com certeza que a diversificação internacional irá melhorar o desempenho da empresa, mas se considerado o desenvolvimento de competências como mediadora, como apresentado no modelo desta tese, pode-se inferir que há relação direta e positiva entre o GRI, as competências e o desempenho para a PME.

Para resultados mais específicos do impacto da evolução gradual da internacionalização no desempenho da PME seria necessário um estudo longitudinal analisando o tempo e o modo, bem como os resultados em cada uma das etapas. Por esse motivo, verifica-se que o modelo aqui proposto, apesar de se basear nos índices mais voltados aos modelos econômicos, como o de Sullivan (1994), corroborou a dinâmica comportamental. O crescente acúmulo de experiência mediada pela consolidação gradativa de processos de aprendizagem resultará no comprometimento de recursos da empresa. (LEONIDOU; KATSIKEAS, 1996).

\subsection{Implicações para a Teoria}

Considerando como estratégia a evolução do GRI, verifica-se que à medida que há um aumento do GRI, há também o desenvolvimento de novas competências, via processo de aprendizagem organizacional, possibilitando à PME reposicionar as estratégias competitivas, com o consequente aumento do GRI, proporcionando-lhe, então, um desempenho superior. As competências nos negócios internacionais refletem a capacidade de a empresa realizar 
atividades nos negócios internacionais efetivamente, e têm um efeito positivo no desempenho da empresa. (KNIGHT; KIM, 2009).

O desenvolvimento das competências identificadas nesta pesquisa possibilita o acadêmico a refletir sobre a importância do desenvolvimento de competências para as PMEs no processo de internacionalização.

\subsection{Implicações Gerenciais para as PMEs}

Os resultados desta pesquisa sugerem às PMEs brasileiras que estas busquem aumentar o seu grau de internacionalização, mesmo que no início do processo o resultado financeiro possa cair, porquanto, com o desenvolvimento de competências, advindas do aumento do GRI, tanto o resultado financeiro como o operacional tenderá a aumentar.

Pela acomodação que o mercado brasileiro proporciona às PMEs, o conhecimento e a habilidade em lidar com o passivo da estranheza será mais desenvolvido com as experiências no mercado internacional, ou seja, com o aumento do GRI.

Com base nos resultados deste trabalho, as PMEs podem sentira necessidade de ter em seu quadro funcional executivos com visão e ações voltadas para o mercado internacional ou mesmo de ter que proporcionar aos seus funcionários treinamentos específicos que possibilitem o desenvolvimento desse olhar internacional.

As competências aqui identificadas podem auxiliar as PMEs a superar a escassez de recursos para ter sucesso em mercados externos. Provavelmente a qualidade do time gerencial das PMEs seja de grande relevância para o sucesso da empresa em mercados externos.

PMEs brasileiras com um maior GRI desenvolverão mais competências, as quais possibilitarão que estas tenham um melhor desempenho organizacional. Espera-se, com este resultado, entusiasmar as PMEs brasileiras a evoluir em seu grau de internacionalização, explorando o mercado externo mediante formas de internacionalização mais complexas, para que possam usufruir dos benefícios de estarem efetivamente presentes no mercado externo. 
É um fato inconteste que a PME se internacionaliza, na sua maioria, via exportação, mas, como se pôde verificar nesta pesquisa, outras estratégias de internacionalização estão sendo operacionalizadas pelas PMEs apesar das barreiras e das dificuldades que elas encontram nesses projetos. Não obstante vários estudos (SUH et al., 2007; KNIGHT; KIM, 2009; RUZZIER et al., 2007) indicarem que a PME sofre com a falta de conhecimento experiencial, esta tese demonstrou que este fator é de suma importância para que a PME se internacionalize, desenvolva mais competências, podendo, assim melhorar o seu desempenho.

Há indícios de que os benefícios não se dariam somente no mercado externo, mas para a organização como um todo, diferenciando as PMEs inclusive no mercado interno.

Políticas específicas para promover o aumento do GRI das PMEs deveriam ser operacionalizadas pelo governo e pelas entidades que possuem esse papel no mercado brasileiro, para encorajá-las a se internacionalizarem cada vez mais. Ações de publicidade positiva do Brasil no exterior, e de financiamentos exclusivos para auxiliar a PME a iniciar uma operação no exterior, podem contribuir para o aumento do GRI e para o consequente desenvolvimento de novas competências para melhorar o desempenho das PMEs brasileiras e, assim, a competitividade.

Para auxiliar esta fase da pesquisa, a doutoranda foi convidada pela consultoria Delloite a fazer parte da rede de discussões da Revista Exame sobre a PME. Muitas discussões estão sendo realizadas nesse chat, inclusive está sendo elaborada uma nova cartilha do empreendedor e, como sugestão da doutoranda, está sendo debatida a inclusão de um capítulo sobre a internacionalização.

A qualidade do time gerencial nos negócios internacionais das PMEs, em particular, parece assegurar o sucesso da PME após o aumento do grau de internacionalização. As competências aqui identificadas, e que se mostraram relevantes para o sucesso da PME, são difíceis de serem rapidamente imitadas (TEECE, 2007; KNIGHT; KIM, 2009; RUZZIER et al., 2007), o que permite à PME se diferenciar não só no mercado externo como também no Brasil. 



\section{CONCLUSÕES}

Este estudo contextualizou e testou um modelo de pesquisa acerca do aumento do GRI da PME brasileira. Especificamente, o trabalho testou uma hipótese central identificando três importantes construtos da internacionalização da PME: o GRI, as competências e o desempenho organizacional. Especificamente, estudou-se a mediação das competências internacionais com o aumento do GRI e o desempenho.

Assim, com base nos resultados obtidos, pôde-se inferir que, para as PMEs pesquisadas, o aumento do GRI desenvolve mais competências e, com isso, há um maior impacto no desempenho da empresa, tanto no desempenho operacional como no financeiro.

Concluiu-se, ademais, que o aumento do GRI, por si só, não possibilita uma melhora no desempenho da PME. Para que as PMEs possam melhorar seu desempenho, via aumento do grau da internacionalização, elas deverão desenvolver novas competências. Essas competências serão desenvolvidas com o aumento do GRI, e assim a PME poderá contar com um melhor desempenho.

Justifica-se, assim, a adequação dos resultados deste trabalho com a RBV, pelo fato de a sua abordagem ao processo de internacionalização ser baseada em recursos e capacidades, o que é escasso nas PMEs brasileiras, além de representar um dos principais obstáculos para as PMEs progredirem nos mercados externos e ter um melhor desempenho. Isto vem confirmar que a dotação de recursos intangíveis tem um forte efeito direto sobre GRI e desempenho.

Para as PMEs brasileiras, fica muito mais difícil desenvolver competências internacionais antes de ingressar no mercado internacional. A extensão do território brasileiro acomoda o empresariado nacional, que não obstante as diversidades, atende a um público homogêneo. Tais resultados vêm encorajar o empresariado das PMEs brasileiras a aumentar o grau de internacionalização, mesmo sem as competências necessárias para atuar no mercado externo, pois com a experiência adquirida por meio da sua atuação no exterior, desenvolverá mais competências, melhorando o desempenho financeiro e operacional. 


\subsection{Limitações e Sugestão para Novos Estudos}

Como em toda pesquisa realizada, esta também possui limitações que, apontadas, poderão auxiliar outros pesquisadores no aprofundamento deste tema ou na elaboração de novos estudos.

Os resultados aqui encontrados se limitam aos dados coletados, ou seja, às PMEs brasileiras e, ainda, às PMEs brasileiras pesquisadas. Convém ressaltar, contudo, que pesquisas realizadas no exterior serviram para formar a base conceitual desta tese e, portanto, os resultados nela obtidos poderão auxiliar no desenvolvimento de novos estudos sobre o GRI, as competências e o desempenho, tanto no Brasil como no exterior, visto que os resultados aqui expostos se mostraram similares aos de estudos internacionais. (RUZZIER et al., 2007; KNIGHT; KIM, 2009).

Outra limitação que pode ser apontada é o fato de que os dados desta tese foram coletados em empresas de 5 a 200 funcionários. Sugere-se, pois, que outros estudos sejam realizados com PMEs com até 499 empregados, que, acredita-se, de acordo com informações do SEBRAE, poderá resultar em um número muito maior de empresas brasileiras e ainda com um GRI mais elevado, proporcionando dados mais robustos e resultados que possam ser generalizados para toda a população de PMES. Um número maior de PMEs com IDE possibilitaria o desenvolvimento de estudos comparativos de PMEs exportadoras com PMEs com operação no exterior, o que não foi possível fazer neste estudo em decorrência da técnica utilizada e também do fato de a pesquisa considerar apenas as 44 PMEs com IDE e as 70 PMEs exportadoras. Por esse motivo, analisaram-se os dados conjuntamente, acrescentando o modo de internacionalização.

Um número maior de empresas respondentes poderia permitir a aplicação de variáveis de controle, como, por exemplo, o setor de atuação. Empresas de segmentos econômicos diferentes podem apresentar comportamentos distintos devido às suas peculiaridades industriais e às características de demanda de seus mercados externos.

Quanto às medidas utilizadas para formar os construtos desta tese, acredita-se que estas podem ser refinadas e ampliadas, principalmente para o GRI, buscando ampliar o contexto 
pesquisado. Como os construtos são de natureza complexa, a relação entre eles exigiu uma simplificação para possibilitar o tratamento específico. Mesmo tendo testado outras relações entre os construtos, outros indicadores poderão também influenciar os resultados, necessitando, em novos estudos, tentar identificá-los. Trabalhar com construtos cujas medidas ainda estão sob análise, como GRI e desempenho, dificultam a identificação das medidas. Neste trabalho, contudo, o que se buscou não foi exaurir as discussões sobre as métricas desses construtos, mas buscar métricas possíveis de serem aplicadas nas PMEs brasileiras. Outra limitação do estudo se deveu ao número de variáveis identificadas em cada construto, pois o tempo disponível para a pesquisa e o número de respondentes foram fatores limitantes ao número de indicadores a serem trabalhados.

Naturalmente, outros indicadores deverão influenciar o desempenho das PMEs internacionalizadas, mas nesta tese o objetivo foi delimitado à análise do aumento do GRI e do desenvolvimento de novas competências. Além disso, podem não ter sido considerados todos os efeitos relevantes, principalmente quanto aos efeitos de moderação, ou o fato de variáveis para controle estatístico poderem levar a problemas de endogeneidade ou, ainda, de se poder encontrar resultados diferentes dos aqui apresentados. Apesar de o modelo final ter sido considerado válido, não se poder julgá-lo como sendo melhor ou pior que outros modelos similares ou que este modelo se aplica a toda a população.

O estudo transversal não possibilitou análises mais robustas para identificar a causalidade do aumento do GRI com competência e com desempenho. Pesquisas longitudinais, como a de Lu e Beamish (2006), permitiram identificar os efeitos do aumento do GRI no desempenho das PMEs e a causalidade entre as variáveis. Por ser um estudo transversal, este estudo identificou a direção entre as variáveis, como no estudo de Camisón e Villar-Lópes (2010).

Outra limitação do estudo refere-se à subjetividade dos dados coletados e com um respondente em cada empresa. Quanto à subjetividade, é muito difícil em pesquisas com PMEs conseguir um número de respostas adequado quando se questiona acerca de dados reais. Mesmo sabendo que as decisões, em sua maioria, não são tomadas por uma só pessoa na organização (LEONIDOU, 1998), pelo tempo disponível e pela acessibilidade uma só pessoa foi questionada. Outro viés da pesquisa pode advir da compreensão das questões. Mesmo que nos pré-teste realizados este fato não tenha sido identificado, pode, no ambiente de pressão cotidiana da empresa, vir a acontecer. Os procedimentos de coleta de dados estão 
sujeitos a restrições, principalmente sobre a confiabilidade de dados de natureza perceptual. (HUBER; POWER, 1985). Adicionalmente, o fato de as perguntas no questionário não terem sido aleatoriamente dispostas, mas sim agrupadas de forma a diminuir o esforço dos respondentes, pode ter introduzido um viés de método. Para diminuir esse viés, as questões não foram organizadas por grupo de construto, mas também não foram distribuídas aleatoriamente

Conforme já mencionado, esta pesquisa buscou fazer inferências sobre relações de causa e efeito, mas, como comentam Hair et al. (2009), a existência de causalidade em ambientes não totalmente controláveis, como no caso das Ciências Sociais, somente pode ser sugerida, mas não provada. Ainda segundo os autores supracitados, pode-se supor a existência de relação de causalidade se: a) há associação suficientemente forte entre as variáveis; b) há antecedência temporal da variável causa em relação à variável efeito; c) não se consegue supor a existência de outras possíveis variáveis causais alternativas; d) existe embasamento teórico para a relação.

Como também identificado no estudo de Knight e Kim (2009), sabe-se que há outros indicadores além dos aqui abordadas, mas como já se trabalhou com um conceito complexo e multidimensional, aqui nesta pesquisa se tornaria ainda mais complexo abordar, por exemplo, outras competências. Sugere-se então, que novos estudos levem em consideração outras habilidades necessárias para que a PME possa se tornarmais competitiva internacionalmente. Os resultados deste trabalho sugerem, por exemplo, abordar as competências do corpo gerencial, ou seja, as competências individuais como reflexo do desenvolvimento de competências organizacionais para atuação internacional.

Não obstante essas limitações, relacionou-se o aumento do GRI ao desenvolvimento de competências organizacionais e à melhoria do desempenho financeiro e operacional das PMEs, e, com base nos resultados obtidos, acredita-se ter contribuído para o desenvolvimento de novos insigts teóricos para a continuidade de estudos com as PMEs e o desenvolvimento de novas competências destas empresas via internacionalização. Acredita-se, também, que este estudo serviu como fonte de encorajamento para a internacionalização das PMEs brasileiras. 
Os resultados desse estudo vêm se juntar à bibliografia existente, contribuindo com informações acerca da PME de um país em desenvolvimento, reforçando a importância das PMEs e do processo de internacionalização para o desenvolvimento de um país e, especificamente, do Brasil. 



\section{REFERÊNCIAS}

AABY, N.E.; SLATER, S. Management Influences on Export Performance: A Review of the Empirical Literature 1978-88. International Marketing Review, v.6 n.4, p.7-25, 1989.

ADUANA Francesa. Le Chiffre du Commerce Extérior. Ano 2005. Disponível em: $<$ http://lekiosque.finances.gouv.fr>. Acesso em: 20/03/2010.

ALABY, M. A. Exportação na pequena e média empresa - bicho de sete cabeças? Guia Log. 2003. Disponível em: <http://www.guialog.com.br/ARTIGO420.htm>. Acesso em: 05/2009.

ALBUQUerQue, V. Política de comércio exterior: epicentros e epifenômenos do desempenho exportador das empresas brasileiras. 2008. Tese (Doutorado). Fundação Getúlio Vargas. Rio de Janeiro.

ALDRICH, H. E.; AUSTER, E. R. Even dwarfs started small: Liabilities of size and age and their strategic implications. In: B. M. Staw and L. L. Cummings (eds.). Research in Organizational Behavior, n. 8, p. 165-198. Greenwich, CT: JAI Press, 1986

ALMEIDA, A. (Org). Internacionalização de empresas brasileiras, perspectivas e riscos (FDC). São Paulo: Elsevier, 2007.

ALVES, A. O planejamento de estudos qualitativos em educação. Caderno de Estudo, São Paulo, n. 77, p. 53-61, maio 1991.

AMINE, L. S.; CAVUSGIL, S. T. Export Marketing Strategies in the British Clothing Industry. European Journal of Marketing, v.20, n.7 p.21-23, 1986

ANDERSEN, O. On The Internationalisation Process of the firms: A Critical Analysis. Journal of International Business Studies, v.24 n. 2 p. 209-231, 1993.

ANDERSEN, O.; BUVIK, A. Firms' internationalization and alternative approaches to the international customer/market selection. International Business Review, v. 11, p. 347-363, 2002.

ANDERSEN, O.; KHEAM, L. S. Resource-based theory and international growth strategies: an exploratory study. International Business Review, v.7, n. 2, p. 163-184, 1998.

ANDERSON, E.; GATIGNON, H. Modes of foreign entry: a transaction cost analysis and propositions. Journal of International Business Studies, v.17, n.3, p.1-26, 1986.

ANDERSSON S. L'internationalisation comme un acte d'esprit d'entreprise-étude d'une entreprise suédoise de produits en caoutchouc. Lindköping, 1996.

et al. International activities in Small Firms: Examining Factors Influencing the

Internationalization and Export Growth of Small Firms. Canadian Journal of Administrative Science, n. 21; v. 1, p. 22-34. 2004. 
ANDERSSON, U.; FORSGREN, M. In Search of Centre of Excellence: network embeddedness and subsidiary roles in multinational corporations. Management International Review, v. 40, p. 329-350, 2000.

ARAÚJO, R. D. Esforços Tecnológicos das Firmas Transnacionais e Domésticas. In: De Negri, J. A.; Salerno, M. S. (org). Inovações, Padrões Tecnológicos e Desempenho das Firmas Industriais Brasileiras. IPEA, Rio de Janeiro.

ARGYROUS, G. The Hight Road to International Trade: Emerging exporters Revisited. Journal of Australian Political Economy, V. 45, p. 46-67, 2000.

ARMARIO, J. M.; DAVID, R. M.; ARMARIO, E. M. Market Orientation and internationalization in Small and Medium-Sized Enterprises. Journal of Small Business Management, n. 46 v. 4, p. 485-511, 2008

AUGER, P. BARNIR, A.; GALLAUGHER, J. M. Strategic orietnation, competition e internet-based electronic commerce. Information Technology and Management, v. 4 p. 139-164, 2003.

AUREGAN P. et al. Modèles d'analyse stratégique : contributions récentes. Les cahiers de recherche, Essca, décembre. 2000

AUTIO, E. et al. Effects of age of entry, Knowledge intensity and inimitability on international growth. Academy of Management Journal. n.43, v. 59, p. 909-924, 2000.

AXINN, C. Export Performance: Do Managerial Perceptions Make a Difference? International Marketing Review, n. 5 v. Summer, p. 61-71, 1988.

BAGOZZI, R. P. Evaluating Structural Equations Models with Unobservable Variables and Measurement Error: A comment. Journal of Marketing Research, v. 18, p. 375 - 381.

BAIRD, I. et al. The choice ok International Strategies by Small Business. Journal os Small Business Management, v. 32, n. 1, p. 48-59, 1994.

BANDEIRA-DE-MELLO, R. GRÁUDED, o quê? SIMPOI, EAESP/FGV, 2009.

; MARCON, R. A Mensuração multivariada da performance e duas componentes de veriância: uma análise dos efeitos do ano, indústria e firma no contexto brasileiro. In: ENCONTRO ANUAL DA ASSOCIAÇÃO NACIONAL DOS PROGRAMAS DE PÓSGRADUAÇÃO EM ADMINISTRAÇÃ̃O, 28., 2004. Curitiba. Anais... Paraná: ANPAD, 2004.

BARBAT, V. Modalités et Processus D'Internationalisation Des PME Sous-Traitantes Françaises. Decisions Marketing, n. 47, Julho/Setembro, 2007.

BARCELOS, E. P.; CYRINO, A. B. Quão internacionalizadas são as nossas multinacionais? proposta de metodologia e resultados da sua aplicação a empresas brasileiras com atuação no exterior. In: ENCONTRO ANUAL DA ASSOCIAÇÃO NACIONAL DOS PROGRAMAS DE PÓS-GRADUAÇÃO EM ADMINISTRAÇÃO, 31., 2007. Rio de Janeio. Anais... Rio de Janeiro: ANPAD, 2007. 
BARETTO, A. Internacionalização de empresas brasileiras: processos, pessoas e networks no investimento direto no exterior. 1998. Tese (Doutorado). Coppead, Universidade Federal do Rio de Janeiro, 1998.

BARNEY, J. B. Is the resource-based "view" a useful perspective for strategic management research? Yes. The Academy of Management Review; v.26, n. 1; 2001.

Firm Resources and Sustained Competitive Advantage. Journal of Management, v.17, n.1, p.99-120, 1991.

Firm Resourde and Sustained Competitive Advantage. Journal of Management, v.17, n. 1, p. 99-120, 1991.

Gaining and sustaining competitive advantage. 2nd ed,Upper Saddle River. NJ:

Prentice Hall, 2002.

BARTLETT, C. A.; GHOSHAL, S. Managing Across Borders. The Transnational Solution Boston, EUA: Harvard Business School Press, 1989.

Makron Books, 1992.

Gerenciando empresas no exterior: a solução transnacional. São Paulo:

mar.-abr./2000.

. Going Global: Lessons from Late Movers. Harvard Business Review,

BASSI, E. Globalização de negócios: construindo estratégias competitivas. São Paulo: Cultura Editores Associados, 1997.

BEAMISH, P.W. The Internacionalisation process for smaller ontario firms: a reseach agenda. in Rugman, A. M. Research in Global Strategic Management. Grenwich: JAI Press Inc., p. 77-92, 1990.

BECKER, T.; PORTER, J. L. Small business plus export trading companies: new formula for export sucess? Journal of Small Business Management, p. 38-43, Out./1983.

BELL, J. The internationalization of small computer software firms- a further challenge to "Stage Theories", European Journal of Marketing, v. 29, n. 8, p. 60-75, 1995.

BENITO, G. R. G.; WELCH, L. S. Foreign market servicing: beyond choice of entry mode. Journal of International Marketing, n.2, v.2, p.7-27, 1994.

BILKEY, W.J.; TESAR, G. The export behavior of smaller-sized wisconsin manufacturing firms. Journal of International Business Studies.Spring/Summer, p. 93-98. 1977.

Variables associated with export profitability. Journal of International Business Studies, v. 13, n. 3, p. 57-72, 1982.

BIJMOLT, T. H. A.; ZWART, P. S. The impact of internal factors on the exports success of dutch small and medium-sized firms. Journal of Small Business Management, v. 32, n. 2,p. 69-83, 1994. 
BIRKINSHAW, J.; MOORE, K. Managing knowledge in global service firms: centers of excellence. Academy of Management Executive, v. 12, n. 4, p.81-92, 1998.

BLANK, M. C; PALMEIRA, E. M. Internacionalização de micro e pequenas empresas - uma visão crítica quanto a eficiência dos incentivos do governo. Observatorio de la Economía Latinoamericana. Revista Acadêmica de Economia, n. 71, dezembro, 2006. Disponível em: <http://www.eumed.net/cursecon/ecolat/br/06/mcb.htm>. Acesso em: 12/01/2007.

BLOODGOOD, J. M. et al. The Internationalization of new hight-potential U.S. ventures: Antecedents and outcomes. Entrepreneurship Theory and Practice, n. 20, v.4, p. 61-76, 1996.

BLUM, L. Palestra sobre a KIS Photo. Université Pierre Mendes France. Grenoble, 2009.

BONACCORSI, A.; DALLI, D. Internationalisation process and entry channels: evidence from small Italian exporters. In: Mulbacher, H. and Jochum, C. (Eds). Proceedings of the European Marketing Academy Conference. Innsbruck, 1990.

BORCH, O. J. et al. Resource configuration, competitive strategies, and corporate entrepreneurship: An empirical examination of small firms. Entrepreneurship Theory and Practice, Fall, p. 49-70. 1999.

BORINI, F. M. Transferência, desenvolvimento e reconhecimento de competências organizacionais em subsidiárias estrangeiras de empresas multinacionais brasileiras. 2008. Tese (doutorado) - Universidade de São Paulo, São Paulo.

BOSHOFF, C.; MELS, G. A causal model to evaluate the relationships among supervision, role stress, organizational commitment and internal service quality. European Journal of Marketing, v. 29, n. 2, p.23-42, 1995.

BOURGEOIS, L. J. Strategy and environment: a conceptual integration. Academy of Manegement Revies, v. 5, n. 1, p. 25-39, 1980.

BRASIL. BANCO CENTRAL DO BRASIL. 2009. Disponível em <www.bacen.gov.br〉. Acessado em: 23/03/2010.

BRITO, L. A. L.; VASCONCELOS, F. C. Firm Performance in an extremely environment: year, industry and firm effects. In: ENCONTRO ANUAL DA ASSOCIAÇÃO NACIONAL DOS PROGRAMAS DE PÓS-GRADUAÇÃO EM ADMINISTRAÇÃO, 27., 2003. Atibaia. Anais... São Paulo: ANPAD, 2003.

BROUTHERS, L. E.; NAKOS, G. The Role of Systematic International Market Selection on Small Firms' Export Performance. Journal of Small Business Management, n. 43 v. 4, p. 363-381, 2005

BUCLEY, P. J. Foreign Direct Investments by Small and Medium Sized Enterprises: The Theoretical Background. Small Business Economics, v. 1 n. 2, p. 89-100, 1989.

; CASSON, M. The future of the multinational enterprise. Londres: Macmillan Books. 1976.

; GHAURI, P. N. The internationalization of the firm. Oxford: ITP,1999. 
BURGEL, O.; MURRAY, G.C. The international market entry choices of start-up companies in high-technology industries. Journal of International Marketing, n. 8, v. 2, p.33-62. 2000.

The internationalisation of British and German start-up companies in hightechnology industries, frontiers of entrepreneurship research. Babson College, Estados Unidos, 1998.

BYRNE, B. M. Structural equation modeling with AMOS: basic concepts, applications, and programming. Nova Jersey: Lawrence Erlbaum Associates. 338p., 2001.

CADOGAN, J.W.; DIAMANTOPOULOS, A.; SIGUAW, J.A. Export market-oriented activities: their antecedents and performance consequences. Journal of International Business Studies, v. 33, n. 3, p. 615-626, 2002.

CAGLIANO, R. et al. Small firms under microscope: international differences in production/operations management practices and performance. Integrated Manufacturing Systems, 12(7), 469-482. 2001.

CALOF, J. L. The impact of size on internationalization. Journal of Small Business Management. Milwaukee, v. 31, n. 4 p. 60-70, Out./1993.

The relationship between firm size and export behavior revisited. Journal of International Business Studies, n. 25, v. 2, p. 367-387, 1994.

; BEAMISH, P. Adapting to foreign markets: explaining internationalization. International Business Review, v.2, n. 2, p. 115-131, 1995.

CÂMARA DE COMÉRCIO E DA INDÚSTRIA FRANCESA - CCI. Relatórios de Trabalho, Paris, 2007.

CAMERON, K. S. Effectiveness as paradox: Consensus and conflict in conceptions of organizational effectiveness. Management Science, n. 32, p. 539-553, 1986.

CAMISÓN, C.; VILLAR-LÓPEZ, A. Effect os SME's international experience on foreing intensity and economic performance: the mediating role of internationally exploitable assets and competitive strategy. Journal of Small Business Management, v. 28, n. 2, p. 116-151, 2010 .

CÂNDIDO, G.; ABREU, A. F. de. Os conceitos de redes e as relações interorganizacionais: um estudo exploratório. In: ENCONTRO ANUAL DA ASSOCIAÇÃO NACIONAL DE PÓS-GRADUAÇÃO EM ADMINISTRAÇÃO, 24., 2000. Florianópolis. Anais... Santa Catarina: ANPAD, 2000.

CANNON, T. Managing international and export marketing. European Journal of Marketing, n. 14, vol. 1 p. 34-49, 1980.

CANTWELL, J. A survey of theories of international production. In: PITELIS, C.;SUGDEN, R. (eds.) The nature of the transnational. London: Routledge,capítulo 2, p.16-63, 1991.

CARDOZA, G.; FORNÉS, G. Documento apresentado na conferência sobre internacionalização de empresas. Harvard (EUA), 2007. 
CARNEIRO, J. M. T. Desempenho de exportação de empresas brasileiras: uma abordagem integrada. 2007. Tese (Doutorado) - Institutode Pós-Gradução e Pesquisa em Administração. COPPEAD. Universidade Federal do Rio de Janeiro.

CARSON, D. et al. Marketing and entrepreneurship in SMEs: an innovative approach. Hemel Hempstead: Prentice Hall (International) 1995.

CARVALHO, M. M.; LAURINDO, F. J. B. Estratégias para competitividade. São Paulo: Futura, 2003.

CARVALHO, S. Idade de entrada internacional, velocidade de internacionalização e seus efeitos sobre o crescimento no exterior de pequenas e médias empresas industriais. 2009. Tese (Doutorado) - Escola de Administração de Empresas da Fundação Getúlio Vargas, São Paulo.

CAVUSGIL, S. T. On the Internationalisation process of firms. European Research, v.8, p. 273-281, 1980.

; NEVIN, J. R. Internal determinants of export marketing behavior: an empirical investigation. Journal of Marketing Research, v. 18, p. 114-119, 1981.

; KIRPALANI, V. Introducing products into export markets: success factors. Journal of Business Research, v.27, p.1-15, 1993.

; ZOU, S. Marketing strategy-performance relationship: an investigation of the empirical link in export market ventures. Journal of Marketing, n.58, p. 1-21, jan./1994.

CENTRO BRASILEIRO DE RELAÇÕES INTERNACIONAIS - CEBRI. Conferência Estadual sobre a internacionalização das Empresas Brasileiras. Palestra do MDIC. Instituto Britânico, setembro de 2009.

CEZARINO, L. O.; CAMPOMAR, M.C. Micro e pequenas empresas: características estruturais e gerenciais. Revista Hispeci e Lema, v. 9, p. 10-12, 2006.

CHANG, S.; SINGH, H. Corporate and industry effects on business unit competitive position. Strategic Management Journal, v. 21, p.739- 752, 2000.

CHORINCAS, J.; MARQUES, I.; RIBEIRO, J. F. "Clusters" e políticas de inovação conceitos, experiências européias e perspectivas de aplicação a Portugal. 2001. Disponível em: <http://www.dpp.pt/gestao/ficheiros/clusters.pd>. Acesso em: 24/09/2007.

CINTRA, R.; MOURÃO, B. Perspectivas e estratégias na internacionalização de empresas brasileiras. Revista do Autor, 11/2005. Disponível em: <www.revistaautor.com.br>.

COASE, R. The nature of the firm. Economica, v. 4 n.16, p.386-405, 1937.

COLLIS, D. J. A resource-based analysis of global competition: the case of the bearings Industry. Strategic Management Journal, v. 12, p. 49-68, 1991.

CONTRACTOR, F. et al. A three-stage theory of international expansion: the link between multinationality and performance in the service sector. Journal of International Business Studies, v.34, n.1, p.5-18, 2003. 
COOPER, D. R.; KLEINSCHMIDT, E. J. The impact of export strategy on export sales performance. Journal of International Business Studies, v.16, p.37-55, Spring, 1985.

; SCHINDLER, P. S. Métodos de pesquisa em administração. Porto Alegre: Bookman, 2003.

COVIELLO, N.; MURNO, H. Networ relationships and the internationalization process of small software firms. International Business Review, v. 6, n. 4, p. 361-386, 1997.

; McAULEY, A. Internationalization and the smaller firm: a review of contemporary empirical research. Management International Review, v. 39, p. 223-244, 1999.

CZINKOTA, M. R. Export development strategies: us promotion policies. Nova Iorque: Praeger, 1982.

; JOHNSTON, W. J. Exporting: does sales volume make a difference? Jounal of International Business Studies, n. 14 (Spring), p. 147-153, 1983.

DAVISON, W. The location of foreign direct investment activity: country characteristics and experience effects. Journal of International Business Studies, v. 11, n. 2, p. 9-22, 1980.

De CLERQ, D. et al. The internationalization of small and medium sized firms. Small Business Economics, v. 24, p. 409-419, 2005.

DELIOS, A.; BEAMISH, P.W. Geographic scope, product diversification, and the corporate performance of japanese firms. Strategic Management Journal, v. 20, n. 8, p 711-727, 1999.

DELLOITE Consultoria. Relatório de pesquisa sobre as PMEs que mais crescem no Brasil, 2007.

DENIS, D. J. et al. Global diversification, industrial diversification, and firm value. Journal of Finance, v. 57, n. 5, p. 1951-1979, 2002.

DERESKY, H. Administração Global. Porto Alegre: Bookman, 2004.

DESS, G. G; ROBINSON, R. B.Measuring Organizational Perfor- mance in the Absence of Objective Measures. Strategic Management Journal, n. 5, p. 265-273, 1984.

et al. Strategic management: creating competitive advantages. 3. ed. Burr Ridge McGraw-Hill, 2007.

DEV, C.S. et al.. Brands across borders: determining factors in choosing franchising or management contracts for entering international markets. Cornell Hotel and Restaurant Administration Quarterly, n. 43, v. 6 p. 91-104, 2002.

DHANARAJ, C.; BEAMISH, P. A resource-based approach to the study of export performance. Journal of Small Business Management, v. 41, n.3, p. 242-261, 2003.

DIAMANTOPOULOS, A.; INGLIS, k. Identifyng differences between hight and low involvement exporters. International Marketing Review, v.5 (verão), p. 52-60, 1988. 
Export performance measurement: refl ective versus formative indicators. International Marketing Review, v. 16 , n. 6, p. 444- 457, 1999.

DIB, L. A. O processo de internacionalização de pequenas e médias empresas e o fenômeno born global: estudo do setor de software no Brasil. Tese 2008. (Doutorado) - Instituto de PósGradução e Pesquisa em Administração, COPPEAD, Universidade Federal do Rio de Janeiro.

DICHTL, E. et al. International orientation as a precondition for export success. Journal of International Business Studies. 10 Trimestre, p. 23-40, 1990.

DILLON, W. R. et al. Marketing research in a marketing environment. Estados Unidos: Richard D. Irwin, INC., 1994.

DIMITRATOS, P. The firm's location in the home country and internationalisation: some evidence from greek smaller firms. Intereconomics, n.7, v.2, Mar.Apr./2002.

et al. Micromultinationals: new types of firms for the global competitive landscape. European Management Journal, v. 21, n. 2, p. 164-174, 2003.

DÖRRENB ÄCHER, C. Measuring corporate internationalisation: a review of measurement concepts and their use. Review of European Economic Policy, v.35, n. 3, p. 119-126, 2000.

DUNNING, J. H. Trade, location of economic activity, and the multinational enterprise: a search for an eclectic approach. In: OHLIN, B. et al. (eds.) The international allocation of economic activity. London: Macmillan, 1977.

The ecletic paradigm of international production: a restatement and some possible extensions. Journal of International Marketing Business Studies, v.19, n.1, p.1-31, Spring 1988. 1993.

Multinational enterprises and the global economy. Workhingan: Addison-Wesley,

Reappraising the eclectic paradigm in an age of alliance capitalism. Journal of International Business Studies, 26. 3- trimestre, p.461-491, 1995.

The nature of transnational corporations and their activities. In: UNITED NATIONS. Transnational corporations and world development. Londres: International Thomson Business Press, p. 27-43, 1996.

Location and the multinational enterprise: a neglected factor? Journal of International Business Studies, Washington, v. 29, n. 1, p. 45-66. 1998.

Some antecedents of internalization theory. Journal of International Business Studies, 34, p.108-115. 2003. 1981.

; PEARCE, R. The world's largest industrial enterprises. Farmborough: Gower Press,

DUTRA, J. S. Gestão por competências. São Paulo: Gente, 2001. 
DRUCKER, P. Administração de organizações sem fins lucrativos: princípios e práticas. São Paulo: Pioneira, 1995

EGGERTSON, T. Economic behavior and institutions. Cambridge: Cambridge University Press, 1990.

EISENHARDT, K. M. Building theories from case study research. Academy of Management Review, v. 14, n. 4, p. 532-550, 1989.

; MARTIN, J. A Dynamic capabilities: what are they? Strategic Management Journal, n. 21, p. 1105-1121, 2000.

EMORY, W. C. Business research methods. Homewood, Illinois: Richard D. Irwin, 1980.

EPSTEIN, M. MANOZINI, J.F. Implementing corporate strategy: from Tableaux de Bord to Balance Scorecards. European Management Journal. April, 1998.

ERRAMILLI, M. K. The experience factor in foreign market entry behavior of service firms. Journal of International Business Studies, v. 22, n. 3 (Third Quarter) p. 479-501, 1991.

; RAO, C.P. Service firms international entry mode choice: a modified transactioncost analysis approach. Journal of Marketing, n. 57, p. 19-38, 1993.

ERICSSON, K.A.; SIMON, H.A. Verbal Reports as Data. Psychological Review, v. 87, p. 215-251, 1980.

et al. Experiential knowledge and cost in the internationalization process. Journal of International Business Studies, Second Quarter, p.337-360, 1997.

ETEMAD, H.; WRIGHT, W. Internactionalization of SMEs: management respondes to a changing environment. Journal of International Marketing, n. 7, v. 4, p. 4-10, 1999.

Internationalization of small and medium-sized enterprises: a grounded theoretical framework and an overview. Canadian Journal of Administrative Sciences, n. 21 v.1, p.121. 2004.

EUROPEAN NETWORK FOR SME RESEARCH - ENSR. Pesquisa sobre PME Documentos da União Européia, 2003.

FAHY, J. A resource-based analysis of sustainable competitive advantage in a global environment. International Business Review, v. 11, n. 1, p. 57-78, 2002.

FERRAZ, G. T.; RIBEIRO, F. J. O desafio das exportações. In: PINHEIRO, A. C.; MARKWALD, R.; PEREIRA, L. Um levantamento de atividades relacionadas às exportações das empresas brasileiras: resultados de pesquisa de campo com 460 empresas exportadoras. Rio de Janeiro: BNDES, 2002.

FIEGENBAUM, A. et al. Strategic reference point theory. Strategic Management Journal, n. 17, p. 219-235, 1996.

FIGUEIREDO, N.G.; MARTINELI, D. P. Inovação e Exportação em Pequenas e Médias Empresas (PME): uma pesquisa em andamento. In: ENCONTRO ANUAL DA 
ASSOCIAÇÃO DOS PROGRAMAS DE PÓS-GRADUAÇÃO EM ADMINISTRAÇÃO, 26., 2002. Salvador. Anais... Bahia: ANPAD, 2002.

FINA, E.; RUGMAN, A. N. A test of internalization theory: the upjohn company. Management International Review, v. 36, n.3, p. 199-123, 1996.

FLEURY, A. F; FLEURY, M. T. L. Estratégias empresariais e formação de competências: um quebra-cabeça caleidoscópio da indústria brasileira. 3. ed. São Paulo: Atlas, 2004.

Atlas, 2007.

; FLEURY, M. T. L. (Org.). Internacionalização e os países emergentes. São Paulo:

; FLEURY, M.T. Competitiveness, competences and corporate strategies: Brazil and China catching up in the global economy. Workshop MINDS - Multidisciplinary InterInstitutional Network on Development and Strategies, BNDES, Rio de Janeiro, jan. 2005.

FLEURY, M.T.; FLEURY, A. Aprendizagem e inovação organizacional: as experiências do Japão, Coréia e Brasil. São Paulo: Atlas, 1995.

FLEURY, A. e FLEURY,M.T.L. A arquitetura das redes empresariais como função do domínio de conhecimento. In: Redes entre organizações. São Paulo: Atlas, 2005.

; BORINI, F. M.; FLEURY, A.; OLIVEIRA, M. M. Internationalization and performance: a comparison of brazilian exporters versus brazilian multinationals. Revista de Economia e Gestão, Belo Horizonte, v.7, n. 14, p. 57- 84, 1ํsem., 2007.

FLEURY, P.; MEIRA, R.; ROCHA, A. A decisão de exportar e a escolha de mercados de exportação: dos aspectos conceituais às práticas gerenciais nas empresas brasileiras de produtos manufaturados. RAE, v. 21, n. 3, p.7-13, jul.-set./1981.

FLORIANI, D. E. A cultura nacional e as negociações comerciais internacionais: um comparativo entre negociadores brasileiros e italianos. In: ENCONTRO ANUAL DA ASSOCIAÇÃO DOS PROGRAMAS DE PÓS-GRADUAÇÃO EM ADMINISTRAÇÃO, 27., 2003. Atibáia. Anais... São Paulo: ANPAD, 2003.

; BORNI, F. M.; FLEURY, M. T. O processo de internacionalização como elemento gerador de capacidade dinâmicas: o caso da WEG na Argentina e na China. In: ENCONTRO DE ESTUDOS EM ESTRATÉGIA, 4., 2009. (3Es) Anais... Recife: ANPAD, 2009.

FORSGREN, M. Managing the internationalization process. Londres: Routledge, 1989.

FORTE, S. H. A. C.; SETTE JR., E. L. M. Internacionalização de empresas: o caso do setor de rochas ornamentais e de revestimento do Estado do Ceará. In: ENCONTRO ANUAL DA ASSOCIAÇÃO DOS PROGRAMAS DE PÓS-GRADUAÇÃO EM ADMINISTRAÇÃO, 29., 2005. Brasília. Anais... Brasília: ANPAD, 2005. (CD-Rom).

; MOREIRA, M. Z. Internacionalização das maiores empresas exportadoras do setor calçadista brasileiro: estudo do perfil, estratégia e desempenho. In: ENCONTRO ANUAL DA ASSOCIAÇÃO DOS PROGRAMAS DE PÓS-GRADUAÇÃO EM ADMINISTRAÇÃO, 31., 2007. Rio de Janeiro. Anais... Rio de Janeiro: ANPAD, 2007. 
et al. Strategy and performance: a study on the internationalization of the major brazilian cashew-nut exporting companies. In: ENCONTRO ANUAL DA ASSOCIAÇÃO DOS PROGRAMAS DE PÓS-GRADUAÇÃO EM ADMINISTRAÇÃO, XXXII., 2008. Rio de Janeiro. Anais... Rio de Janeiro: ANPAD, 2008.

FROST, T. The geographic sources of foreign subsidiaries innovations. Strategic Management Journal, v.22, p. 101-123, 2001.

FUCHS, M. Export performance and managerial capabilities in German SMEs. Nova Iorque: Social Science Eletronic Publishing Inc., 2009.

FUJITA, M. Small and medium-sized transnational corporations: salient features. Small Business Economics, n. 7, p. 251-271, 1995.

GANKEMA, H. G. J. et al. The internationalization process of small and medium-sized enterprises: an evaluation of stage theory. Journal of Small Business Management, v. 38, n. 4, p. 15 , Out./2000.

GARSON, G. D. (2007). Structural equation modeling. Disponível em: <http://www2.chass.ncsu.edu/garson/pa765/structur.htm>. Acesso em: 03/2010.

GERINGER, M. J. et al. Diversification strategy and internationalization: implications for MNE performance. Strategic Management Journal, v. 10, p. 109-119, 1989.

GENCTÜRK, E. F.; KOTABE, M. The effect of export assistance program usage on export performance: a contingency explanation. Journal of International Marketing, v. 9, n. 2, p.51-72, 2001.

GHAURI, P.; GRONHAUG, K. Research methods in business studies: a practical guide. Harlow, England; Nova Iorque: Financial Times Prentice Hall, 2005.

GHEMAWAT, P. Redefining global strategy. Crossing Borders in a World Where Differences Still Matter. Harvard Business Scholl Press, 2007.

Semiglobalization and international business strategy. Journal of International Business Studies, v. 10, 1057/palgrave.jibs.8400013, 2003.

GHISI, F.A. et al. Capacidade de exportação e caráter inovador das PMEs: uma pesquisa no Estado de São Paulo. In: SEMINÁRIO DE ADMINISTRAÇÃO - SEMEAD, 5., 2001. São Paulo. Anais... São Paulo: USP, 2001.

GHOSAL, S. Global strategy: an organizing framework. Strategic Management Journal, v. 8, p. 425-440, 1987.

GINSBERG, A. Operationalizing organizational strategy : toward an integrative framework. Academy of Management Review, v. 9, n. 3, p. 548-557, 1984.

GOLDSZMIDT, R. G. B. et al. O efeito país sobre o desempenho da firma: Uma abordagem multinível. In: ENCONTRO DE ESTUDOS EM ESTRATÉGIA, 3., 2007. São Paulo. Anais... São Paulo: ANPAD, 2007. 
GOMES, L.; RAMASWAMY, K. An empirical examination of the form of the relationship between multinationality and performance. Journal of International Business Studies, $1^{\text {st }}$ Quarter, v.30, n.1, p.173-187, 1999.

GOULART, L; ARRUDA, C. BRASIL internacionalização de empresas brasileiras. São Paulo: Qualitymark, 1996.

GRANT, R. M. Multinationality and performance among British manufacturing companies. Journal of International Business Studies, v. 18, p. 79-89, 1987.

The resource-based theory of competitive advantage: implications for strategy formulation. California Management Review, v. 33, n. 3, p. 114-135, 1991.

Toward a knowledge-based theory of the firm. Strategic Management Journal, v. 17, p. 108-122, (Winter Special Issue), 1996.

GREVE H. R. Performance, aspirations, and risky organizational change. Administrative Science Quarterly, v.43, n.1, March, 1998.

HAIR JR., J.F. et al. Análise multivariada de dados. 6. ed. São Paulo: Bookman, 2009.

HAKANSSON, H.; WALUSZEWSKI, A. Path Dependence: restricting or facilitating technical development. Journal of Business Research, v. 55, p-561-570, 2002.

HAMEL, G.; PRAHALAD, C.K. Competing for the Future. Boston: Harvard Business School Press, 1990.

HARBISON, J. R. ; PEKAR, P. J. Alianças estratégicas. Tradução: Maria Lúcia Leite Rosa. São Paulo: Futura, 1999.

HASSEL, A. Two dimensions of the internationalisation of firms. MPIfG Working Paper 01/3. Cologne: Max Planck Institute for the Study of Societies, 2001.

et al. Two dimensions of the internationalization of firms. Journal of Management Studies, n. 40, v.3, 2003.

HAWAWINI, G. et al. Is performance driven by industry - or firm-specific factors? A new look at the evidence. Strategic Management Journal, v.24, p. 1-16, 2003.

HEDLUND, G.; KVERNELAND, A. Are strategies for foreign market entry changing? The case of Swedish investment in Japan. International Studies of Management \& Organization, v.15, p.41-59, 1985.

HELFAT, C. et al. Dynamic capabilities: understanding strategic change in organizations. Malden: Blackwell Publishing, 2007.

HEMAIS, C.; HILAL, A. O processo de internacionalização da firma segundo a Escola Nórdica de negócios internacionais. In: ROCHA, A. (ed.) A internacionalização das empresas brasileiras: estudos de gestão internacional, Rio de Janeiro: Mauad. Capítulo 2, p.15-40, 2002. 
HEMAIS, C.; HILAL, A. Teorias, paradigma e tendências em negócios internacionais: de Hymer ao empreendedorismo. In: Hemais C. (org.). $\mathrm{O}$ desafio dos mercados externos. Rio de Janeiro: Mauad, 2004.

Escola Nórdica de Negócios Internacionais: evidências empíricas de empresas brasileiras. In: V Workshop Em Internacionalização de Empresas, 5., 2005. Rio de Janeiro. Anais... Rio de Janeiro: COPEAD/UFRJ, 2005.

HENDERSON, R.; MITCHELL, W. The interactions of organizational and competitive influences on strategy and performance. Strategic Management Journal, v.18, special summer issue, p. 5-14, 1997.

HILAL, A.; HEMAIS, C. Escola Nórdica de negócios internacionais: evidências empíricas de empresas brasileiras. In: ROCHA, A.; BLUNDI, D. (eds.) As empresas brasileiras na era da internacionalização. II Workshop em Internacionalização de Empresas. Anais... Rio de Janeiro: COPPEAD/UFRJ, 2001.

HILL, C. W. L. International business: competing in the global marketplace. New York : Mc Graw Hill, 2005.

HITT, M.; HOSKISSON, R.; KIM, H. International diversification: effects on innovation and firm performance in product-diversified firms. Academy of Management Journal, v.40, n.4, p.767-798, 1997.

HOFSTEDE, G. Culture's Consequences: international differences in work-related values. Beverly Hills: Sage Publications, 1980.

Sílabo, 1997.

Culturas e organizações: compreender a nossa programação mental. Lisboa:

Culture's consequences: comparing values, behaviors, institutions, and organizations across nations. 2. ed. Thousand Oaks: Sage Publications, 2001.

et al. What do business leaders pursue? A study in fifteen countries. Journal of International Business Studies, v. 33, n. 4, p. 785-808, Oct.-Dec./2002.

; USUNIER, J. C. Hofstede's dimensions of culture and their influence on international business negotiations. In: GHAURI, P. N. International business negotiations. Oxford: Pergamon, 1996.

HOLLENSTEIN, H. Determinants of international activities: are SMEs different? Small Business Economics, n. 24, p. 431-450, 2005.

HOLZMULLER, H. H.; KASPER, H. The decision-maker and export activities a cross national comparison of the foreign orientation of Austrian managers. Management International Review, v. 30, p. 217-230, 1990a.

On a theory of export performance: personal and organizational determinants of export trade activities observed in small and medium-sized firms. Management International Review, v.31, special issue, p.45-70, 1990b. 
; STOTTINGER, B. Structural modeling of success factors in exporting: crossvalidation and further development of an export performance model. Journal of International Marketing, v. 4, n. 2, p. 29-55, 1996.

HOOLEY, G. J. et al. The performance impact of marketing resources. Journal of Business Research, v.58, n. 1; p. 18-36, 2005.

HOPPEN, N. et al. Um guia prático para a avaliação de artigos de pesquisa em sistemas de informação. Apostila de Mestrado - UFRGS, Porto Alegre, 2000.

HU, L. T. et al. Can test statistics in covariance structure analysis be trusted? Psychological Bulletin, n. 112, v.2. p.351-362.1992.

HUBER, G.; POWER, D. J. Retrospective reports of strategic-level managers: guidelines for increasing their accuracy. Strategic Management Journal, Hoboken, n. 6, p. 171-180, 1985.

HUNT, S. D. A general theory of competition. Thousand Oaks, California. Sages Publications, 2000.

HUNTLEY, L. R.; PERRY, E. (2003). Interpreting the structural equation model. Disponível em: <http://www.oseda.missouri.edu/modot/planning/interpreting_sem.shtml>. Acessado em: 03/2010.

HYMER, S. The international operations of national firms: a study of direct foreign investment. Doctorate Thesis. Cambridge, MA: The MIT Press, 236p., 1960/1976.

IBEH, K.I.N.; YOUNG, S., Exporting as an entrepreneurial act: an empirical study of Nigerian firm's. European Journal of Marketing, v. 35, n. 5/6, p. 566-686, 2001.

et al. Micromultinationals: some preliminary evidence on an emergent 'star' of the international entrepreneurship field. Journal of International Entrepreneurship, n. 2 p. 289-303, 2004.

IBGE. FUNDAÇÃO INSTITUTO BRASILEIRO DE GEOGRAFIA E ESTATÍSTICA. Disponível em: <www.ibge.gov.br> Acesso em: 04/2009.

IETTO-GILLIES, G. Alternative approaches to the explanation of international production. In: JOHN, R. (ed.) Global business strategy. London: International Thomson Business Press. Capítulo 5, p.113-151. 1997.

Different Conceptual frameworks for the assessment of the degree of internationalisation: an empirical analysis of various indices for the top 100 transnational Corporations. Transnational Corporations, v. 7 n. 1, p. 17-39, 1998. Press., 2001.

Transnational corporations fragmentation amidst integration. Londres. Routledge ; SECCOMBE-HETT, T. What do internationalization indices measure? Research Working Papers in International Business. Centre for International Business Studies, South Bank University, Londres, n. 6, v.97, ISSN 1366-6290, 1997. 
IGLESIAS, T.; VEIGA, J. O desafio das exportações. In: PINHEIRO, Armando C.; MARKWALD, Ricardo; PEREIRA, Lia. Um levantamento de atividades relacionadas às exportações das empresas brasileiras: resultados de pesquisa de campo com 460 empresas exportadoras. Rio de Janeiro: BNDES, 2002.

INTERNATIONAL BUREAU (EUA). Disponível em: 〈www.census.gov/ipc/www/idb/> Acessado em: 03/2010.

JANTUNEN, A. et al. Entrepreneurial orientation, dynamic capabilities and international performance. Journal of International Entrepreneurship, n.3, v.3, p. 223-243, 2005.

JOÃO, B. N. Das competências essenciais ás estratégias baseadas no conhecimento. In: ENCONTRO ANUAL DA ASSOCIAÇÃO DOS PROGRAMAS DE PÓS-GRADUAÇÃO EM ADMINISTRAÇÃO, 25., 2001. Campinas. Anais... São Paulo: ANPAD, 2001.

JOHANSON, J. Internationalization in industrial systems - a network approach. In: HOOD, N. e VAHLNE, J. (eds.) Strategies in global competition. New York: Croom Helm. p.287$314,1988$.

Business relationship learning and commitment in the internationalization process. Journal of International Entrepreneurship, 1, p.83-101. 2003.

JOHNSON, J. P. et al. Cross-cultural Competence in International Business: toward a definition and a model. Journal of International Business Studies, v. 37, p.525-543, 2006.

JOHANSON, J.; MATTSSON, L. International marketing and internationalization processes - a network approach. In: PALIWODA, S.; TURNBULL, P. (eds.) Research in international marketing. Londres: Croom Helm. 1986.

; VAHLNE, J. E. The internationalization process of the firm - a model of knowledge development and increasing foreign market commitments. Journal of International Business Studies, Washington, p. 23-32, 1977.

v.7, n.4, p.11-24, 1990.

The mechanism of internationalization. International Marketing Review,

JOHANSON, J.; WIEDERSHEIM-PAUL, F. The Internationalization of the firm - four Swedish cases. Journal of Management Studies, outubro, p. 305-322, 1975.

JÖRESKOG, K. G. Structural equation modeling with ordinal variables using LISREL. (2004). Disponível em: <http://www.ssicentral.com/lisrel/techdocs/ordinal.pdf>. Acesso em: $03 / 2010$.

JULIEN, P.A; RAMANGALAHY, C. Competitive strategy and performance in exporting SMEs: an empirical investigation of their export information search and competencies. Entrepreneurship Theory and Practice, v. 27, n. 3, p. 227-45, 2003.

KALANTARIDIS C. Internationalization, Strategic Behavior and the Small Firm: A Comparative Investigation. Journal of Small Business Management, n. 42, v. 3, p. 245-262, 2004. 
KAPLAN, R. S.; NORTON, D. P.The balanced scorecard \pm measures that drive performance, Harvard Business Review, p. 71-9, January/February, 1992.

KATSIKEAS, C. et al. Firm-level export performance assessment: review, evaluation and development. Academy of Marketing Science, v.28, n.4, p.493-511, fall 2000

KAYNAK, E. Editorial. Journal of Global Marketing, v.6, n. 3, p. 1-4, 1992.

KINDLEBERGER, C.P. Economia Internacional. São Paulo: Mestre Jou, 1974.

KLEM, L. Path analysis. In: GRIMM, L. G.; YARNOLD, P. R. Reading and understanding multivariate statistics. Washington, DC: American Psychological Association, 1995.

KLINE, R. B. Principles and practice of structural equation modeling. 2 ed. Nova Iorque: Guilford, 2005.

KLOTZLE, M.C.; THOMÉ, C.C. Fatores Associados ao Desempenho Exportador de Micros, Pequenas e Médias Empresas Brasileiras. Revista de Adminsitração (RAUSP), v. 41, n. 3, p. 339-346, 2006.

KNIGHT, G. Cross-Cultural reliability and validity of a scale to measure firm entrepreneurial orientation. Journal of Business Venturing, v. 12, p. 213-225, 1997.

Entrepreneurship and marketing strategy: the SME under globalization. Journal of International Marketing, v. 8, n. 2, p. 12-32, 2000.

KNIGHT, G. Innovation, organizational capabilities, and the born-global firm. Journal of International Business Studies, v. 35, p. 124-141, 2004.

; CAVUSGIL, S. The born global firm: a challenge to traditional internationalization theory. Advances in International Marketing, v. 8, p. 11-26, 1996.

Innovation, organizational capabilities, and the born-global firm. Journal of

International Business Studies, v. 35, n. 2, p. 124-141, 2004.

; KIM, D. International business competence and the contemporary firm. Journal of International Business Studies, n. 40, p.255-273, 2009.

KOBRIN, S. J. An empirical analysis of the determinants of global integration. Strateg. Manage Journal. Summer Special, n. 17, v. 37, 1991.

$\mathrm{KOH}$, A. Relationships among organizational characteristics, marketing strategy and export performance. International Marketing Review, n. 8, p. 46-60, 1991.

KOTABE, M.; CZINKOTA, M. R. State government promotion of manufacturing exports: a gap analysis. Journal of International Business Studies, n. 23, v. 4, p.637-658, 1992.

KOTLER, P.; KELLER, K. Admisnistração de Marketing. 12a ed. São Paulo: Prentice Hall, 2006. 
KUTSCHKER, M. Re-engineering of business processes in multinational corporations. In: International Research Conference of the Carnegie Bosch Institute. Anais... Katholische Universitat, Eichstatt, Germany. Nov. 2, 1994.

LAGES, L.; LAGES, C. The STEP Scale: A measure of short-term export performance improvement. Journal of International Marketing, v.12, n.1, p.36-56, 2004.

et al. Bringing export performance metrics into annual reports: The APEV Scale and the PERFEX Scale. Journal of International Marketing, v.13, n.3, p.79-104, 2005.

LAGES, L. F.; MONTGOMERY, D. B. Export performance as an antecedent of export commitment and marketing strategy adaptation: evidence form small and medium-sized exporters. European Journal of Marketing, v.38, n.9/10, p.1186-1214, 2004.

LE BOTERF, G. De la compétence à la navigation professionelle. Paris: Les Éditions d'Organization, 1998.

LE BOUlaIRE M; RETOUR D., Stratégies et Compétences Concepts \& Pratiques. Paris: Communication GRACCO, le 29 juin 2006.

LECERF, M. Lês Petites e Moyennes Entreprises face a la mondalization. Tese (doutorado). Universidade de Paris 1 - Pantheon, Sorbonne. Jan. 2006.

LEE, C. et al. Internal capabilities, external networks, and performance: a study on technology-based ventures. Strategic Management Journal, v. 22, n. 6/7, p. 615-641, 2001.

LEONIDOU, L. C. An Analysis of the Barriers Hinfering Small Business Export Development. Journal of Small Business Management, n. 42, v.3, p. 229-302, 2004.

et al. Identifying Managerial Influences on Exporting: Past Research and Future

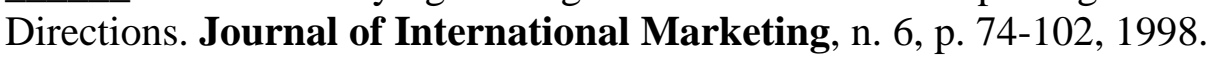

et al. Marketing strategy determinants of export performance: a meta-analysis. J Bus Res, v. 55, n.1, p.51-67, 2002.

; KATSIKEAS, C. S. The Export Development Process: An Integrative Review of Empirical Models. Journal of International Business Studies, n. 27, vol. 3 p. 517-551, 1996.

LEVITT, T. The Globalization of markets. Harvard Business Review, p. 92-102, Maio/Junho, 1983.

LIESCH, P.; KNIGHT, G. Information internationalization and hurdle rates in small and medium enterprise internationalization. Jounal of International Business Studies, n.30, v.1, p. 383-394, 1999.

LIM, J. et al. An empirical test of an export adoption model. Management International Review, n. 31 v. 1, p. 51-62, 1991.

LONGENECKER, J. G. et al. Administração de pequenas empresas. São Paulo: Makron Books, 1998. 
LU J.W.; BEAMISH P.W. The internationalization and performance of SMEs. Strategic Management Journal, v. 22, n.6/7 p. 565-586, 2001.

Partnering strategies and performance of SMEs' international joint ventures.

Journal of Business Venturing, n. 21, p. 461- 486, 2006.

MACIARIELLO, J. A.; KIRBY, C. J. Management control systems: using adaptive systems to attain control. 2. ed. New Jersey: Prentice-Hall, 1994.

MADSEN, T. K. Successful export marketing management: some empirical evidence. International Marketing Review, v. 6, n. 4, p. 41-57, 1989.

et al. Differences and similarities between Born Globals and other types of exporters.

Advances in International Marketing, n. 10, p. 247-225, 2000.

; SERVAIS, P. The internationalization of born globals: an evolutionary process?

International Business Review, v.6, n.6, p.561-583, 1997

MAJOCCHI, A.; ZUCCHELLA, A. Internationalization and performances. International Small Business Journal, Londres, v.21, n.3, 2003.

MAJOCCHI, A. et al. Firm size, business experience and export intensity in SME's: A longitudinal approach to complex relationships. International Business Review, n. 14, v. 6, p.719-738, 2005.

MALHOTRA, N. K. Pesquisa de marketing: uma orientação aplicada. Porto Alegre: Bookman, 2001.

MANOLOVA, T. S. et al. Internationalization of small firms: international factors revisited. International Small Business Journal, n.20, v. 1, p. 9-13, 2002.

MARSCHAN-PIEKKARI, R.; WELCH, C. Handbook of qualitative research methods for international business. MA. (EUA): Edward Elgar Publishing, Inc., 2004.

MARSHALL, C.; ROSSMAN, G. B. Designing qualitative research. Thousand Oaks, CA: Sage Publications, 2006.

MARUYAMA, G. M. Basics of structural equation modeling. London : Sage Publications, 1998.

MATHEWS, J. A. Dragon multinationals: new players in 21st century globalization. Asia Pacific J Manage, v. 23, p. 5-27, 2006.

McDONALD, F. et al. Cautions International Entrepreneurs: The case of the Mittelstand. Journal of International Entrepreneurship, n. 1, v. 4, p. 363-381, 2003.

McDOUGALL, P.P. et al. Explaining the formation of international new ventures: the limits of theories from international business research. Journal of Business Venturing, n. 9 v. 6, p. 469-487. 1994.

; OVIATT, B. New Venture Internationalization, Strategic Change, and Performance: A Follow-up Study. Journal of Business Venturing, v. 11, n. 1, p. 23-40, 1996. 
McGAHAN, A. M.; PORTER, M. How much does industry matter, really? Strategic Management Journal, v.18, Summer Special Issue, p.15-30, 1997.

MELHADO, T. Medidas de Ajuste de Modelos de Equações Estruturais. 2004. Dissertação (Mestrado) - Instituto de Matemática e Estatística, Universidade de São Paulo, São Paulo.

MINGOTI, S. A. Análise de dados através de métodos de estatística multivariada: uma abordagem aplicada. Belo Horizonte: UFMG, 295p., 2005.

MINISTÉRIO DO DESENVOLVIMENTO DA INDÚSTRIA E DO COMÉRCIO EXTERIOR - MDIC. Brasília, DF. Disponível em: <www.mdic.gov.br>. Acessado em: 03/ 2010.

MEYER, C. How the right measures help teams excel. Harvard Business Review, v. 72, n.3, May-June, 1994.

MILES, M. B.; HUBERMAN, A. M. Qualitative data analysis: an expanded sourcebook. Thousand Oaks, CA: Sage Publications, 1994.

MILLS, J. et al. Competing through competences. Cambridge: Cambridge University Press, 2002.

MOEN, O.; SERVAIS, P. Born global or gradual global? examining the export behavior of small and medium-sized enterprises. Journal of International Marketing, v. 10, n. 3, p. 4972, 2002.

MOORE, K. A strategy for subsidiaries: centers of excellence to build subsidiaryspecific advantages. Management International Review, v. 41, n. 3, p.275-290,2001.

MORGAN, R. E.; KATSIKEAS, C. S. Obstacles to export initiation and expansion. International Journal of Management Science, n. 25, v. 6, p. 677-690, 1997.

MOREIRA, L. F. Modelo para determinação do grau de globalização da empresa. 2009. Tese (doutorado) - Universidade de São Paulo, São Paulo.

MTIGWE, B. Theoretical milestones in international business: the journey to international entrepreneurship theory. Journal of International Entrepreneurship, 4, p.5-25. 2006.

NARVER, J. C.; SLATER, S. F. The Effect of a Market Orientation on Business Profitability. Journal of Marketing, v. 54, n. 4, p. 20-35, 1990.

NELSEN, R. WINTER, S. An evolutionary theory of economic change. Cambridge: Belknap Press, 1982.

NIELSEN, A. P. Understanding dynamic capabilities through knowledge management. Journal of knowledge management, Kempston, v. 10 n. 4, p. 59-71, 2006.

NOHRIA, N.; GHOSHAL, S. The differentiated network, Jossey-Bass: San Francisco, CA., 1997. 
NORDSTRÖM, K. The internationalization process of the firm: searching new patterns and explanations. Doctoral dissertation, IIB. Stockholm: Stockholm School of Economics. 1991.

; VAHLNE, J. Is the Globe shrinking? Psychic distance and the establishment of Swedish sales subsidiaries during the last 100 years. International Trade and Finance Association's Annual Conference. Anais... Laredo, Texas: Abril de 1992.

NUMMELA, N. et al. Attitude towards Internationalization- A prerequisite for successful internationalization? Canadian Journal of Administrative Sciences. V. 21, n. 1, p. 51-64, 2004.

OECD. Globalization of industry: overview and sector reports. Paris: OECD, 1996.

OCDE. Entrepreneurship and SMEs in transition economics -The Visegrad ConferenceLEED, 1997.

OECD. small and medium enterprise outlook 2000. Paris: OECD, 2000.

OECD. Businesses views on red tape, administrative and regulatory burdens on small and medium sized enterprises. Paris: OECD, 2004.

OECD. Enhancing the role of SMEs in global value chains: final synthesis report. (2007). Disponível em: <http://www.oecd.org/dataoecd>. Acesso em: 01/2009.

O ESTADO de S. Paulo. De carona, pequenas empresas se tornam globais. Encarte: ECONOMIA. São Paulo, 29 de setembro de 2009.

OLIVEIRA, D. P.R. Planejamento estratégico: conceitos, metodologia e prática. 6 ed. São Paulo: Atlas, 2006.

OLSSON, U. H. et al. The performance of ML, GLS, and WLS estimation in structural equation modeling under conditions of misspecification and nonnormality. Structural Equation Modeling, n. 7, v. 4, p. 557-595, 2000.

OVIATT, B.; McDOUGALL P. P. Toward a theory of international new ventures. Journal of International Business Studies, v. 25, n. 1, p. 45-64, 1994.

OVIATT, B.; McDOUGALL P. P. Global start-ups: entrepreneurs on a worldwide stage. Academy of Management Executive, n. 9 v. 2, p.30-43, 1995.

PANGARKAR, N. Internationalization and performance of small - and medium- sized enterprise. Journal of World Business, n. 43, v. 4, p. 475-485, 2008.

PATIBANDLA, M. Firm size and export behaviour : an Indian case study. Journal of Development Studies, n. 31, v.6, p. 868-882, 1995

PELHAM, A. M.; WILSON, D. T. A longitudinal study of the impact of market structure, firm structure, strategy, and market orientation culture on dimensions of small-firm performance. Journal of the Academy of Marketing Science, v. 24, n. 1, p. 27-43, 1996

PENG, M.W. The resource-based view and international business. Journal of Management, v. 27, n. 6, p. 803-829, 2001. 
PENROSE, E. The theory of the growth of the firm. Oxford: Oxford University Press, 1959.

PERMULTTER, H.V. The Tortuous Evolution of the Multinational Corporation. Columbia Journal of World Business, Jan.-Fev., p. 9-18, 1969.

PHILIPS, L.W.; BAGOZZI, R.P. On measuring organizational properties of distributional channels: methodology issues in the use of key informants. Research Marketing, v. 8, JAI Press Inc., p. 313-369, 1986.

PORTER, M. Competitive strategy. New York: Free Press, 1980.

Competitive advantage: creating and sustaining competitive performance. New York: Free Press, 1985.

The competitive advantage of nations. New York: Free Press, 1990.

. Clusters and the new economics of competition. Harvard Business Review, Nov.Dec., p. 77-90, 1998.

PORTER, M. Competição: estratégias competitivas essenciais. 4. ed. Rio de Janeiro: Campus, 1999.

POWELL, T. C. How much does industry matter? An alternative empirical test. Strategic Management Journal, v. 17, p. 323-334, 1996.

PRAHALAD, C.K., HAMEL, G. The core competence in the corporation. Harvard Business Review. Mai./Jun., p.79-91, 1990.

PRATER, E.; GHOSH, S. Current operational practices of U.S. small and medium-sized enterprises in europe. Journal of Small Business Management. Milwaukee. v 43, n. 2, p. 155-169, 2005.

PROENÇA, A. Dinâmica estratégica sob uma perspectiva analítica: refinando o entendimento gerencial. Arché Interdisciplinar, n. 23, p. 95 - 133, 1999.

QIAN, G. Multinationality, product diversification, and profitability of emerging US small and medium-sized enterprise. Journal of Business Venturing, v.17, p.611-633, 2002.

RACELA, O. C. et al. Market Orientation, International Business Relationships and Perceived Export Performance. International Marketing Review, v. 24, n.2, p. 144-163, 2007.

RAMASWAMY, K. Multinationality, configuration, and performance: a study of MNEs in the US drug and pharmaceutical industry. Journal of International Management, n.1, p. 231-253, 1995.

et al. Measuring the degree of internationalisation of a firm: A comment. Journal of International Business Studies, n. 26. v. 1 p. 167-177, 1996.

RASHEED, H. S. Foreing entry mode and performance: the moderating effecs of enviroment. Journal of Small Business Management, n. 43, v. 1, p. 41-54, 2005. 
RAO, T.R.; NAIDU, G.M. Are the stages of internationalization empirically supportable? Journal of Global Marketing, n. 6 v. 1/2, p. 147-170, 1992.

RENNIE, M. Born global. McKinsey Quarterly, n.4, p. 45-52, 1993.

REID, S.D. the decision-maker and export entry and expansion. Journal of International Business Studies, n. 12, v. 2, p. 101-112, 1981.

RETOUR, D. O DRH na dianteira do processo da gestão por competências. Management et Avenir, n. 4, p.187-200, abril, 2005.

REUBER, A. R.; FISCHER, E. The influence of the management team's international experience on the internationalization behaviors of small and medium-sized enterprises. Journal of International Business Studies, v. 28, n. 4, winter, 1997.

RING, P.S. et al. Perspectives on how governments matter. Academy of Management Review, v. 30, n. 2, p. 308-320, 2005.

RIGDON, E. E. Structural equation modeling. In: Modern methods for business research, G. A. Marcoulides (editor). Mahwah, NJ: Lawrence Erlbaum Associates, Publishers, p. 251-294, 1998.

ROCHA, A. Segmentação do mercado de pequenas e médias empresas para uma nova tecnologia. In: CHRISTENSEN, C; ROCHA, A.(Orgs.). Marketing de tecnologia: textos e casos. São Paulo: Atlas, 1989.

. Por que as empresas brasileiras não se internacionalizam? In: ROCHA, A. (org.). As novas fronteiras: a multinacionalização das empresas brasileiras. Rio de Janeiro: Mauad, 2003.

; BLUNDI, D. Revisitando as empresas exportadoras: uma análise do comprometimento das empresas brasileiras com o mercado externo. Núcleo de Pesquisa em Internacionalização de Empresas - COPPEAD/ UFRJ, Rio de Janeiro, 2002.

RONEN, S.; SHENKAR, O. Clustering countries on attitudinal dimensions: a review and synthesis. Academy of Management Review, v.10, n.3, p.435-454, 1985.

ROOT, F. R. Entry strategies for international markets. Nova Iorque: Lexington Books, 1994.

ROOT, F. J. Foreing market entry strategies. Nova Iorque: Amacon, 1987.

ROSSI, C. A. V.; SLONGO, L. A. Pesquisa de satisfação de clientes: o estado da arte e a proposição de um método brasileiro. Revista de Administração Contemporânea (RAC), v.2, n. 1, jan./abr. 1998.

ROSSITER, J.R. The C-OAR-SE procedure for scale development in marketing. International Journal of Research in Marketing, v. 19, p. 305-335, 2002.

ROTH, K. International configuration and coordination archetypes for medium-sized firms in global industries. Journal of International Business Studies, 23, 533-549, 1992. 
RUAS, R. Gestão por competências: uma contribuição à perspectiva estratégica da gestão de pessoas. In: ENCONTRO ANUAL DA ASSOCIAÇÃO DOS PROGRAMAS DE PÓSGRADUAÇÃO EM ADMINISTRAÇÃO, 27., 2003. Atibaia. Anais... São Paulo: ANPAD 2003.

. Gestão por competências: uma contribuição à estratégia das organizações. In: RUAS, R.; ANTONELlO, C. S.; BOFF, L. H. (2005). Aprendizagem organizacional e competências. Porto Alegre: Bookman, 2005.

RUGMAN A.; VERBEKE, A. Subsidiary specific advantages in multinational enterprises. Strategic Management Journal, vol.22, p.237-250, 2001.

RUIGROK, W.; WAGNER, H. Internationalization and performance: an organizational learning perspective. Management International Review, v.1, n.43, p.63-83, 2003.

RUZZIER, M. et al. The internationalization of SMEs: developing and testing a multidimensional measure in Slovenian firms. Entrepreneurship \& Regional Development, n. 19, p. 161-183, março, 2007.

RUZZIER, M. et al. Human capital and SME internationalization: a structural equation modeling study. Canadian Journal of Administrative Sciences. n.24, v.1, p. 15-29, 2007.

SANCHES, Marcos Rogério. Indicadores formativos em modelos de equações estruturais. 2005. Dissertação (Mestrado) - Instituto de Matemática e Estatística da Universidade de São Paulo, São Paulo.

SCHENDEL, D. Editor's introduction to the 1997 summer special issue: the interaction of organizational and competitive influences on strategy and performance. Strategic Management Journal, v.18 (special issue), p.1-3, 1997.

SCHREYÖGG, G.; KLIESCH-EBERL, M. How dynamic can organizational capabilities be? Towards a dual-process model of capability dynamization. Strategic Management Journal, v. 28, n. 9, p 913-933, 2007.

SCHUMACKER, R. E; LOMAX R. G. A beginner's guide to structural equation modeling. New Jersey: Lawrence Erlbaum Associates, 1996.

SCHWAB, D. P. Research methods for organizational studies. Mahwah. New Jersey: Lawrence Erlbaum Associates, 2005.

SEBENIUS, J. K. Como negociar através das fronteiras. HSM Management, Setembro e outubro de 2002.

SEBRAE. As micro e pequenas empresas na Exportação brasileira - Brasil e Estados. Observatório SEBRAE - Agosto 2006. Disponível em: <http://www.sebrae.com.br/br/pesquisa_exportacao4/>. Acesso em: 22 Nov. 2007.

Pesquisa em MPE participantes do Projeto, 2008.

SECRETARIA DE COMÉRCIO EXTERIOR - SECEX. 2009. Brasília, DF. Disponível em: <http://www2.desenvolvimento.gov.br/sitio/secex/secex/informativo.php>. Acessado em: $03 / 2010$. 
SELLTIZ, C. et al. Research methods in social relations. Nova Iorque: Holt, Rinehart, and Winston, 1976.

SERINGHAUS, F.H.R. Export promotion in developing countries: status and prospects. Journal of Global Marketing, n. 6, v. 4,p. 7-31. 1993

SETHI, D.; JUDGE, W. Reprising liabilities of foreignness with an integrated perspective of the costs and benefits of doing business abroad. International Business Review, v.18, n. 4, p. 404-416, 2009.

SHAN W., SONG J., Foreign direct investment and the sourcing of technological advanatage: evidence from the biotechnology industry. Journal of International Business Studies, v. 28, n.2, p. 237-284, 1997.

SHARMA, D. D.; JOHANSON, J. Technical consultancy in internationalization. International Marketing Review, p. 20-29, winter, 1987.

SHOHAM, A. Export performance: a conceptualization and empirical assessment. Journal of International Marketing, n. 63, p. 59-81, 1998.

SHUMAN, J. C. ; SEEGER, J. A. The theory and practice of strategic management in smaller rapid growth companies. American Journal of Small Business, 11 (1), p. 7- 18, 1986.

SIMON, H. As campeãs ocultas: estratégias de pequenas e médias empresas que conquistaram o mundo. Porto Alegre. Bookman, 2003.

SINGH, D. A. Export performance of emerging market firms. International Business Review, n. 18, v. 4, p. 1 -33, 2009.

SLATER, S. F.; NARVER, J. C. Superior customer value and performance: the strong evidence for a market-driven culture. Marketing Science Institute, n. 92, v. 125, CambridgeMassachusetts, 1992.

SMALlBONE, D.; WYER, P. Export Activity in SMEs, CEEDR. Working Paper Series, n. 9, 1995.

SMITH A., Stratégie investment multinational corporations and trade policy. European Economic Review, v. 31, n.1, 1987.

SMITH, S. E. et al. Higher level skills training and SMEs. International Small Business Journal, v. 16, n.2, p. 84 - 95, Jan-Mar/1998.

SOBEET. Sociedade brasileira de estudos de empresas transnacionais e da globalização econômica. Relatório de pesquisa. Documento recebido por e-mail em 20 de maio de 2008.

STALK, G. et al. Competing on capabilities: the new rules of corporate strategy. Harvard Business Review, March-April, p. 57-69, 1992.

STYLES, C. Export performance measures in Australia and the United Kingdom. Journal of International Marketing, v.6, n.3, p.12-36, 1998. 
; SEYMOUR, R. G. Opportunities for marketing researchers in international entrepreneurship. International Marketing Review, v. 3, n. 2; p. 126-145, 2006.

STÖTTINGER, B.; SCHEGELMILCH, B. Psychic distance: a concept past its due date? International Marketing Review, v.17, n.2. p.169-173, 2000.

; _ Explaining export development through psychic distance: enlightening or elusive? International Marketing Review, v.15, n.5, p.357-372, 1998.

SUH, T. et al. Smaller firms' perceived cost and attractiveness in international markets. Journal of Global Marketing, v. 21, n. 1, p. 5-17, 2007.

SULLIVAN, D. Measuring the degree of internationalisation of a firm. Journal of International Business Studies, n. 34, v. 2, p. 165-186, 1994.

Measuring the degree of internationalization of a firm: a reply. Journal of International Business Studies, v. 27, n. 1, 1996.

SULLIVAN, D.; BAURSCHMIDT, A. Incremental internationalization: a test of Johansson and Vahlne's thesis. Management International Review, v. 30, n.1, p. 19-30, 1990.

TANURE, B. Gestão à empresa brasileira: uma comparação entre América Latina, Estados Unidos Europa e Ásia. São Paulo: Atlas, 2005.

TEECE, D. J.; PISANO, G. The dynamic capabilities of firms: an introduction. Industrial and Coporate Change, n. 3, v. 3, p. 537-556, 1994.

et al. Dynamic capabilities and strategic management. Strategic Management Journal, v. 18, n. 7, p. 509-533, 1997.

TEECE, D. J. Explicating dynamic capabilities: The nature and micro-foundations of (sustainable) enterprise performance. Strategic Management Journal, v. 28, p. 1319-1350, 2007.

THACH, S.V.; AXINN C. N. Patron assessments of amusement park attributes. Journal of Travel Research, p. 51-60, 1994.

THOMAS, D.; EDEN, L. What is the shape of the multinationality-performance relationship? Multinational Business Review, v. 12, n. 1,p. 89-99, 2004.

TODD, P. R. An Empirical Investigation of Entrepreneurial Orientation, Internationalization, and Performance of SMES. 2006. Tese (doutorado) - Universidade do Estado de Cleveland.

TROMPENAARS, F.; TURNER, H. C. Riding the waves of cultures. 2. ed. Londres: Nicholas Brealey publishing, 2001.

UNIDO. SME cluster and network development in developing countries: the experience of UNIDO. Private Sector Development Branch - PSD. Technical Working Paper, n. 2. UNIDO: Viena, 1999.

UNITED NATIONS CENTER FOR TRADE AND DEVELOPMENT - UNCTAD. Small and medium-sized transnational corporations. United Nations: New York. 1993. 
World investment report 1995: Transnational corporations and competitiveness. Nova Iorque: United Nations Publication, 1995

World Investment Report - WIR. (2007). Transnational corporation, extractive industries and development. New York; Geneva: United Nations, 295 p. Disponível em: <http://www.unctad.org>. Acesso em: 15/12/2009.

URBAN, T. P. O processo de internacionalização de uma multinacional brasileira. 2006. Dissertação (Mestrado) - Universidade de São Paulo, São Paulo.

U.S. Census Bureau News. A profile of U.S. exporting companies, 2005-2006. U.S. Department of Commerce, Washington - DC. Janeiro 11, 2008. Disponível em: <http://www.census.gov/foreign-trade/Press-Release/edb/2006/text.pdf>. Acesso em: 20/03/2010.

USUNIER, J. C. Culture aspects of International Business Negotiations. In: GHAURI, P. N. International business negotiations. Oxford: Pergamon, 1996.

VATNE, E. Local resource mobilisation and internationalisation strategies in small and medium sized enterprises. Environment and Planning, v. 27, n.1, p. 63-80, 1995.

VELDE, M. V. D. et al. Guide to management research methods. Malden, MA: Blackwell Publishing, 2004.

VERNON, R. International investment and international trade in the product cycle. Quarterly Journal of Economics, v. 80, p. 190-207, 1966.

VERSTRAETE, T.; FILION, L. J. L'entrepreneuriat: une perspective internationale. Editorial de la Revue Management International, v. 6, n. 1, 2001.

WAGNER, J. Firm size and firm dynamics. Small Business Economics, v.7, p. 29-39, 1995.

WAKELIN, K. Innovation and export behaviour at the firm level. Research Policy, v. 26 p. 829-841, 1998.

WELCH, L.S.; LUOSTARINEM, R. Internationalisation: evolution of a concept. Journal of General Management, n. 14, v. 2, p. 34-55. 1988.

WELLS, L.T. Third wold multinationals: the rise of foreign investment from developing countries. Cambridge, MA: The MIT Press, 1983.

WESTHEAD, P. et al. Internationalization of private firms: environmental turbulence and organizational strategies and resources. Entrepreneurship \& Regional Development, v.16, p. 501-522, 2004.

WERNEFELT, B. A resource based view f the firm. Strategic Management Journal, 5, 171-180, 1984.

WHITELOCK, J. Theories of internationalisation and their impact on market entry. International Marketing Review, n. 19, p.342-347. 2002. 
WICKRAMASEKERA, R.; OCZKOWSKI, E. Stage models re-visited: a measure of the stage of intenationalisation of a firm. Management International Review, n. 46, v.1, 2006.

WIEDERSHEIM-PAUL, F. et al. Pre-export activity: the first step in internationalization. Journal of International Business Studies, v. 9, p. 47-58 Spring/Summer, 1978.

WINFRIED, R. et al. the internationalization-performance relationship at Swiss firms: a test of the S-Shape and extreme degrees of internationalization. Management International Review (MIR), 3rd Quarter, v. 47, n. 3, p. 349-368, 2007.

WILLIANSON, O. Markets and hierarchies: analysis and antitrust implications. New York; Free Press, 1975.

WILSON, H. Internationalization of Small and Médium-Sized Enterprise (SMEs). In: International business theories, policies and practices. Ed. M.Tayeb, M.Harlow, UK: Pearson Education, p. 190-220, 2000.

YIN, R. K. Estudo de caso: planejamento e métodos. 2. ed. Porto Alegre: Bookman, 1984.

ZAHRA, S. A. et al. international expansion by new venture firms: international diversity, mode of market entry, tecnological learning, and performance. Academy of Management Journal, n. 43, v. 5, p. 925-950, 2000.

ZARIFIAN, P. Objetivo competência. São Paulo: Atlas, 2001.

ZOLLO, M.; WINTER, S. Deliberate learning and the evolution of dynamic capabilities. Organization Science, n. 13, v.3, p. 339-351, 2002.

ZOU, S. et al. The EXPERF scale: a cross-national generalized export performance measure. Journal of International Marketing, v.6, n.3, 1998.

; STAN, S. The determinants of export performance: a review of the empirical literature between 1987 and 1997. International Marketing Review, v.15, n.5, p.333-356, 1998. 



\section{GLOSSÁRIO}

Cargas Fatoriais - De acordo com a concepção clássica de mensuração, as cargas fatoriais podem ser interpretadas como expressão da relevância do fator para a mensuração de seus indicadores. Quanto maior a carga fatorial de uma variável no fator, mais representativo é esse indicador como instrumento de medição do fator.

Distribuição qui-quadrado $\left(\mathrm{c}^{2}\right)$ - utilizada para a estimação de ajuste de um modelo estrutural, fornece estimadores qui-quadrados para testar a hipótese nula (H0) de que $\mathrm{S}=\mathrm{S}(\mathrm{q})$, ou seja, de que todos os resíduos são iguais a zero. Caso o valor $\mathrm{c}^{2}$ for elevado, o modelo não se ajustará aos dados empíricos e a hipótese nula será rejeitada.

De forma geral, a distribuição qui-quadrada apresenta a seguinte representação: $c^{2}=(N-1)$. $\mathrm{F}$ (gl, a); onde $\mathrm{N}$ é o tamanho da amostra, e $\mathrm{F}$ corresponde à função de distribuição quiquadrada, cujos parâmetros são o número de graus de liberdade (gl) e o nível de significância do teste (a). Portanto, a estatística $c^{2}$ é bastante influenciada pelo tamanho da amostra.

Grau de liberdade (gl) - equivale à diferença entre a quantidade de elementos não-repetidos existentes na matriz de covariância e o número de parâmetros a serem estimados.

Quanto maior o número de graus de liberdade de um modelo, mais difícil será o ajuste aos dados amostrais e maior será possibilidade de rejeitá-lo. Isso porque a maior parte dos parâmetros estará fixada previamente; Sendo assim, será menor o número de parâmetros que poderão ser ajustados livremente para a resolução das equações estruturais. De forma inversa, um modelo pode ser mais facilmente ajustado com a liberação dos parâmetros para estimação, até o caso extremo em que $\mathrm{gl}=0$. Nesse caso, se o modelo for identificável, o ajuste será perfeito.

Dessa forma, a liberação para estimação de um número reduzido de parâmetros - modelo mais restrito - ocasiona o aumento dos graus de liberdade do modelo. E, simultaneamente, dificulta o ajuste do modelo, haja vista a diminuição da flexibilidade proveniente do número reduzido de parâmetros que podem oscilar livremente para melhor ajuste do modelo

Hipótese Nula - hipótese que é formulada com a intenção de ser refutada, mediante evidência estatística, em favor de uma hipótese alternativa. A probabilidade estatística para a rejeição ou não da hipótese de pesquisa é determinada pelo nível de significância do teste.

Em modelos estruturais, as hipóteses nulas (Ho) são de duas naturezas. Primeiro, se o parâmetro estimado apresenta valor correspondente a zero. Nesse caso, a sua estimativa não é relevante para o modelo. Segundo, se o modelo estrutural proposto equivale ao modelo populacional. Portanto, os resultados dos testes estatísticos serão relevantes caso (i) a Ho seja rejeitada na estimativa de parâmetros; e (ii) a Ho não seja rejeitada na avaliação de modelos.

Índices de Ajuste (goodness-of-fit statistics) - medidores do nível de adequação do modelo aos dados da amostra. Há diversos indicadores de ajuste do modelo - também, denominados de critérios de adequação do modelo, ou índices de ajuste - cada um desenvolvido com o propósito de complementar ou suplementar um determinado campo de análise.

- Ajuste geral do modelo estrutural como um todo, ou critério estatístico. Esse critério objetiva determinar se o ajuste do modelo testado está em conformidade com os dados empíricos. 
- Indicadores de parcimônia apontam modificações para a redução do modelo em termos de parâmetros e variáveis, simultaneamente, à melhoria de seu ajuste. A importância da parcimônia decorre do conflito existente entre o ajuste do modelo e sua

Interpretação. Isso porque podem ser obtidos melhores índices de ajuste, simplesmente, com a adição de parâmetros e conseqüente diminuição dos graus de liberdade do modelo. Esses procedimentos obliteram e engessam a capacidade de interpretação do modelo. A parcimônia corresponde a um modelo com alto nível de ajuste e de capacidade interpretativa, simultaneamente. Modelos parcimoniosos diminuem a quantidade de modelos alternativos ou equivalentes.

Monte Carlo - procedimento de simulação que estima os parâmetros populacionais a partir da simulação da função de densidade de probabilidade dos parâmetros de entrada A partir dos dados existentes ou das condições pré-estabelecidas, são geradas distribuições empíricas para a análise do comportamento de variáveis. São utilizados para estudos de problemas relacionados à má-especificação de modelos, e procuram estimar resultados associados à estimativa dos parâmetros, dos índices de ajuste do modelo (goodness-of-fit), e dos Errospadrão.

Nível de significância do teste - probabilidade de que a hipótese nula seja rejeitada quando ela é verdadeira. Corresponde, também, aos termos alfa (a) e erro do tipo I. Em geral, o nível de significância para a avaliação de hipóteses de dados multivariados é de $5 \%$, ou $1 \%$. Este último nível $(1 \%)$ é utilizado para testes estatísticos mais restritivos, que visam evitar a ocorrência do erro do tipo I. Para um a seja fixado em 5\%, o intervalo de confiança (teste bicaudal) da estimativa de um parâmetro populacional é de $95 \%$. Nesse caso, a probabilidade de rejeição indevida da hipótese nula é de $2,5 \%$ em cada extremidade de uma curva de distribuição normal.

Poder de significância do teste - o poder do teste (p) é a probabilidade de que uma hipótese falsa - um modelo incorreto, em nosso caso - seja rejeitada. De outra forma, o poder de inferência ou estatístico de um teste é igual a $1-b$, em que b é a probabilidade associada à ocorrência do erro do tipo II, qual seja, a não-rejeição de uma hipótese nula quando ela é falsa. Quanto maior for o poder estatístico ou de inferência do teste, maior será a probabilidade de detecção de uma falsa Ho. O poder estatístico de um teste é influenciado por diversos fatores. Os principais elementos relativos a modelos estruturais são: (i) tamanho da amostra (N). Há uma relação direta p e N. Quando maior N, maior será p, ou seja, maior será o rigor estatístico do teste. Por vezes, isso pode constituir um entrave. Esse é um problema normalmente verificado no teste estatístico dos estimadores qui-quadrados $\left(\mathrm{c}^{2}\right)$ que avaliam a adequação geral do modelo estrutural.

Amostras muito elevadas podem superdimensionar o estimador $\mathrm{c}^{2} \mathrm{e}$ impossibilitar a conclusão se uma eventual significância do teste é, por um lado, decorrente da existência de erros de especificação, ou, por outro lado, se é devida ao rigor provocado pelo tamanho elevado da amostra. Ademais, os estimadores qui-quadrados não são acurados para amostras pequenas, ou seja que contenham menos de 100 observações $(\mathrm{N}<100)$. Nesses casos, a estatística c ${ }^{2}$ tende a ser grande, ocasionando a rejeição da hipótese nula, (ii) p está relacionado com o nível de significância do teste, ou seja, com a probabilidade de ocorrência do erro do tipo I (a). Quando menor a, menor será p; (iii) p é influenciado pela configuração e adequação do modelo estrutural, como, por exemplo, pelo número de indicadores dos fatores. Quanto maior 
o número de variáveis observacionais por fator, maior será o poder do teste. O poder do teste é maior quando as relações existentes no modelo são fortes; (iv) p depende do valor especifico do parâmetro que constitui a hipótese alternativa. Isto é, do effect size, ou do valor do parâmetro que será confrontado com o valor de referência que representa a hipótese nula. Por exemplo, caso o effect size seja elevado, a detecção da diferença entre hipóteses será mais fácil e, por conseguinte, menor será o poder requerido do teste; e (v) o número de graus de liberdade (gl) influenciam o poder do teste. Quanto maior gl de um modelo, maior será o poder de inferência do teste.

Um poder estatístico de $\mathrm{p}>0,85$ é considerado ideal. Contudo, em estudos multivariados, um poder estatístico próximo a 0,80 , a um nível de significância de $5 \%(a=0,05)$, é um valor comumente aceito.

p value - a probabilidade de um valor $-p$ value, como o próprio nome expressa, é a probabilidade estatística de que a estimativa de um parâmetro esteja dentro do intervalo de confiança para a sua ocorrência. É utilizada para expressar a existência de significância estatística na estimativa de um parâmetro, na relação entre parâmetros, ou na comparação de modelos, e.g., carga fatorial, coeficiente estrutural, correlação entre fatores, teste quiquadrado de modelos estruturais.

Significância estatística - um resultado é estatisticamente significativo quando a probabilidade de sua ocorrência - ou a sua distribuição de freqüência - ocasionar a rejeição da hipótese nula, a um determinado nível de significância do teste. De forma prática, um valor apresenta significância estatística quando o valor da probabilidade de sua ocorrência $-p$ value - for inferior ao nível de significância do teste (a).

Teste qui-quadrado ou Teste $\mathbf{T}$ - para o teste de um modelo estrutural, esse teste estima a significância estatística da estatística qui-quadrada $\left(\mathrm{c}^{2}\right)$. É um teste de não-conformidade às avessas, ou seja, seu objetivo não é refutar a Ho, como no teste t; pelo contrário, é não rejeitála (uma hipótese nunca é aceita, somente rejeitada ou não rejeitada). $\mathrm{O}$ valor elevado do teste T sinaliza o nível de "insucesso" da rejeição do modelo. A estatística c² não terá significância estatística se o modelo se ajustar bem aos dados, pois a hipótese nula não será recusada. Nesse caso, o $p$ value será superior a 0,05 , ou seja, superior ao nível de significância do teste de $5 \%$. Em modelos de equações estruturais, o teste qui-quadrado é utilizado para testar a hipótese nula de que o modelo especificado corresponde à matriz de covariância populacional. Valores elevados da estatística $\mathrm{c}^{2}$, correspondem a um $p$ value baixo, e, por conseguinte, falseiam a hipótese nula, ocasionando a rejeição do modelo proposto.

t value - razão entre o parâmetro estimado e o erro-padrão correspondente. Esse valor é utilizado para estimar a significância estatística dos parâmetros. Parâmetros cujas estimativas apresentam valores da estatística $t$ muito baixos sinalizam a existência de erro-padrão elevado, e devem ser eliminados do modelo. A existência de Erros-padrão demasiadamente elevados não possibilita a determinação da significância do parâmetro. Por outro lado, caso o erropadrão seja muito próximo a zero, é possível que o teste estatístico do parâmetro não possa ser realizado, pois a estatística $t$ tenderá ao infinito. Quando essa razão apresenta distribuição normal, podemos utilizar a distribuição $\mathrm{Z}$ para testar se a estimativa é estatisticamente diferente de zero. Desse modo, caso o valor $t$ seja maior que $+1,96$ ou menor que $-1,96$, a estimativa do parâmetro é considerada significativa a um nível de teste $a=5 \%$ (teste bicaudal 
com percentil de $97,5 \%$ da distribuição normal padronizada). Portanto, nesse caso, a hipótese nula é rejeitada e o parâmetro deve ser preservado no modelo. Com exceção das variâncias dos erros, os demais parâmetros não-significativos podem ser eliminados de um modelo estrutural.

Validade de construto: O quanto um conjunto de variáveis medidas realmente representa o construto latente teórico que aquelas variáveis são planejadas para medir.

Parâmetro: Representação numérica de alguma característica de uma população. Em SEM, relações são as características de interesse para as quais os procedimentos de modelagem geram estimativas. Parâmetros são características numéricas das relações SEM, comparáveis com coeficientes de regressão em regressão múltipla.

Causalidade: Princípio pelo qual causa e efeito são estabelecidos entre duas variáveis. Ele requer que exista um grau suficiente de associação (covariância) entre as duas variáveis, que uma variável ocorra antes da outra (que uma variável seja claramente o resultado da outra), e que não existam outras causas razoáveis para o resultado. 


\section{APÊNDICES}

APÊNDICE A: Questionário Aplicado

APÊNDICE B: Protocolo de Entrevistas

APÊNDICE C: Carta de Apresentação do Questionário

APÊNDICE D: Teste ANOVA 



\section{APÊNDICE A: Questionário Aplicado - Survey}

Internacionalização das PMEs Brasileiras

Esta pesquisa está sendo realizada para uma tese de doutorado da Universidade do Estado de São Paulo (USP) com o objetivo de identificar o grau de internacionalização das Pequenas e Médias Empresas Brasileiras (PMEs).

A experiência que a sua empresa já acumulou pode trazer grandes contribuições. Solicitamos que, caso o Executivo principal da empresa não possa responder ao questionário, este seja respondido pela pessoa que tem mais conhecimento sobre as operações no exterior.

Ao responder este questionário você estará concorrendo a um I Pod (Apple) que será sorteado no dia 21 de dezembro e estará incluído na lista de pessoas que receberão os resultados consolidados desta pesquisa.

Todos os dados serão tratados de maneira estritamente confidencial. Para tanto, os resultados da pesquisa serão apresentados somente de forma agregada.

Dinorá Eliete Floriani

Doutoranda USP

Professora UNIVALI

Telefone: (11) 74241061

e-mail:dinora@univali.br
Profa. Dra. Maria Tereza Leme Fleury

Professora Titular

Faculdade de Economia e Administração

Telefone: (11) 3091-5836

e-mail: mtfleury@usp.br

\begin{tabular}{|l|l|l|l|}
\hline & $\begin{array}{l}\text { V1 Em qual operação abaixo a sua } \\
\text { empresa atua no exterior? }\end{array}$ & $\begin{array}{c}\text { V2 Ano que iniciou em } \\
\text { cada operação }\end{array}$ & \multicolumn{1}{|c|}{ Conceito } \\
\hline ( ) & Exportação indireta & $\begin{array}{l}\text { Por meio de trading ou de empresa } \\
\text { comercial exportadora no Brasil. }\end{array}$ \\
\hline ( ) & Exportação direta & $\begin{array}{l}\text { Para distribuidores no exterior ou } \\
\text { diretamente para clientes no } \\
\text { exterior. }\end{array}$ \\
\hline ( ) & $\begin{array}{l}\text { Representante exclusivo no } \\
\text { exterior }\end{array}$ & $\begin{array}{l}\text { Responsável por divulgar, vender e } \\
\text { distribuir o seu produto no exterior }\end{array}$ \\
\hline ( ) & $\begin{array}{l}\text { Escritórios de comercialização } \\
\text { próprios }\end{array}$ & $\begin{array}{l}\text { A empresa possui escritórios } \\
\text { próprios no exterior para vender } \\
\text { seus produtos }\end{array}$ \\
\hline ( ) & $\begin{array}{l}\text { Centros de distribuição próprios } \\
\text { (CD) }\end{array}$ & $\begin{array}{l}\text { A empresa possui Centros próprios } \\
\text { no exterior para distribuir seus } \\
\text { produtos }\end{array}$ \\
\hline ( ) & Franquia, licenciamento para & parceiros internacionais & $\begin{array}{l}\text { A empresa disponibiliza marca, } \\
\text { tecnologia, etc. para outra empresa } \\
\text { atuar no exterior. }\end{array}$ \\
\hline ( ) & Lojas próprias no exterior & $\begin{array}{l}\text { A empresa possui lojas próprias no } \\
\text { exterior }\end{array}$ \\
\hline ( ) & Produção terceirizada no exterior. & $\begin{array}{l}\text { A empresa terceiriza a sua produção } \\
\text { para outra empresa no exterior }\end{array}$ \\
\hline ( ) & Joint- Venture & $\begin{array}{l}\text { A empresa possui parcerias no } \\
\text { exterior }\end{array}$ \\
\hline ( ) & Produção própria & $\begin{array}{l}\text { A empresa possui uma empresa no } \\
\text { exterior para a produção }\end{array}$ \\
\hline ( ) & Centro de Pesquisa & $\begin{array}{l}\text { A empresa desenvolve produtos ou } \\
\text { serviços no exterior }\end{array}$ \\
\hline
\end{tabular}




\begin{tabular}{|l|l|l|}
\hline \multicolumn{2}{|l|}{$\begin{array}{l}\text { V3a - Quais os países em que a empresa atua em cada uma das operações de } \\
\text { internacionalização? }\end{array}$} & $\begin{array}{l}\text { V3 b } \\
\text { Quantidade } \\
\text { total de países. }\end{array}$ \\
\hline Exportação indireta & & \\
\hline Exportação direta & & \\
\hline Representante exclusivo no exterior & & \\
\hline $\begin{array}{l}\text { Escritórios de comercialização } \\
\text { próprios no exterior }\end{array}$ & & \\
\hline Centros de distribuição próprios (CD) & & \\
\hline $\begin{array}{l}\text { Franquia no exterior, licenciamento } \\
\text { para parceiros internacionais }\end{array}$ & & \\
\hline Lojas próprias no exterior & & \\
\hline Produção terceirizada no exterior. & & \\
\hline Joint- Venture/parceria no exterior & & \\
\hline Produção própria no exterior & & \\
\hline Centro de Pesquisa no exterior & & \\
\hline
\end{tabular}

\section{Sobre a sua empresa}

V6 Quanto representa aproximadamente na receita da sua empresa a receita de exportação direta se comparado às receitas de vendas totais da empresa? $\%$

V7.1Qual o número aproximado de funcionários diretos no Brasil em 2009?

V7.2Qual o número aproximado de funcionários diretos no exterior em 2009 ?

V8 Qual o ano de fundação da sua empresa?

V9 Qual o setor de Atuação:

( ) Alimentos ( ) Tecnologia ( ) madeireira/mobiliário

( ) construção ( ) máquinas e equipamentos ( ) metalúrgico

( ) Papel/celulose ( ) Mineração ( ) Perfumes/cosméticos

( ) Químicos ( )Serviços ( ) Tecnologia ( ) Veículos e autopeças

( ) Têxteis/calçado/moda ( ) Outro

V10.1 Quantos executivos da sua empresa já trabalharam ou estudaram no exterior por pelo menos, 1 ano? (Diretores/Gerentes)

\begin{tabular}{|c|c|c|c|c|c|}
\hline \multirow{2}{*}{$\begin{array}{l}\text { V11 Indique o Grau de concordância ou discordância nas opções } \\
\text { a seguir: ( quanto mais próximo de } 1 \text { assinalar, estará indicando } \\
\text { que discorda da afirmação; quanto mais próximo de 5, estará } \\
\text { indicando que concorda totalmente) } \\
\text { V11.1 Os gerentes na nossa empresa tendem a ver o mundo, em } \\
\text { vez de ver somente o Brasil como mercado alvo }\end{array}$} & \multicolumn{3}{|c|}{$\begin{array}{l}\text { Discordo } \\
\text { Totalmente }\end{array}$} & \multicolumn{2}{|c|}{$\begin{array}{l}\text { Concordo } \\
\text { Totalmente }\end{array}$} \\
\hline & 1 & 2 & 3 & 4 & 5 \\
\hline $\begin{array}{l}\text { V11.2A cultura organizacional que prevalece na nossa empresa é } \\
\text { conduzida para explorar novos negócios no exterior }\end{array}$ & 1 & 2 & 3 & 4 & 5 \\
\hline $\begin{array}{l}\text { V11.30s gerentes desenvolvem os recursos humanos e outros } \\
\text { recursos para atingir seus objetivos no mercado internacional }\end{array}$ & 1 & 2 & 3 & 4 & 5 \\
\hline $\begin{array}{l}\text { V11.4Nossa empresa é reconhecida pelos avanços tecnológicos e } \\
\text { está avançada tecnologicamente nos mercados internacionais }\end{array}$ & 1 & 2 & 3 & 4 & 5 \\
\hline $\begin{array}{l}\text { V11.5Inventamos muitas das tecnologias embutidas no nosso } \\
\text { produto }\end{array}$ & 1 & 2 & 3 & 4 & 5 \\
\hline $\begin{array}{l}\text { V11.6No design e na manufatura do nosso produto, nós } \\
\text { empregamos alguns dos melhores especialistas da indústria. }\end{array}$ & 1 & 2 & 3 & 4 & 5 \\
\hline $\begin{array}{l}\text { V11.7Nossa empresa se preocupa com o cliente, adaptando } \\
\text { nossos produtos às necessidades do cliente }\end{array}$ & 1 & 2 & 3 & 4 & 5 \\
\hline $\begin{array}{l}\text { V11.8Nossos gerentes entendem como cada um pode contribuir } \\
\text { para criar valor para o cliente no mercado internacional. }\end{array}$ & 1 & 2 & 3 & 4 & 5 \\
\hline $\begin{array}{l}\text { V11.9Nossa empresa se preocupa e monitora as ações dos } \\
\text { concorrentes no mercado internacional }\end{array}$ & 1 & 2 & 3 & 4 & 5 \\
\hline $\begin{array}{l}\text { V11.10Se o concorrente lançar uma intensiva campanha no } \\
\text { mercado internacional, nós deveremos responder imediatamente }\end{array}$ & 1 & 2 & 3 & 4 & 5 \\
\hline $\begin{array}{l}\text { V11.11Nossas funções do negócio } \\
\text { (Marketing/vendas, } \\
\text { manufatura, finanças) são integradas para atender às } \\
\text { necessidades do mercado internacional? }\end{array}$ & 1 & 2 & 3 & 4 & 5 \\
\hline
\end{tabular}




\begin{tabular}{|c|c|c|c|c|c|}
\hline \multirow{2}{*}{$\begin{array}{l}\text { V12 Sobre o desempenho geral da empresa } \\
\begin{array}{l}\text { V12.4Após o início das operações no exterior o volume de vendas } \\
\text { aumentou }\end{array}\end{array}$} & \multicolumn{3}{|c|}{$\begin{array}{l}\text { Discordo } \\
\text { totalmente }\end{array}$} & \multicolumn{2}{|c|}{$\begin{array}{r}\text { Concordo } \\
\text { totalmente }\end{array}$} \\
\hline & 1 & 2 & 3 & 4 & 5 \\
\hline $\begin{array}{l}\text { V12.5Após o início das operações no exterior a rentabilidade líquida da } \\
\text { empresa aumentou }\end{array}$ & 1 & 2 & 3 & 4 & 5 \\
\hline V12.60 retorno sobre os ativos cresceu após a operação no exterior & 1 & 2 & 3 & 4 & 5 \\
\hline $\begin{array}{l}\text { V12.7A produtividade operacional aumentou após o início das operações } \\
\text { no exterior }\end{array}$ & 1 & 2 & 3 & 4 & 5 \\
\hline
\end{tabular}

\begin{tabular}{|c|c|c|c|c|c|}
\hline \multirow{2}{*}{$\begin{array}{l}\text { V13 Sobre a(s) operação (ões) no exterior... } \\
\text { V13.1Tem aumentado a lucratividade geral da nossa empresa }\end{array}$} & \multicolumn{3}{|c|}{$\begin{array}{l}\text { Discordo } \\
\text { totalmente }\end{array}$} & \multicolumn{2}{|c|}{$\begin{array}{r}\text { Concordo } \\
\text { totalmente }\end{array}$} \\
\hline & 1 & 2 & 3 & 4 & 5 \\
\hline Alcançou um rápido crescimento & 1 & 2 & 3 & 4 & 5 \\
\hline Melhorou a competitividade global da nossa empresa em geral & 1 & 2 & 3 & 4 & 5 \\
\hline Fortaleceu nossa posição estratégica & 1 & 2 & 3 & 4 & 5 \\
\hline $\begin{array}{l}\text { V13.6Aumentou significativamente a participação de mercado da nossa } \\
\text { empresa em geral }\end{array}$ & 1 & 2 & 3 & 4 & 5 \\
\hline O desempenho da nossa operação no exterior tem sido muito satisfatório & 1 & 2 & 3 & 4 & 5 \\
\hline
\end{tabular}

\begin{tabular}{|c|c|c|c|c|c|}
\hline \multirow{2}{*}{$\begin{array}{l}\text { Quais as diferenças percebidas quando sua empresa era somente } \\
\text { exportadora e após o início da operação no exterior } \\
\text { Melhorou o Reconhecimento de Marca }\end{array}$} & \multicolumn{3}{|c|}{\begin{tabular}{|l|} 
Discordo \\
Totalmente
\end{tabular}} & \multicolumn{2}{|c|}{$\begin{array}{r}\text { Concordo } \\
\text { Totalmente }\end{array}$} \\
\hline & 1 & 2 & 3 & 4 & 5 \\
\hline A nossa empresa cresceu & 1 & 2 & 3 & 4 & 5 \\
\hline Melhoramos a tecnologia utilizada & 1 & 2 & 3 & 4 & 5 \\
\hline Inovamos nossos produtos & 1 & 2 & 3 & 4 & 5 \\
\hline Aumentamos o nosso Market Share no Brasil & 1 & 2 & 3 & 4 & 5 \\
\hline Aumentou a satisfação do consumidor da empresa & 1 & 2 & 3 & 4 & 5 \\
\hline Aumentou a satisfação dos funcionários & 1 & 2 & 3 & 4 & 5 \\
\hline Desenvolvemos novas competências & 1 & 2 & 3 & 4 & 5 \\
\hline $\begin{array}{l}\text { Fortalecemos as competências já reconhecidas pelo mercado } \\
\text { nacional e internacional }\end{array}$ & 1 & 2 & 3 & 4 & 5 \\
\hline
\end{tabular}

\begin{tabular}{|l|c|c|c|c|c|}
\hline $\begin{array}{l}\text { Como você classificaria sua situação se comparada ao do } \\
\text { concorrente: (Quanto mais próximo do } 1 \text { sua situação é pior do } \\
\text { que a do concorrente, quanto mais próxima do } 5 \text { melhor do que } \\
\text { a do concorrente a situação será) }\end{array}$ & $\begin{array}{l}\text { Pior do que o do } \\
\text { Concorrente }\end{array}$ & $\begin{array}{r}\text { Melhor do que o } \\
\text { do } \\
\text { concorrente }\end{array}$ \\
\hline O processo de planejamento de Marketing internacional & 1 & 2 & 3 & 4 & 5 \\
\hline O controle e avaliação das atividades de Marketing internacional & 1 & 2 & 3 & 4 & 5 \\
\hline A habilidade para segmentar e identificar mercados no exterior & 1 & 2 & 3 & 4 & 5 \\
\hline $\begin{array}{l}\text { A habilidade para usar ferramentas de Marketing (design, formar } \\
\text { preço, publicidade) para diferenciar os produtos }\end{array}$ & 1 & 2 & 3 & 4 & 5 \\
\hline
\end{tabular}

\begin{tabular}{|c|c|c|c|c|c|}
\hline \multirow{2}{*}{$\begin{array}{l}\text { Quais as vantagens de se operar de forma mais complexa } \\
\text { no exterior? Lembrando que operar de forma mais } \\
\text { complexa no exterior é por meio de lojas, assistência } \\
\text { própria, distribuição própria, fábricas no exterior } \\
\text { A Disponibilidade de recursos naturais }\end{array}$} & \multicolumn{4}{|c|}{$\begin{array}{l}\text { Pouco } \\
\text { Vantajoso }\end{array}$} & $\begin{array}{r}\text { Muito } \\
\text { Vantojoso }\end{array}$ \\
\hline & 1 & 2 & 3 & 4 & 5 \\
\hline A disponibilidade de Fornecedores & 1 & 2 & 3 & 4 & 5 \\
\hline O Custo de transporte & 1 & 2 & 3 & 4 & 5 \\
\hline A Disponibilidade de mão de obra & 1 & 2 & 3 & 4 & 5 \\
\hline O Custo dos salários & 1 & 2 & 3 & 4 & 5 \\
\hline Fornecedora da nossa própria empresa no exterior & 1 & 2 & 3 & 4 & 5 \\
\hline O risco de taxas de câmbio & 1 & 2 & 3 & 4 & 5 \\
\hline A Carga tributária menor, subsídios & 1 & 2 & 3 & 4 & 5 \\
\hline A Regulamentação do mercado de trabalho & 1 & 2 & 3 & 4 & 5 \\
\hline
\end{tabular}




\begin{tabular}{|c|c|c|c|c|c|}
\hline & & & & \multicolumn{2}{|c|}{ conclusão } \\
\hline A Regulamentação ambiental & 1 & 2 & 3 & 4 & 5 \\
\hline A Burocracia & 1 & 2 & 3 & 4 & 5 \\
\hline Exportar para outros países & 1 & 2 & 3 & 4 & 5 \\
\hline Manter/desenvolver mercados que a empresa já atua & 1 & 2 & 3 & 4 & 5 \\
\hline Entrar/desenvolver novos mercados & 1 & 2 & 3 & 4 & 5 \\
\hline Estar no mercado do principal cliente & 1 & 2 & 3 & 4 & 5 \\
\hline Estar onde os competidores atuam & 1 & 2 & 3 & 4 & 5 \\
\hline Evitar as Barreiras comerciais & 1 & 2 & 3 & 4 & 5 \\
\hline
\end{tabular}

\begin{tabular}{|c|c|c|c|c|c|}
\hline \multirow{2}{*}{$\begin{array}{l}\text { Quais as principais dificuldades de se operar de forma } \\
\text { mais complexa no exterior? } \\
\text { Adaptar-se à cultura do país }\end{array}$} & \multicolumn{3}{|c|}{$\begin{array}{l}\text { Baixa } \\
\text { dificuldade }\end{array}$} & \multicolumn{2}{|c|}{$\begin{array}{r}\text { Alta } \\
\text { dificuldade }\end{array}$} \\
\hline & 1 & 2 & 3 & 4 & 5 \\
\hline Lidar com os funcionários estrangeiros & 1 & 2 & 3 & 4 & 5 \\
\hline Adequar a empresa à legislação local & 1 & 2 & 3 & 4 & 5 \\
\hline O idioma & 1 & 2 & 3 & 4 & 5 \\
\hline $\begin{array}{l}\text { Transferir as competências da matriz para a operação no } \\
\text { exterior }\end{array}$ & 1 & 2 & 3 & 4 & 5 \\
\hline Os custos para abrir a operação no exterior & 1 & 2 & 3 & 4 & 5 \\
\hline A falta de apoio financeiro do governo brasileiro & 1 & 2 & 3 & 4 & 5 \\
\hline
\end{tabular}

\begin{tabular}{|l|l|l|l|l|l|l|}
\hline $\begin{array}{l}\text { Dentre os grupos abaixo, como foi o auxilio dado à sua } \\
\text { empresa para iniciar a operação no exterior? }\end{array}$ & $\begin{array}{l}\text { Nada } \\
\text { Auxiliou }\end{array}$ & \multicolumn{3}{l|}{$\begin{array}{l}\text { Muito } \\
\text { Auxiliou }\end{array}$} & $\begin{array}{c}\text { Não se } \\
\text { Aplica }\end{array}$ \\
\hline Os funcionários da própria empresa & 1 & 2 & 3 & 4 & 5 & \\
\hline $\begin{array}{l}\text { Novos funcionários com as novas competências } \\
\text { requisitadas }\end{array}$ & 1 & 2 & 3 & 4 & 5 & \\
\hline Auditores/Bancos/ Consultores & 1 & 2 & 3 & 4 & 5 & \\
\hline Clientes ou fornecedores & 1 & 2 & 3 & 4 & 5 & \\
\hline Governo Federal & 1 & 2 & 3 & 4 & 5 & \\
\hline SEBRAE/APEX & 1 & 2 & 3 & 4 & 5 & \\
\hline Associação Comercial/Câmaras de Comércio e Indústria & 1 & 2 & 3 & 4 & 5 & \\
\hline Universidades & 1 & 2 & 3 & 4 & 5 & \\
\hline A parceria que temos com uma empresa estrangeira & 1 & 2 & 3 & 4 & 5 & \\
\hline A parceria que temos com uma empresa brasileira & 1 & 2 & 3 & 4 & 5 & \\
\hline Outros empresários (sem relação comercial) & 1 & 2 & 3 & 4 & 5 & \\
\hline
\end{tabular}

Qual a tendência do Investimento da sua empresa voltado para a internacionalização em 2010 se comparado com 2009.
( ) Aumentar mais de $30 \%$
( ) Aumentar mais de $10 \%$
( ) Redução de mais de $10 \%$ ( ) Redução de mais de $30 \%$
( ) Permanecer igual $\%$
( ) Não investir

As receitas totais anuais da sua empresa são:
( ) menos de
R\$ 1 milhão/ano
( ) entre R\$ 1 milhão e R\$ 10 milhões
( ) entre 10 milhões e R\$ 50 milhões
( ) entre R\$ 50 milhões ( ) entre 200 milhões e R $\$ 200$ milhões
e R\$ 1 bilhão
( ) mais de e R\$ 1 bilhão

Indique o Estado ou Região de sua localização:
( ) Região Norte
( ) Rio de Janeiro
( ) Paraná
( ) Região Nordeste
( ) Santa Catarina
( ) Rio Grande do Sul
( ) Região Centro Oeste
( ) São Paulo
( ) Paraná
Sua empresa é de capital: ( ) Nacional ( ) estrangeiro ( ) Misto 


\section{APÊNDICE B: Protocolo de Entrevista}

- $\quad$ Explicar operação no exterior.

- $\quad$ Explicar competência

- $\quad$ Explicar desempenho

Pontos a serem debatidos:

1) Fator impulsionador para atuar no exterior

2) Obstáculos para poder atuar no exterior.

3) Atributos necessários para atuar no exterior

4) Competências imprescindíveis para atuar no exterior

5) Orientação internacional

6) Gerentes / mercado externo

7) A cultura organizacional / novos negócios no exterior

8) Treinamento para os funcionários voltados ao mercado externo

9) Diferencial da sua empresa no mercado internacional

10) O cliente no mercado externo

11) Concorrência internacional

12) Comunicação no mercado externo

13) Inovação Internacional

14) Orientação internacional

15) Habilidades de Marketing Internacional

16) Orientação para o mercado internacional 



\section{APÊNDICE C}

\section{TSP}

Prezados Senhores,

Esta é uma pesquisa de doutorado da USP (Universidade de São Paulo) sobre a Internacionalização de Pequenas e Médias Empresas (PMEs) Brasileiras.

A sua participação é fundamental para concluir este estudo e analisarmos a atual situação da internacionalização das PMEs, auxiliando as empresas a se tornarem sempre mais competitivas no mercado internacional.

Para responder ao questionário, basta clicar no link abaixo:

http://www.surveymonkey.com/s.aspx?sm=hFgt7Abn92ElyrZvoON1og 3d 3d

Ao finalizar, o questionário será enviado automaticamente ao nosso banco de dados.

Lembramos que nenhum dado será divulgado individualmente, todas as informações serão tabuladas e agrupadas para análise.

Para as empresas que responderem ao questionário até o dia 20/12/2009 será sorteado um I-Pod (Apple) e, todos os participantes receberão os resultados finais desta pesquisa.

Muito obrigada pela sua participação,

Dinorá Floriani

Doutoranda
Profa. Maria Tereza Fleury

Coordenadora da pesquisa 



\section{APÊNDICE D: ANOVA ${ }^{1}$}

Para o teste da Análise de Variância o construto GRI foi composto por cinco variáveis, ou seja: GRI: a) Número de países em que as empresas exportam; b) Receita de vendas na exportação/vendas totais; c) Número de executivos com experiência de estudo e trabalho no exterior por mais de 1 ano; d) Funcionários no exterior/funcionários totais; e) Tempo de experiência com exportação.

Para esta análise efetuou-se uma divisão das empresas respondentes em exportadoras e empresas com operação no exterior. As empresas, cada qual em seu grupo, (exportadoras e com operação no exterior) foram divididas em:

- $\quad$ baixo grau de internacionalização (GRI = <33\%);

- médio grau de internacionalização (GRI entre <33\% e >66\%);

- $\quad$ alto grau de internacionalização (GRI >66\%).

O objetivo deste teste estatístico foi auxiliar na elaboração das conclusões dessa tese, verificando o comportamento do desempenho financeiro e operacional das PMEs pesquisadas com os diferentes estágios do GRI (baixo, médio e alto).

Verificou-se, também, o comportamento do desenvolvimento de novas competências com os mesmos estágios do GRI, acima indicados, das PMEs pesquisadas.

Tabela 1: GRI, Competência e Desempenho (ANOVA)

\begin{tabular}{llrrrrr}
\hline & \multicolumn{1}{c}{$\begin{array}{c}\text { Soma dos } \\
\text { Quadrados }\end{array}$} & df & Média dos Q & F & Sig. \\
\hline \multirow{2}{*}{ inova } & 5,03 & 5 & 1,01 & 1,196 & 0,316 \\
& Between Groups & 88,41 & 105 & 0,84 & & \\
& Within Groups & 93,44 & 110 & & & \\
\cline { 2 - 6 } hmkt & Between Groups & 3,12 & 5 & 0,62 & 0,944 & 0,456 \\
& Within Groups & 69,48 & 105 & 0,66 & & \\
& Total & 72,61 & 110 & & & \\
& Between Groups & 7,94 & 5 & 1,59 & 2,944 & $0,015^{* *}$ \\
& Within Groups & 57,70 & 107 & 0,54 & & \\
\hline
\end{tabular}

continua

\footnotetext{
${ }^{1}$ Como o objetivo desse item foi o de auxiliar nas conclusões, não se realizou outros testes estatísticos para verificar a significância da mudança de comportamento entre um GRI e outro.
} 


\begin{tabular}{|c|c|c|c|c|c|c|}
\hline & & & & & & onclusão \\
\hline & Between Groups & 9,81 & 5 & 1,96 & 2,356 & $0,045 * *$ \\
\hline & Within Groups & 87,42 & 105 & 0,83 & & \\
\hline omkim & Total & 97,22 & 110 & & & \\
\hline & Between Groups & 94,40 & 5 & 18,88 & 3,669 & $0,004 *$ \\
\hline Des & Within Groups & 545,52 & 106 & 5,15 & & \\
\hline Oper & Total & 639,92 & 111 & & & \\
\hline & Between Groups & 83,89 & 5 & 16,78 & 2,403 & $0,041 * *$ \\
\hline Des & Within Groups & 740,07 & 106 & 6,98 & & \\
\hline Finac & Total & 823,96 & 111 & & & \\
\hline
\end{tabular}

* Signif: 0,05

** Signif: 0,10

Fonte: Dados da pesquisa, 2010

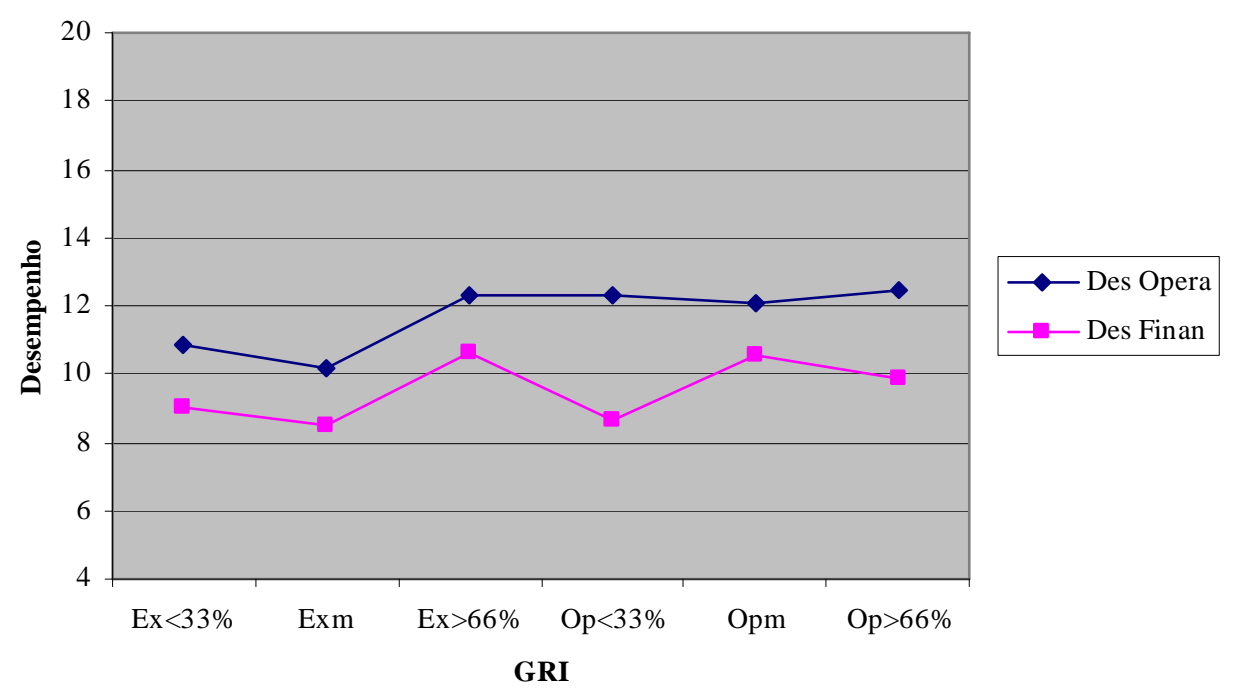

Gráfico 01 - Curva (ANOVA) para Exportadoras e Curva para IED GRI e desempenho Fonte: Dados da Pesquisa, 2010

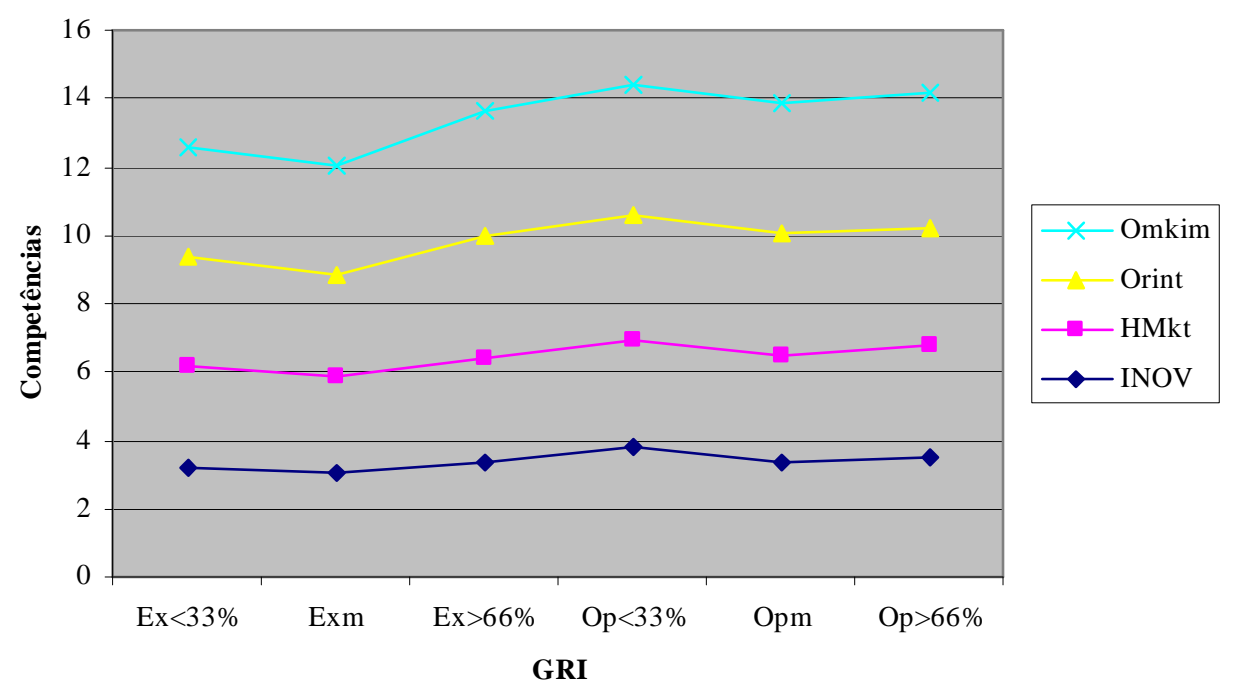

Gráfico 02 - Relação de competência com GRI

Fonte: Dados da pesquisa, 2010 
ANEXOS

ANEXO 01: Diagrama Final 1a

ANEXO 02: Diagrama Final $1 b$ 

ANEXO 01 - Diagrama completo H1a

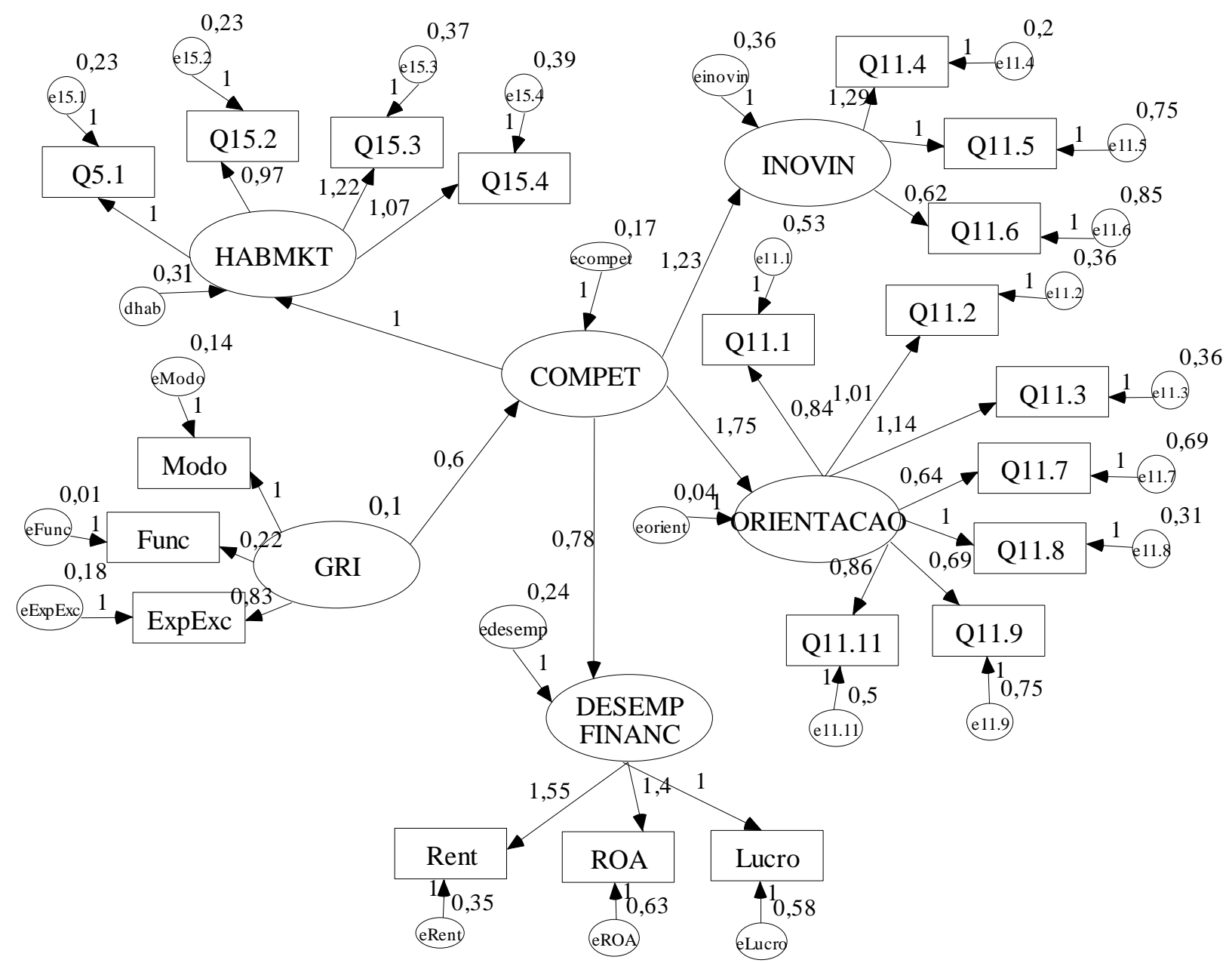

Fonte: AMOS. Dados da Pesquisa, 2010 



\section{ANEXO 02 - Diagrama Completo H1b}

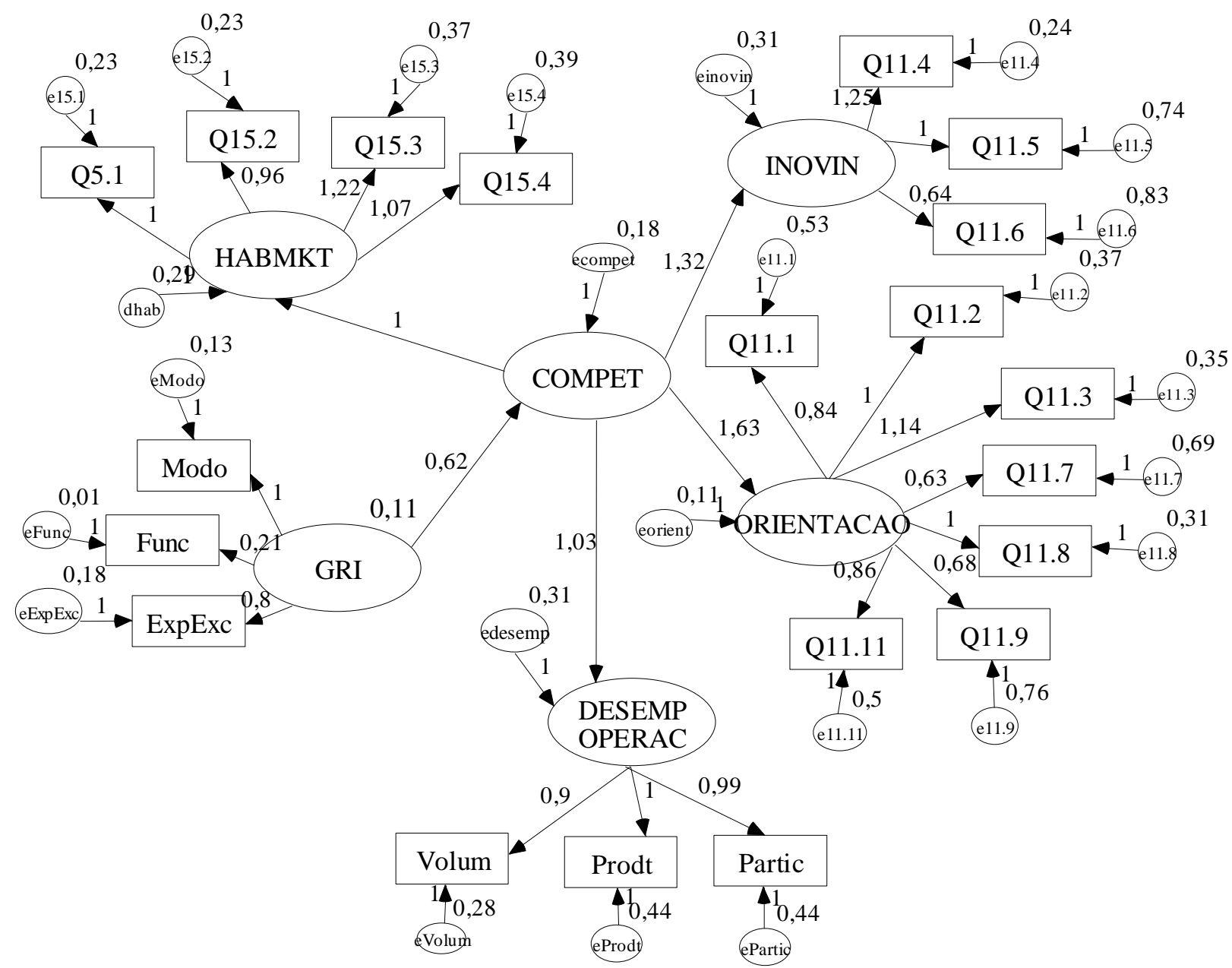

Fonte: AMOS. Dados da Pesquisa, 2010 